\title{
Biodiversity of terrestrial algal \\ communities from soil and air-exposed substrates using a molecular approach
}

\author{
Dissertation \\ zur Erlangung des mathematisch-naturwissenschaftlichen \\ Doktorgrades \\ „Doctor rerum naturalium“ \\ der Georg-August-Universität Göttingen \\ im Promotionsprogramm Biologie \\ der Georg-August-University School of Science (GAUSS)
}

\author{
vorgelegt von \\ Christine Hallmann \\ aus Bremen
}

Göttingen, 2015 
Betreuungsausschuss:

Prof. Dr. Thomas Friedl, Albrecht-von-Haller-Institut für Pflanzenwissenschaften, Abteilung Experimentelle Phykologie und Sammlung von Algenkulturen, Universität Göttingen

PD Dr. Michael Hoppert, Institut für Mikrobiologie und Genetik, Abteilung für Allgemeine Mikrobiologie, Universität Göttingen

Mitglieder der Prüfungskommission:

Referent:

Prof. Dr. Thomas Friedl, Albrecht-von-Haller-Institut für Pflanzenwissenschaften, Abteilung Experimentelle Phykologie und Sammlung von Algenkulturen, Universität Göttingen

Korreferent:

PD Dr. Michael Hoppert, Institut für Mikrobiologie und Genetik, Abteilung für Allgemeine Mikrobiologie, Universität Göttingen

weitere Mitglieder der Prüfungskommission:

Prof. Dr. Hermann Behling, Albrecht-von-Haller-Institut für Pflanzenwissenschaften, Abteilung Palynologie und Klimadynamik, Universität Göttingen

Prof. Dr. Erwin Bergmeier, Albrecht-von-Haller-Institut für Pflanzenwissenschaften, Abteilung Vegetationsanalyse und Phytodiversität, Universität Göttingen

Prof. Dr. Rolf Daniel, Institut für Mikrobiologie und Genetik, Abteilung für Genomische und Angewandte Mikrobiologie, Universität Göttingen

Prof. Dr. Joachim Reitner, Geowissenschaftliches Zentrum, Abteilung Geobiologie, Universität Göttingen

Tag der mündlichen Prüfung: 24.06.2015 


\section{Table of contents}

General Introduction

Results

Chapter 1 Molecular diversity of phototrophic biofilms on building stone 6

Chapter 2 Cryptogam covers on sepulchral monuments and re-colonization of a marble surface after cleaning

Chapter 3 Molecular diversity on a marble monument: a case study.

Chapter 4 Biodiversity of green phototrophic biofilms on artificial hard surfaces: a case study of aero-terrestrial algae in an urban environment using molecular approaches

Chapter 5 Green algal communities from soil and tree bark in middle European forests: a molecular comparison

Chapter 6 Diversity of green algae in grassland and forest soils under different management types - a culture-independent approach

Summary

Danksagung

Publications 


\section{General Introduction}

Eukaryotic microalgae are widespread phototrophic organisms not only in aqueous habitats like freshwater or the marine environment, but are also common and abundant in diverse terrestrial habitats (Hoffmann, 1989; López-Bautista et al., 2007; Karsten et al., 2007; Rindi et al., 2010; Holzinger and Karsten, 2013; Ettl and Gärtner, 2014). Among terrestrial algae, the green algae, along with the prokaryotic cyanobacteria, may be the most diverse group (Hoffmann, 1989; Rindi, 2007; Rindi, 2011). The eukaryotic terrestrial green algae comprise both phyla Chlorophyta and Streptophyta (Lewis and McCourt, 2004; Pröschold and Leliaert, 2007). Terrestrial green algae are particularly diverse in the Chlorophyta where they are distributed on at least three lineages, the classes Trebouxiophyceae, Chlorophyceae and Ulvophyceae (Friedl and Rybalka, 2012; Leliaert et al., 2012). Out of these three classes the Trebouxiophyceae appear to comprise predominantly terrestrial algae as most of its members are known from dry habitats exposed to air (aeroterrestrial algae), soil or lichen symbiosis (Friedl and Rybalka, 2012; Leliaert et al., 2012). With respect to colonization of land the Streptophyta may have been the most successful lineage, because the embryophytes have their origin within the Streptophyta (Karol et al., 2001; Turmel et al., 2007; Wodniok et al., 2011). Common terrestrial algal groups of the Streptophyta are members of the Klebsormidiophyceae (Rindi et al., 2011; Ryšánek et al., 2015). In general, several independent origins of "land plants", i.e. terrestrial green algae have been discussed (Lewis and Lewis, 2005; Lewis, 2007).

Terrestrial algae are obvious at almost all air exposed substrates, e.g. rocks, building stone, monument surfaces (Crispim et al., 2003; Hoppert et al., 2004; Macedo et al., 2009), artificial substrates in urban environment (such as house facades and roof tiles; Karsten et al., 2007), tree barks (Gärtner, 1994; Lüttge and Büdel, 2010; Neustupa and Štifterová, 2013) where green algae often form conspicuous green phototrophic biofilms or crusts, as well as soils. The green algal communities (as well as the cyanobacterial communities) on stone surfaces may be involved in biodeterioration of their substrates growing epi- and endolithically on rocks as well as building material and monument surfaces (Saiz-Jimenez, 1995; Warscheid and Braams, 2000; Crispim et al., 2003; Gaylarde et al., 2003; Hoppert et al., 2005; López-Bautista et al., 2007; Cutler et al., 2013). They also contribute to undesirable coloration observed in urban habitats on various man-made substrates, e.g. building facades and roof tiles (Barberousse et al., 2006; Rindi, 2007; Gladis-Schmacka 
et al., 2014). Soils are the most important non-aqueous habitats for terrestrial algal communities (Zenova et al., 1995). They have beneficial functions in soil, e.g. provide organic matter as food source, perform nitrogen fixation, and interact with higher plants (Metting, 1981; Starks et al., 1981). These green algal communities together with cyanobacteria are among the first organisms colonizing bare soils, deserts or disturbed sites and promote soil stability and constitute water-stable aggregates to prevent erosion (Johansen, 1993; Lewis and Lewis, 2005; Büdel et al., 2014).

Traditionally, the composition of terrestrial green algal communities have been assessed by the establishment of enrichment cultures followed by the development of pure unialgal cultures. These isolates have been identified by microscopic features which, however, are often rather spare in distinctive characters which may cause uncertainties in the identification. Only single terrestrial green algal isolates have been identified at the molecular level, i.e. by comparisons of DNA sequence signatures which enable an unambiguous identification and re-identification of algal species. Using traditional culture methods only, there have been considerable uncertainties in the diversity of terrestrial green algal communities due to different identification strategies depending on the authors and taxonomic uncertainties of previously published floristic lists (Hoffmann, 1989; Lukešová and Hoffmann, 1996; Neustupa and Škaloud, 2010). A culture-independent molecular approach provides unambiguous identification of green algal communities e.g. in terrestrial environments. Even if the recovered species may not be exactly named in case of lack of appropriate reference sequences or taxonomic problems, the algal taxa can be unambiguously recovered by their unique molecular signature. This enables not only a more reliable approach to determine the diversity of an algal community, but also permits comparisons among the algal communities of the same and different habitats. 


\section{Aim of the thesis}

The main objective of this thesis was to test the reliability of a molecular approach for the diversity assessment of terrestrial green algal communities using several exemplar habitats, i.e. open air-exposed-ones as well as soil. It should be further evaluated in as much the green algal species composition can be unambiguously determined so that comparisons of different communities at the same habitat/substrate along a gradient of abiotic parameters or between different habitats and substrates are possible. 18S rRNA gene sequences were used determined from environmental clone libraries. This approach was compared with corresponding analyses based on enrichment cultures or unialgal isolates in selected cases, i.e. chapters 4 and 6 .

Chapter 1 describes the diversity of air-exposed phototrophic biofilms, including cyanobacteria, on natural building stone. The communities of two wall areas with different expositions towards sun were compared. Chapter $\mathbf{2}$ and Chapter $\mathbf{3}$ present the assessment of biofilms consisting green algae and fungi covering stone monuments, their composition and potential involvement in biodeterioration. Additionally, the re-colonization after cleaning and restauration procedures were investigated. The analysis of a green algal biofilm on an exemplar artificial hard substrate in an urban environment is outlined in Chapter 4. In Chapter 5 also a natural air-exposed substrate, different types of tree bark, was studied in the framework of the German Biodiversity Exploratories, a large scale research project which attempts to uncover effects of management types and intensities of biodiversity. Finally and also in frame of the latter project, in Chapter 6, the green algal diversities of different forest and grassland soils from defined research plots at three different geographic regions in Germany were compared. 


\section{References}

Barberousse, H., Lombardo, R.J., Tell, G. and Couté, A. (2006) Factors involved in the colonisation of building façades by algae and cyanobacteria in France. Biofouling 22: 69-77.

Büdel, B., Colesie, C., Green, T.A., Grube, M., Suau, R.L., et al. (2014) Improved appreciation of the functioning and importance of biological soil crusts in Europe: the Soil Crust International Project (SCIN). Biodivers Conserv 23: 1639-1658.

Crispim, C.A., Gaylarde, P.M. and Gaylarde, C.C. (2003) Algal and cyanobacterial biofilms on calcareous historic buildings. Curr Microbiol 46: 79-82.

Cutler, N.A., Viles, H.A., Ahmad, S., McCabe, S. and Smith, B.J. (2013) Algal 'greening'and the conservation of stone heritage structures. Sci Total Environ 442: 152-164.

Ettl, H. and Gärtner, G. (2014) Syllabus der Boden-, Luft- und Flechtenalgen. Gustav Fischer, Stuttgart.

Friedl, T. and Rybalka, N. (2012) Systematics of the green algae: A brief introduction to the current status. In Lüttge, U., Beyschlag, W., Francis, D. and Cushman, J. (eds) Progress in Botany No. 73. Springer, Heidelberg, pp. 259-280.

Gärtner, G. (1994) Zur Taxonomie aerophiler grüner Algenanflüge an Baumrinden. Ber nat-med Verein Innsbruck 81: 51-59.

Gaylarde, C., Silva, M.R. and Warscheid, T. (2003) Microbial impact on building materials: an overview. Mater Struct 36: 342-352.

Gladis-Schmacka, F., Glatzel, S., Karsten, U., Böttcher, H. and Schumann, R. (2014) Influence of local climate and climate change on aeroterrestrial phototrophic biofilms. Biofouling 30: 401-414.

Hoffmann, L. (1989) Algae of terrestrial habitats. Bot Rev 55: 77-105.

Holzinger, A. and Karsten, U. (2013) Desiccation stress and tolerance in green algae: consequences for ultrastructure, physiological, and molecular mechanisms. Front Plant Sci 4 article 327.

Hoppert, M., Flies, C., Pohl, W., Günzl, B. and Schneider, J. (2004) Colonization strategies of lithobiontic organisms on carbonate rocks. Environ Geol 46: 4212-4428.

Hoppert, M., König, S. and Hegermann, J. (2005) Mikroalgen auf Oberflächen von Baumaterialien. Zeitschrift der Deutschen Gesellschaft für Geowissenschaften 156: 93-101.

Johansen, J.R. (1993) Cryptogamic crusts of semiarid and arid lands of North America. J Phycol 29: $140-147$.

Karol, K.G., McCourt, R.M., Cimino, M.T. and Delwiche, C.F. (2001) The closest living relatives of land plants. Science 294: 2351-2353.

Karsten, U., Schumann, T. and Mostaert, A.S. (2007) Aeroterrestrial algae growing on man-made surfaces: What are their secrets of ecological success? In Seckbach, J. (ed) Algae and Cyanobacteria in Extreme Environments. Springer Verlag, Dordrecht, the Netherlands, pp. 583-597.

Leliaert, F., Smith, D.R., Moreau, H., Herron, M.D., Verbruggen, H., Delwiche, C.F. and De Clerck, O. (2012) Phylogeny and molecular evolution of the green algae. CRC Crit Rev Plant Sci 31: 1-46.

Lewis, L.A. and McCourt, R.M. (2004) Green algae and the origin of land plants. Am J Bot 91: 1535-1556.

Lewis, L.A. and Lewis, P.O. (2005) Unearthing the molecular phylodiversity of desert soil green algae (Chlorophyta). Syst Biol 54: 936-947.

Lewis, L.A. (2007) Chlorophyta on land. In Seckbach, J. (ed) Algae and Cyanobacteria in Extreme Environments. Springer Verlag, Dordrecht, the Netherlands, pp. 569-582. 
López-Bautista, J.M., Rindi, F. and Casamatta, D. (2007) The systematics of subaerial algae. In Seckbach, J. (ed) Algae and Cyanobacteria in Extreme Environments. Springer Verlag, Dordrecht, the Netherlands, pp. 599-617.

Lukešová, A. and Hoffmann, L. (1996) Soil algae from acid rain impacted forest areas of Krusne hory Mts. 1. Algal communities. Vegetatio 125: 123-136.

Lüttge, U. and Büdel, B. (2010) Resurrection kinetics of photosynthesis in desiccation-tolerant terrestrial green algae (Chlorophyta) on tree bark. Plant Biol (Stuttg) 12: 437-444.

Macedo, M.F., Miller, A.Z., Dionísio, A. and Saiz-Jimenez, C. (2009) Biodiversity of cyanobacteria and green algae on monuments in the Mediterranean Basin: an overview. Microbiology 155: 3476-3490.

Metting, B. (1981) The systematics and ecology of soil algae. Bot Rev 47: 195-312.

Neustupa, J. and Škaloud, P. (2010) Diversity of subaerial algae and cyanobacteria growing on bark and wood in the lowland tropical forests of Singapore. Plant Ecol Evol 143: 51-62.

Neustupa, J. and Štifterová, A. (2013) Distribution patterns of subaerial corticolous microalgae in two European regions. Plant Ecol Evol 146: 279-289.

Pröschold, T. and Leliaert, F. (2007) Systematics of the green algae: Conflict of classic and modern approaches. In Brodie, J. and Lewis, J.M. (eds.) Unravelling the algae: the past, present, and future of algal systematics. Taylor and Francis, pp. 123-153.

Rindi, F. (2007) Diversity, ecology and distribution of green algae and Cyanobacteria in urban habitats. In Seckbach, J. (ed) Algae and Cyanobacteria in Extreme Environments. Springer Verlag, Dordrecht, the Netherlands, pp. 583-597.

Rindi, F., Allali, H.A., Lam, D.W. and López-Bautista, J.M. (2010) An overview of the biodiversity and biogeography of terrestrial green algae. In Rescigno, V. and Maletta, S. (eds) Biodiversity Hotspots. Nova Science Publishers, Hauppauge, New York, pp. 105-122.

Rindi, F. (2011) Terrestrial green algae: systematics, biogeography and expected responses to climate change. In Hodkinson T.R., Jones, M.B., Waldren, S. and Parnell, J.A.N. (eds) Climate Change, Ecology and Systematics. Cambridge University Press, Cambridge, pp. 201-227.

Rindi, F., Mikhailyuk, T.I., Sluiman, H.J., Friedl, T. and López-Bautista, J.M. (2011) Phylogenetic relationships in Interfilum and Klebsormidium (Klebsormidiophyceae, Streptophyta). Mol Phylogenet Evol 58: 218-231.

Ryšánek, D., Hrčková, K. and Škaloud, P. (2015) Global ubiquity and local endemism of freeliving terrestrial protists: phylogeographic assessment of the streptophyte alga Klebsormidium. Environmental microbiology. Environ Microbiol 17: 689-698.

Saiz-Jimenez, C. (1995) Deposition of anthropogenic compounds on monuments and their effect on airborne microorganisms. Aerobiologia 11: 161-175.

Starks, T.L., Shubert, L.E. and Trainor, F.R. (1981) Ecology of soil algae: a review. Phycologia 20: 65-80.

Turmel, M., Pombert, J.F., Charlebois, P., Otis, C. and Lemieux, C. (2007) The green algal ancestry of land plants as revealed by the chloroplast genome. Int J Plant Sci 168: 679-689.

Warscheid, T. and Braams, J. (2000) Biodeterioration of stone: a review. Int Biodeterior Biodegradation 46: 343-368.

Wodniok, S., Brinkmann, H., Glöckner, G., Heidel, A.J., Philippe, H., Melkonian, M. and Becker, B. (2011) Origin of land plants: do conjugating green algae hold the key? BMC Evol Biol 11: 104.

Zenova, G.M., Shtina, E.A., Dedysh, S.N., Glagoleva, O.B., Likhacheva, A.A. and Gracheva, T.A. (1995) Ecological relations of algae in biocenoses. Mikrobiologiya 64: 121-133. 


\title{
Chapter 1: \\ Molecular diversity of phototrophic biofilms \\ on building stone
}

\author{
Christine Hallmann ${ }^{1}$, Lorena Stannek ${ }^{2}$, Diana Fritzlar ${ }^{2}$, Dorothea Hause-Reitner ${ }^{3}$, \\ Thomas Friedl $^{1,3}$ and Michael Hoppert ${ }^{2,3}$ \\ Published in FEMS Microbiology Ecology (2013) 84: 355-372 \\ 'Department of Experimental Phycology and Culture Collection of Algae (SAG), \\ Albrecht-von-Haller-Institute for Plant Sciences, Georg-August-University, \\ Göttingen, Germany \\ Institute for Microbiology and Genetics, Georg-August-University, \\ Göttingen, Germany \\ ${ }^{3}$ Courant Research Center Geobiology, Georg-August-University, \\ Göttingen, Germany
}

Author contributions to the work:

Performed the experiments: CH, LS, DF.

Analyzed data: $\mathrm{CH}$.

Performed scanning electron microscopy: DHR, $\mathrm{CH}$.

Wrote the paper: $\mathrm{CH}, \mathrm{MH}, \mathrm{TF}$.

Conceived and designed the experiments: $\mathrm{MH}, \mathrm{CH}$. 


\begin{abstract}
Composition and diversity of aeroterrestrial phototrophic microbial communities are up to now poorly understood. Here, we present a comparative study addressing the composition of algal communities on sandstone substrata based upon the analysis of rRNA gene clone libraries from environmental samples and crude cultures. From a west-facing, shaded wall area of the mediaeval castle ruin Gleichen (Thuringia, Germany), sequences mainly related to the green algae Prasiococcus and Trebouxia (Trebouxiophyceae) were retrieved. A south-west-facing, sun-exposed wall area was mainly colonized by Apatococcus and a Phyllosiphon-related alga. Just a few species, in particular Stichococcus-related strains, were ubiquitous in both areas. Samples from a basement vault exposed to low irradiance exhibited Chlorophyceae like Chromochloris and Bracteacoccus. Thus, most green algae on the daylight-exposed walls were affiliated to Trebouxiophyceae, whereas Chlorophyceae were dominant in samples taken from the site kept under low irradiance. Accordingly, cyanobacterial communities were different: the sun-exposed area was dominated by Synechococcus-related organisms, while on the shaded wall area, cyanobacteria were almost absent. The filamentous Leptolyngbya dominated samples from the basement vault. Scanning electron microscopy revealed endolithic algal morphotypes (coccoid algae and diatoms) dominant in open pores between mineral particles. Here, the organisms may be also involved in biogenic weathering of stone.
\end{abstract}

Keywords: green algae, cyanobacteria, environmental sample, 18S rRNA gene, scanning electron microscopy. 


\section{Introduction}

Phototrophic microorganisms are important primary producers on hard rock substrata as well as on building facades (e.g. Karsten et al., 2007a; Horath and Bachofen, 2009). Eukaryotic microalgae and cyanobacteria, along with fungi and lichens, have also been recognized as important factors for rock weathering and stone decay (e.g. Welton et al., 2003; Büdel et al., 2004; Gorbushina, 2007). The rock substratum itself mostly provides harsh environmental conditions. Temperature may vary by several tens of degrees Centigrade during a day, accompanied by rapid desiccation (or freezing); that is, the availability of water is extremely limited (e.g. Walker and Pace, 2007). The availability of nitrogen and sulphur compounds as well as phosphate strongly depends on the substratum and other nutrient sources in the immediate surrounding, for example precipitation, soil, bird droppings and volatile emissions (e.g. Karsten et al., 2003).

It has been recognized that in extreme habitats, the productivity of the organisms must be close to lowest possible limits (e.g. Johnston and Vestal, 1991). Despite adverse conditions, the mineral substrata may be colonized on the surface (epilithic) or inside the substratum (endolithic) by relatively highly diverse communities of phototrophic and heterotrophic microorganisms (mainly fungi and bacteria).

Several studies identifying algae according to their morphology reported differences in algal diversity depending on diverse substrata including stone (e.g. Bellinzoni et al., 2003; Crispim et al., 2003; Uher, 2008; Macedo et al., 2009; Khaybullina et al., 2010). However, so far only few studies based on a culture-independent approach using rRNA gene as phylogenetic marker were performed for mineral substrata (e.g. Horath and Bachofen, 2009; Cuzman et al., 2010; Ragon et al., 2012). Also knowledge on factors that may determine the algal diversity on different but closely neighbouring sites is still lacking. It is obvious that - apart from irradiance - composition of the algal communities is determined by other physical parameters as well. In soil, the $\mathrm{pH}$ appears to be one factor that influences the dominance of the major groups of photoautotrophic organisms: cyanobacteria are known to prefer neutral and alkaline soils (Shields and Durell, 1964; Brock, 1973), whereas green algae prefer acidic soils (Starks et al., 1981; Lukešová and Hoffmann, 1995). In addition, cyanobacterial and green algal communities in soil may be influenced by soil type (Garcia-Pichel et al., 2001) and land use (Zancan et al., 2006). Previous studies of phototrophic communities on various building stones and rock substrata demonstrated that nutrients have less influence on the community structure than, 
for example, UV radiation, pH and aspect (Bellinzoni et al., 2003; Furey et al., 2007). Microalgal and cyanobacterial resting stages may easily resist adverse environmental conditions (e.g. Häubner et al., 2006; Lennon and Jones, 2011). These resting stages and other kinds of propagules may be present as a 'seed bank' (Lennon and Jones, 2011). They may turn active after environmental conditions change. Thus, it may be assumed that a multitude of organisms will be detectable and even culturable from habitats with adverse environmental conditions, despite these organisms may be inactive and just present in low numbers in their natural habitat.

In this study, we show that the composition of phototrophic microbial algal communities including cyanobacteria differed markedly between apparently similar substrata. This is mainly due to differences in the exposure to sunlight (and hence water availability) and the occurrence of gypsum crusts. We used a molecular approach that allowed the identification of microalgae including cyanobacteria down to generic or even species level. We also discuss the results in view of possible biodeterioration mechanisms.

\section{Materials and methods}

\section{Sampling sites}

The sampling sites were several wall sections of the castle Gleichen, near Gotha, Thuringia, Germany $\left(50^{\circ} 52^{\prime} 49^{\prime \prime} \mathrm{N}, 10^{\circ} 50^{\prime} 20^{\prime \prime} \mathrm{E}\right)$. In this location, the average regional annual temperature is $8.1{ }^{\circ} \mathrm{C}$, the sunshine duration is about $1500 \mathrm{~h}$ per year, and annual precipitation is about $560 \mathrm{~mm}$ (data taken from Deutscher Wetterdienst Offenbach, Germany). In the year of sampling (sampling date May 15, 2009), precipitation was higher than the long year average (March-May $173 \mathrm{~mm}$, compared with $120 \mathrm{~mm}$ long year average in these months). Average temperatures in March $\left(4.2{ }^{\circ} \mathrm{C}\right)$, April $\left(11.2{ }^{\circ} \mathrm{C}\right)$ and May $\left(13.2^{\circ} \mathrm{C}\right)$ were slightly higher than the respective long year averages in the first two months $\left(2.8^{\circ} \mathrm{C}, 7.5^{\circ} \mathrm{C}\right.$ and $13.2^{\circ} \mathrm{C}$, respectively).

Samples were taken from two walls. A south-west-facing wall facade (wall area A; slope $90^{\circ}$, aspect value $210^{\circ}$ ) was exposed to direct sunlight for 8-10 $\mathrm{h}$ during these months. A west-facing facade (wall area $\mathrm{B}$; slope $90^{\circ}$, aspect value $275^{\circ}$ ), due to the existing architectural structures, was reached by direct sunlight just in the afternoon for $3 \mathrm{~h}$ (from $4.00 \mathrm{~h} \mathrm{pm}$ onwards, without direct sunlight in March). A third sampling site (basement vault) was not reached by direct sunlight. The walls consisted of various types of dimension stones (Stück et al., 2011; see below). 


\section{Sampling and cultivation}

Samples of approximately $100 \mu 1$ dry volume were collected in May 2009 from southwest-facing wall area A (Fig. 1a, b), west-facing wall area B (Fig. 1c, d) and a basement vault in a distance of $5 \mathrm{~m}$ from the entrance (Fig. 1e, f). The samples were scraped off with a sterile scalpel and collected in sterile $2 \mathrm{ml}$ reaction tubes. Biofilm samples used for establishing the clone libraries were randomly taken from each wall area. All samples in area A were taken from sandstone (Gleichenberger Rhätsandstein) (c.f. Stück et al., 2011). Wall joints were mostly closed, that is, filled with gypsum mortar. Area B exhibited a variety of limestone and sandstone lithologies (travertine, Grenzdolomit, Rhätsandstein). Most wall joints were open. Again, just samples from sandstone (Rhätsandstein) were taken into consideration for this study. Samples from green biofilms grown in the inner faces of forming scales were collected from the basement vault (Fig. 1e-h).

For establishing crude cultures, aliquots of the biofilm samples were suspended in flasks with $20 \mathrm{ml}$ 3N BBM+V medium (Starr and Zeikus, 1993) for green algae, BG11 medium (Rippka and Herdman, 1993) for cyanobacteria and Diat medium for diatoms (c.f. http://www.uni-goettingen. de/de/186449.html). The crude cultures were incubated at $18{ }^{\circ} \mathrm{C}$ on a $14: 10 \mathrm{~h}$ light:dark cycle at $25 \mu \mathrm{mol}$ photons $\mathrm{m}^{-2} \mathrm{~s}^{-1}$ from white fluorescent light for four weeks.

\section{DNA extraction}

General procedures for handling and examination of DNA were performed according to Sambrook et al. (2000). Genomic DNA was extracted from collected environmental biofilm samples and crude cultures. If applicable, cultures grown on $3 \mathrm{~N}$ BBM+V or BG11 were mixed prior to DNA extraction. Cells were disrupted by shaking in a MiniBeadBeater (Biospec Products, Bartlesville, OK) in the presence of equivalent amounts of acid-washed glass beads (120-200 $\mu \mathrm{m}$ and 425-600 $\mu \mathrm{m}$ in diameter; Sigma-Aldrich, St. Louis, MO) and vortexed briefly. The samples were treated in the bead beater for $30 \mathrm{~s}$ at $5.000 \mathrm{rpm}$. DNA was extracted with the Invisorb Spin Plant Mini Kit (STRATEC Molecular, Berlin, Germany), following the manufacturer's instructions.

The MoBio PowerSoil DNA isolation Kit (MoBio Laboratories Inc. Carlsbad, CA) was used for extraction of genomic DNA from samples of endolithic biofilms according to the manufacturer's instructions. Extraction results were evaluated after electrophoresis on a $1 \%(\mathrm{w} / \mathrm{v})$ agarose gel. Isolated DNA was stored at $-20{ }^{\circ} \mathrm{C}$ until further processing. 

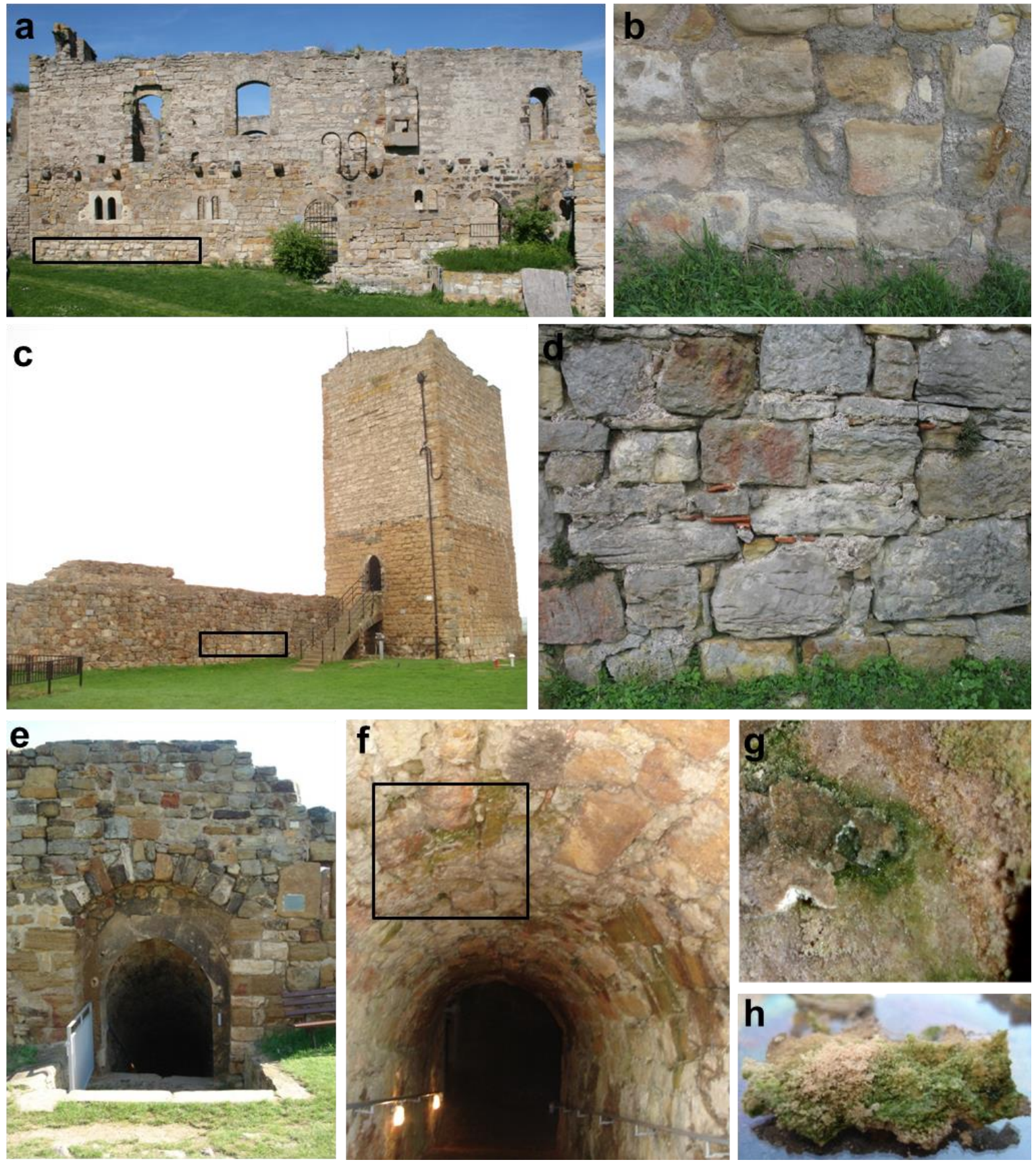

Fig. 1. Sampling sites on Gleichen castle. (a) Wall area A, sun-exposed. (b) Wall A in detail, with wall joints mostly filled with mortar. (c) Shaded wall area B. (d) Wall area B in detail, most wall joints open. (e) and (f) Dark basement vault, with scale samples removed from the basement vault. $(\mathrm{g})$ and $(\mathrm{h})$ Scales with green biofilm. Black frames: sampling areas. 


\section{PCR amplification}

For amplification of eukaryotic rRNA genes from DNA preparations, PCR was performed as follows: $18 \mathrm{~S}$ rRNA genes were first amplified using eukaryotic specific primers $20 \mathrm{~F}$ (5' GTAGTCATATGCTTGTCTC 3') and 18L (5' CACCTACGGAAACCTTGTTACGACTT 3'; Hamby et al., 1988) followed by a second amplification (semi-nested PCR) with the primers 20F and the newly developed CH1750R (5' CTTCCTCTARTGGGAGG 3'), complementary to positions 1734-1751 of the 18S rRNA gene sequence of Chlorella vulgaris SAG 211-11b (accession number X13688), specific for green algae (this study). For cyanobacteria from environmental samples and crude cultures, the primers PCR1 and PCR18 (Wilmotte et al., 1993) were used for amplification of 16S rRNA genes.

Approximately $30 \mathrm{ng}$ of the extracted DNA was used as template in each amplification reaction. The reaction mixture $(25 \mu \mathrm{l})$ contained each $\mathrm{dNTP}$ at a concentration of $0.1 \mathrm{mM}, 2.5 \mu \mathrm{l}$ of $10 \mathrm{x}$ reaction buffer, $2 \mathrm{mM} \mathrm{MgCl}_{2}$, each primer at a concentration of $0.2 \mu \mathrm{M}, 2 \mathrm{U}$ of Taq DNA polymerase (Bioline, Luckenwalde, Germany) and $4 \%(\mathrm{v} / \mathrm{v})$ dimethyl sulfoxide (DMSO) solution. PCR was performed in a thermocycler Primus $96^{\text {Plus }}$ (MWG-Biotech, Ebersberg, Germany) using the following programme for the primer set $20 \mathrm{~F} / 18 \mathrm{~L}$ : initial denaturation at $95{ }^{\circ} \mathrm{C}$ for $5 \mathrm{~min}$, followed by 35 cycles of denaturation at $94{ }^{\circ} \mathrm{C}$ for $1 \mathrm{~min}$, annealing at $50{ }^{\circ} \mathrm{C}$ for $1 \mathrm{~min}$, extension at $72{ }^{\circ} \mathrm{C}$ for $3 \mathrm{~min}$ and final extension at $72{ }^{\circ} \mathrm{C}$ for $10 \mathrm{~min}$. For the semi-nested PCR with the primer set 20F/CH1750R, a 1:25 dilution of the primary PCR product was used as template. The following programme was used: initial denaturation at $95{ }^{\circ} \mathrm{C}$ for $5 \mathrm{~min}$, followed by 25 cycles of denaturation at $94{ }^{\circ} \mathrm{C}$ for $1 \mathrm{~min}$, annealing at $54{ }^{\circ} \mathrm{C}$ for $1 \mathrm{~min}$, extension at $72{ }^{\circ} \mathrm{C}$ for $3 \mathrm{~min}$ and final extension at $72{ }^{\circ} \mathrm{C}$ for $10 \mathrm{~min}$. For the cyanobacterial primer set PCR1/PCR18, initial denaturation was at $95{ }^{\circ} \mathrm{C}$ for $5 \mathrm{~min}$, followed by 35 cycles of denaturation at $94{ }^{\circ} \mathrm{C}$ for $30 \mathrm{~s}$, annealing at $52{ }^{\circ} \mathrm{C}$ for $30 \mathrm{~s}$, extension at $72{ }^{\circ} \mathrm{C}$ for $2 \mathrm{~min}$ and a final extension at $72{ }^{\circ} \mathrm{C}$ for $30 \mathrm{~min}$.

From two crude cultures obtained from basement vault scales, diatom rRNA genes were amplified with specific primers as described in Pniewski et al. (2010). All PCR products were purified using the Invisorb DNA CleanUp Kit (STRATEC Molecular). Aliquots of $2 \mu 1$ of the purified amplicons were analysed by electrophoresis on a $1 \%(\mathrm{w} / \mathrm{v})$ agarose gel. 


\section{rRNA gene cloning and sequencing}

Cloning was carried out with the TOPO TA cloning kit (Invitrogen, Carlsbad, CA) with TOP 10 chemically competent One Shot Escherichia coli cells (Invitrogen), as supplied by the manufacturer. In the plasmid blue/white screening, white E. coli colonies containing correct DNA insertions were further identified by direct amplification of the inserted DNA fragment with a vector-specific primer set M13F/M13R (Invitrogen). Positive clones were cultivated overnight in $2 \mathrm{ml}$ reaction tubes with $1 \mathrm{ml} \mathrm{LB}$ medium containing $100 \mu \mathrm{g}$ ampicillin. Plasmid DNA was purified with the Invisorb Spin Plasmid Mini Two kit (STRATEC Molecular) and stored at $-20^{\circ} \mathrm{C}$.

Sequencing reactions were performed with the Dye Terminator Cycle Sequencing v3.1 kit (Applied Biosystems, Darmstadt, Germany) and an ABI Prism 3100 (Applied Biosystems) automated sequencer. All eukaryotic clones were sequenced with the $18 \mathrm{~S}$ standard sequencing primer 895R (5' AAATCCAAGAATTTCACCTC 3'), resulting in partial sequences, including the hypervariable regions V2-V4 (Neefs and De Wachter, 1990; Hodač et al., 2012; Lee and Gutell, 2012). Prokaryotic clones were sequenced with PCR1 (Wilmotte et al., 1993), resulting in partial sequences including the hypervariable regions V1-V3 (Santamaria et al., 2012).

\section{Phylogenetic and statistical analysis}

The sequences were edited and assembled using SeqAssem (Hepperle, 2004). Sequences shorter than $400 \mathrm{bp}$ were excluded from further analysis. The remaining sequences were compared with available sequences in NCBI by BLASTN (Altschul et al., 1990; http://www.ncbi.nlm.nih.gov/). Next, relative sequences were imported into the ARB program (Ludwig et al., 2004; http://www.arb-home.de). In addition, internal sequences provided by SAG Culture Collection of Algae (University of Göttingen) were included in the comparisons. To determine preliminary phylogenetic affiliations, the sequences were aligned with homologous rRNA gene sequences using the automatic alignment tool of the ARB program package.

Potential chimeras were checked by Bellerophon (Huber et al., 2004); in addition, the first and the last $300 \mathrm{bp}$ of putative chimeras were compared with similar rRNA gene sequences in NCBI. Chimeric sequences were excluded from the data set.

Rarefaction curves and operational taxonomic units (OTUs) were calculated with MOTHUR (Schloss et al., 2009). OTUs were defined on the basis of $\geq 98 \%$ sequence similarity for $18 \mathrm{~S}$ and $16 \mathrm{~S}$ rRNA gene sequences (Romari and Vaulot, 2004; Marande 
et al., 2009; Michaud et al., 2012; Stock et al., 2012). Representative sequences of each OTU were selected and sequenced completely (Moon-van der Staay et al., 2001; Ragon et al., 2012) with standard sequencing primers. Representative sequences were deposited in GenBank under the following accession numbers: JX127160 - JX127192.

For phylogenetic analyses, alignments of rRNA gene sequences were performed using MAFFT, version 6 (Katoh and Toh, 2008), and small corrections were made by eye. Complete rRNA gene sequences were subjected to phylogenetic analyses using the maximum likelihood (ML) method by RAxML (Stamatakis et al., 2008), in conjunction with the GTR $+\Gamma+\mathrm{I}$ model with 100 bootstrap replicates. In addition, Bayesian posterior probabilities (MB) were calculated with MrBayes 3.2 (Huelsenbeck and Ronquist, 2001). Two parallel Markov chain Monte Carlo (MCMC) runs for two million generations each with one cold and three heated chains were conducted using the GTR $+\Gamma+\mathrm{I}$ model, with trees sampled every 100 generations.

To quantify differences between groups of samples, SIMPER (Similarity percentages) analysis was conducted using the program PAST, version 1.98 (Hammer et al., 2001). A similarity matrix was calculated based on the abundances (in percentages) of the algal OTUs. As a similarity measure, Bray-Curtis distance index was used. The significance of differences was tested by one-way ANOSIM using the same similarity measure.

\section{Light and electron microscopy}

Light microscopic observations were performed using an Olympus BX60 microscope (Tokyo, Japan) with Nomarski DIC optics equipped with a ColorView III camera (Soft Imaging Systems, Münster, Germany). Micrographs were processed using the $\mathrm{Ce}^{\wedge}{ }^{\wedge} \mathrm{D}$ image software (Soft Imaging Systems).

For scanning electron microscopy (SEM), samples were fixed immediately after sampling in $2 \%$ (w/v) glutardialdehyde (EM grade, Sigma-Aldrich, Deisenhofen, Germany) and stored at $4{ }^{\circ} \mathrm{C}$ until further processing. Samples were dehydrated in an ascending ethanol series (15-99\%), mounted on SEM sample holders and sputtered with Au-Pd (7.3 nm for $120 \mathrm{~s}$ ). Samples were visualized in a SEM LEO 1530 Gemini (Zeiss, Oberkochen, Germany) combined with an INCA X-ACT EDX. Electron micrographs were colorized with Hornil StylePix (www.hornil. com/en/products/stylepix). Methods for transmission electron microscopy were performed as described in Hallmann et al. (2011a). 


\section{Results}

\section{Macro- and microscopic observations}

For this study, samples were taken from two south-west- and west-facing wall areas (A and B) and from scales formed on sandstone on a basement vault. All sampled sites exhibited obvious colonization by cryptogams, including algal ('green') biofilms. Thalli of endolithic lichens were abundant on sandstone at the base of wall area A. In addition, a thin gypsum crust (W. Wedekind, personal communication) covered small sections of wall area A. Green biofilms were occasionally found under these crusts. On wall area B, thalli of crustose lichens were also present, but endolithic lichens were not observed. Along the basement vault, thick green coverings in the inner faces of scales (Fig. 1g, h) were observed.

SEM of the fracture faces of the scales from the basement vault revealed a dense cover by either filamentous (Fig. 2a and inset) or coccoid (Fig. 2b) morphotypes and diatoms (Fig. 2c, d). The coccoid cells were located in open pores and between small chips of the mineral particles (clay particles intermixed with gypsum according to EDX analysis). The filamentous morphotypes (putatively cyanobacteria, see below) built up a dense biofilm on the mineral particles (Fig. 2a).

Diatoms were identified as Diadesmis contenta D.G. Mann (Fig. 2c) and Achnanthidium minutissimum Czarnecki (Fig. 2d) (Krammer and Lange-Bertalot, 1986-2004). Additional diatom phylotypes were retrieved from two crude cultures by rRNA gene analysis (see below). Various morphotypes of green algae were detected by light microscopy of the crude cultures, for example the cell package-forming green alga Prasiococcus calcarius (Fig. 3a). Also filamentous cyanobacteria were observed in these cultures (Fig. 3b).

\section{rRNA gene analysis of the phototrophic community}

Analyses of $16 \mathrm{~S}$ and $18 \mathrm{~S}$ rRNA genes aiming at detection of eukaryotic algae and cyanobacteria were performed for environmental samples and for crude cultures. Enrichment in crude cultures allows detection of organisms that are present in the original sample in just extremely low numbers of individuals, which may leave these species undiscovered in the environmental biofilm. 

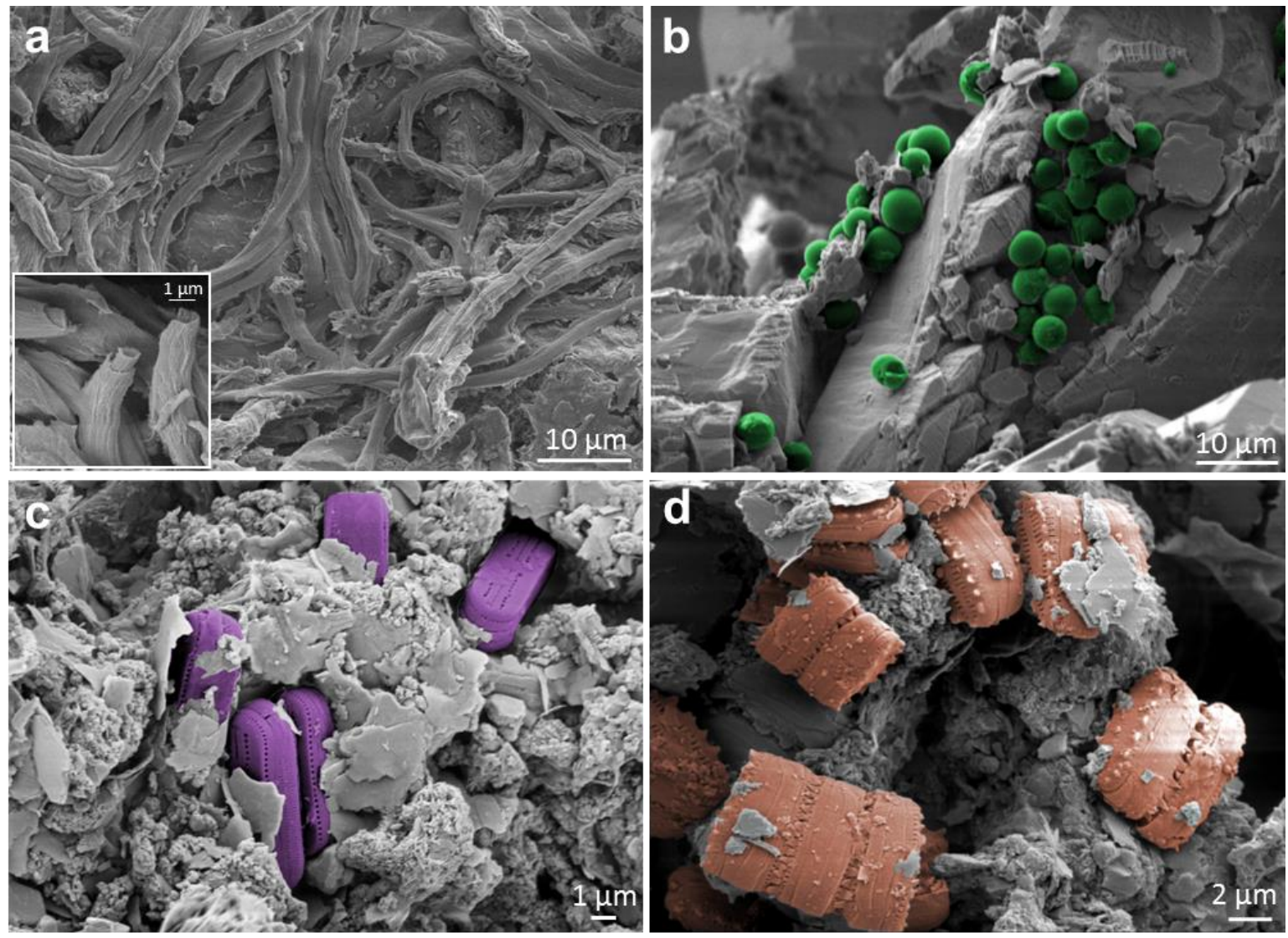

Fig. 2. Scanning electron microscopy images of scales as depicted in Fig. 1h. (a) Filamentous morphotypes cover the inner face of a scale as a dense biofilm. Inset: sheathed filaments in closeup. (b) Coccoid algal cells between small chips (green pseudocolor). (c) Diatoms (Diadesmis contenta) located in open pores (magenta pseudocolor). (d) Chains of the diatom Achnanthidium minutissimum (orange pseudocolor).

\section{Cyanobacteria}

16S rRNA gene clone libraries were established from four environmental samples of wall area A and six of wall B. Four clone libraries from basement vault scale samples were established from crude cultures.

A total of 11 cyanobacterial OTUs were recovered. With respect to cyanobacteria, wall areas A and B differed markedly (Fig. 4). On wall area A, 47 of 75 clones were assigned to cyanobacteria, with the majority of them (46) representing Synechococcus-like OTUs (cyanobacterial OTU 3 and 11, Table 1, Fig. 4). On wall area B, just seven of 70 sequenced clones were represented by cyanobacteria. 

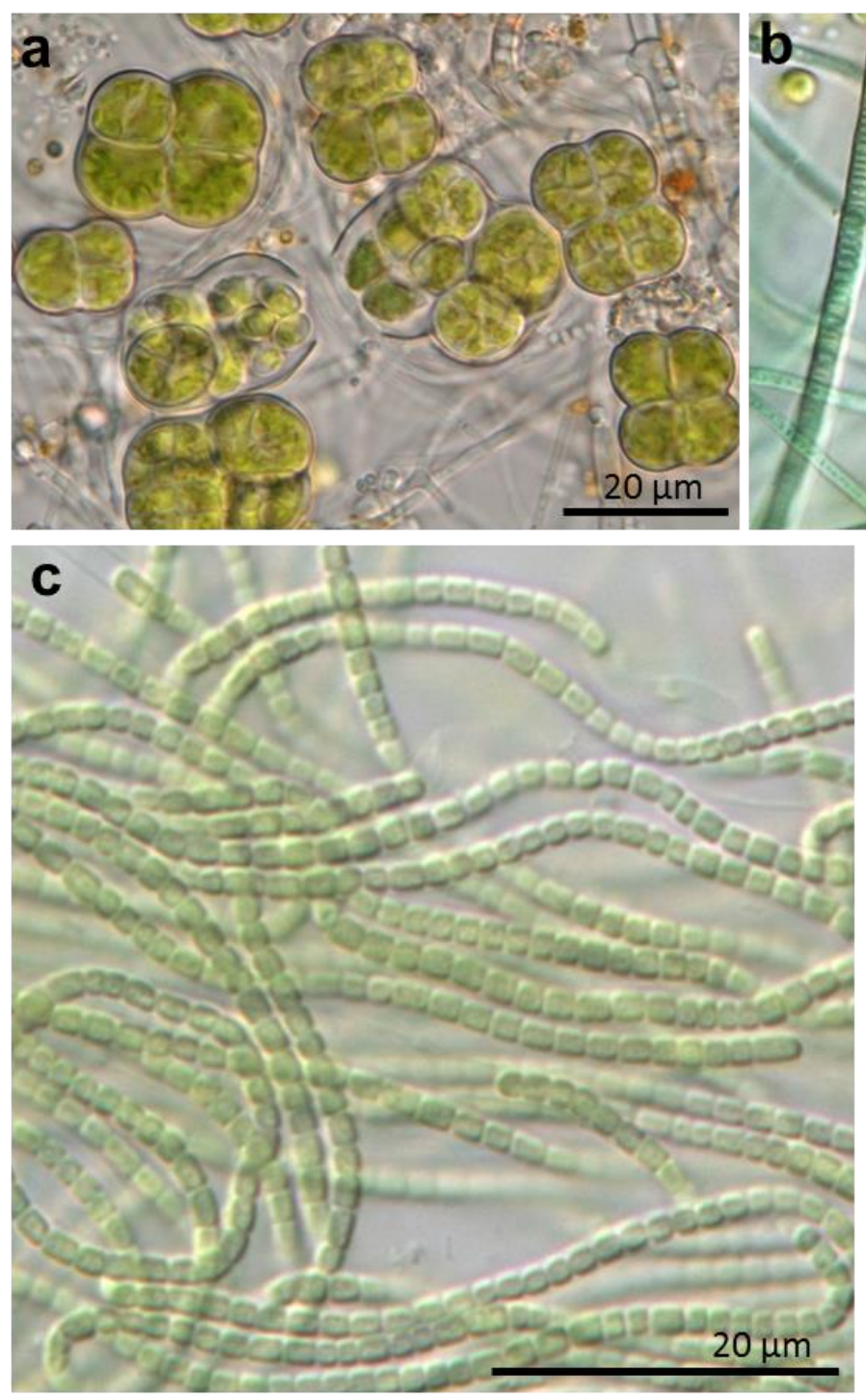
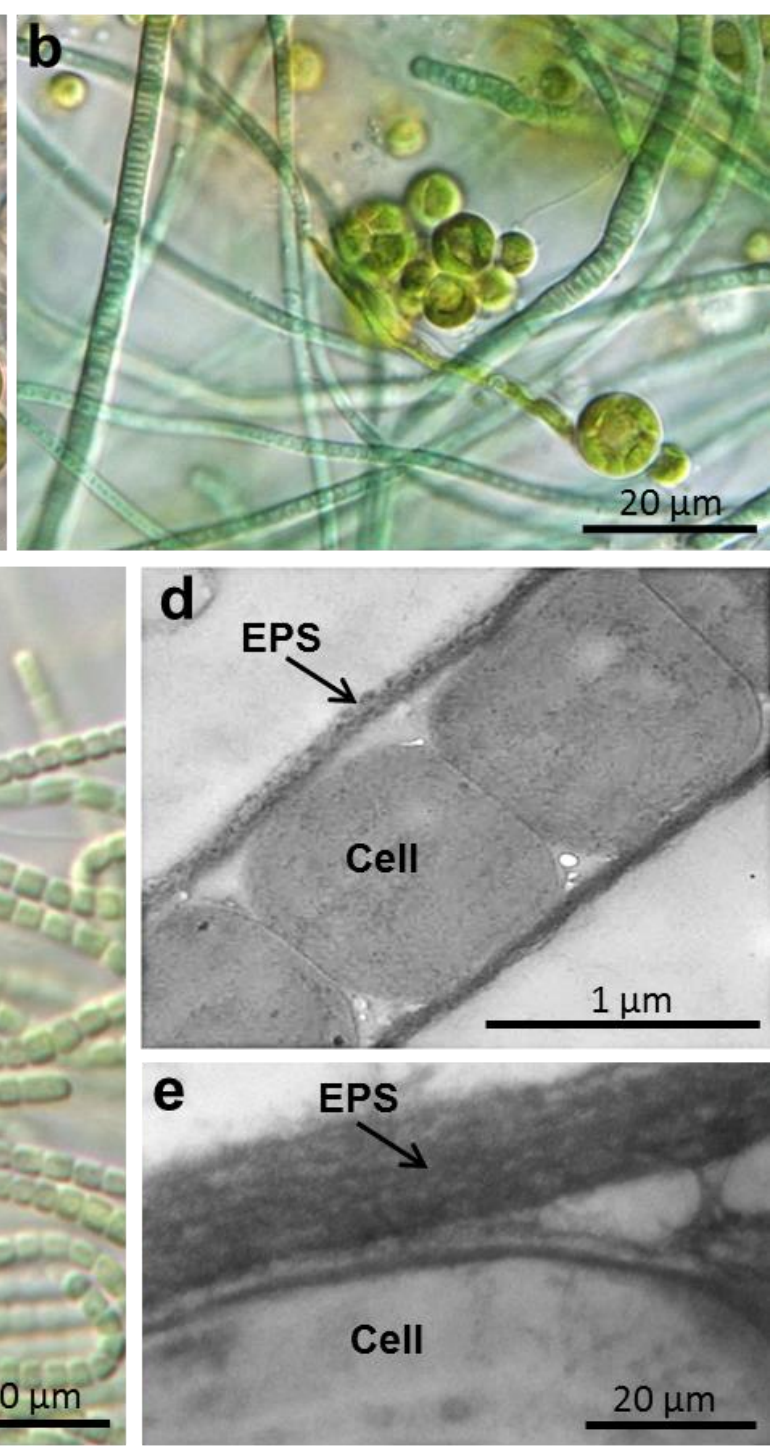

Fig. 3. Different morphotypes of cyanobacteria and green algae. (a) Crude culture with cell packages of Prasiococcus calcarius. (b) Crude culture with green algae and filamentous cyanobacteria. (c) Light micrograph of a Leptolyngbya sp. isolate. (d) and (e) Electron micrographs of a filament of Leptolyngbya, obtained by transmission electron microscopy of ultrathin sections with a multilayered exopolysaccharide (EPS) sheath; close-up view in (e).

From basement vault scale samples (Fig. 1g, h), 14 clones were retrieved, but with a dominance of clones representing Leptolyngbya-like cyanobacterial OTU 2 (Fig. 3c). This was in accordance with a high frequency of sheathed filamentous cyanobacteria as observed by electron microscopy of respective samples (Fig. 3d, e). In addition, three OTUs could be assigned to uncultured cyanobacteria (OTU 4, 5 and 6), three OTUs related to Chroococcus, one OTU related to Microcoleus vaginatus and one OTU representing Leptolyngbya-like cyanobacterial OTU 1 (Table 1, Fig. 5). 
Table 1. Distribution of cyanobacterial OTUs on different wall areas.

\begin{tabular}{|c|c|c|c|c|c|c|}
\hline \multicolumn{4}{|c|}{ No. of clones } & \multirow[b]{2}{*}{ Representative clone } & \multirow[b]{2}{*}{ Acc. No. } & \multirow[b]{2}{*}{ Closest relative ( $\%$ similarity) } \\
\hline OTU $98 \%$ & 6 Wall A & Wall B & Scale & & & \\
\hline 1 & & 1 & & 3GB21_K52 & JX127187 & Leptolyngbya sp. ANT.L52.1, AY493584 (99\%)* \\
\hline 2 & & & 10 & 3GSCS_K18* & JX127186 & Leptolyngbya frigida strain ANT.LMA.1, AY493573 (96 \%) \\
\hline 4 & & & 3 & 3GSCR_K16* & JX127185 & Uncultured bacterium clone AK4AB1_05A, GQ396895 (99\%), Chroococcodiopsis-related \\
\hline 5 & & 1 & & 3GB20_K48 & JX127184 & Uncultured bacterium clone 139, HM241004 $(96 \%)^{\star}$, Chroococcodiopsis-related \\
\hline 8 & & 1 & & 3GB1-7_K19 & JX127190 & Chroococcus sp. strain 2T05h, FR798926 (97\% \%) \\
\hline 9 & & 1 & & 3GB1-7_K20 & JX127192 & Chroococcus sp. strain 2T05h, FR798926 (92\%) \\
\hline 10 & & 1 & & 3GB1-7_K18 & JX127191 & Chroococcus sp. strain 2T05h, FR798926 (96\%) \\
\hline 11 & 5 & & & 3GA1-12_K89 & JX127189 & Uncultured cyanobacterium clone GG3, JQ404415 (98\%)*, Synechococcus-related \\
\hline
\end{tabular}

*Representative full length sequence in phylogenetic analysis.

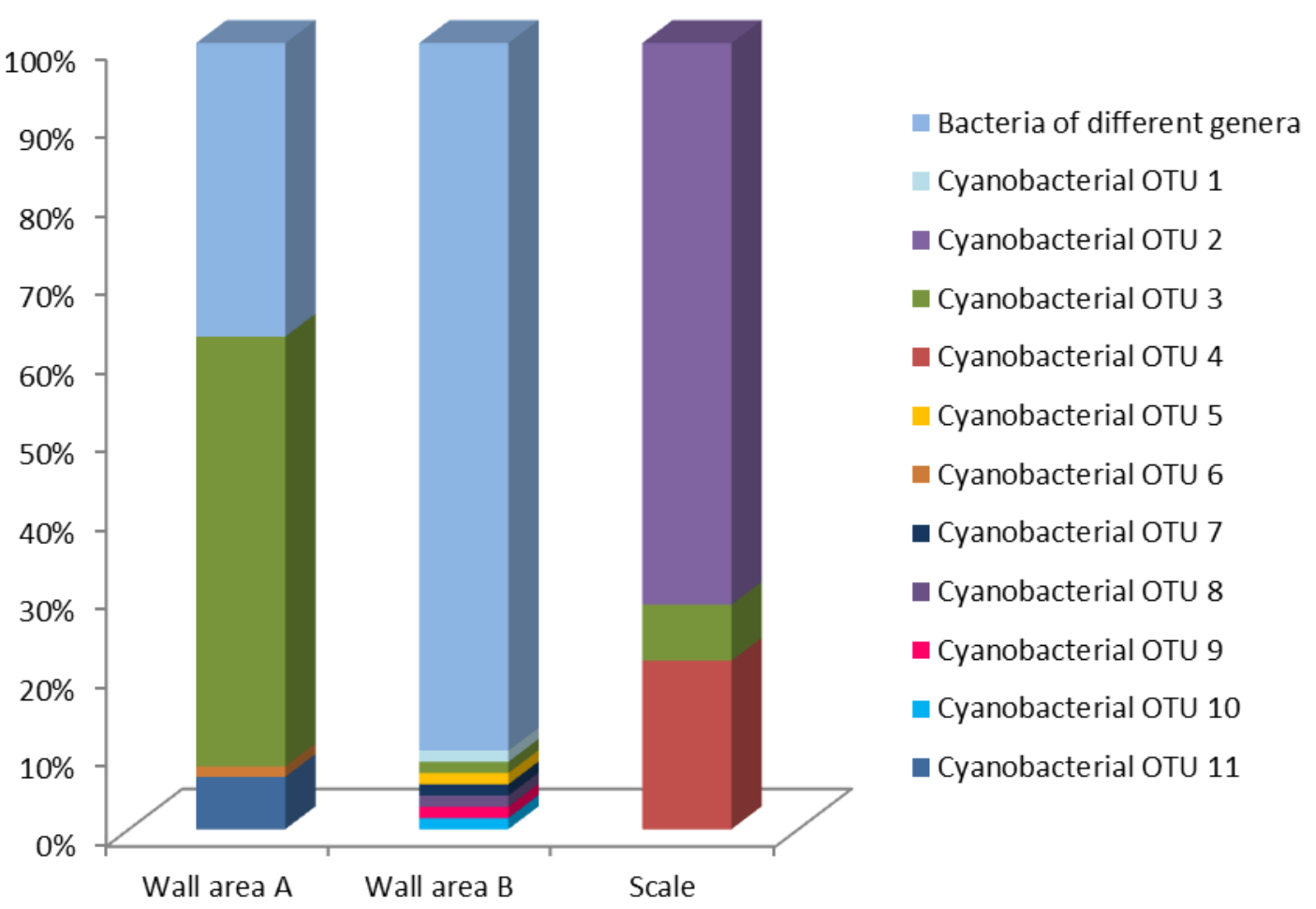

Fig. 4. Relative abundance of cyanobacterial operational taxonomic units (OTUs; $98 \%$ cut-off), obtained after analysis of 16S rRNA gene sequences, reveals clear differences between the southwest-facing wall area A, the west-facing wall area B and scale samples from the basement vault. 


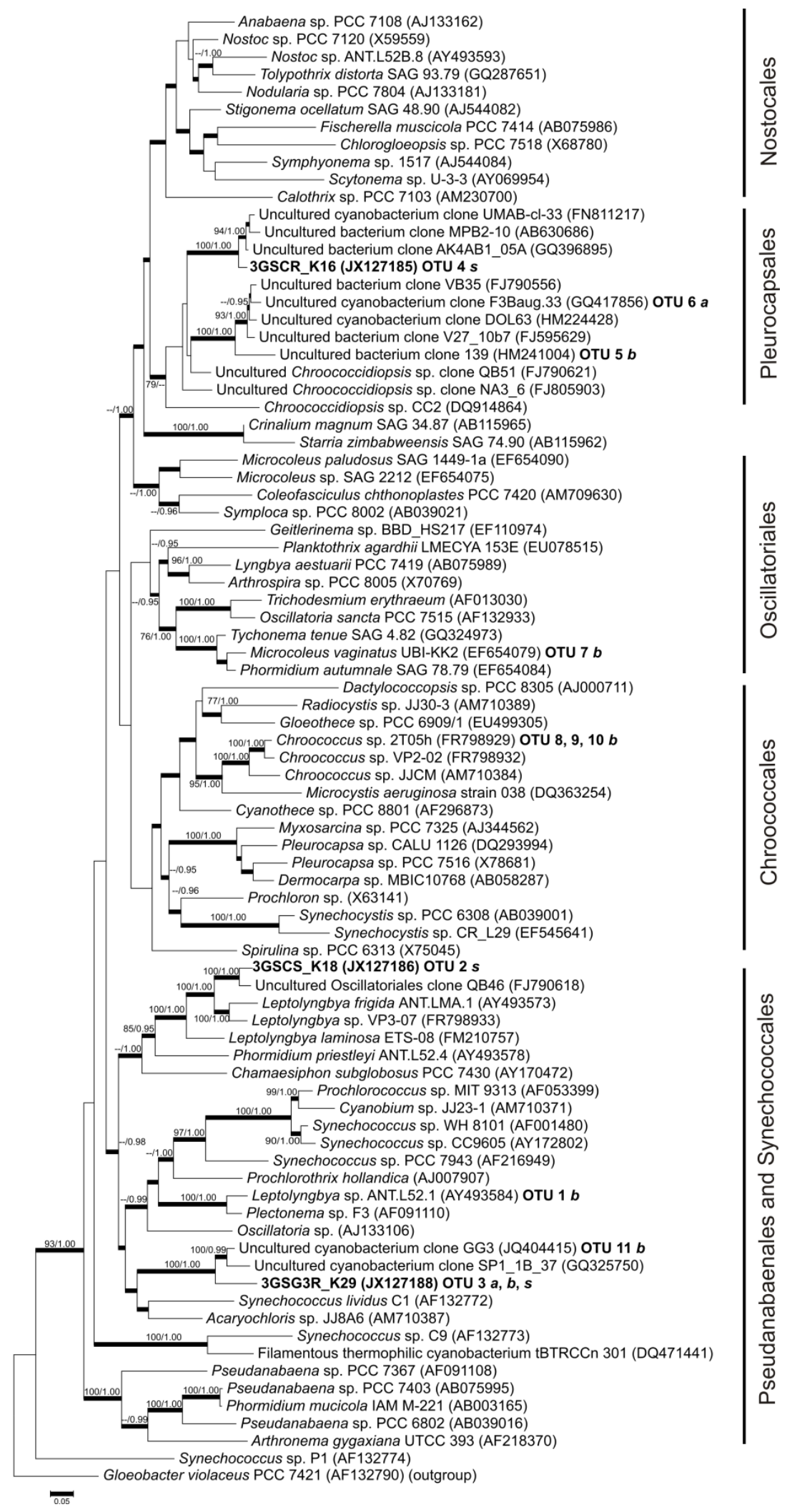

Fig. 5. Phylogenetic tree of cyanobacteria based on $16 \mathrm{~S}$ rRNA gene sequences. Maximum likelihood method (RAxML) based on 84 taxa and 1490 positions. Thick lines indicate internal nodes that were received in maximum likelihood and Bayesian trees. Support values given as ML (maximum likelihood; > $75 \%$ bootstrap values)/MB (MrBayes; > 0.95 Bayesian posterior probabilities). Sequences in bold represent full $16 \mathrm{~S}$ rRNA gene sequences of clones; a: wall A; b: wall B, s: scale. 


\section{Green Algae}

DNA preparations from environmental samples and from crude cultures were analysed with general eukaryotic primers and specific green algal primers as described in the methods section. In total, 648 18S rRNA partial sequences including 482 green algal clones were recovered from all sampling sites. These resulted in 22 green algal OTUs at a cut-off of $98 \%$ sequence homologies (Table 2).

Rarefaction curves (Fig. 6) calculated for the biofilm samples of wall areas A and B and the basement vault scale samples reveal the clone library coverage for algal sequences. For wall area $\mathrm{A}$, the rarefaction curve reached almost a plateau, and for wall area B, nearly full coverage of OTUs was reached. For the scale samples (biofilm samples and crude cultures), saturation was not reached.

On wall area A, 149 green algal clones representing 11 OTUs and eight fungal clones were found. Samples from wall area B yielded in 253 green algal clones representing 10 OTUs; 24 clones represented fungi. From scales, 214 clones were established, which were distributed on green algae (80 clones) representing 12 OTUs, flagellates (11 clones), fungi (13 clones) and mosses (110 clones). The green algal clones were processed for further statistical and phylogenetic analyses.

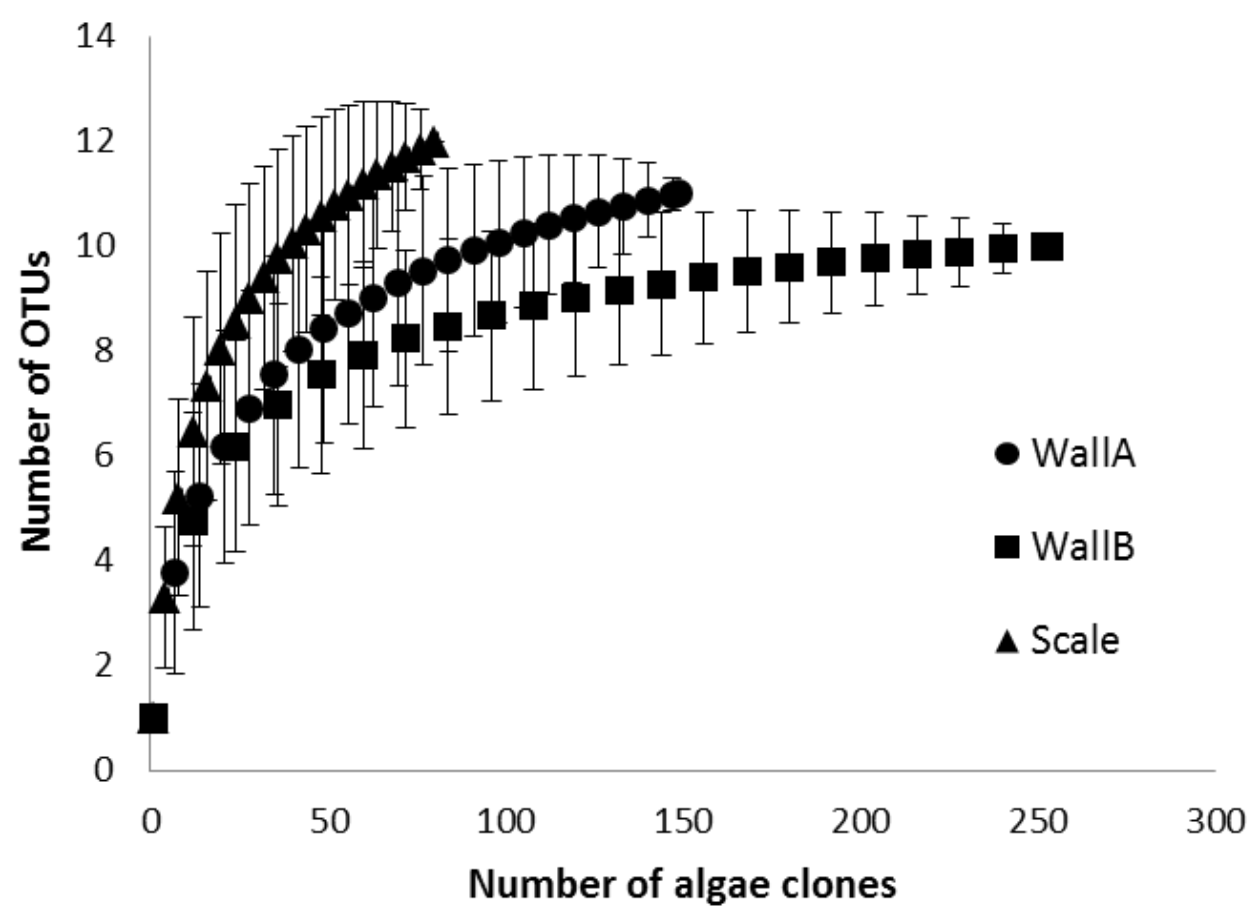

Fig. 6. Rarefaction curves determined for $18 \mathrm{~S}$ rRNA gene clone libraries. The OTUs include the green algal sequences from both wall areas (A and B) and from scale samples. 
Table 2. Distribution of green algal OTUs on different wall areas.

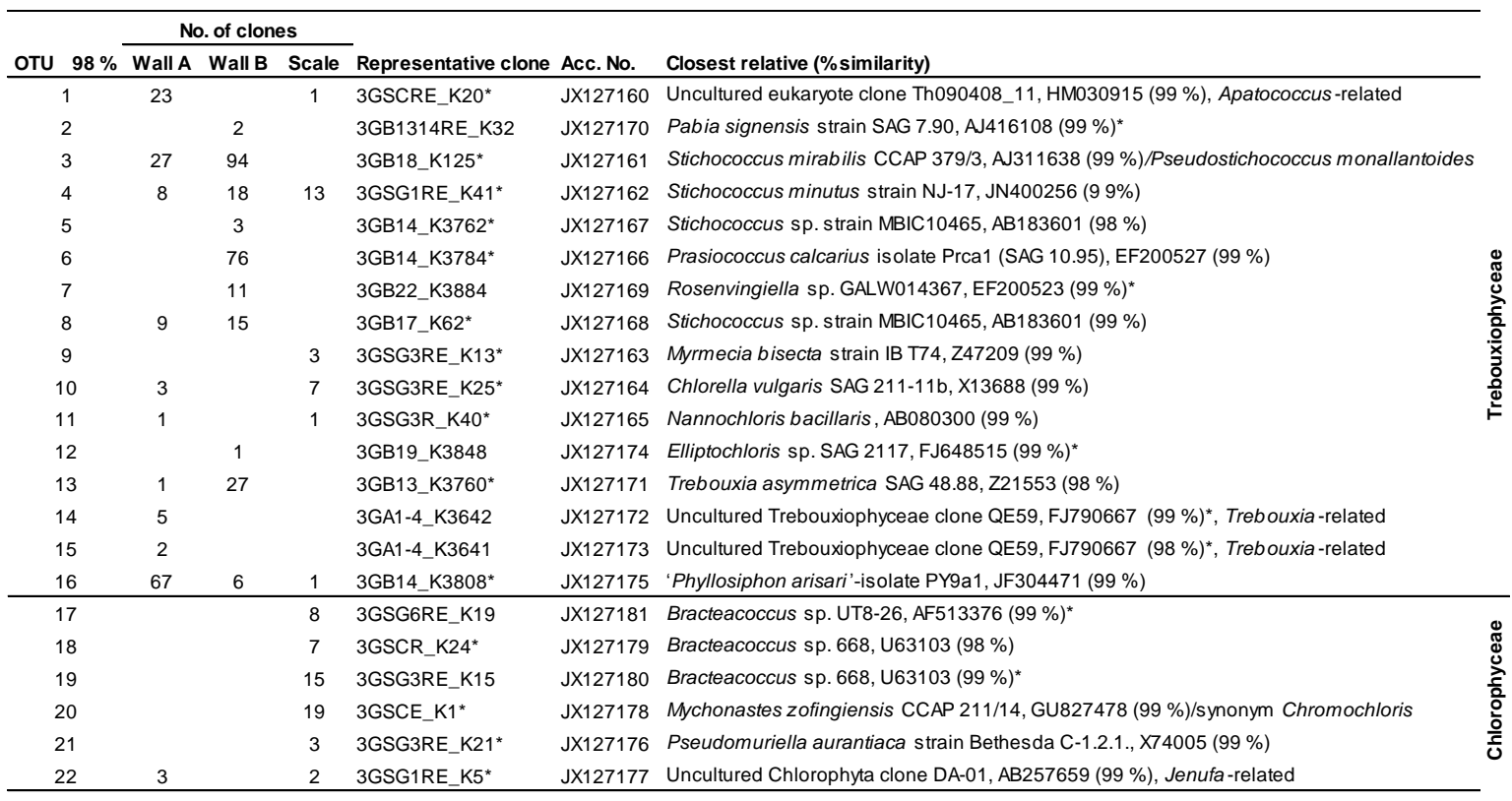

*Representative full-length sequence in phylogenetic analysis.

The composition of the green algal communities in wall areas A and B was apparently different, according to the analysis of clones from environmental DNA (Table 2, Figs. 7-9). Whereas Apatococcus lobatus and Phyllosiphon arisari-related sequences were highly abundant on wall area A but either absent or rare on wall area $\mathrm{B}$, P. calcarius- and Trebouxia asymmetrica-related sequences were detected nearly exclusively on wall area B. Only five green algal OTUs were shared between both wall areas, out of which three Stichococcus-related OTUs were in fact abundant (green algal OTUs 3, 4 and 8; Table 2).

The composition of the algal community from the basement vault scale samples has little in common with the communities from wall areas A and B (Fig. 7). Just the Stichococcus minutus (green algal OTU 4)- and P. arisari (green algal OTU 16)-related OTUs were shared by all three sampling sites.

With respect to wall areas A and B, crude cultures revealed only sequences belonging to Trebouxiophyceae, affiliated to green algal OTUs 2, 3 and 4. From the basement vault scale samples, just a single green algal OTU (a Chromochloris zofingiensis relative, Chlorophyceae) was recovered in the environmental clone library. In contrast to crude cultures from wall area samples, a high number of otherwise undetected OTUs were retrieved from crude cultures of scale samples (Table 2). Again, Chromochloris zopfingiensis-like green alga was abundant in these clone libraries. In addition, Bracteacoccus- and Stichococcus-related sequences were frequent. 


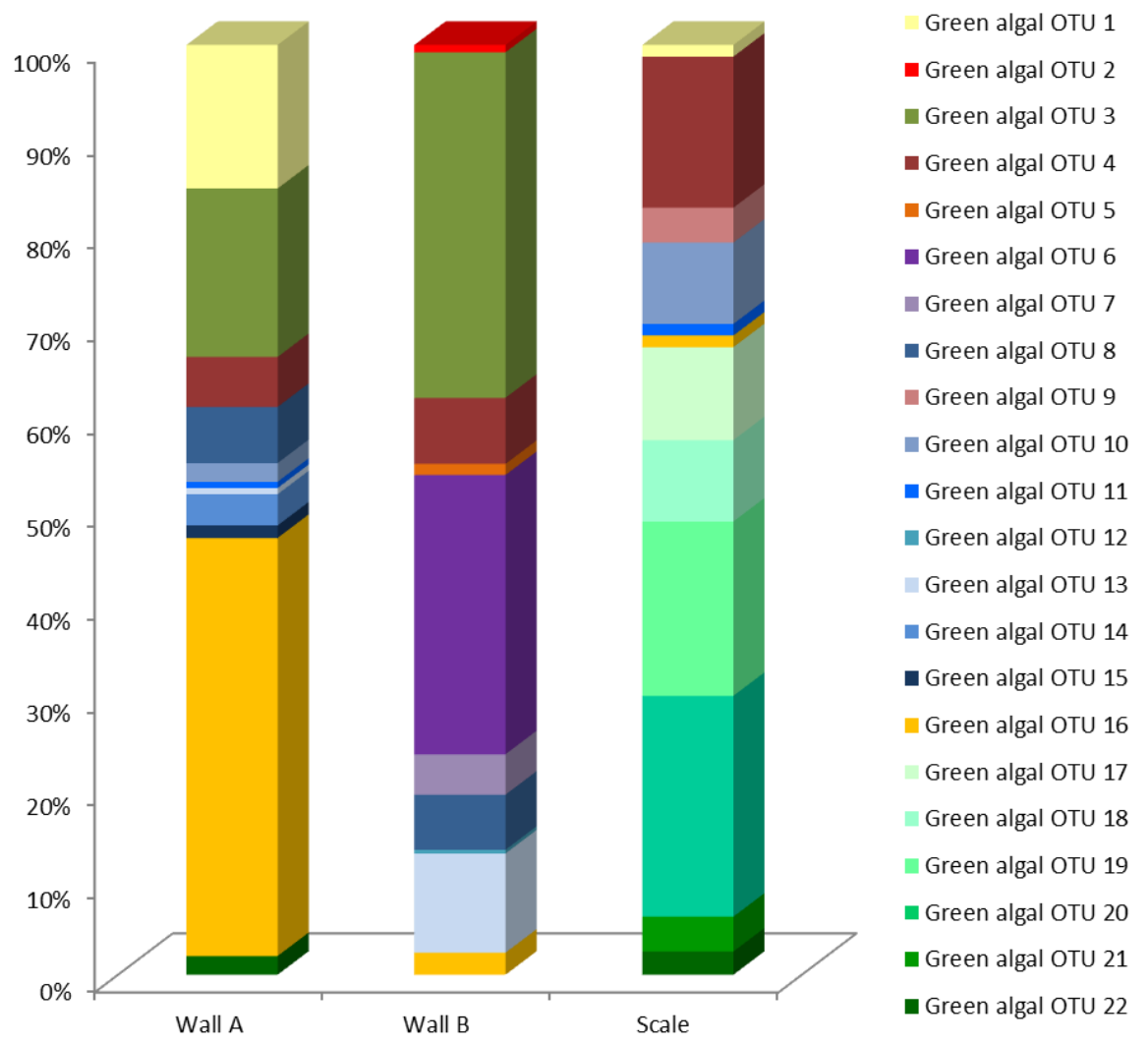

Fig. 7. Relative abundance of green algal operational taxonomic units (OTUs; $98 \%$ cut-off) obtained after analysis of $18 \mathrm{~S}$ rRNA gene sequences.

In summary, phylogenetic analysis revealed most green algal OTUs belonging to the green algal class of Trebouxiophyceae (16 OTUs; Fig. 8); only 6 OTUs represented Chlorophyceae (Fig. 9). In addition, one member of the Ulvophyceae (Trentepohlia sp.) was found in two clones on wall area A (data not shown). Interestingly, on wall areas A and B, Trebouxiophyceae were dominant. Only one OTU, retrieved from environmental DNA cloning on wall area A, a Jenufa sp.-related clone, could be assigned to the green algal class of Chlorophyceae. All other chlorophycean clones were retrieved from environmental material and crude cultures of scale samples. 


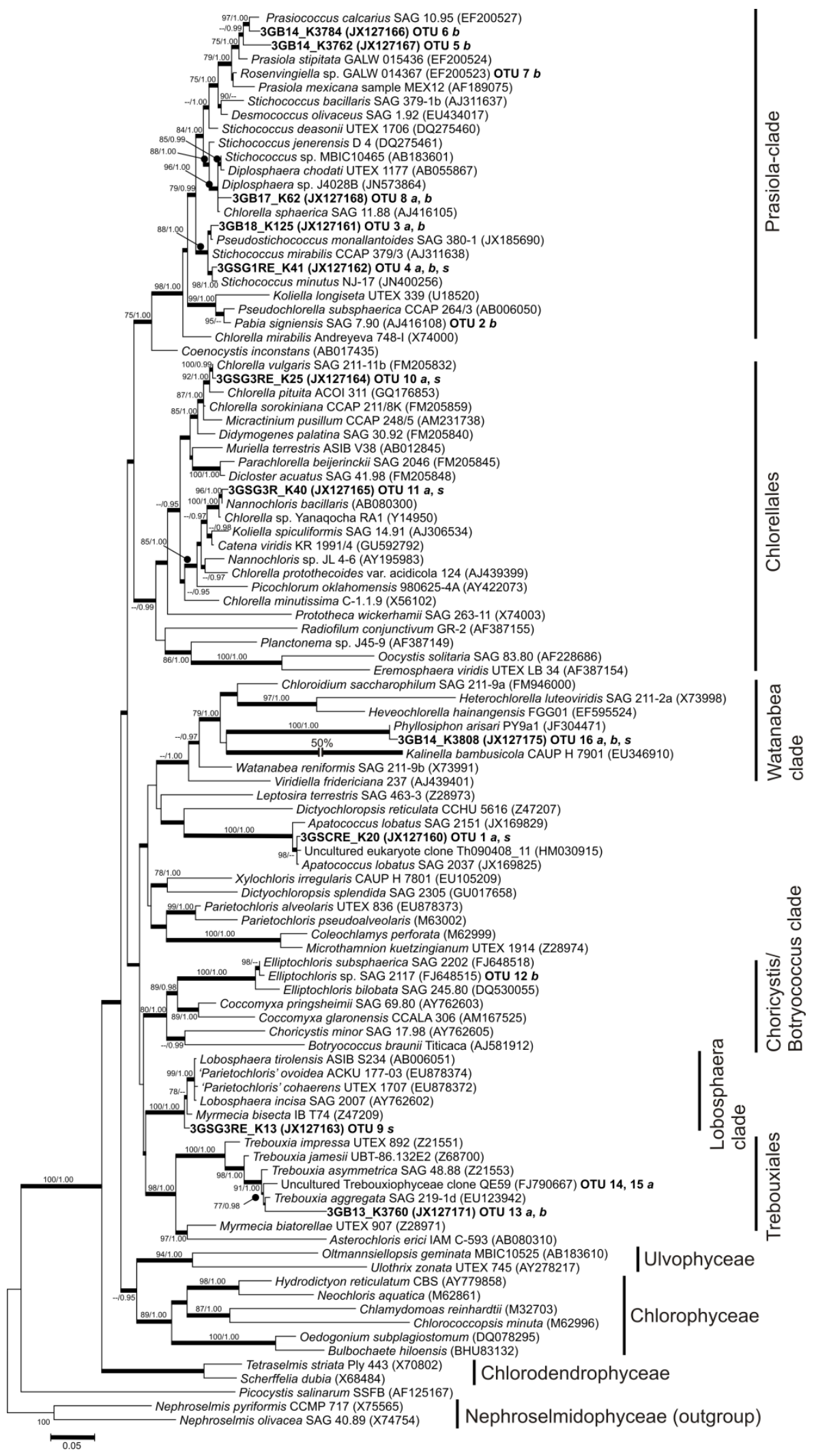

Fig. 8. Phylogenetic tree of Trebouxiophyceae based on $18 \mathrm{~S}$ rRNA gene sequences. Maximum likelihood method (RAxML) based on 102 taxa and 1798 positions. Thick lines indicate internal nodes that were received in maximum likelihood and Bayesian trees. Support values given as ML (maximum likelihood; > $75 \%$ bootstrap values)/MB (MrBayes; > 0.95 Bayesian posterior probabilities). Sequences in bold represent full $18 \mathrm{~S}$ rRNA gene sequences of clones; a: wall A; b: wall B, s: scale. 


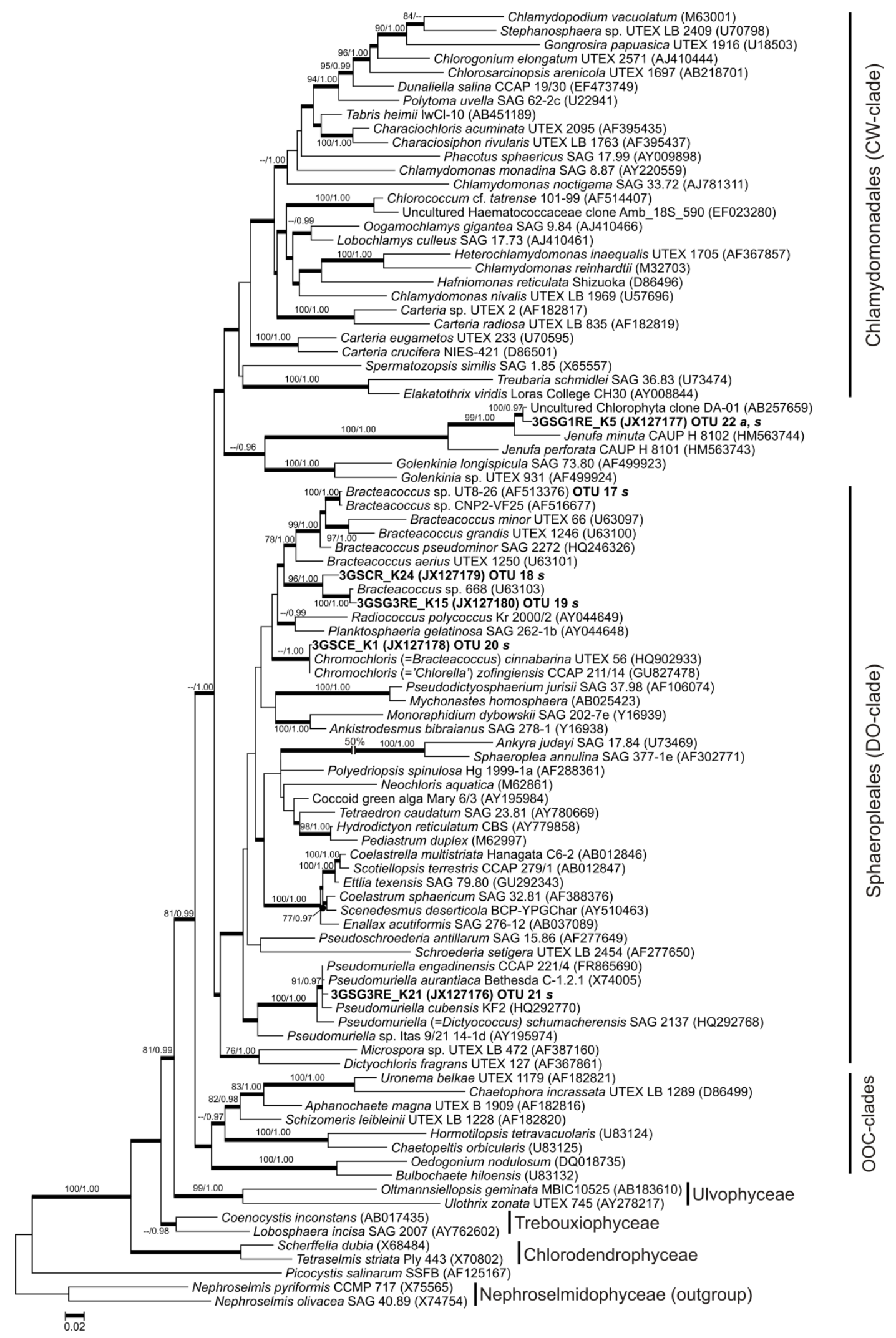

Fig. 9. Phylogenetic tree of Chlorophyceae based on 18S rRNA gene sequences. Maximum likelihood method (RAxML) based on 93 taxa and 1780 positions. Thick lines indicate internal nodes that were received in maximum likelihood and Bayesian trees. Support values given as ML (maximum likelihood; > $75 \%$ bootstrap values)/MB (MrBayes; > 0.95 Bayesian posterior probabilities). Sequences in bold represent full-length sequences of clones; a: wall A; b: wall B, s: scale. 


\section{Diatoms}

From scale samples developed with diatom specific 18S rRNA gene primers, 39 clones closely related to Nitzschia amphibia (AJ867277, $98 \%$ similarity), and 15 clones related to Phaeodactylum tricornutum (AJ269501, $96 \%$ similarity) were identified according to BLAST database queries. However, the latter clones were assigned to Diadesmis sp. in the ARB phylogenies. In addition, one sequence showed $99 \%$ similarity to Spumella sp. strain Mbc 3C (Chrysophyceae).

\section{Distinction among sites}

The rRNA gene sequence data were used for statistical analysis to compare community compositions between the different locations. SIMPER analysis documented the dissimilarity between the daylight-exposed wall areas and the endolithic biofilm of scale samples $(93.4 \%$ between wall area A and scale samples, and $96.6 \%$ between wall area B and scale samples; ANOSIM significance: P < 0.01). In contrast, both the daylight-exposed wall areas showed $76.4 \%$ dissimilarity. 


\section{Discussion}

The molecular phylogenetic approach in our study revealed clear differences in the composition of green algal and cyanobacterial communities between two wall areas made of apparently similar substrata (sandstone) located at the same building. The wall areas experienced different exposures to sunlight and differed by the presence or absence of gypsum mortar and crusts. The composition of the fungal microbial communities at the same building was already found to differ at small scales in a previous study (Hallmann et al., 2011b). A previous study on different substrata from geographically distant locations revealed the substrate type as most significant factor to determine prokaryotic communities. For eukaryotic communities, the geographic location appeared to be more significant (locations in France and Ireland, Ragon et al., 2012).

Although we used only partial rRNA gene sequences to assess the community compositions, we employed full rRNA gene sequences for robust phylogenetic analyses. 18S rRNA partial gene analysis of the hypervariable regions V2-V4 or just the V4 region are recommended as DNA barcodes for various algal groups, for example dinoflagellates and diatoms (Zimmermann et al., 2011; Ki, 2012; Pawlowski et al., 2012). Similarly, for 16S rRNA genes, the suitability of the hypervariable regions V1-V3 in phylogenetic analyses turned out to be comparable to full-length sequences (Jeraldo et al., 2011). Consequently, partial rRNA gene sequences are still commonly used in microbial biodiversity studies using a culture-independent approach (Santos et al., 2010).

\section{Cyanobacterial communities}

There is an obvious difference between the two wall areas concerning the abundance of cyanobacterial clones. Whereas just seven cyanobacterial clones could be retrieved from area $\mathrm{B}$, more than $50 \%$ of the clones recovered from area $\mathrm{A}$ represented two OTUs (OTU 3 and 11, c.f. Table 1), that is, Synechococcus-like cyanobacteria. The latter two OTUs had their next relatives in BLASTN queries with $98 \%$ and $96 \%$ similarities in Synechococcus-like cyanobacteria retrieved from a marble sculpture (JQ404415; China, Beijing, Forbidden City). Phylogenetic analysis (Fig. 5) revealed an uncultured cyanobacterium from gypsum crusts (GQ325750 from Tunisia; Stivaletta et al., 2010) as another next-closest relative. Although our Synechococcus-related clones are closely related to each other, generally Synechoccoccus strains belong to several deeply branching lineages within the cyanobacteria. This has been shown recently for a number of isolates 
mainly obtained from freshwater (Robertson et al., 2001). With respect to our findings, it should be noted that some Synechococcus isolates could be retrieved from saline and hypersaline environments, including gypsum crusts (e.g. Oren and Seckbach, 2001; Crispim and Gaylarde, 2005). The predominance of Synechococcus in our samples may be also well explained by the presence of a thin gypsum layer on the stone surface (c.f. Fig. 1b). It is generally accepted that cyanobacteria instead of green algae dominate alkali - including hypersaline - environments (e.g. Oren and Seckbach, 2001). Gypsum was one component of the used mortar and may have been dissolved by precipitation (c.f. Hoppert et al., 2010). Typically, the cyanobacteria grow inside the crust, in particular at the boundary layer between crust and stone substratum (Saiz-Jiminez et al., 1990). In the dry and cold Antarctic habitat, hypolithic growth at the contact face between stone and underlying ground has been observed for cyanobacteria (see Cary et al. (2010) for a review). This layer of active growth also defines the fracture plane of the gypsum crust (Hoppert et al., 2010). For Synechococcus, in particular, the binding of calcium ions on the negatively charged surface layers of cells has been described, which contributes to dissolution and biogenic weathering of limestone (Schultze-Lam and Beveridge, 1994).

Leptolyngbya (cyanobacterial OTU 2; Table 1) was abundantly recovered under large basement vault scales (c.f. Fig. 1g, h). Here, the fracture face of the scale is composed of clay particles intermixed with gypsum. Moreover, the site is moist and just exposed to dim light for few hours per day. Leptolyngbya has been predominant in phototrophic biofilms from hypogean sites (Zammit et al., 2011), but was also detected in diverse endolithic microbial habitats such as travertine (travertine terraces of the Yellowstone National Park), alpine dolomite, and even deep sea basalt and gypsum crusts in Tunisia (Norris and Castenholz, 2006; Horath and Bachofen, 2009; Stivaletta et al., 2010). Leptolyngbya OTU 2 is closely related to an uncultured cyanobacterium recovered from a hypolithic biofilm on quartz rock (FJ790618; Wong et al., 2010).

Further cyanobacterial OTUs recovered from clone libraries represented M. vaginatus and Chroococcus sp. Both species/genera are common cyanobacteria of terrestrial habitats also colonizing dimension stone (e.g. Ortega-Calvo et al., 1991; Cuzman et al., 2010). The cyanobacterial OTUs 4, 5 and 6 from the clone libraries were phylogenetically closely related to Chroococcidiopsis. Their close relatives were from terrestrial or hypolithic sites (GQ396895, HM241004, FJ790556, HM224428). The dominance of either Synechococcus on wall area A or Leptolyngbya and other cyanobacteria in the scale samples may be due to 
the different exposure times to direct sunlight, high calcium concentration in gypsum crusts (as compared with scales) or different moisture regimes at these sites.

In fact, filamentous cyanobacteria were only detected on shaded wall area B and in the scale samples. According to a recent study on microbial biofilms on monuments of the Angkor Wat temple complex (Cambodia), filamentous cyanobacteria like Microcoleus vaginatus and Leptolyngbya appeared to be more prevalent in moist areas as well (internal walls; Gaylarde et al., 2012). However, both filamentous cyanobacteria are also important colonizers of soil crusts and deserts with specific adaptations to desiccation stress like exopolysaccharide sheaths (Garcia-Pichel et al., 2001; Büdel et al., 2009; Pereira et al., 2009).

\section{Eukaryotic algal communities}

All eukaryotic algae retrieved in our clone libraries belonged to two classes of green algae, either Trebouxiophyceae or Chlorophyceae. Most OTUs from wall areas A and B were members of Trebouxiophyceae (15 out of 16). Three distinct groups of clones (OTUs 3, 4 and 8), phylogenetically related to Pseudostichococcus monallantoides strain SAG 380-1 (Stichococcus mirabilis strain CCAP 379/3 with $99 \%$ similarity in BLAST queries), S. minutus, strain NJ-17 and Diplosphaera sp. strain J4028B (Stichococcus sp. strain MBIC10465 with $99 \%$ similarity in BLAST queries), were retrieved in high abundance from both walls (c.f. Table 2 and Fig. 8).

Green algal OTU 5 was recovered only from wall area B and in low clone numbers; it was phylogenetically affiliated to P. calcarius (Stichococcus sp. strain MBIC10465, with $98 \%$ similarity in BLAST queries). Another P. calcarius-related sequence, OTU 6, was also found only at wall area B, but with high clone numbers. For OTU 6, both phylogenetic analyses and BLAST queries concurred on the species same identification, the cell package forming P. calcarius (c.f. Table 2, Figs. 3a, 8). The species has been described as a widely distributed subaerial alga on moist soil, calcareous rock and stone walls (Ettl and Gärtner, 1995), including the Antarctic region (Belcher, 1969; Broady, 1983). There, P. calcarius was observed to be dominant in epilithic communities at high-salinity sites where irradiation is infrequent or moisture is available (Broady, 1996).

Obviously, the 'Stichococcus' morphotypes within the Prasiola clade are phylogenetically diverse and also differ with respect to their abundance in specific sites. In scale samples, the $S$. minutus-related clones could be retrieved just from crude cultures. 
No environmental clone from scale samples, though, was related to Stichococcus, which accounts for a minor 'contamination' of the site by this clone.

Surprisingly, A. lobatus-related clones could not be retrieved from shaded wall area B. On wall area B, the highly abundant Prasiococcus (being absent on wall area A) appears to be better adapted to this site. Apatococcus, like Stichococcus, is known as a genus of cosmopolitan algae. Cell packages of A. lobatus were described from tree bark, wood, walls, rocks (Ettl and Gärtner, 1995) and man-made substrata (Rindi et al., 2010). The sequences revealed in this study were closely related to A. lobatus strain SAG 2037. The resistance of Apatococcus against air pollution in towns and xeric conditions is well known (Barkman, 1969). In this particular case on wall area B, Apatococcus, although exhibiting wide ecological amplitude, might be less competitive. As Apatococcus is mixotroph (Gustavs, 2010) and is able to grow under shaded conditions, eventually lack of organic substrates on this site may be a reason for the absence of A. lobatus-related clones.

Clones closely affiliated to the rather uncommon green alga $P$. arisari Kühn could be retrieved from wall area $\mathrm{A}$ in high numbers (six sequences from area $\mathrm{B}$, one sequence from scale samples). The green alga $P$. arisari has been described as a plant parasitic alga penetrating Arisarum leaves in coastal Mediterranean and in tropical climates, but was also described for temperate climates (Aboal and Werner, 2011). Due to this fact, it can be assumed that the reference sequence is a misidentification. This reference sequence, in fact, seems to be assigned to Lobosphaeropsis pyrenoidosa Reisigl (T. Darienko, personal communication). Lobosphaeropsis pyrenoidosa was discovered in soil (Ettl and Gärtner, 1995), on tree bark (Freystein et al., 2008) and on stone (T. Darienko, personal communication).

From wall area A, only one chlorophycean alga related to Jenufa minuta was retrieved. Isolates were obtained from tree bark in Singapur (Němcová et al., 2011) and from soil in Germany (Hodač et al., 2012), and detected in clone libraries from endolithic samples in the Alps, Switzerland (Horath and Bachofen, 2009). All six chlorophycean OTUs detected in this study were retrieved from crude cultures of scale samples. Interestingly, enrichment cultures of samples from other wall areas did not result in an enrichment of Chlorophyceae, which accounts for a 'seed bank' of chlorophycean algae particularly in scales. Except Jenufa, these Chlorophyceae belong to the order Sphaeropleales, which includes vegetatively non-motile unicellular or colonial taxa (Lewis and McCourt, 2004). 
SEM of scales revealed the dominance of one coccoid morphotype (Fig. 2b), along with cyanobacteria and diatoms, from the basement vault scale sample. This morphotype was assigned to an OTU related to C. zofingiensis (GU827478, formerly Chlorella, Muriella, 'Myconastes'; Hindák, 1982; Ettl and Gärtner, 1995; Krienitz et al., 2011; Fucíková and Lewis, 2012). The same OTU was also abundant in environmental samples from scales. The aerophytic alga has been found on rather sandy soil and moist substrata. This implies that Chromochloris is adapted to rather moist terrestrial environments (Ettl and Gärtner, 1995).

As the other chlorophycean OTUs could only be retrieved from crude cultures, they must be present just in minor proportions in the original sample. These clones are, like Chromochloris, rather soil algae than algae normally found on hard rock substrata and on wall areas A and B. This feature is also pointed out by SIMPER analysis: wall areas A and B are clearly distinct from the scale samples, in particular caused by presence/absence of Chlorophyceae.

The diatoms observed in the scale samples are cosmopolitan species, not necessarily restricted to terrestrial habitats. Diadesmis contenta is known, for example, for cave systems in Austria and Czech Republic (Schagerl, 1991; Poulíčková and Hašler, 2007) and was also found in lichen thalli (Lakatos et al., 2004). Achnanthidium minutissimum was retrieved, for example from aquatic systems (Potapova and Hamilton, 2007) and caves (Poulíčková and Hašler, 2007). Interestingly, one clone related to the flagellate Spumella sp. was retrieved in the scale samples. Chrysophyceaen algae are well known from freshwater and soil habitats (Boenigk et al., 2005), but could be also retrieved from moss (Škaloud, 2009).

\section{Diversity patterns of the phototrophic community and possible biodeterioration mechanisms}

It is reasonable to assume that algal communities found in the dark and moist environment of a basement vault differ from communities exposed to sunlight and, hence, to desiccation stress. However, it may not be expected that algal communities on two walls with (seemingly) similar environmental conditions are clearly distinct from each other.

Although undoubted reasons for these distinctions have yet to be elucidated, two differences between the wall areas are obvious: (1) different sun exposure time per day attended by water availability and (2) wall joints filled with gypsum mortar on wall area A in contrast to open wall joints on wall area B, resulting in the formation of thin gypsum 
crusts on wall area A. This accounts for clearly distinct ecological adaptations of microalgae on either wall area A or wall area B. It should be taken into account that in addition to the crucial criterion of the available moisture, also the chemical properties of the substratum substantially influence the settlement of specific algae (Darienko and Hoffmann, 2003; Rindi, 2007).

However, crude culturing leads to enrichment of other algal genera that may be well present in low numbers in the environment, but readily capable of multiplying under appropriate conditions. Obviously, these 'seed banks' differ between the various sampled sites. Although various Chlorophyceae are present in basement vault scales, the same genera appear to be nearly completely absent on walls.

Knowledge on the diversity, ecophysiology and dispersal strategies of these algae are still in its infancy (Karsten et al., 2005; Rindi, 2007). The different ecological adaptations of, for example, Lobosphaeropsis pyrenoidosa (P. arisari) or P. calcarius being dominant on either wall area A or B are largely unknown. Generally, algae exhibit a variety of adaptations to the terrestrial habitat (Häubner et al., 2006). Dry periods (in summer with low precipitation or due to frost drought) require adaptations to desiccation. These adaptations are manifested by certain cytological features such as thickened cell walls (Klebsormidium, Holzinger et al., 2011; Karsten and Holzinger, 2012; Zygogonium, Hoppert et al., 2004) and mucilaginous sheaths (Coccomyxa, Karsten et al., 2005). These structures may retain water for a certain time period and help to withstand high osmotic stress during desiccation. The accumulation of exopolysaccharides (EPS) as a protection against desiccation has already been reported (Shepherd and Beilby, 1999). Equally important are mechanisms protecting against high radiation, such as the accumulation of carotenoids and the formation of MAAs (mycosporine-like amino acids; Karsten et al., 2007b). Additionally, the presence of polyols, for example ribitol, which were considered as effective stress metabolites, was demonstrated in representative aeroterrestrial algae (Gustavs et al., 2011). Moreover, resting stages such as spores persist for years (Karsten et al., 2005).

In a recent study, different wall areas of the castle Gleichen were mapped, and distinct weathering patterns like formation of crusts or flakes and salt efflorescences were reported for wall area A (Stück et al., 2011). In our study, no direct evidence for biodeterioration, such as traces of actively penetrating endolithic organisms or mineral dissolution around single cells by microalgae, could be found, although it must be expected that the mass development of cyanobacterial and algal layers will destabilize pores and clefts just by 
mechanical forces (Warscheid et al., 1991; Crispim and Gaylarde, 2005). The secretion of organic acids at least by some organisms must be expected. It is obvious that the algae and cyanobacteria use pre-existing fracture planes under crusts or scales (these fracture planes were also observed without any apparent colonization), but may then accelerate detachment of these features. Just because of the high number of individuals (as implied by clone library data), key players of colonization and therefore putative agents of biogenic weathering could be clearly defined: In case of wall area A, the abundant cyanobacterium Synechococcus (-like), but also Phyllosiphon (Lobosphaeropsis pyrenoidosa) and Stichococcus/Pseudostichococcus, must be taken into account. On wall area B, besides Stichococcus, Prasiococcus was highly abundant. Finally, the basement scale sample was dominated by Chromochloris zopfingiensis and Leptolyngbya. These dominating organisms were also accompanied by a set of distinct other species, except from a few generalists (in our case, just Stichococcus). It has to be expected that these organisms also exert different mechanisms of biogenic weathering on the material surface. Thus, also effects of biogenic weathering regimes may differ on a very small scale.

Factors that influence the dominance of specific phylotypes were obviously irradiance, moisture and presence or absence of gypsum crusts. However, a more detailed analysis of the relevance of these determinants will require further quantification of these physical and chemical parameters of the substratum and long-term measurements of microclimatic conditions.

\section{Acknowledgements}

We are indebted to Tatyana Darienko for her helpful discussion concerning the Phyllosiphon-related sequence (Angewandte Ökologie, University of Rostock). Support of Heidrun Stück, Wanja Wedekind and Siegfried Siegesmund (Geoscience Centre, GeorgAugust-University, Göttingen) with respect to sandstone lithologies is gratefully acknowledged. This project was funded by the Deutsche Bundesstiftung Umwelt (DBU). Parts of this work were also supported by the German Science Foundation (DFG) by a grant extended to T. F. (Fr 905/16-1) and by the German Federal Ministry of Education and Research, BMBF (AlgaTerra project, grant 01 LC0026) within the BIOLOG program. This is Courant Research Centre Geobiology publication no. 114. 


\section{References}

Aboal, M. and Werner, O. (2011) Morphology, fine structure, life cycle and phylogenetic analysis of Phyllosiphon arisari, a siphonous parasitic green alga. Eur J Phycol 46: 181-192.

Altschul, S.F., Gish, W., Miller, W., Meyers, E.W. and Lipman, D.J. (1990) Basic local alignment search tool. J Mol Biol 215: 403-410.

Barkman, J.J. (1969) Phytosociology and ecology of cryptogamic epiphytes. Van Gorcum and Company, Assen, the Netherlands.

Belcher, J.H. (1969) Prasiococcus calcarius (Boye Petersen) Vischer in the South Sandwich Islands. Br Phycol J 4: 119-120.

Bellinzoni, A.M., Caneva, G. and Ricci, S. (2003) Ecological trends in travertine colonization by pioneer algae and plant communities. Int Biodeterior Biodegradation 51: 203-210.

Boenigk, J., Pfandl, K., Stadler, P. and Chatzinotas, A. (2005) High diversity of the 'Spumella-like' flagellates: an investigation based on the SSU rRNA gene sequences of isolates from habitats located in six different geographic regions. Environ Microbiol 7: 685-697.

Broady, P.A. (1983) The Antarctic distribution and ecology of the terrestrial chlorophytan alga Prasiococcus calcarius (Boye Petersen) Vischer. Polar Biol 1: 211-216.

Broady, P.A. (1996) Diversity, distribution and dispersal of Antarctic terrestrial algae. Biodivers Conserv 5: 1307-1335.

Brock, TD (1973) Lower pH limit for existence of blue-green algae: evolutionary and ecological implications. Science 179: 480-483.

Büdel, B., Weber, B., Kühl, M., Pfanz, H., Sültemeyer, D. and Wessels, D. (2004) Reshaping of sandstone surfaces by cryptoendolithic cyanobacteria: bioalkalization causes chemical weathering in arid landscapes. Geobiology 2: 261-268.

Büdel, B., Darienko, T., Deutschewitz, K., Dojani, S., Friedl, T., et al. (2009) Southern African biological soil crusts are ubiquitous and highly diverse in drylands, being restricted by rainfall frequency. Microb Ecol 57: 229-247.

Cary, S.C., McDonald, I.R., Barrett, J.E. and Cowan, D.A. (2010) On the rocks: the microbiology of Antarctic Dry Valley soils. Nat Rev Microbiol 8: 129-138.

Crispim, C.A. and Gaylarde, C.C. (2005) Cyanobacteria and biodeterioration of cultural heritage: a review. Microb Ecol 49: 1-9.

Crispim, C.A., Gaylarde, P.M. and Gaylarde, C.C. (2003) Algal and cyanobacterial biofilms on calcareous historic buildings. Curr Microbiol 46: 79-82.

Cuzman, O.A., Ventura, S., Sili, C., Mascalchi, C., Turchetti, T., D’Acqui L.P. and Tiano, P. (2010) Biodiversity of phototrophic biofilms dwelling on monumental fountains. Microb Ecol 60: 81-95.

Darienko, T. and Hoffmann, L. (2003) Algal growth on cultural monuments in Ukraine. Biologia Bratislava 58: 575-587.

Ettl, H. and Gärtner, G. (1995) Syllabus der Boden-, Luft- und Flechtenalgen. Gustav Fischer, Stuttgart.

Freystein, K, Salisch, M. and Reisser, W. (2008) Algal biofilms on tree bark to monitor airborne pollutants. Biologia 63: 866-872.

Fucíková, K. and Lewis, L.A. (2012) Intersection of Chlorella, Muriella and Bracteacoccus: resurrecting the genus Chromochloris Kol et Chodat (Chlorophyceae, Chlorophyta). Fottea 12: 83-93. 
Furey, P.C., Lowe, R.L. and Johansen, J.R. (2007) Wet wall algal community response to in-field nutrient manipulation in the Great Smoky Mountains National Park, USA. Algol Stud 125: 17-43.

Garcia-Pichel, F., López-Cortés, A. and Nübel, U. (2001) Phylogenetic and morphological diversity of cyanobacteria in soil desert crusts from the Colorado plateau. Appl Environ Microbiol 67: 1902-1910.

Gaylarde, C.C., Rodríguez, C.H., Navarro-Noya, Y.E. and Ortega-Morales, B.O. (2012) Microbial biofilms on the sandstone monuments of the Angkor Wat complex, Cambodia. Curr Microbiol 64: 85-92.

Gorbushina, A.A. (2007) Life on the rocks. Environ Microbiol 9: 1613-1631.

Gustavs, L. (2010) Biodiversity and ecophysiology of aeroterrestrial green algae (Trebouxiophyceae, Chlorophyta). PhD Thesis, Faculty of Mathematics and Natural Sciences, Rostock.

Gustavs, L., Görs, M. and Karsten, U. (2011) Polyol patterns in biofilm-forming aeroterrestrial green algae (Trebouxiophyceae, Chlorophyta). J Phycol 47: 533-537.

Hallmann, C., Rüdrich, J., Enseleit, M., Friedl, T. and Hoppert, M. (2011a) Microbial diversity on a marble monument: a case study. Environ Earth Sci 63: 1701-1711.

Hallmann, C., Fritzlar, D., Stannek, L. and Hoppert, M. (2011b) Ascomycete fungi on dimension stone of the "Burg Gleichen", Thuringia. Environ Earth Sci 63: 1713-1722.

Hamby, R.K., Sims, L., Issel, L. and Zimmer, E. (1988) Direct ribosomal RNA sequencing: optimization of extraction and sequencing methods for work with higher plants. $\mathrm{Pl} \mathrm{Mol}$ Biol Rep 6: 175-192.

Hammer, Ø., Harper, D.A.T. and Ryan, P.D. (2001) PAST: Paleontological Statistics Software Package for education and data analysis. Palaeontol Electronica 4: 1-9.

Häubner, N., Schumann, R. and Karsten, U. (2006) Aeroterrestrial microalgae growing in biofilms on facades-response to temperature and water stress. Microb Ecol 51: 285-293.

Hepperle, D. (2004) SeqAssem $\odot$. A sequence analysis tool, counting assembler and trace data visualization tool for molecular sequences. Win32-Version. Distributed by the author via: http://www.seqeuntix.de.

Hindák, F. (1982) Taxonomic position of the chlorococcal alga Chlorella zofingiensis Dönz 1934 (Chlorophyceae). Arch Hydrobiol Suppl Algol Stud 30: 13-23.

Hodač, L., Hallmann, C., Rosenkranz, H., Faßhauer, F. and Friedl, T. (2012) Molecular evidence for the wide distribution of two lineages of terrestrial green algae (Chlorophyta) over tropics to temperate zone. ISRN Ecol 2012: 795924.

Holzinger, A., Lütz, C. and Karsten, U. (2011) Desiccation stress causes structural and ultrastructural alterations in the aeroterrestrial green alga Klebsormidium crenulatum (Klebsormidiophyceae, Streptophyta) isolated from alpine soil crust. J Phycol 47: 591-602.

Hoppert, M., Reimer, R., Kemmling, A., Schröder, A., Günzl, B. and Heinken, T. (2004) Structure and reactivity of a biological crust from a xeric sandy soil in Central Europe. Geomicrobiol J 21: 183-191.

Hoppert, M., Hallmann, C., Stannek, L., Fritzlar, D. and Enseleit, M. (2010) Makro- und Mikroflora in Fuge und Gestein. In Siegesmund, S. and Hoppert, M. (eds) Die Drei Gleichen Baudenkmäler und Naturraum, Edition Leipzig, Leipzig, pp. 254-263.

Horath, T. and Bachofen, R. (2009) Molecular characterization of an endolithic microbial community in dolomite rock in the central Alps (Switzerland). Microb Ecol 58: 290-306.

Huber, T., Faulkner, G. and Hugenholtz, P. (2004) Bellerophon; a program to detect chimeric sequences in multiple sequence alignments. Bioinformatics 20: 2317-2319. 
Huelsenbeck, J.P. and Ronquist, F. (2001) MrBayes: Bayesian inference of phylogenetic trees. Bioinformatics 17: 754-755.

Jeraldo, P., Chia, N. and Goldenfeld, N. (2011) On the suitability of short reads of 16S rRNA for phylogeny-based analyses in environmental surveys. Environ Microbiol 13: 3000-3009.

Johnston, C.G. and Vestal, J.R. (1991) Photosynthetic carbon incorporation and turnover in the Antarctic cryptoendolithic microbial communities: are they the slowest-growing communities on earth? Appl Environ Microbiol 57: 2308-2311.

Karsten, U., Eixler, S., Görs, S. and Schumann, R. (2003) Klimawandel und der mögliche Einfluss auf das Algenwachstum. Altbauinstandsetzung 5: 51-58.

Karsten, U., Schumann, R., Häubner, N. and Friedl, T. (2005) Lebensraum Fassade: Aeroterrestrische Mikroalgen. Biol unserer Zeit 35: 20-30.

Karsten, U., Schumann, T. and Mostaert, A.S. (2007a) Aeroterrestrial algae growing on man-made surfaces: What are their secrets of ecological success? In Seckbach, J. (ed) Algae and Cyanobacteria in Extreme Environments. Springer Verlag, Dordrecht, the Netherlands, pp. 583-597.

Karsten, U., Lembcke, S. and Schumann, R. (2007b) The effects of ultraviolet radiation on photosynthetic performance, growth and sunscreen compounds in aeroterrestrial biofilm algae isolated from building facades. Planta 225: 991-1000.

Karsten, U. and Holzinger, A. (2012) Light, temperature and desiccation effects on photosynthetic activity, and drought-induced ultrastructural changes in the green alga Klebsormidium dissectum (Streptophyta) from a high alpine soil crust. Microb Ecol 63: 51-63.

Katoh, K. and Toh, H. (2008) Recent developments in the MAFFT multiple sequence alignment program. Brief Bioinform 9: 286-298.

Khaybullina, L.S., Gaysina, L.A., Johansen, J.R. and Krautová, M. (2010) Examination of terrestrial algae of the Great Smoky Mountains National Park, USA. Fottea 10: 201-215.

$\mathrm{Ki}$, J.S. (2012) Hypervariable regions (V1-V9) of the dinoflagellate 18S rRNA using a large dataset for marker considerations. J Appl Phycol 24: 1035-1043.

Krammer, K. and Lange-Bertalot, H. (1986-2004) Bacillariophyceae, Teil 1-5. Süßwasserflora Mitteleuropa Band 2/1-2/5. Ettl, H., Gerloff, J., Heynung, H. and Mollenhauer, D. (eds), Gustav Fischer Verlag, Stuttgart, New York.

Krienitz, L., Bock, C., Dadheech, P.K. and Pröschold, T. (2011) Taxonomic reassessment of the genus Mychonastes (Chlorophyceae, Chlorophyta) including the description of eight new species. Phycologia 50: 89-106.

Lakatos, M., Lange-Bertalot, H. and Büdel, B. (2004) Diatoms living inside the thallus of the green algal lichen Coenogonium linkii in neotropical lowland rain forests. $J$ Phycol 40: 70-73.

Lee, J.C. and Gutell, R.R. (2012) A Comparison of the crystal structure of eukaryotic and bacterial SSU ribosomal RNAs reveals common structural features in the hypervariable regions. PLoS ONE 7: e38203.

Lennon, J.T. and Jones, S.E. (2011) Microbial seed banks: the ecological and evolutionary implications of dormancy. Nat Rev Microbiol 9: 119-130.

Lewis, L.A. and McCourt, R.M. (2004) Green algae and the origin of land plants. Am J Bot 91: 1535-1556.

Ludwig, W., Strunk, O., Westram, R., Richter, L., Meier, H., et al. (2004) ARB: a software environment for sequence data. Nucl Acids Res 32: 1363-1371.

Lukešová, A. and Hoffmann, L. (1995) Soil algae from acid rain impacted forest areas of Krušné hory mountains (Czech Republic). 2. Effects of pH on growth. Algol Stud 78: 39-51. 
Macedo, M.F., Miller, A.Z., Dionísio, A. and Saiz-Jimenez, C. (2009) Biodiversity of cyanobacteria and green algae on monuments in the Mediterranean Basin: an overview. Microbiology 155: 3476-3490.

Marande, W., López-García, P. and Moreira, D. (2009) Eukaryotic diversity and phylogeny using small- and large-subunit ribosomal RNA genes from environmental samples. Environ Microbiol 11: 3179-3188.

Michaud, A.B., Šabacká, M. and Priscu, J.C. (2012) Cyanobacterial diversity across landscape units in a polar desert: Taylor Valley, Antarctica. FEMS Microbiol Ecol 82: 268-278.

Moon-van der Staay, S.Y., De Wachter, R. and Vaulot, D. (2001) Oceanic 18S rDNA sequences from picoplankton reveal unsuspected eukaryotic diversity. Nature 409: 607-610.

Neefs, J.M. and De Wachter, R. (1990) A proposal of the secondary structure of a variable area of eukaryotic small ribosomal subunit RNA involving the existence of a pseudoknot. Nucleic Acids Res 18: 5695-5704.

Němcová, Y., Eliáš, M., Škaloud, P., Hodač, L. and Neustupa, J. (2011) Jenufa gen. nov.: a new genus of coccoid green algae (Chlorophyceae, incertae sedis) previously recorded by environmental sequencing. J Phycol 47: 928-938.

Norris, T.B. and Castenholz, R.W. (2006) Endolithic photosynthetic communities within ancient and recent travertine deposits in Yellowstone National Park. FEMS Microbiol Ecol 57: 470-483.

Oren, A. and Seckbach, J. (2001) Oxygenic photosynthetic organisms in extreme environments. Nova Hedwigia Beih 123: 13-31.

Ortega-Calvo, J.J., Hernandez-Marine, M. and Saiz-Jimenez, C. (1991) Biodeterioration of building materials by cyanobacteria and algae. Int Biodeterior Biodegradation 28: 165-185.

Pawlowski, J., Audic, S., Adl, S., Bass, D., Belbahri, L., et al. (2012) CBOL protist working group: barcoding eukaryotic richness beyond the animal, plant and fungal kingdoms. PLoS Biol 10: e1001419.

Pereira, S, .Zille, A., Micheletti, E., Moradas-Ferreira, P., De Philippis, R. and Tamagnini, P. (2009) Complexity of cyanobacterial exopolysaccharides: composition, structures, inducing factors and putative genes involved in their biosynthesis and assembly. FEMS Microbiol Rev 33: 917-941.

Pniewski, F., Friedl, T. and Latała, A. (2010) Identification of diatom isolates from the Gulf of Gdańsk: testing of species identifications using morphology, 18S rDNA sequencing and DNA barcodes of strains from the culture collection of Baltic Algae (CCBA). Oceanol Hydrobiol Stud 39: 3-20.

Potapova, M. and Hamilton, P.B. (2007) Morphological and ecological variation within the Achnanthidium minutissimum (Bacillariophyceae) species complex. J Phycol 43: 561-575.

Poulíčková, A. and Hašler, P. (2007) Aerophytic diatoms from caves in central Moravia (Czech Republic). Preslia 79: 185-204.

Ragon, M., Fontaine, M.C., Moreira, D. and López-García, P. (2012) Different biogeographic patterns of prokaryotes and microbial eukaryotes in epilithic biofilms. Mol Ecol 21: 3852-3868.

Rindi, F. (2007) Diversity, ecology and distribution of green algae and cyanobacteria in urban habitats. In Seckbach, J. (ed) Algae and Cyanobacteria in Extreme Environments. Springer Verlag, Dordrecht, the Netherlands, pp. 583-597.

Rindi, F., Allali, H.A., Lam, D.W. and López-Bautista, J.M. (2010) An overview of the biodiversity and biogeography of terrestrial green algae. In Rescigno, V. and Maletta, S. (eds) Biodiversity Hotspots. Nova Science Publishers, Hauppauge, New York, pp. 105-122. 
Rippka, R. and Herdman, M. (1993) Pasteur culture collection of cyanobacterial strains in axenic culture. Catalogue of Strains. Institut Pasteur, Paris. Vol. 1, pp. 103.

Robertson, B.R., Tezuka, N. and Watanabe, M.M. (2001) Phylogenetic analyses of Synechococcus strains (cyanobacteria) using sequences of 16S rDNA and part of the phycocyanin operon reveal multiple evolutionary lines and reflect phycobilin content. Int J Syst Evol Microbiol 51: 861-871.

Romari, K. and Vaulot, D. (2004) Composition and temporal variability of picoeukaryote communities at a coastal site of the English Channel from 18S rDNA sequences. Limnol Oceanogr 49: 784-798.

Saiz-Jiminez, C., Garcia-Rowe, J., Garcia Del Cura, M.A., Ortega-Calvo, J.J., Roeskens, E. and Van Grieken, R. (1990) Endolithic cyanobacteria in Maastricht limestone. Sci Total Environ 94: 209-220.

Sambrook, J., MacCallum, P. and Russel, D. (2000) Molecular Cloning: A Laboratory Manual, 3rd edn. CSH Laboratory Press, Cold Spring Harbour, NY.

Santamaria, M., Fosso, B., Consiglio, A., De Caro, G., Grillo, G., et al. (2012) Reference database for taxonomic assignment in metagenomics. Brief Bioinform bbs036.

Santos, H.F., Cury, J.C., Carmo, F.L., Rosado, A.S. and Peixoto, R.S. (2010) 18S rDNA sequences from microeukaryotes reveal oil indicators in mangrove sediment. PLOS ONE 5: e12437.

Schagerl, M. (1991) Die Algen der Lampenflora in der Hermannshöhle bei Kirchberg/Wechsel (Niederösterreich). Verh Zool-Bot Ges Österreich 128: 83-106.

Schloss, P.D., Westcott, S.L., Ryabin, T., Hall, J.R., Hartmann, M., et al. (2009) Introducing mothur: open-source, platform-independent, community-supported software for describing and comparing microbial communities. Appl Environ Microbiol 75: 7537-7541.

Schultze-Lam, S. and Beveridge, T.J. (1994) Physicochemical characteristics of the mineralforming S-layer from the cyanobacterium Synechococcus strain GL24. Can J Microbiol 40: 216-223.

Shepherd, V.A. and Beilby, M.J. (1999) The effect of an extracellular mucilage on the response to osmotic shock in the charophyte alga Lamprothamnium papulosum. J Membr Biol 170: 229-242.

Shields, L.M. and Durell, L.W. (1964) Algae in relation to soil fertility. Bot Rev 30: 92-128.

Škaloud, P. (2009) Species composition and diversity of aeroterrestrial algae and cyanobacteria of the Boreč Hill ventaroles. Fottea 9: 65-80.

Stamatakis, A., Hoover, P. and Rougemont, J. (2008) A rapid bootstrap algorithm for the RAxML web-servers. Syst Biol 57: 758-771.

Starks, T.L., Shubert, L.E. and Trainor, F.R. (1981) Ecology of soil algae: a review. Phycologia 20: 65-80.

Starr, R.C. and Zeikus, J.A. (1993) UTEX - The culture collection of algae at the University of Texas at Austin. J Phycol Suppl 29: 1-106.

Stivaletta, N., Ĺopez-Garćia, P., Boihem, L., Millie, D.F. and Barbieri, R. (2010) Biomarkers of endolithic communities within gypsum crusts (Southern Tunisia). Geomicrobiol $J$ 27: 101-110.

Stock, A., Breiner, H.W., Pachiadaki, M., Edgcomb, V., Filker, S., et al. (2012) Microbial eukaryote life in the new hypersaline deep-sea basin Thetis. Extremophiles 16: 21-34.

Stück, H., Siegesmund, S. and Rüdrich, J. (2011) Weathering behaviour and construction suitability of dimension stones from the Drei Gleichen area (Thuringia, Germany). Environ Earth Sci 63: 1763-1786.

Uher, B. (2008) Spatial distribution of cyanobacteria and algae from the tombstone in a historic cemetery in Bratislava, Slovakia. Fottea 9: 81-92. 
Walker, J.J. and Pace, N.R. (2007) Endolithic microbial ecosystems. Annu Rev Microbiol 61: 331-347.

Warscheid, T., Oelting, M. and Krumbein, W.E. (1991) Physicochemical aspects of biodeterioration processes on rocks with special regard to organic pollutants. Int Biodeterior Biodegradation 28: 37-48.

Welton, R.G., Cuthbert, S.J., McLean, R., Hursthouse, A. and Hughes, J. (2003) A preliminary study of the phycological degradation of natural stone masonry. Environ Geochem Health 25: 139-145.

Wilmotte, A., Van der Auwera, G. and De Wachter, R. (1993) Structure of the 16S ribosomal RNA of the thermophilic cyanobacterium Chlorogloeopsis HTF ('Mastigocladus laminosus HTF') strain PCC7518, and phylogenetic analysis. FEBS Lett 317: 96-100.

Wong, F.K., Lacap, D.C., Lau, M.C., Aitchison, J.C., Cowan. D.A. and Pointing, S.B. (2010) Hypolithic microbial community of quartz pavement in the high-altitude tundra of central Tibet. Microb Ecol 60: 730-739.

Zammit, G., Billi, D., Shubert, E., Kaštovský, J. and Albertano, P. (2011) The biodiversity of subaerophytic phototrophic biofilms from Maltese hypogea. Fottea 11: 187-201.

Zancan, S., Trevisan, R. and Paoletti, M.G. (2006) Soil algae composition under different agroecosystems in North-Eastern Italy. Agric Ecosyst Environ 112: 1-12.

Zimmermann, J., Jahn, R. and Gemeinholzer, B. (2011) Barcoding diatoms: evaluation of the V4 subregion on the 18S rRNA gene, including new primers and protocols. Org Divers Evol 11: 173-192. 


\title{
Chapter 2:
}

\section{Cryptogam covers on sepulchral monuments and re-colonization of a marble surface after cleaning}

Christine Hallmann ${ }^{1}$, Wanja Wedekind ${ }^{2}$, Dorothea Hause-Reitner ${ }^{3}$ and Michael Hoppert ${ }^{3,4}$

Published in Environmental Earth Sciences (2013) 69: 1149-1160

\author{
${ }^{1}$ Department of Experimental Phycology and Culture Collection of Algae (SAG), \\ Albrecht-von-Haller-Institute for Plant Sciences, Georg-August-University, \\ Göttingen, Germany \\ ${ }^{2}$ Department of Structural Geology, Geoscience Centre, Georg-August-University, \\ Göttingen, Germany \\ ${ }^{3}$ Courant Research Center Geobiology, Georg-August-University, \\ Göttingen, Germany \\ ${ }^{4}$ Institute for Microbiology and Genetics, Georg-August-University, \\ Göttingen, Germany
}

Author contributions to the work:

Performed the experiments: $\mathrm{CH}$.

Analyzed data: $\mathrm{CH}$.

Cleaning procedures of the sculpture: WW.

Performed scanning electron microscopy: DHR, $\mathrm{CH}$.

Wrote the paper: $\mathrm{CH}, \mathrm{MH}$.

Conceived and designed the experiments: $\mathrm{MH}, \mathrm{CH}, \mathrm{WW}$. 


\begin{abstract}
Re-colonization of freshly cleaned surfaces by aeroterrestrial microbial communities is up to now poorly understood. Here, we present a comparative study addressing the composition of algal and fungal communities on a marble sculpture, based upon the analysis of 18S rRNA gene clone libraries from environmental samples. The samples were taken from a blackish and greenish biofilm cover before surface cleaning and 1 year after cleaning treatment, when traces of re-colonization became visible to the naked eye. The composition of the fungal community indicated clear differences between the old grown biofilm and the treated surface. While the former was dominated by the ascomycetes Rhinocladiella, Glyphium and Capnodiales, the black yeast Sarcinomyces was clearly dominant 1 year after cleaning, but could not be retrieved from the old grown black biofilm. The green algal community was dominated by different phylotypes of the lichen algae Trebouxia, as well as the cosmopolitan green algae Apatococcus and Stichococcus. No essential differences in the green algal community before and after cleaning could be observed.
\end{abstract}

Keywords: environmental samples, fungi, green algae, lichen, 18S rRNA gene. 


\section{Introduction}

Open-air sculptures and historic buildings exposed to weather and pollution are deteriorated by physical and chemical factors, as well as by microbial contamination (Saiz-Jimenez, 1995; Zanardini et al., 2000; Polo et al., 2010).

Microbial communities on stone surfaces are composed of bacteria including cyanobacteria, fungi, algae and lichens (Warscheid and Braams, 2000; McNamara and Mitchell, 2005). Phototrophs, like cyanobacteria and algae, are primary colonizers (Grant, 1982) and also provide nutrients for heterotrophic microorganisms, e.g. fungi (Gaylarde et al., 2012). All these microorganisms may be involved in biodeterioration, e.g. biopitting by penetration of fungi in the material surface but also as staining caused by algae and black pigmented fungi (Sterflinger and Krumbein, 1997; McNamara et al., 2006; Polo et al., 2010 and references therein). A multitude of studies documented the deterioration of marble monuments and building facades by weathering, pollution and microbial communities (Gromov, 1963; Lamenti et al., 2000; Gorbushina et al., 2002; Moropoulou et al., 2002; Cappitelli et al., 2007; Weber et al., 2007; Sert and Sterflinger, 2010; Hallmann et al., 2011a).

Different cleaning methods and conservation procedures were developed, based on chemical compounds (Young and Urquhart, 1998; Moropoulou et al., 2002; Polo et al., 2010), excimer laser cleaning (Maravelaki-Kalaitzaki et al., 1999), protective synthetic resins (Cappitelli et al., 2007) or application of biomimetic apatite (Yang et al., 2012). Even biological treatments with sulfate reducing bacteria for black crust removal were established (Cappitelli et al., 2006; Konkol et al., 2008).

So far only few studies were devoted to comparative analysis concerning recolonization by microorganisms after cleaning procedures. Lamenti et al. (2000) observed the re-colonization of marble statues by phototrophic biofilms for 6 years after restoration by culturing method. Polo et al. (2010) analyzed microbial communities by denaturing gradient gel electrophoresis (DGGE) before and immediately after biological and chemical remediation of oolithic limestone sculptures. Lan et al. (2010) stated obvious differences between the eukaryotic community of an old and a newly developed biofilm on sandstone of a Temple building of Angkor Thom in Cambodia, while the bacterial communities of both biofilms were almost similar.

In our study, an "old grown" blackish and greenish biofilm (surface left untreated tens of years) and a newly developed biofilm on the surface of a sepulchral marble 
sculpture 1 year after cleaning were analyzed and compared by environmental cloning and sequencing. The focus was on green algal and fungal communities, to identify the emerging colonizers in an early period of (re-) colonization.

\section{Materials and methods}

\section{Sampling}

The sampling site was a marble sculpture on the historical Bartholomäus cemetery in Göttingen, Lower Saxony, Germany $\left(51^{\circ} 32^{\prime} 27.49^{\prime \prime} \mathrm{N}, 9^{\circ} 55^{\prime} 54.52^{\prime \prime} \mathrm{E}\right)$. The sculpture was created in 1802 by the sculptor Johann Christian Ruhl (1764-1842) and was placed on the grave of Carl von Hahn. The grave was situated under a tree and near a main street.

The sculpture, made of Tuscan Carrara marble, was covered with a blackish and greenish biofilm dominated by fungi and green algae. At some spots, also crustose and foliose lichens were abundant (cf. Figs. 1a, b, 2a). The grave was restored in 2009/2010, including a surface cleaning of the sculpture. The cleaning was performed as follows: the cryptogam cover was removed with soft brushes and wooden tools; then, the surface was cleaned with a vapor stem cleaner. Since dark stains could be not removed by this procedure, the surface was treated several times with a diluted hydrogen peroxide solution. A resulting foam layer on the surface was removed by rinsing with water. The surface was then impregnated with a thin layer of calcium silicate. A small area situated on the back of the sculpture was left untreated. All samples were collected in April 2011, 1 year after cleaning and restoration. Samples of approx. $100 \mu \mathrm{l}$ dry volume were taken from the cleaned white marble monument ("cleaned surface", sample A) and from the small area covered with the old grown black biofilm ("'uncleaned surface", sample B) which had been left untreated during cleaning. The samples were scraped off with a sterile scalpel and collected in sterile $1.5 \mathrm{ml}$ reaction tubes.

\section{DNA extraction}

Genomic DNA was extracted from collected environmental biofilm samples. For the cell disruption by shaking in a Mini-BeadBeater (Biospec Products, Bartlesville, OK, USA) equivalent amounts of acid washed glass beads (120-200 $\mu \mathrm{m}$ and 425-600 $\mu \mathrm{m}$ in diameter; Sigma-Aldrich, ST. Louis, MO, USA) were added to $2 \mathrm{ml}$ reaction tubes containing the samples. The samples were treated in the bead beater for $30 \mathrm{~s}$ at $5.000 \mathrm{rpm}$. 


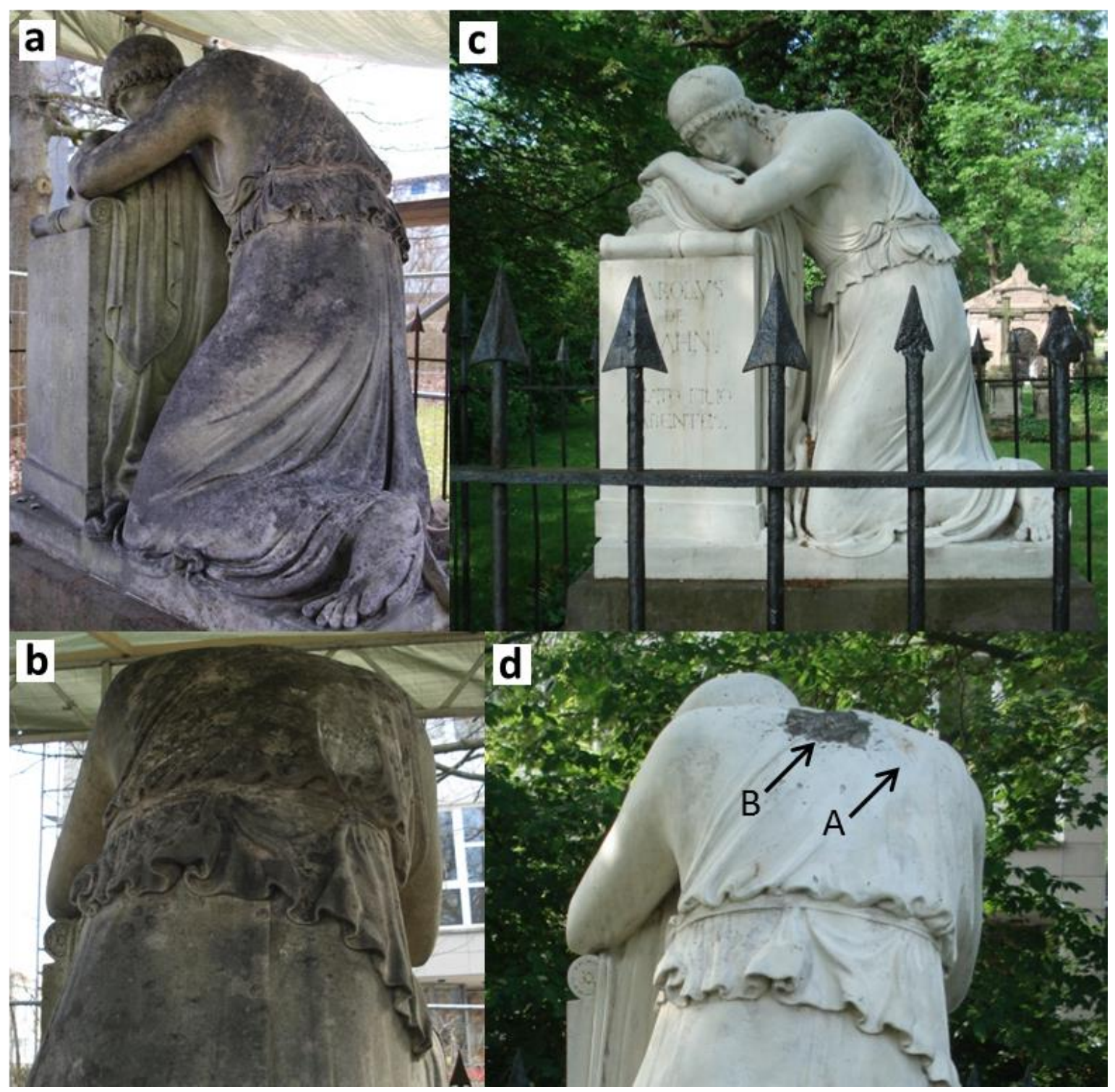

Fig. 1. Sampling site on sepulchral monument. (a) Monument covered with blackish and greenish biofilm. (b) Back view of the untreated monument. (c) Monument 1 year after cleaning treatment. (d) Back view after cleaning. The arrows mark the sites where samples A and B were taken (A cleaned surface, B uncleaned surface).

DNA was extracted with the Invisorb Spin Plant Mini Kit (STRATEC Molecular, Berlin, Germany), following the manufacturer's instructions. Extraction results were checked on a $1 \%(\mathrm{w} / \mathrm{v})$ agarose gel. Isolated DNA was stored at $-20{ }^{\circ} \mathrm{C}$ until further processing.

\section{Polymerase chain reaction amplification}

For isolated biofilm DNA the polymerase chain reaction (PCR) amplification was performed with two primer combinations for $18 \mathrm{~S}$ rRNA gene, using eukaryotic standard primers 20F (5' GTAGTCATATGCTTGTCTC 3') and 
18L (5' CACCTACGGAAACCTTGTTACGACTT 3'); Hamby et al., 1988). In a second approach, the samples were first amplified with $20 \mathrm{~F} / 18 \mathrm{~L}$ and in a second round (seminested PCR) with 20F and the green algal-specific primer CH1750R (5' CTTCCTCTAGRTGGGAGG 3'; Hallmann et al., 2013). About 30 ng of the extracted DNA was used as template. The amplification reaction mixture $(25 \mu \mathrm{l})$ contained each dNTP at a concentration of $0.1 \mathrm{mM}, 5 \mu \mathrm{l}$ of $10 \mathrm{x}$ reaction buffer, $2 \mathrm{mM} \mathrm{MgCl}_{2}$, each primer at a concentration of $0.2 \mu \mathrm{M}, 2 \mathrm{U}$ of Taq DNA polymerase (Bioline, Luckenwalde, Germany) and $4 \%$ (v/v) dimethyl sulfoxide (DMSO)-solution. PCR was performed in a thermocycler TProfessional Basic (Biometra, Göttingen, Germany) using the following program for the primer set $20 \mathrm{~F} / 18 \mathrm{~L}$ : initial denaturation at $95{ }^{\circ} \mathrm{C}$ for $5 \mathrm{~min}$, followed by 35 cycles of denaturation at $94{ }^{\circ} \mathrm{C}$ for $1 \mathrm{~min}$, annealing at $50{ }^{\circ} \mathrm{C}$ for $1 \mathrm{~min}$, extension at $72{ }^{\circ} \mathrm{C}$ for $3 \mathrm{~min}$ and final extension at $72{ }^{\circ} \mathrm{C}$ for $10 \mathrm{~min}$. For the semi-nested PCR with the primer set 20F/CH1750R, the first PCR product of 20F/18L was diluted 1:25 and used as template; then the following program was used: initial denaturation at $95{ }^{\circ} \mathrm{C}$ for $5 \mathrm{~min}$, followed by 25 cycles of denaturation at $94{ }^{\circ} \mathrm{C}$ for $1 \mathrm{~min}$, annealing at $54{ }^{\circ} \mathrm{C}$ for $1 \mathrm{~min}$, extension at $72{ }^{\circ} \mathrm{C}$ for $3 \mathrm{~min}$, and final extension at $72{ }^{\circ} \mathrm{C}$ for $10 \mathrm{~min}$. The PCR products were purified using the Invisorb Spin PCRapid Kit (STRATEC Molecular). Aliquots of $2 \mu \mathrm{l}$ of purified amplicons were analyzed by electrophoresis on a $1 \%(\mathrm{w} / \mathrm{v})$ agarose gel.

\section{$18 S$ rRNA gene cloning and sequencing}

Cloning was carried out with the TOPO TA cloning kit (Invitrogen, Carlsbad, CA, USA) with TOP 10 chemically competent one Shot Escherichia coli cells (Invitrogen), as supplied by the manufacturer. All eukaryotic clones were sequenced with the $18 \mathrm{~S}$ rRNA gene standard sequencing primer 895R (5', AAATCCAAGAATTTCACCTC 3') resulting in partial sequences including the hypervariable regions V2-V4 (Hodač et al., 2012). Sequencing reactions were performed by Macrogen Inc. (Seoul, South Korea).

\section{Phylogenetic analysis}

The sequences were manually corrected using the sequence analysis program SeqAssem (Hepperle, 2004). Sequences shorter than $400 \mathrm{bp}$ were excluded from further analysis. These sequences were compared with similar sequences of reference organisms by performing a BLASTN search at NCBI (Altschul et al., 1990; http://www.ncbi.nlm.nih.gov/). Next relative sequences were imported into the ARB program (Ludwig et al., 2004; http://www.arb-home.de). In addition, sequences provided by SAG Culture Collection of 
Algae (University of Göttingen) were included in the comparisons. To determine the first phylogenetic affiliation the partial sequences were aligned with the homologous eukaryotic $18 \mathrm{~S}$ rRNA gene sequences using the automatic alignment tool of the ARB program package. Potential chimeras were checked by Bellerophon (Huber et al., 2004). In addition, the first and the last $300 \mathrm{bp}$ of putative chimeras were compared with similar rRNA gene sequences in NCBI. Chimeras were excluded from the dataset.

Rarefaction curves and operational taxonomic units (OTUs) were calculated with MOTHUR (Schloss et al., 2009). OTUs were defined on $\geq 98 \%$ sequence similarity for 18S rRNA genes (Ragon et al., 2012). One sequence of each OTU with respect to green algae was selected and sequenced completely with $18 \mathrm{~S}$ standard sequencing primers: $34 \mathrm{~F}$, 370R, 891F, 1122F, 1122R, 1422F. Representative sequences were deposited in GenBank under the following accession numbers: JX391005 - JX391026. The alignments for phylogenetic analysis were performed using MAFFT version 6 (Katoh and Toh, 2008); small corrections were done by eye. The phylogenetic tree was constructed with full-length sequences using the RAxML search algorithm for maximum likelihood (ML; Stamatakis et al., 2008), using the GTR $+\Gamma+\mathrm{I}$ model with 100 replicates. The confidence of the tree topologies was tested by bootstrap analysis implemented in RAxML (100 replicates) and by Bayesian posterior probabilities (MB) using MrBayes 3.2 (Huelsenbeck and Ronquist, 2001). Two parallel Markov chain Monte Carlo (MCMC) runs for two million generations each with one cold and three heated chains were conducted using the GTR $+\Gamma+\mathrm{I}$ model, with trees sampled every 100 generations.

\section{Light and scanning electron microscopy}

Light microscopic observations were performed using an Olympus BX60 microscope (Tokyo, Japan) with Nomarski DIC optics with a ColorView III camera (Soft Imaging Systems, Münster, Germany) attached and micrographs were processed using the Cell^D image software (Soft Imaging Systems). For scanning electron microscopy (SEM), samples were fixed immediately after sampling in $2 \% \mathrm{w} / \mathrm{v}$ glutardialdehyde (EM grade, Sigma-Aldrich, Deisenhofen, Germany) and stored at $4{ }^{\circ} \mathrm{C}$ until further processing. Samples were dehydrated in an ascending ethanol series (15\% to $99 \%)$, mounted on SEM sample holders and sputtered with Au-Pd (13.9 nm for $120 \mathrm{~s})$. Samples were visualized in a SEM LEO 1530 Gemini (Zeiss, Oberkochen, Germany) combined with an INCA X-ACT EDX. 


\section{Results}

Before surface cleaning, the marble sculpture exhibited obvious colonization by cryptogams, including fungi, algae and lichens (Fig. 1a, b). Surface cleaning was done mechanically with water, diluted hydrogen peroxide solution and a soft brush; if necessary, also mild detergent was used. After cleaning, the white marble appeared to be completely free of surface staining or colonization to the naked eye, except from a rectangular $5 \times 10 \mathrm{~cm}$ area, which remained untreated. During cleaning, care was taken that neither water nor chemicals came in contact to the uncleaned area. One year after cleaning treatment (Fig. 1c, d) the monument appeared still white but some blackish spots, visible to the naked eye, already reappeared. On the sampling area B thalli of the foliose lichen Physcia sp. were obvious (Fig. 2a). SEM of a lichen thallus revealed reproductive structures like soredia (Fig. 2b, $b_{1}$ ). Light microscopy showed supposedly pre-lichenized Trebouxia cells surrounded by fungal hyphae (Fig. 2c). Lichen thalli were attached to the substrate by rhizines. These rootlike fungal structures were firmly associated with mineral particles detached from the surface of the sculpture (SEM, Fig. 3a-d). SEM also revealed the presence of a plant pathogenic fungus on the lichen thallus. A chasmothecium (fruiting body) of a powdery mildew fungus (family Erysiphaceae) was anchored by appendices on the substratum (Fig. 3e, f)

Sequencing of $18 \mathrm{~S}$ rRNA genes aiming at detection of eukaryotic algae and fungi was performed for environmental samples. In total 222 18S rRNA gene sequences were retrieved, 112 sequences from sample A (cleaned surface) and 110 sequences from sample B (uncleaned surface). Overall, 22 OTUs were received on the $98 \%$ sequence similarity level. Altogether 17 OTUs were retrieved from sample A and 14 OTUs from sample B. Rarefaction curves (Fig. 4) calculated for both samples showed the clone library coverage for algal and fungal sequences. The rarefaction curve from sample B reached almost a plateau. This was not the case for sample A, though also nearly full coverage of OTUs was reached. With respect to green algae the samples indicated few differences (Fig. 5). Altogether ten green algal OTUs were retrieved, nine OTUs (69 clones) from sample A and seven OTUs (71 clones) from sample B. Phylogenetic analysis (Fig. 6) revealed that all sequences belong to the green algal class Trebouxiophyceae. 


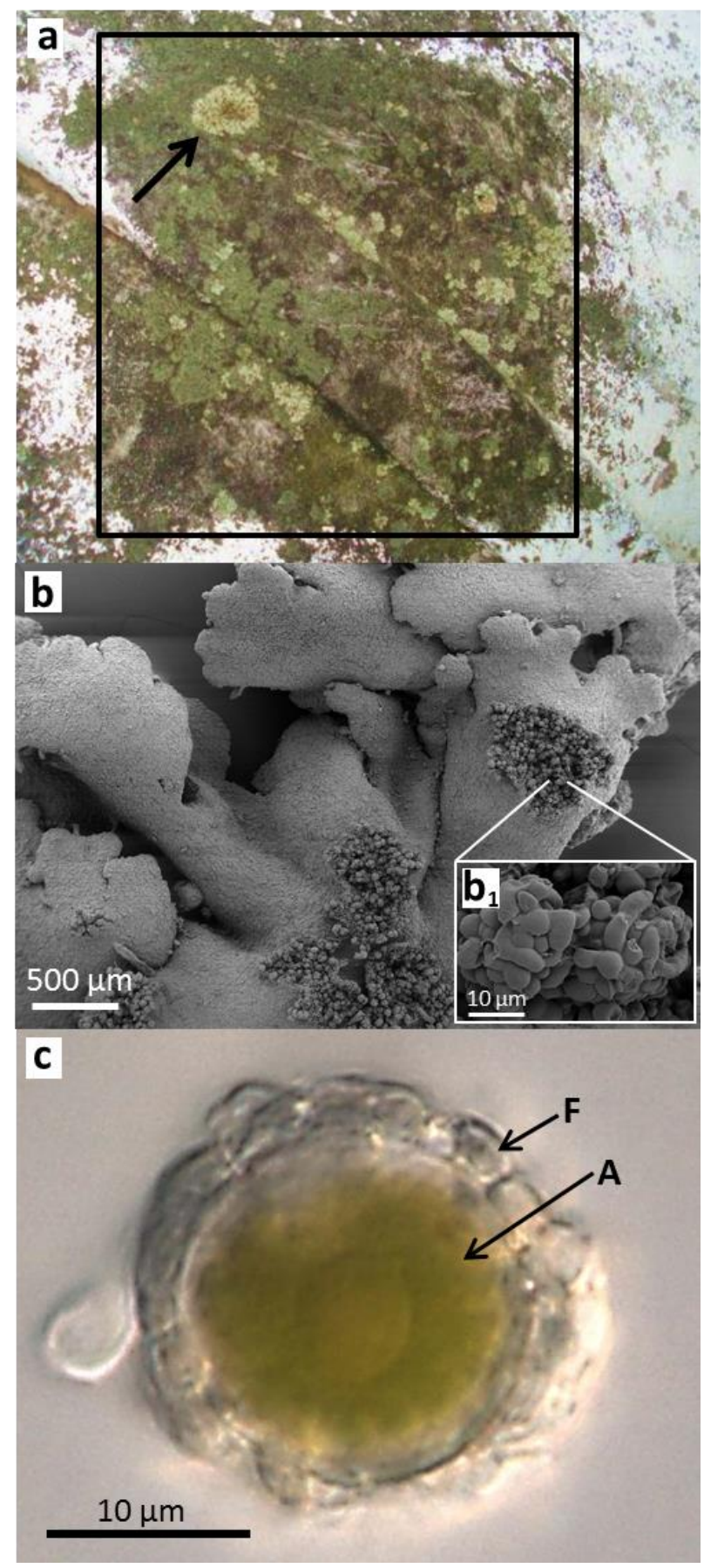

Fig. 2. Lichen thalli on old grown biofilm (sampling site B). (a) Overview image of sampling site $B$, with lichen thallus of Physcia sp. (black arrow). (b) Scanning electron micrograph of a lichen thallus with several soralia, inset $\left(b_{1}\right)$ close-up view of soredia in a soralium. (c) Light micrograph of a lichenized Trebouxia cell (F fungal hyphae, A algal cell). 

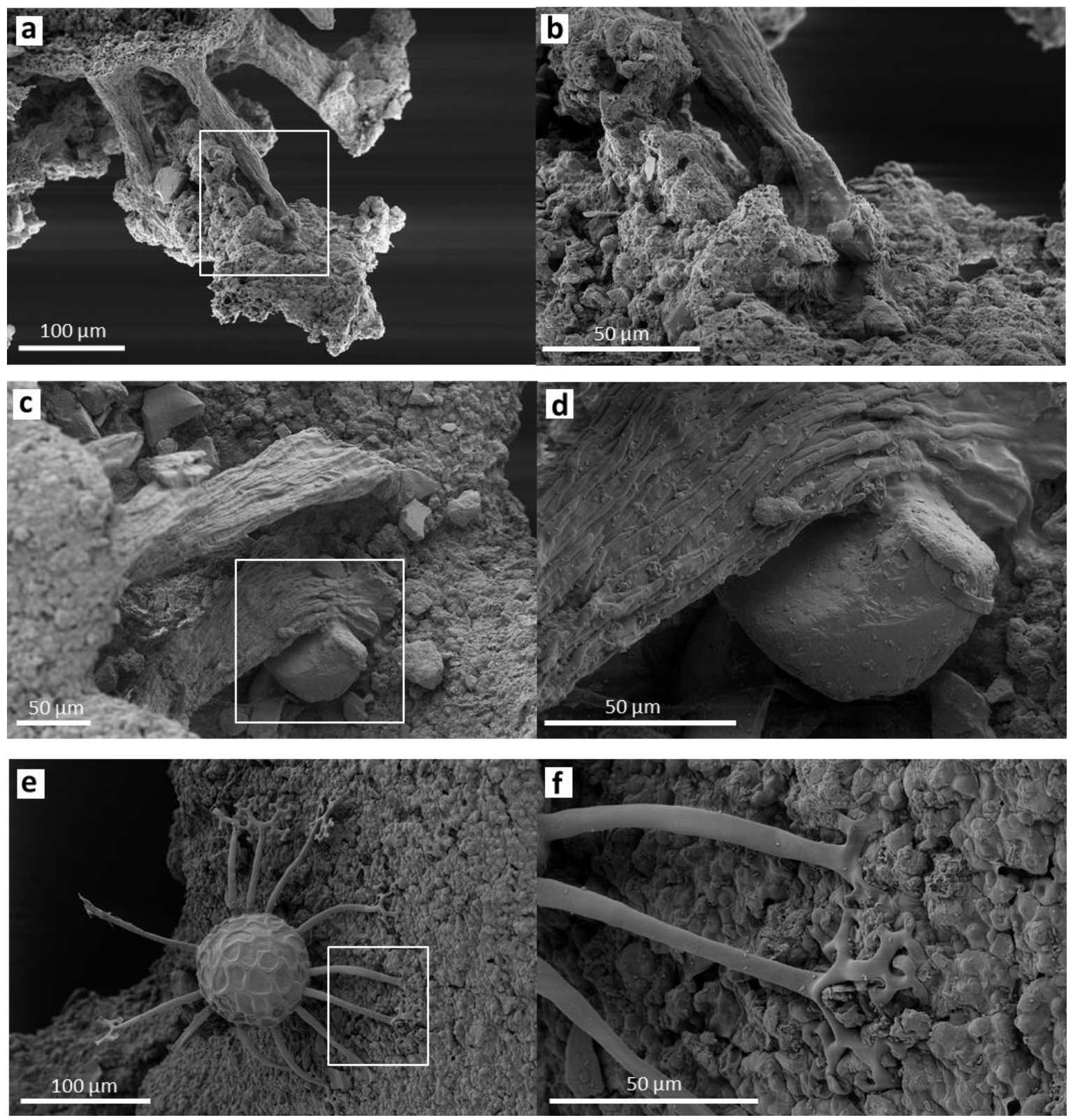

Fig. 3. Features of lichen thalli taken from old grown biofilm visualized by scanning electron microscopy. (a), (c) Overview of lichen-fungi hyphae associated with mineral particles, (b), (d) in detail. (e), (f) Chasmothecium of an Erysiphaceae representative attached on a lichen thallus, (f) detail of appendices of the chasmothecium anchored to the substratum. 


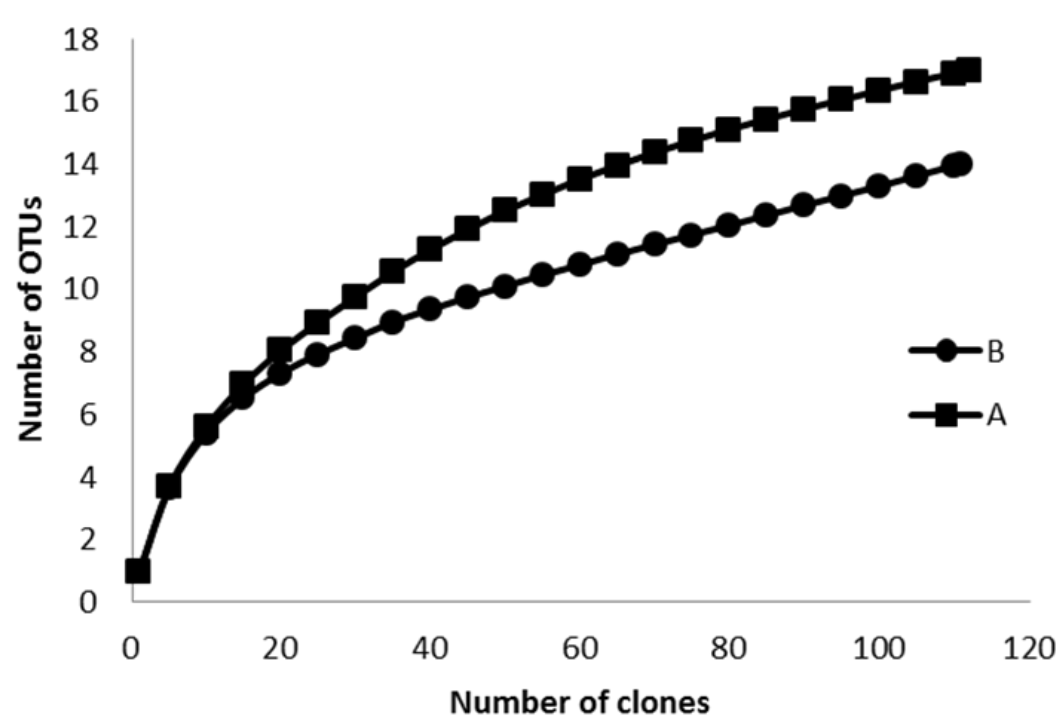

Fig. 4. Rarefaction curves determined for $18 \mathrm{~S}$ rRNA gene clone libraries. The OTUs include green algal and fungal sequences from samples taken after cleaning treatment (A) and from the uncleaned surface (B).

The green algal composition indicated a high similarity between both samples, six OTUs were shared by both (Table 1), one OTU were found only in sample B and three OTUs in sample A. In both sampling areas the Trebouxia-related OTU 5 showed a clear dominance, with 27 clones from sample A and 34 clones from sample B (Table 1; Fig. 6). Furthermore, four OTUs could be assigned to other Trebouxia-related OTUs, with high clone numbers for OTU 4 and OTU 6 in both sampling areas. Stichococcus- and Diplosphaera-related sequences were more abundant in sample A than in sample B, Desmococcus- (OTU 1) and Apatococcus-related (OTU 10) sequences were detected exclusively in sample A. Apatococcus sp.-related sequences could be separated in two distinct OTUs (Fig. 6), phylogenetically affiliated to Apatococcus lobatus SAG 2151 (OTU 10, exclusively in sample A, see above) and Apatococcus lobatus SAG 2037 (OTU 9), with respectively four clones in samples A and B.

With regard to fungi, both sampling areas differ markedly (Fig. 7). Altogether 12 fungal OTUs were retrieved, eight OTUs (43 clones) from sample A and seven OTUs (39 clones) from sample B. Just three OTUs were shared by both sampling sites (Table 2); next relatives according to BLASTN analysis were members of the family Teratosphaeriaceae (OTU 11), Rhinocladiella sp. (OTU 19) and Glyphium elatum (OTU 20).

The most abundant OTU in sample B was Rhinocladiella sp. (OTU 19, 22 clones), with $99 \%$ sequence similarity to the reference as revealed by BLASTN, while only two 
Table 1. Distribution of green algal OTUs in the samples of the cleaned (A) and uncleaned (B) surface.

\begin{tabular}{|c|c|c|c|c|c|}
\hline \multirow[b]{2}{*}{ OTU $98 \%$} & \multicolumn{2}{|c|}{ No. of clones } & \multirow[b]{2}{*}{ Representative clone } & \multirow[b]{2}{*}{ Acc. No. } & \multirow[b]{2}{*}{ Closest relative (\% similarity) } \\
\hline & A & B & & & \\
\hline 1 & 1 & & FGSwan_K6/(A) & JX391007 & Desmococcus olivaceus SAG 1.92, EU434017 (99\%)* \\
\hline 3 & 5 & 1 & FGSwa_K37/(A) & JX391006 & Diplosphaera sp. W1268, JN573889 (99\%)* \\
\hline 4 & 6 & 16 & FGSsan_K9/(B)* & JX391008 & Uncultured marine eukaryote clone NA2_1H8, EF526889 (99\%), Trebouxia sp. \\
\hline 5 & 27 & 34 & FGSwan_K31/(A)* & JX391009 & Uncultured marine eukaryote clone NA2_1H8, EF526889 (99\%), Trebouxia sp. \\
\hline 7 & 2 & & FGSwa_K17/(A) & JX391012 & Uncultured eukaryote clone Th090408_47, HM030919 (99\%)*, Trebouxia sp. \\
\hline 8 & & 1 & FGSsa_K43/(B) & JX391011 & Uncultured Trebouxiophyceae clone QE44, FJ790663 (98\%), Trebouxia sp. \\
\hline 9 & 4 & 4 & FGSwa_K32/(A)* & JX391013 & Uncultured eukaryote clone Th090408_11, HM030915 (99\%), Apatococcus sp. \\
\hline 10 & 1 & & FGSwa_K16/(A)* & JX391014 & Uncultured eukaryote clone Th090408_11, HM030915 (99\%), Apatococcus sp. \\
\hline
\end{tabular}

*Representative full-length sequence in phylogenetic analysis.

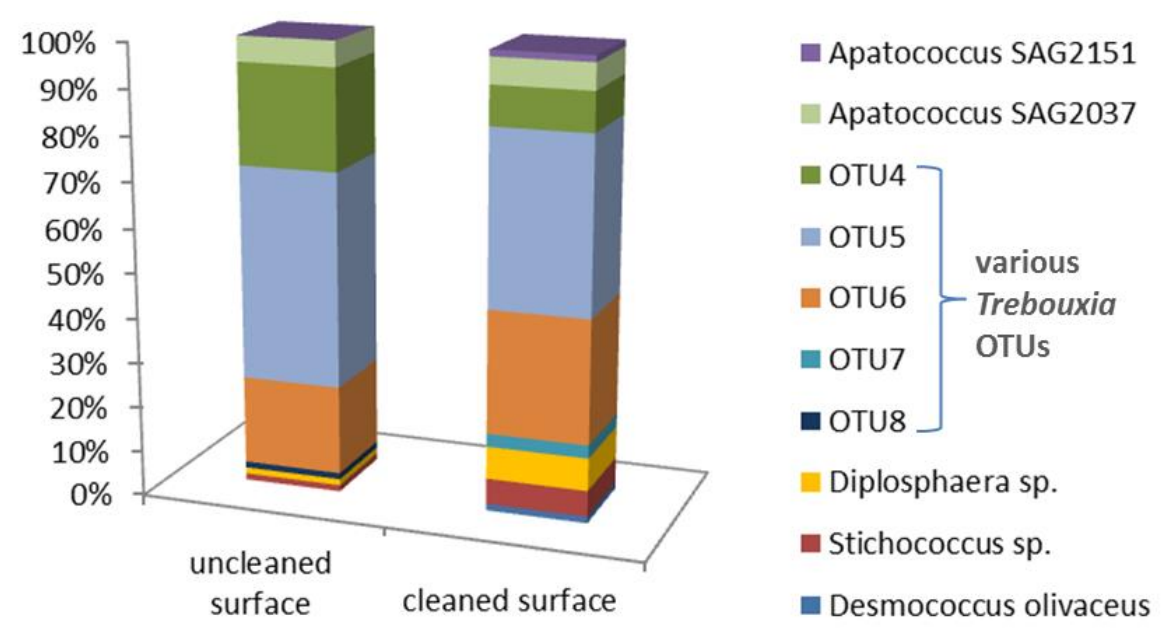

Fig. 5. Distribution of green algal OTUs (98\% cutoff) revealed few differences between the uncleaned surface and the surface after cleaning.

clones were discovered in the sample A. OTUs exclusively found in sample B were related to Bulgaria inquinans (OTU 13), a Capnodiales family member (OTU 15), Caloplaca demissa lichen fungus (OTU 16) and a Davidiellaceae family member (OTU 17). The most abundant OTU in sample A 1 year after cleaning treatment was Sarcinomyces sp.-related OTU (OTU 14, 31 clones), with $99 \%$ similarity to the reference. Furthermore, exclusively found in this sample were OTUs related to Cladosporium bruhnei (OTU 12), Exophiala aquamarina (OTU 18), the uncultured Banisveld eukaryote clone (100\% sequence similarity)/Rhodotorula aurantiaca JCM 3771 (AB030354) with $99 \%$ sequence similarity (OTU 21) and Cryptococcus albidus (OTU 22). 


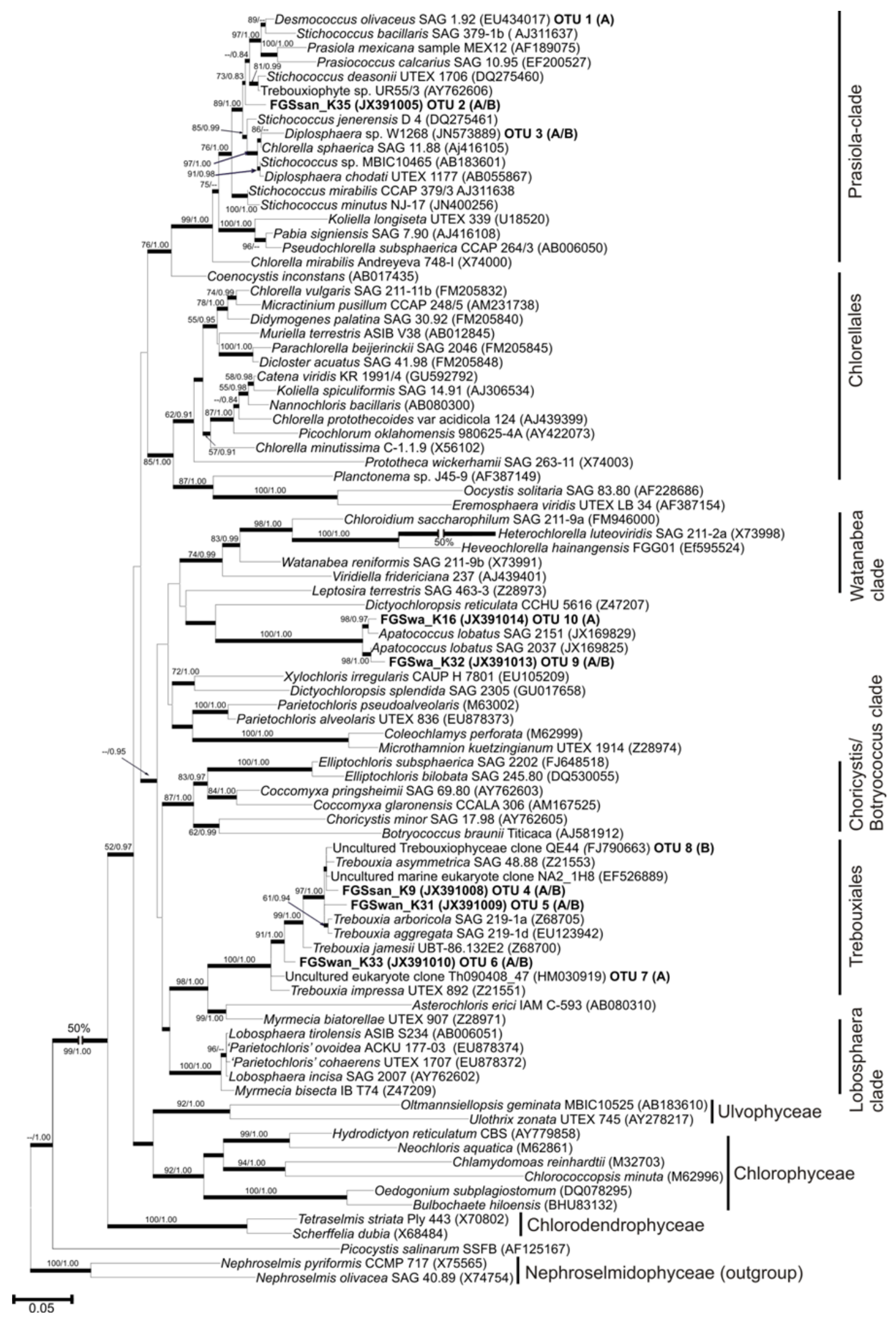

Fig. 6. Phylogenetic tree of Trebouxiophyceae based on 18S rRNA gene sequences. Maximum likelihood method (RAxML) based on 89 taxa and 1.801 positions. Thick lines indicate internal nodes that were received in maximum likelihood and Bayesian trees. Support values given as ML (50\% bootstrap values)/MB (0.95 Bayesian posterior probabilities). Sequences in bold represent full 18S rRNA gene sequences of clones; A cleaned surface, B uncleaned surface. 
Table 2. Distribution of fungal OTUs in the samples of the cleaned (A) and uncleaned (B) surface.

\begin{tabular}{ccclll}
\hline & \multicolumn{2}{l}{ No. of clones } & & & \\
\cline { 2 - 3 } OTU 98 \% & A & B & Representative clone & Acc. No. & Closest relative (\%similarity) \\
\hline 11 & 3 & 1 & FGSwe_K21/(A) & JX391015 & Teratosphaeriaceae sp. strain CCFEE 5508, GU250358 (99\%) \\
12 & 1 & & FGSwe_K48/(A) & JX391016 & Cladosporium bruhnei strain CPC 5101, AY251096 (99\%) \\
13 & & 1 & FGSsan_K4(/B) & JX391019 & Bulgaria inquinans isolate 93, EU107259 (98\%) \\
14 & 31 & & FGSwe_K18/(A) & JX391018 & Sarcinomyces sp. isolate MA 4760, AJ972809 (99\%) \\
15 & & 8 & FGSse_K24/(B) & JX391017 & Capnodiales sp. strain CCFEE 5502, GU250357 (100\%) \\
16 & & 1 & FGSse_K7/(B) & JX391024 & Caloplaca demissa, AF515609 (98\%) \\
17 & & 1 & FGSse_K17/(B) & JX391020 & Davidiellaceae sp. strain CCFEE 5414, GU250343 (97\%) \\
18 & 1 & & FGSwe_K3/(A) & JX391021 & Exophiala aquamarina strain CBS 119918, JN856012 (98\%) \\
19 & 2 & 22 & FGSse_K11/(B) & JX391022 & Rhinocladiella sp. Isolate MA 4765, AJ972862 (99\%) \\
20 & 1 & 5 & FGSse_K4/(B) & JX391023 & Glyphium elatum strain CBS 268.34, AF346419 (99\%) \\
21 & 3 & & FGSwe_K23/(A) & JX391025 & Uncult. Banisveld euk. clone P1-3m6, EU091832 (100\%), \\
& & & & Rhodotorula aurantiaca (99 \%) \\
22 & 1 & & FGSwe_K28(A) & JX391026 & Cryptococcus albidus strain WY-1, HQ231895 (99\%) \\
\hline
\end{tabular}

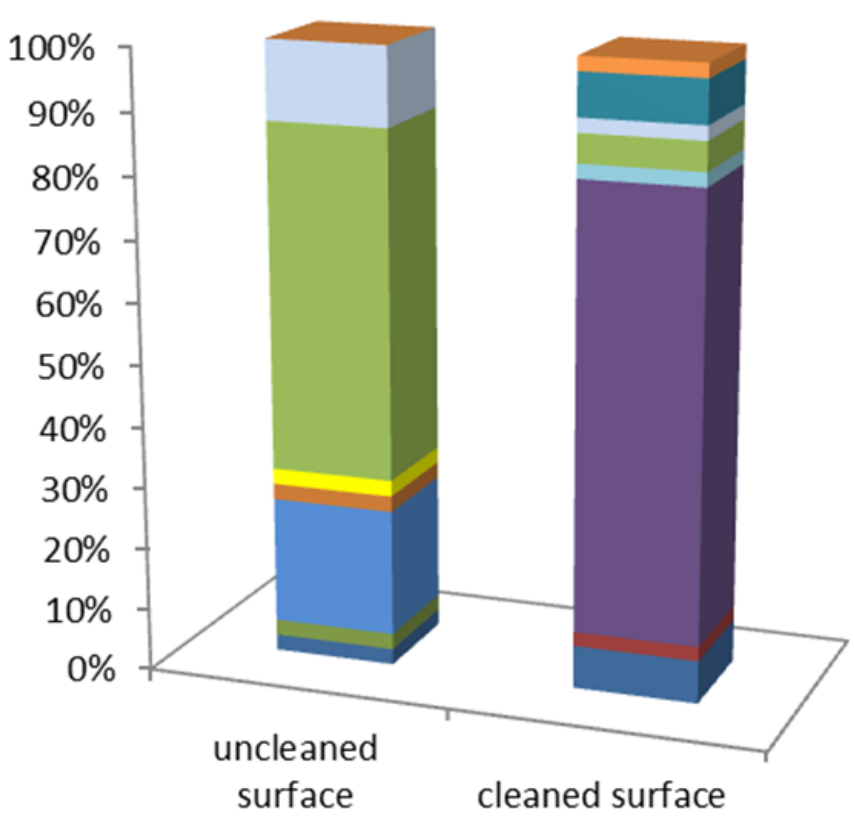

- Cryptococcus albidus

nhodotorula sp.

Glyphium elatum

nhinocladiella sp.

Exophiala aquamarina

Davidiellaceae sp.

- Caloplaca demissa

n Capnodiales sp.

घ Sarcinomyces sp.

Bulgaria inquinans

Cladosporium bruhnei

- Teratosphaeriaceae sp.

Fig. 7. Distribution of fungal OTUs (98\% cutoff) revealed clear differences between the uncleaned surface and the surface after cleaning. 


\section{Discussion}

Colonization of monuments, including marble sculptures, has been already documented in various studies (e.g. Albertano and Urzì, 1999; Ortega-Calvo et al., 1995; Lamenti et al., 2000; Gorbushina et al., 2002; Hallmann et al., 2011a). In the case presented here, the surface of the marble sculpture was affected by biodeterioration in two different ways. Heavy blackish stains covered the entire surface and single mineral particles were detached from the surface and became attached to the lichen plectenchyme. Thus, one may expect that both effects may be temporarily stopped or reduced by surface cleaning and other treatments. However, by far most of previous studies just show colonization at one time point, and the gradual decrease of the cleaning effect by recolonization has been rarely addressed so far. One may speculate that after (re-) colonization has completed, the microbial communities are stable for several years ("old grown", biofilms), representing a snapshot of a "climax" community. Our study documents the re-colonization 1 year after cleaning treatment in comparison to the "old grown" biofilm on the same marble sculpture.

The green algal sequences in the "old grown" biofilm (sample B) and on the cleaned surface (sample A) belong all to Trebouxiophyceae; members of this green algal class are mostly aerophytic or soil algae (Friedl and Rybalka, 2012). Adaptations against desiccation and UV irradiation like thick cell walls, mucilage sheaths and Mycosporine-like amino acids (MAAS) are common for aerophytic algae (Karsten et al., 2005a, 2005b). The occurrence of the trebouxiophycean genera Apatococcus, Desmococcus, Stichococcus, Diplosphaera and Trebouxia on stone substrates is well known (Hallmann et al., 2011a; Ragon et al., 2012).

On the $98 \%$ similarity level two OTUs of Apatococcus were detected; the phylogenetic analysis confirmed two distinct groups (cf. Fig. 6). The cell package forming green algae Apatococcus lobatus is the most common aerophytic alga (Gärtner, 1994), abundant on natural stone substrata in the urban environment (Rindi, 2007). The resistance of Apatococcus against pollution, desiccation and high UV radiation is mainly due to thick cell walls and typical cytosolic "stress metabolites" like the polyols ribitol and erythritol (Barkman, 1969; Gustavs et al., 2011). Apatococcus was detected in both samples (old grown biofilm and cleaned area). Hitherto, lichen symbiosis for Apatococcus lobatus could not be definitively proven (Gärtner and Ingolić, 1989), but a close association with fungal hyphae was observed (Edlich, 1936). Desmococcus, another cell packages forming 
trebouxiophyte, but phylogenetically distant from Apatococcus (Fig. 6), a very common aeroterrestrial green algae (Rindi, 2007) was also detected on the cleaned surface.

The dominance of different phylotypes of the lichen photosymbiont Trebouxia on both surfaces may be surprising since lichen thalli were present in the old grown biofilm, but not detected on the cleaned surface. However, Trebouxia has been frequently described in terrestrial habitats even when identifiable lichens were absent (Gärtner, 1994; Macedo et al., 2009). Furthermore, soredia (asexual reproductive structures) were observed by SEM on the surface of a lichen thallus (Fig. 2b) and single Trebouxia cells were closely associated with fungal hyphae (cf. Fig. 2c). This lichenization without an identifiable lichen thallus, in particular as asexual propagules or thallus fragments, is common for Trebouxia (Ahmadjian, 1988). Thus, various OTUs of Trebouxia could be detected possibly because of these dispersal structures of different lichens, colonizing tree bark and stone monuments nearby the cleaned sculpture, while obvious lichen thalli were absent on the cleaned sampling site A.

The green alga Stichococcus and Diplosphaera, both affiliated to Prasiolales-clade, were also discovered on both sampling areas. Stichococcus and Diplosphaera are known as lichen photobionts (Thüs et al., 2011). In addition, Stichococcus is an ubiquitous and rapid colonizer known from nitrogen rich sites (Ettl and Gärtner, 1995). Since the monument is situated under a tree, bird droppings (Hallmann et al., 2011a) may contribute to favorable conditions for Stichococcus. Generally, these photosynthetic microorganisms cause staining by photosynthetic pigments and may be involved in stone decay by secretion of organic acids and indirectly by supporting growth of other microorganisms like fungi and bacteria (Ariño et al., 1997; Polo et al., 2010).

Interestingly, fungal OTUs markedly differed in our studied samples. Eight of 12 fungal OTUs belong to the classes Dothideomycetes and Eurotiomycetes, which include numerous rock inhabiting fungi involved in stone biodeterioration (Gorbushina et al., 1993; Wollenzien et al., 1997; Ruibal et al., 2009).

The most abundant OTU 14 on the cleaned surface (sample A) is related to Sarcinomyces sp. isolate MA 4760, next related to Sarcinomyces petricola (Sert et al., 2007; Wollenzien et al., 1997), whereas the most abundant OTU 19 retrieved from the old grown biofilm (sample B) is related to Rhinocladiella sp. MA 4765 isolated from antique marble in Turkey (Sert et al., 2007). The black filamentous Rhinocladiella is free living, but also parasitic on lichens (Harutyunyan et al., 2008): Sarcinomyces is affiliated to meristematic black yeasts. 
Whereas Sarcinomyces sp. was totally absent in the old grown biofilm, small number of Rhinocladiella sp. clones were also found on the cleaned surface. Thus one may speculate that Sarcinomyces appears to be a rapid colonizer, but was presumably outcompeted in our old grown biofilm by other fungi like Rhinocladiella. Just two OTUs in addition to Rhinocladiella sp. were shared by both surfaces, with just one clone in either sample A or sample B: Glyphium elatum (normally on wood, non-lichenized) and one OTU included in the family Teratosphaeriaceae (associated with Eucalyptus leaf diseases and stem cankers).

Only present in the old grown biofilm was Bulgaria inquinans, a saprobiontic fungus on tree bark, a species of the order Capnodiales, an epiphytic black fungus on plant leaves and often associated with the honeydew. In addition, exclusive in the old biofilm were Caloplaca demissa, a lichen fungus, with cyanobacteria instead of green algae in the thallus and a species of the family Davidiellaceae (with some cryptoendolithic representatives; Selbmann et al., 2005; Hallmann et al., 2011b).

Only presented on the cleaned surface were free living fungi like Cladosporium, well known from marble (Wollenzien et al., 1995), Exophiala aquamarina (a black yeast), an uncultured Banisveld eukaryotic clone (next related culture Rhodotorula aurantiaca, a yeast) and Cryptococcus albidus (cosmopolitan, e.g. on plants).

Most fungi were affiliated to "black fungi". In these groups the black pigment melanin is incorporated in vegetative hyphae, which provides protection against high UV irradiance (Bell and Wheeler, 1986). It is reasonable to assume that, besides algal pigments, melanin contributes to the blackish color of the old grown biofilm. Black fungi are frequently found in conjunction with honeydew coverings: Typically, honeydew is secreted by plant-sucking aphids and scale insects (e.g. Auclair, 1963). When the plant is massively infested by these insects, the resulting honeydew coverings of surfaces located underneath the plant are colonized by black fungi (Hallmann et al., 2011a). The investigated marble sculpture was situated under a tree, which causes a favorable microclimate (protection against high irradiation and evaporation; e.g. Weber et al., 2007) and provides nutrients as honeydew, dead plant material and bird droppings for microbial growth. A continuous input from the canopy is also documented by powdery mildew fruiting bodies (chasmothecia) scattered on the surface of the lichen thalli (Fig. 3e). Powdery mildew is a fungal disease affecting the tree leaves (Glawe, 2008 and references therein). 
Little experience has been collected so far on recolonization of stone surfaces by microorganisms after cleaning. Though directly after cleaning with biocides, no remaining organisms could be detected (Polo et al., 2010), a long-term experiment documented re-colonization after cleaning treatment over 6 years (Lamenti et al., 2000). However, just enrichment culturing was used in this approach, which will greatly alter the microbial community before analysis. Twelve months after cleaning Coccomyxa sp. was observed as the dominant first colonizer. Six years after cleaning treatment, the community was again identical to an unrestored statue with green algae like Coccomyxa, Apatococcus and Stichococcus.

Miller et al. (2008) analyzed the biofilm development on a stone surface under laboratory conditions, using a molecular approach. One month after inoculation of the cleaned surface with an active growing microbial culture a green layer was observed; fungi were observed after 3 months. The detected eukaryotic phototrophic microorganisms belonged to the genera Stichococcus, Trebouxia, Myrmecia and Chlorella.

In our study, we could show that the cleaned re-colonized surface differs with respect to the fungal community, but not with respect to the green algal community, 1 year after re-colonization started. Up to now, this effect appears to be unavoidable, if not repeated cleaning and/or biocide treatment is applied. It must be kept in mind that early recolonizers of a cleaned surface might be even more deleterious with respect to biogenic weathering than an old grown biofilm community (cf. Gaylarde et al., 2012).

\section{Acknowledgment}

This is Courant Research Centre Geobiology publication no. 113.

\section{References}

Ahmadjian, V. (1988) The lichen alga Trebouxia: does it occur free-living? Plant Syst Evol 158: 243-247.

Albertano, P. and Urzì, C. (1999) Structural interactions among epilithic cyanobacteria and heterotrophic microorganisms in Roman hypogea. Microb Ecol 38: 244-252.

Altschul, S.F., Gish, W., Miller, W., Myers, E.W. and Lipman, D.J. (1990) Basic local alignment search tool. J Mol Biol 215: 403-410.

Ariño, X., Hernandez-Marine, M. and Saiz-Jimenez, C. (1997) Colonization of Roman tombs by calcifying cyanobacteria. Phycologia 36: 366-373.

Auclair, J.L. (1963) Aphid feeding and nutrition. Ann Rev Entomol 8: 439-490.

Barkman, J.J. (1969) Phytosociology and ecology of cryptogamic epiphytes. Van Gorcum Ltd., Assen. 
Bell, A.A. and Wheeler, M.H. (1986) Biosynthesis and functions of fungal melanins. Annu Rev Phytopathol 24: 411-451.

Cappitelli, F., Zanardini, E., Ranalli, G., Mello, E., Daffonchio, D. and Sorlini, C. (2006) Improved methodology for bioremoval of black crusts on historical stone artworks by use of sulfatereducing bacteria. Appl Environ Microbiol 72: 3733-3737.

Cappitelli, F., Principi, P., Pedrazzani, R., Toniolo, L. and Sorlini, C. (2007) Bacterial and fungal deterioration of the Milan cathedral marble treated with protective synthetic resins. Sci Total Environ 385: 172-181.

Edlich, F. (1936) Einwirkung von Temperatur und Wasser auf aerophile Algen. Arch Microbiol 7: 62-109.

Ettl, H. and Gärtner, G. (1995) Syllabus der Boden-, Luft- und Flechtenalgen. Gustav Fischer, Stuttgart.

Friedl, T. and Rybalka, N. (2012) Systematics of the green algae: A brief introduction to the current status. In Lüttge, U., Beyschlag, W., Francis, D. and Cushman, J. (eds) Progress in Botany No. 73. Springer, Heidelberg, pp. 259-280.

Gärtner, G. (1994) Zur Taxonomie aerophiler grüner Algenanflüge an Baumrinden. Ber nat-med Verein Innsbruck 81: 51-59.

Gärtner, G. and Ingolić, E. (1989) Ein Beitrag zur Kenntnis von Apatococcus lobatus (Chlorophyta, Chaetophorales, Leptosiroideae). Plant Syst Evol 164: 133-143.

Gaylarde, C.C., Rodríguez, C.H., Navarro-Noya, Y.E. and Ortega-Morales, B.O. (2012) Microbial biofilms on the sandstone monuments of the Angkor Wat complex, Cambodia. Curr Microbiol 64: 85-92.

Glawe, D.A. (2008) The Powdery Mildews: a review of the world's most familiar (yet poorly known) plant pathogens. Annu Rev Phytopathol 46: 27-51.

Gorbushina, A.A., Krumbein, W.E., Hamman, C.H., Panina, L., Soukharjevski, S. and Wollenzien, U. (1993) Role of black fungi in color-change and biodeterioration of antique marbles. Geomicrobiol J 11: 205-221.

Gorbushina, A.A., Lyalikova, N.N., Vlasov, D.Yu. and Khizhnyak, T.V. (2002) Microbial communities on the monuments of Moscow and St. Petersburg: biodiversity and trophic relations. Microbiology 71: 350-356.

Grant, C. (1982) Fouling of terrestrial substrates by algae and implications for control- a review. Intl Biodeterior Bull 18: 57-65.

Gromov, B.V. (1963) The microflora of deteriorating brick, plaster and marble. Vestn Len Univ Ser Biol 3: 69-77.

Gustavs, L., Görs, M. and Karsten, U. (2011) Polyol patterns in biofilm-forming aeroterrestrial green algae (Trebouxiophyceae, Chlorophyta). J Phycol 47: 533-537.

Hallmann, C., Rüdrich, J., Enseleit, M., Friedl, T. and Hoppert, M. (2011a) Microbial diversity on a marble monument: a case study. Environ Earth Sci 63: 1701-1711.

Hallmann, C., Fritzlar, D., Stannek, L. and Hoppert, M. (2011b) Ascomycete fungi on dimension stone of the "Burg Gleichen", Thuringia. Environ Earth Sci 63: 1713-1722.

Hallmann, C., Stannek, L., Fritzlar, D., Hause-Reitner, D., Friedl, T. and Hoppert, M. (2013) Molecular diversity of phototrophic biofilms on building stone. FEMS Microbiol Ecol 84: 355-372.

Hamby, R.K., Sim, L.E., Issel, L.E. and Zimmer, E.A. (1988) Direct RNA sequencing: optimization of extraction and sequencing techniques for work with higher plants. Plant Mol Biol Rep 6: 179-197.

Harutyunyan, S., Muggia, L. and Grube, M. (2008) Black fungi in lichens from seasonally arid habitats. Stud Mycol 61: 83-90. 
Hepperle, D. (2004) SeqAssem . A sequence analysis tool, counting assembler and trace data visualization tool for molecular sequences. Win32-Version. Distributed by the author via: http:// www.seqeuntix.de.

Hodač, L., Hallmann, C., Rosenkranz, H., Faßhauer, F. and Friedl, T. (2012) Molecular evidence for the wide distribution of two lineages of terrestrial green algae (Chlorophyta) over tropics to temperate zone. ISRN Ecol 2012: 795924.

Huber, T., Faulkner, G. and Hugenholtz, P. (2004) Bellerophon; a program to detect chimeric sequences in multiple sequence alignments. Bioinformatics 20: 2317-2319.

Huelsenbeck, J.P. and Ronquist, F. (2001) MRBAYSE: Bayesian inference of phylogenetic trees. Bioinformatics 17: 754-755.

Karsten, U., Schumann, R., Häubner, N. and Friedl, T. (2005a) Lebensraum Fassade: aeroterrestrische Mikroalgen. Biol unserer Zeit 1: 20-30.

Karsten, U., Friedl, T., Schumann, R., Hoyer, K. and Lembcke, S. (2005b) Mycosporine-like amino acids and phylogenies in green algae: Prasiola and its relatives from the Trebouxiophyceae (Chlorophyta). J Phycol 41: 557-566.

Katoh, K. and Toh, H. (2008) Recent developments in the MAFFT multiple sequence alignment program. Brief Bioinform 9: 286-298.

Konkol, N.R., McNamara, C.J., Blanchette, R.A., May, E. and Mitchell, R. (2008) Microbes can damage but also help restore artifacts. Microbe 3: 563-567.

Lamenti, G., Tiano, P. and Tomaselli, L. (2000) Biodeterioration of ornamental marble statues in the Boboli Gardens (Florence, Italy). J Appl Phycol 12: 427-433.

Lan, W., Li, H., Wang, W.D., Katayama, Y. and Gu, J.D. (2010) Microbial community analysis of fresh and old microbial biofilms on Bayon temple sandstone of Angkor Thom, Cambodia. Microb Ecol 60: 105-115.

Ludwig, W., Strunk, O., Westram, R., Richter, L., Meier, H., et al. (2004) ARB: a software environment for sequence data. Nucl Acids Res 32: 1363-1371.

Macedo, M.F., Miller, A.Z., Dionísio, A. and Saiz-Jimenez, C. (2009) Biodiversity of cyanobacteria and green algae on monuments in the Mediterranean Basin: an overview. Microbiology 155: 3476-3490.

Maravelaki-Kalaitzaki, P., Zafiropulos, V. and Fotakis, C. (1999) Excimer laser cleaning of encrustation on Pentelic marble: procedure and evaluation of the effects. Appl Surf Sci 148: 92-104.

McNamara, C.J. and Mitchell, R. (2005) Microbial deterioration of historic stone. Front Ecol Environ 3: 445-451.

McNamara, C.J., Perry, T.D. IV, Bearce, K.A., Hernandez-Duque, G. and Mitchell, R. (2006) Epilithic and endolithic bacterial communities in limestone from Maya archeological site. Microb Ecol 51: 51-64.

Miller, A.Z., Laiz, L., Gonzalez, J.M., Dionísio, A., Macedo, M.F. and Saiz-Jimenez, C. (2008) Reproducing stone monument photosynthetic-based colonization under laboratory conditions. Sci Total Environ 405: 278-285.

Moropoulou, A., Tsiourva, Th., Bisbikou, K., Tsantila, V., Biscontin, G., et al. (2002) Evaluation of cleaning procedures on the facades of the bank of Greece historical building in the center of Athens. Build. Environ 37: 753760.

Ortega-Calvo, J.J., Ariño, X., Hernandez-Marine M and Saiz-Jimenez, C. (1995) Factors affecting the weathering and colonization of monuments by phototrophic microorganisms. Sci Total Environ 167: 329-341. 
Polo, A., Cappitelli, F., Brusetti, L., Principi, P., Villa, F., et al. (2010) Feasibility of removing surface deposits on stone using biological and chemical remediation methods. Microb Ecol 60: $1-14$.

Ragon, M., Fontaine, M.C., Moreira, D. and López-García, P. (2012) Different biogeographic patterns of prokaryotes and microbial eukaryotes in epilithic biofilms. Mol Ecol 21: 38523868.

Rindi, F. (2007) Diversity, distribution and ecology of green algae and cyanobacteria in urban habitats. In Seckbach, J. (ed) Algae and Cyanobacteria in Extreme Environments. Springer, Dordrecht, pp. 571-582.

Ruibal, C., Gueidan, C., Selbmann, L., Gorbushina, A.A., Crous, P.W., et al. (2009) Phylogeny of rock-inhabiting fungi related to Dothideomycetes. Stud Mycol 64: 123-133.

Saiz-Jimenez, C. (1995) Deposition of anthropogenic compounds on monuments and their effect on airborne microorganisms. Aerobiologia 11: 161-175.

Schloss, P.D., Westcott, S.L., Ryabin, T., Hall, J.R., Hartmann, M., et al. (2009) Introducing mothur: open-source, platform-independent, community-supported software for describing and comparing microbial communities. Appl Environ Microbiol 75: 7537-7541.

Selbmann, L., de Hoog, G.S., Mazzaglia, A., Friedmann, E.I. and Onofri, S. (2005) Fungi at the edge of life: cryptoendolithic black fungi from Antarctic desert. Stud Mycol 51: 1-32.

Sert, H.B. and Sterflinger, K. (2010) A new Coniosporium species from historical marble monuments. Mycol Progress 9: 353-359.

Sert, H.B., Sümbül, H. and Sterflinger, K. (2007) Microcolonial fungi from antique marbles in Perge/Side/Termessos (Antalya/Turkey). Antonie Van Leeuwenhoek 91: 217-227.

Stamatakis, A., Hoover, P. and Rougemont, J. (2008) A rapid bootstrap algorithm for the RAxML web servers. Syst Biol 57: 758-771.

Sterflinger, K. and Krumbein, W.E. (1997) Dematiaceous fungi as a major agent of biopitting for Mediterranean marbles and limestones. Geomicrobiol J 14: 219-230.

Thüs, H., Muggia, L., Pérez-Ortega, S., Favero-Longo, S.E., Joneson, S., et al. (2011) Revisiting photobiont diversity in the lichen family Verrucariaceae (Ascomycota). Eur J Phycol 46: 399-415.

Warscheid, T. and Braams, J. (2000) Biodeterioration of stone: a review. Int Biodeter Biodegr 46: 343-368.

Weber, J., Beseler, S. and Sterflinger, K. (2007) Thin-section microscopy of decayed crystalline marble from the garden sculptures of Schoenbrunn Palace in Vienna. Mater Charact 58: 1042-1051.

Wollenzien, U., de Hoog, G.S., Krumbein, W.E. and Urzí, C. (1995) On the isolation of microcolonial fungi occurring on and in marble and other calcareous rocks. Sci Total Environ 167: 287-294.

Wollenzien, U., de Hoog, G.S., Krumbein, W. and Uijthof, J.M.J. (1997) Sarcinomyces petricola, a new microcolonial fungus from marble in the Mediterranean basin. Antonie Van Leeuwenhoek 71: 281-288.

Yang, F.W., Liu, Y., Zhu, Y.C., Long, S.J., Zuo, G.F., et al. (2012) Conservation of weathered historic sandstone with biomimetic apatite. Chin Sci Bull 57: 2171-2176.

Young, M.E. and Urquhart, D.C.M. (1998) Algal growth on building sandstones: effects of chemical stone cleaning methods. Q J Eng Geol Hydrogeol 31: 315-324.

Zanardini, E., Abbruscato, P., Ghedini, N., Realini, M. and Sorlini, C. (2000) Influence of atmospheric pollutants on the biodeterioration of stone. Int Biodeter Biodegr 45: 35-42. 


\title{
Chapter 3: \\ Microbial diversity on a marble monument: \\ a case study
}

\begin{abstract}
Christine Hallmann ${ }^{1}$, Jörg Rüdrich ${ }^{2}$, Matthias Enseleit ${ }^{3}$, Thomas Friedl ${ }^{1}$ and Michael Hoppert ${ }^{3,4}$
\end{abstract}

Published in Environmental Earth Sciences (2011) 63: 1701-1711

\footnotetext{
${ }^{1}$ Department of Experimental Phycology and Culture Collection of Algae (SAG), Albrecht-von-Haller-Institute for Plant Sciences, Georg-August-University, Göttingen, Germany

${ }^{2}$ Department of Structural Geology, Geoscience Centre, Georg-August-University, Göttingen, Germany

${ }^{3}$ Institute for Microbiology and Genetics, Georg-August-University, Göttingen, Germany

${ }^{4}$ Courant Research Center Geobiology, Georg-August-University, Göttingen, Germany
}

Author contributions to the work:

Performed the experiments: $\mathrm{CH}$.

Analyzed data: $\mathrm{CH}$.

Performed electron microscopy and fluorescence light microscopy: ME.

Wrote the paper: $\mathrm{CH}, \mathrm{MH}, \mathrm{TF}$.

Conceived and designed the experiments: $\mathrm{MH}, \mathrm{JR}, \mathrm{CH}$. 


\begin{abstract}
In the presented case study, ascomycete fungi and green algae on a marble monument were identified by comparisons of the $18 \mathrm{~S}$ rRNA gene sequences, which were obtained from DNA either from environmental samples or from enrichment cultures. The organisms were found to be responsible for either black or green surface coverings on different areas of the monument surface. Most fungi were related to plant-inhabiting genera, corresponding to a heavy soiling of the marble surface with honeydew. Whereas green algae of the genera Stichococcus, Chloroidium and Apatococcus were found to be dominant in all samples, isolates of two additional genera were recovered only from enrichment cultures. A reference strain of Apatococcus lobatus and an isolate of Prasiolopsis sp. were investigated with respect to putative surface adhesive structures of the cell envelope. The Prasiolopsis cell walls were covered with a thin adhesive exopolysaccharide layer involved in biofilm formation.
\end{abstract}

Keywords: marble monument, biofilm, ascomycete fungi, green algae, cell wall, exopolysaccharide. 


\section{Introduction}

Biodeterioration of dimension stone primarily affects material surfaces. Some endolithic organisms actively penetrate the surface and are also found in layers up to several millimeters underneath the surface (e.g. Ascaso et al., 1998; Hoppert et al., 2004a). Though several important pro- and eukaryotic organisms have already been recognized as deteriorative agents, up to now little is known about the whole microbial community (see Gorbushina, 2007 and Macedo et al., 2009 for review). It must be expected that a microbial biofilm is composed of at least several dozens of species. These various organisms act in different ways on the material; a whole spectrum of deteriorative activities may be expected: from neutral (or even protective, e.g. Zuo et al., 2005) to deteriorative by penetration of the surface (Warscheid and Braams, 2000; Kemmling et al., 2004). It remains difficult to assign the deteriorative activity to a certain microbial species within a biofilm. Microbial activity also varies over seasons and is influenced by rainfall, surface cleaning or input of nitrogen, phosphate and other essential compounds.

The present case study aims at the identification of organisms by two complementary approaches: analyses of 18S rRNA gene sequences (either directly from environmental DNA or via enrichment culture) and isolation of strains. The former approach is inevitable for elucidation of microbial diversity, since most (pro- and eukaryotic) microorganisms are unculturable. The latter, "classical" approach underestimates the diversity as it recovers too few of the actually present species, but has two advantages. It enables studying the physiology of organisms in pure culture and allows recovering and identification of species that are present on the surface in such low numbers of individuals that they escape DNA extraction and sequencing. These species may actually not have an important role in the biofilm at the time of sampling, but may be present as resting stages and become more abundant when the environmental conditions (e.g. insolation, humidity) change.

For the present case study, a marble sculpture, which is part of the monument “Gegendenkmal” (Fig. 1a; Hamburger Dammtordamm, created by Alfred Hrdlicka 1983-1986), was selected. The object is covered with grayish and black crusts of hitherto unknown origin as well as greenish (obviously algal) biofilms. The aim of this case study was the application of both molecular and enrichment/isolation approaches to identify the organisms and to characterize cell wall features that are possibly relevant to biofilm formation. Here, we focus on green algal and fungal organisms. Members of these groups 
dominate the biofilm, from the first microscopic inspection of the surface, with by far highest biomasses.

\section{Materials and methods}

\section{Sampling}

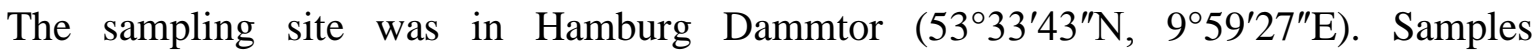
(approximately $100 \mu 1$ dry volume) were collected in May 2008 from an SSW exposed part of the sculpture called "Hamburger Feuersturm". The samples were taken from two sites as depicted in Fig. 1b, c. Areas of $1 \mathrm{~cm}^{2}$ from a green surface covering (Fig. 1b, sample A) and from a dark gray/black covering (Fig. 1c, sample B), respectively, were scraped off with a sterile scalpel. The samples were stored at ambient temperature in sterile $2 \mathrm{ml}$ reaction tubes.

\section{Cultivation and isolation}

For the cultivation of microalgae, small amounts of the biofilm samples were either directly plated on agarized (1.5\%) culture medium MIEB12 (Schlösser, 1994) in Petri dishes, or inoculated in $10 \mathrm{ml}$ volumes of liquid MIEB12 medium in culture tubes (enrichment culture). Cultures were kept under continuous illumination (25 $\mu \mathrm{mol}$ photons $\mathrm{m}^{-2} \mathrm{~s}^{-1}$, white fluorescent tubes) and $18{ }^{\circ} \mathrm{C}$ for 4 weeks. From the liquid cultures, $100 \mu \mathrm{l}$ aliquots were then plated on solid MIEB12 medium and incubated under the same conditions as for liquid media. Single colonies of different appearance were selected and transferred on fresh agar plates until unialgal cultures were obtained.

A reference strain, Apatococcus lobatus SAG 2037, was taken from the Culture Collection of Algae (SAG; Georg-August-Universität Göttingen, Germany) and cultured on agarized or liquid Bold's Basal medium with vitamins (Schlösser, 1994).

\section{Nucleic acid extraction, PCR, cloning and sequencing}

DNA was extracted from the environmental samples as well as from the liquid cultures. All steps were performed with sterilized (autoclaved, nuclease-free) reagents. For DNA extraction, equivalents of 20-50 $\mu 1$ packed cell volume, either obtained from the original biofilm or from liquid cultures, were used. The biofilm samples or pelleted cells were resuspended in $100 \mu \mathrm{l}$ lysis buffer (Invisorb Spin Plant Mini Kit, Invitek, Berlin, Germany). 

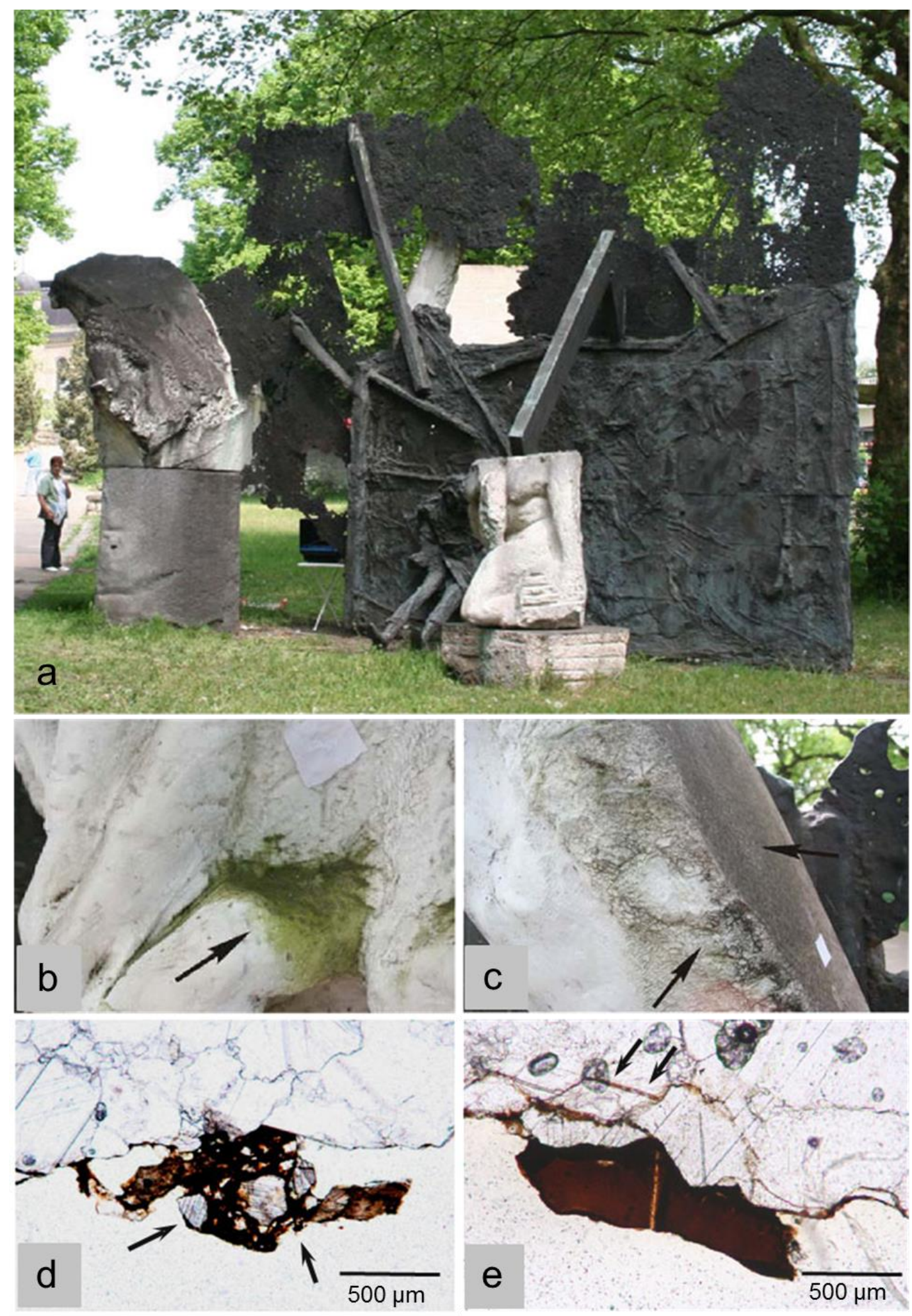

Fig. 1. The monument and macroscopically visible surface stains. (a) The monument "Gegendenkmal", created by Alfred Hrdlicka 1983-1986, located in Hamburg-Altona. The marble sculpture at the left is nearly completely covered with a dark gray/black stain. (b), (c) Part of the sculpture "Hamburger Feuersturm" with a green (b) and dark-grayish (c) surface stain, as marked by arrows. (d), (e) Thin petrographic sections perpendicular to the surface from an area as depicted in (c). Small fragments, embedded in a dark matrix, adhere to the surface (arrows, d). Microfractures along grain boundaries, filled with a dark matrix (arrows). 
After one volume of resuspended cells was mixed with an approximately equivalent volume of glass beads (425-600 $\mu \mathrm{m}$ diameter; acid-washed beads, Sigma-Aldrich, St. Louis, MO, USA) and vortexed briefly, the cells were mechanically disrupted by shaking in a Mini-BeadBeater (Biospec, Bartlesville, OK, USA) in several intervals of $30 \mathrm{~s}$ and one interval of $50 \mathrm{~s}$ at $5.000 \mathrm{rpm}$. DNA was then extracted with the Invisorb Spin Plant Mini Kit (Invitek, Berlin, Germany) in the extraction buffers, following the manufacturer's instructions. Results were checked on a $1 \%(\mathrm{w} / \mathrm{v})$ agarose gel. Isolated DNA was stored at $-20{ }^{\circ} \mathrm{C}$ until further processing. The eukaryote-specific primer combinations NS1/18L and NS1/LR 1850 were used (Table 1) to amplify the $18 \mathrm{~S}$ and the $18 \mathrm{~S}$ with adjacent ITS1/5.8S/ITS2 regions of rRNA gene, respectively.

About $30 \mathrm{ng}$ of the extracted DNA was used as template. The amplification reaction mixture $(50 \mu \mathrm{l})$ contained each deoxynucleotide triphosphate at a concentration of $0.1 \mathrm{mM}$, $5 \mu \mathrm{l}$ of tenfold concentrated reaction buffer, $2 \mathrm{mM} \mathrm{MgCl}_{2}, 0.2 \mu \mathrm{M}$ primers, $2 \mathrm{U}$ of Taq DNA polymerase (reagents and manufacturer's protocol: Bioline, Luckenwalde, Germany) and $4 \%(\mathrm{v} / \mathrm{v})$ dimethyl sulfoxide (DMSO)-solution. Polymerase chain reaction was carried out on a PTC 200 thermocycler (MJ Research, Waltham, MA, USA) using the following program for the primer pair NS1/LR1850: initial denaturation at $95{ }^{\circ} \mathrm{C}$ for $5 \mathrm{~min}$, followed by 33 cycles of denaturation at $94{ }^{\circ} \mathrm{C}$ for $40 \mathrm{~s}$, annealing at $52{ }^{\circ} \mathrm{C}$ for $90 \mathrm{~s}$, extension at $72{ }^{\circ} \mathrm{C}$ for $90 \mathrm{~s}$, followed by 6 cycles of denaturation at $94{ }^{\circ} \mathrm{C}$ and final extension at $72{ }^{\circ} \mathrm{C}$ for $2 \mathrm{~min}$. For the primer pair NS1/18L, denaturation was for $1 \mathrm{~min}$, annealing for $45 \mathrm{~s}$, extension for $3 \mathrm{~min}$, the additional 6 cycles were omitted and final extension was for 7 min. The PCR products were purified using the Invisorb Spin PCRapid Kit (Invitek, Berlin, Germany). Aliquots $(2 \mu \mathrm{l})$ of purified amplicons were analyzed by electrophoresis on a $1 \%(\mathrm{w} / \mathrm{v})$ agarose gel. Cloning of the PCR product was performed with the TOPO TA cloning kit (Invitrogen, Carlsbad, CA, USA) and the pCR2.1-TOPO vector.

Table 1. Primers used in this study.

\begin{tabular}{lll}
\hline Primer & Sequence (5'-3') & References \\
\hline NS1 (forward) & GTAGTCATATGCTTGTCT & White et al. (1990) \\
18L (reverse) & CACCTACGGAAACCTTGTTACGACTT & Hamby et al. (1988) \\
LR1850 (reverse) & CCTCACGGTACTTGTTC & Friedl (1996) \\
M13F (forward) & TGTAAAACGACGGCCAGT & Invitrogen \\
M13R (reverse) & GGAAACAGCTATGACCATG & Invitrogen \\
895R (sequencing primer) & AAATCCAAGAATTCACCTC & SAG \\
\hline
\end{tabular}


Ligations were transformed into competent cells of Escherichia coli TOP 10, as supplied by the manufacturer. In the plasmid screening, white E. coli colonies containing correct DNA insertions were identified by direct amplification of the inserted DNA fragment with a vector-specific primer set M13F/M13R (Table 1).

Clones were cultivated overnight in LidBac reaction tubes (Qiagen, Hilden, Germany) with $1 \mathrm{ml} \mathrm{LB}$ medium containing $100 \mu \mathrm{g}$ ampicillin. Plasmid DNA was prepared from the clones with a NucleoSpin-Plasmid kit (Macherey and Nagel, Düren, Germany) following the manufacturer's instructions.

Sequencing reactions were performed with a Dye Terminator Cycle Sequencing v3.1 kit (Applied Biosystems, Darmstadt, Germany) and an ABI Prism 3100 (Applied Biosystems) automated sequencer. All clones were sequenced with the $18 \mathrm{~S}$ sequencing primer 895R (Table 1) resulting in about $600 \mathrm{bp}$ sequences. Sequences were processed using the sequence analysis program SeqAssem (Sequentix, Klein Raden, Germany) and manually aligned using the program BioEdit v7.0.5.3 (Meusnier et al., 2008). The final sequences were compared by BLASTn analysis [National Center for Biotechnology Information (NCBI), http://www.ncbi.nlm.nih.gov].

\section{Light and electron microscopy}

For fluorescence light microscopy, cells taken from unialgal or pure cultures were marked with concanavalin A, coupled to fluorescein isothiocyanate (Con A-FITC; Sigma-Aldrich). The dye was applied in $50 \mathrm{mM}$ potassium phosphate buffer, supplemented with $10 \mu \mathrm{M}$ magnesium chloride and $10 \mu \mathrm{M}$ calcium chloride at a dilution of $1 / 1,000$ of the original stock solution. The sample was inspected under a fluorescence light microscope (Axioscope, Zeiss, Göttingen, Germany; excitation wavelength $495 \mathrm{~nm}$, emission wavelength $517 \mathrm{~nm}$, Zeiss filter set 09).

Petrographic thin sections of approximately $30 \mu \mathrm{m}$ in thickness were performed according to established procedures (Adams et al., 1984) and visualized by standard bright field microscopy.

For electron microscopy, cells from unialgal or pure cultures were harvested by centrifugation at $10.000 \mathrm{x} \mathrm{g}$, resuspended in $50 \mathrm{mM}$ potassium phosphate buffer, chemically fixed in $0.5 \%(\mathrm{w} / \mathrm{v})$ formaldehyde and $0.3 \%(\mathrm{w} / \mathrm{v})$ glutaraldehyde solution for 90 min at $0{ }^{\circ} \mathrm{C}$, dehydrated in a graded methanol series and embedded in Lowicryl $\mathrm{K} 4 \mathrm{M}$ resin (Roth et al., 1981; Hoppert and Holzenburg, 1998). Resin sections of 80-100 nm thickness were cut with glass knives. Localization studies were performed with the lectin 
concanavalin A (Sigma-Aldrich), coupled to colloidal gold (Con A-Gold), as already described (Kämper et al., 2004). In brief, sections were incubated on drops of dilutions $(1 / 10,1 / 100,1 / 1,000)$ of the Con A-gold marker for $90 \mathrm{~min}$, then washed for $5 \mathrm{~min}$ per step for three times on drops of PBS containing $0.01 \%(\mathrm{v} / \mathrm{v})$ Tween 20. Finally, the sections were stained with $0.5 \%$ (w/v) phosphotungstic acid, $\mathrm{pH} 7.0$, for $3 \mathrm{~min}$. Electron microscopy was performed in a Zeiss EM 902 transmission electron microscope (Zeiss SMT, Oberkochen, Germany), equipped with a $1 \mathrm{~K}$ digital camera, at $80 \mathrm{kV}$ acceleration voltage and at calibrated magnifications.

\section{Results}

\section{Diversity of fungal and algal organisms}

The monument "Gegendenkmal" consists of several bronze and marble sculptures. In this study, the sculpture "Hamburger Feuersturm', made of Carrara marble, was under investigation. The sculpture showed a mixture of greenish and grayish/black stains (Fig. 1), as well as green layers on the fracture surfaces of chips and scales (cf. Warscheid and Braams, 2000). The sculpture was manufactured from Bianco Carrara C, a pure calcite marble, as determined by X-ray diffractometry (data not shown).

Thin petrographic sections, perpendicular to the surface, show open grain boundaries between the calcite crystals in the marble microstructure (Fig. 1d, e), which illustrates the increased porosity and a slight sugar-like crumbling of the marble surface. The grayish stain, mainly on the top parts of the marble sculptures, was the most obvious feature (Fig. 1a, c). In petrographic sections, the stain appears to be homogeneous, slightly red-brown and translucent. It encloses crystals on the marble surface (Fig. 1d) and infiltrates the surface along open grain boundaries (Fig. 1e). Though the cause of this heavy soiling could not be identified, it was observed that honeydew covered the sculptures in the affected areas. The honeydew was dripping off a plane tree canopy (Platanus x hispanica), placed directly above the monument, as well as a lime tree canopy (Tilia platyphyllos) nearby. Another obvious feature was represented by green stains of algal biofilms, primarily growing in cavities, where water cannot drain off fast.

To investigate the participation of microorganisms in these surface coverings, material from approximately $1 \mathrm{~cm}^{2}$ surface was used for further processing. Green layers under scales were not enclosed in this study, because they represented just a small fraction of the (putatively) biogenic stains. Sample A was taken from a green algal biofilm (Fig. 1b) and 
sample B from the black covering as depicted in Fig. 1c. The samples were first inspected by light microscopy to verify the presence of dominant species. Actually, green algal (sample A) and fungal (sample B) morphotypes dominated the microbial biomass of the biofilm (Fig. 2a, b). Thus, our further studies aimed at the identification of the species from both these groups. Most of the algal morphotypes correspond to Apatococcus and Chloroidium ellipsoideum (Darienko et al., 2010). No stratification of the biofilms could be observed: filamentous fungi (if present) and green algae were interwoven in a homogeneous surface covering. In enrichment cultures, inoculated with samples from the original biofilm, besides Chloroidium-morphotypes, rod-shaped Stichococcus-like cells dominated (Fig. 2c). Unialgal cultures could be obtained for some of the dominant Stichococcus and Apatococcus like morphotypes (cf. Fig. 3a, b). In addition, a xanthophyte alga (Fig. 3c) and a Prasiolopsis (Pseudopleurococcus) -like morphotype (Fig. 3d; see below) could be isolated.

Sequences obtained from clone libraries of environmental DNA samples also recovered Stichococcus (S. mirabilis related) and Apatococcus, however, failed to detect Prasiolopsis and xanthophytes (Table 2). Instead, Trebouxia (a frequent lichen alga) was found. Besides the dominating Stichococcus spp. algae, a variety of ascomycete fungi was found exclusively in sample B. Among the fungi, members of the ascomycete genera, Batcheloromyces, Teratosphaeria, Thelocarpon and Sarcinomyces, were recovered, each with more than one clone. Batcheloromyces, Teratosphaeria and Guignardia are known as plant-inhabiting ascomycetes (Crous et al., 2004). Thelocarpon represents a lichenicolous ascomycete genus. The genus Sarcinomyces describes black yeasts from various habitats (Cooke, 1961).

The clone libraries from the enrichment cultures showed lower diversities. Stichoccoccus bacillaris-like algae were dominant (Table 3) and no fungal organisms could be detected. It has to be stated, nevertheless, that not all organisms could be assessed by the clone library analysis. The observed xanthophycean algae as well as Prasiolopsis, which were observed in the cultures, were not recovered by clone libraries from environmental samples. The identity of the Prasiolopsis genus was confirmed by 18S rRNA gene sequencing of preparations obtained from unialgal cultures. 

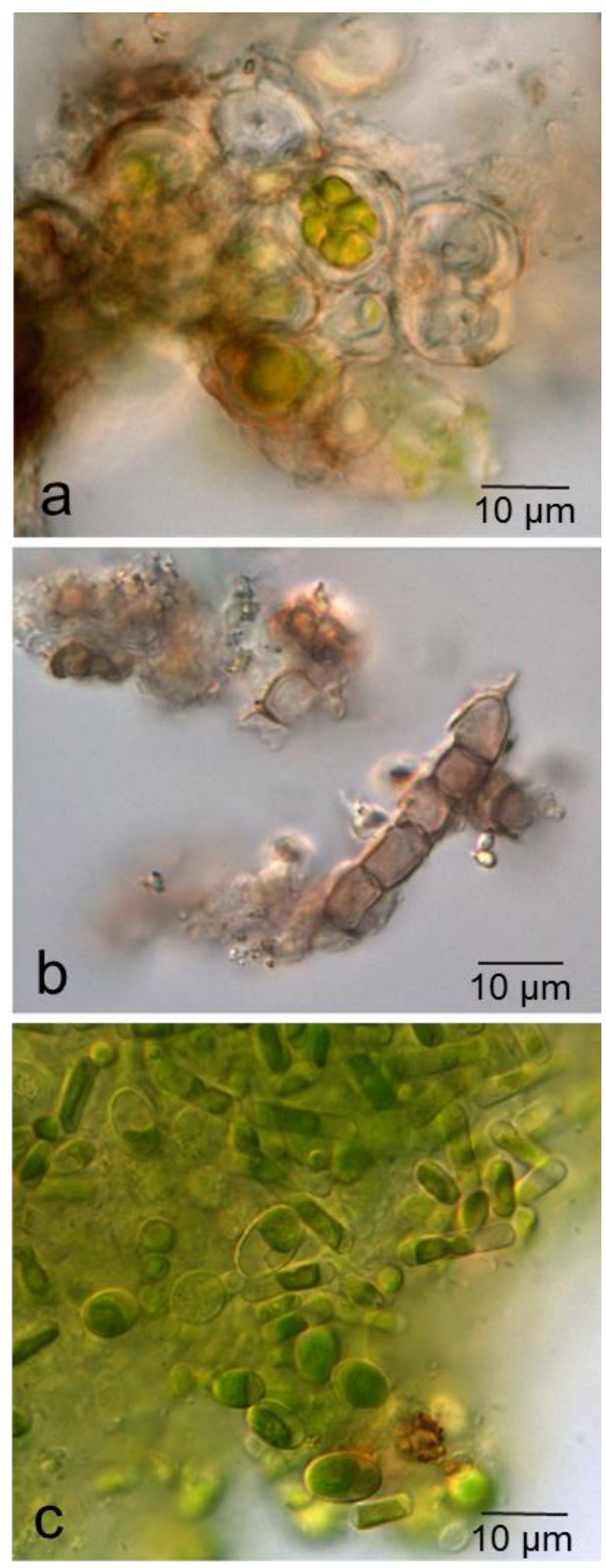

Fig. 2. Microscopic analysis of environmental samples and enrichment cultures. (a) Agglomeration of coccoid algae taken from the marble surface. (b) Ascomycete fungal morphotype (putative conidial fragment) taken from the surface. (c) Unicellular green algal morphotypes in an enrichment culture. 


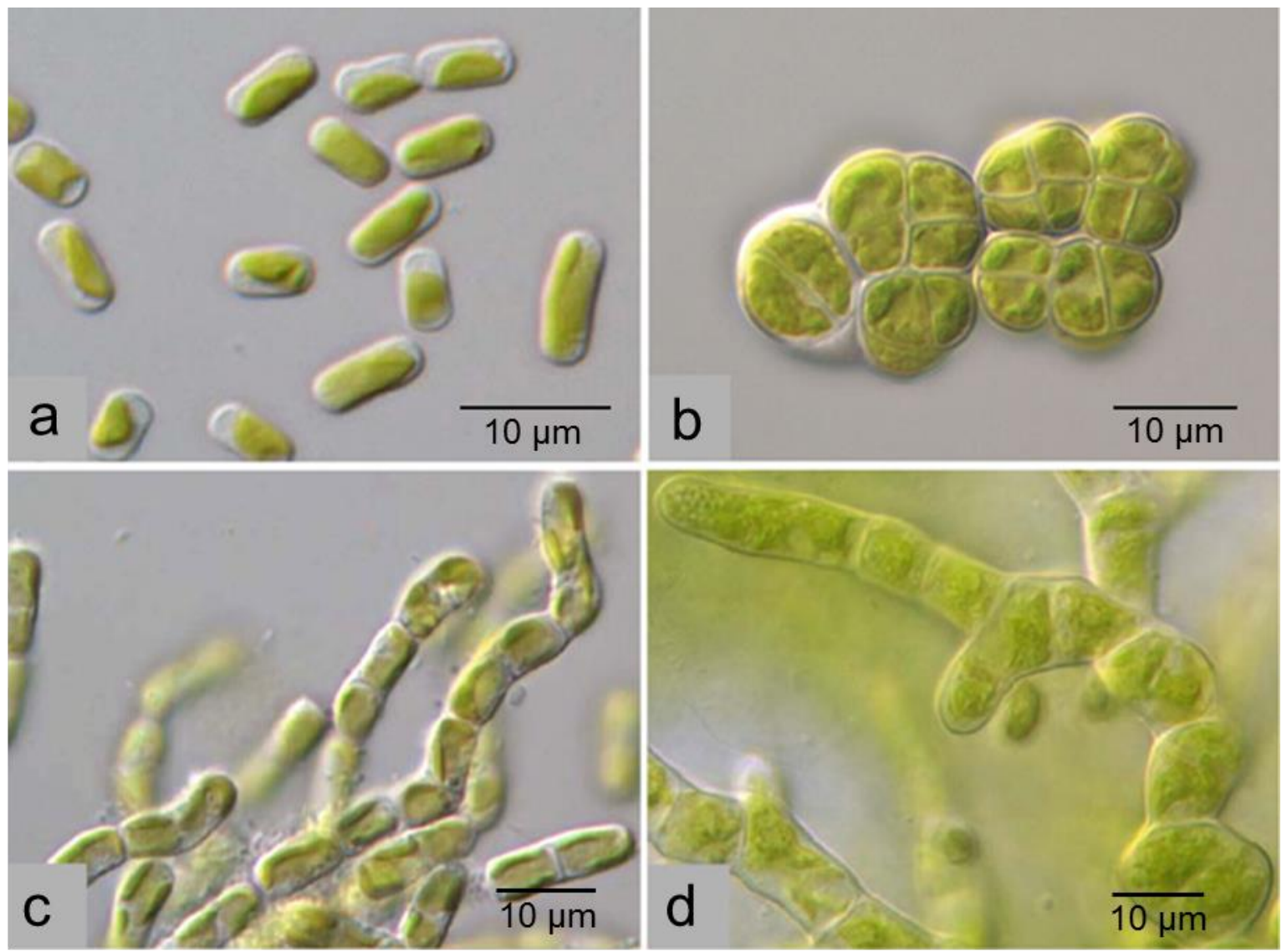

Fig. 3. Morphotypes of the investigated algal strains. (a) Stichococcus sp., (b) Apatococcus lobatus SAG 2037, (c) a Xanthophycean algae, (d) Prasiolopsis sp.

\section{Cell surface features of selected species}

The branched filamentous Prasiolopsis was selected for further morphological studies. The organism was compared with a contrasting morphotype, represented by Apatococcus lobatus SAG 2037, which forms irregular packages consisting of several dozens of cells (Figs. 3b, 4a). These algae represent the most different biofilm morphotypes in this study, i.e., unicellular coccoid and branched filamentous (Figs. 3b, d, 4).

With respect to biofilm formation, we were particularly interested in cell surface features that are involved in adhesion, such as secreted polysaccharides (e.g. Tsuneda et al., 2003). In search of such features, polysaccharide-specific stains were applied (Figs. 4, 5). In ultrathin sections of the algal cell walls, a thin irregular layer on the surface of the Prasiolopsis cell walls was observed (Fig. 4e, arrows), whereas the cell walls of Apatococcus did not show any additional layers (Fig. 4b). To detect possible heteropolysaccharides of the cell envelope, staining with labeled concanavalin A (Con A) was applied. In both algae, the cell periphery showed certain fluorescence signals 
(Fig. 4a, d). Localization with Con A-gold revealed, at electron microscopic resolution, a scattered distribution of gold markers over the whole cell wall section of Apatococcus (Fig. 4c), and a very distinct marked outer layer in Prasiolopsis (Fig. 4f). This accounts for a thin layer of exopolysaccharides (EP) in Prasiolopsis. This layer appears to be involved in adhesion of separate Prasiolopsis filaments as depicted in Fig. 5. Here, the cells adhere to each other by the thin EP layer (Fig. 5b).

Table 2. 18S rRNA gene analysis of clones obtained from environmental samples.

\begin{tabular}{|c|c|c|c|}
\hline \multirow[b]{2}{*}{ Closest relative species } & \multicolumn{2}{|c|}{ Number of clones } & \multirow{2}{*}{$\begin{array}{l}\% \text { sequence similarity to } \\
\text { closest relative species }\end{array}$} \\
\hline & (sample & ample B) & \\
\hline \multicolumn{4}{|l|}{ Algae } \\
\hline Stichococcus mirabilis & 10 & 24 & $98-99$ \\
\hline Uncultured Trebouxia sp. & 1 & 1 & $97-98$ \\
\hline Apatococcus sp. & 2 & - & $98-99$ \\
\hline Stichococcus sp. & 1 & 1 & 99 \\
\hline Stichococcus jenerensis & 1 & - & 98 \\
\hline Chloroidium mirabilis & 1 & - & 98 \\
\hline Stichococcus bacillaris & 1 & - & 96 \\
\hline \multicolumn{4}{|l|}{ Acomycete fungi } \\
\hline Batcheloromyces proteae & - & 5 & $98-99$ \\
\hline Teratosphaeria microspora & - & 3 & 96 \\
\hline Thelocarpon laureri & - & 3 & $95-97$ \\
\hline Sarcinomyces sp. & - & 2 & $93-97$ \\
\hline Guignardia mangiferae & - & 1 & 100 \\
\hline Phaeoramularia hachijoensis & - & 1 & 98 \\
\hline Phialophora sp. & - & 1 & 98 \\
\hline Conisporium perforans & - & 1 & 97 \\
\hline Spencermartinsia sp. & - & 1 & 97 \\
\hline Xenomeris raetica & - & 1 & 97 \\
\hline Symbiotaphrina kochii & - & 1 & 97 \\
\hline Mycocalicium polyporaeum & - & 1 & 96 \\
\hline Aureobasidium pullulans & - & 1 & 95 \\
\hline Harpidium rutilans & - & 1 & 95 \\
\hline Pseudofusicoccum stromaticum & - & 1 & 93 \\
\hline
\end{tabular}


Table 3. 18S rRNA gene analysis of clones obtained from enrichment cultures.

\begin{tabular}{lccc}
\hline \multirow{2}{*}{ Closest relative species } & \multicolumn{2}{c}{ Number of clones } & \% sequence similarity to \\
\cline { 2 - 4 } (sample A) (sample B) & closest relative species \\
\hline Algae & 21 & 12 & $98-100$ \\
Stichococcus bacillaris & 4 & 2 & $98-100$ \\
Chloroidium ellipsoideum & 3 & 1 & 99 \\
Chloroidium angustoellipsoideum & - & 3 & 98 \\
Stichococcus mirabilis & 2 & - & 100 \\
Stichococcus deasonii & & & \\
\hline
\end{tabular}

\section{Discussion}

Our case study aims at the elucidation of surface stains caused by microbial impact. Besides general climatic features (such as precipitation, insolation or temperature), especially local factors (the effect of honeydew) determine the biofilm formation and its taxonomic composition.

The sampling site in Hamburg experiences an oceanic climate, with average annual precipitation of $774 \mathrm{~mm}$ and an average annual temperature of $9{ }^{\circ} \mathrm{C}$. The average temperature in May 2008, however, was approximately $15^{\circ} \mathrm{C}\left(3{ }^{\circ} \mathrm{C}\right.$ higher than the longtime average for May). Precipitation was just about $25 \%$ of the long-time average for May (54 mm) (data were taken from Deutscher Wetterdienst, Offenbach). Thus, the biofilms developed under relatively warm and dry conditions. It is, however, still difficult to draw a relation between climate and the detected organisms: most of the detected species are distributed worldwide, with seemingly broad ecological amplitude, a finding typical for most microorganisms known so far (c.f. Finlay and Esteban, 2004). Thus, a "biogeography" of microbial species is yet to be revealed (Hedlund and Staley, 2004; Martiny et al., 2006). From the data presented here, however, one feature is obvious. Molecular analysis of $18 \mathrm{~S}$ rRNA gene clone libraries from sample B revealed a high diversity of ascomycete fungi, as compared with sample A, dominated by algae (Table 2). Sample B was taken from an area intensively soiled by honeydew. Sample A was taken from a cavity (Fig. 1b), where, due to the complex geometry of the sculpture, immediate soiling with honeydew can be excluded. Here, the photoautotrophic algae are dominant. These cavities will retain rainwater for longer time than the exposed surfaces. Rainwater may also transport some dissolved carbohydrates (see below) from the honeydew layer to 
the cavity but, in toto, the conditions are obviously more favorable for algae than for ascomycetes.

Intriguingly, among the most frequently found clones from sample $\mathrm{B}$, the closest related species are known as plant associated or plant pathogenic. Batcheloromyces proteae and Teratospora (Mycosphaerella) microspora are (opportunistic) pathogens, which are causative agents of black leaf spot disease (Crous et al., 2004). Also Spencermartinsia sp. is a plant-inhabiting fungus and an opportunistic phytopathogen (Phillips et al., 2008), as well as Xenomeris raetica. Members of the genus Xenomeris are possibly infectious agents of tree canker (Jasalavich et al., 2000).

Phialophora comprises plant- and human-pathogenic species, as well as saprophytic, wood-decaying non-pathogens (Abliz et al., 2004). Guignardia magniferae is an endophytic, but not necessarily a plant-pathogenic, fungus (Suryanarayanan et al., 2004). Undoubtedly, the plant- associated fungi were transferred from the tree canopies to the marble surface, by honeydew droplets. Honeydew is a carbohydrate-rich secretion mainly consisting of monosaccharides, as well as the trisaccharide melezitose $(O-\alpha-D$ glucopyranosyl- $(\rightarrow 3)-O-\beta$ - $D$-fructofuranosyl-(2 $\rightarrow 1)-\alpha$ - $D$-glucopyranoside), which can be easily used by fungi and other microorganisms as growth substrates (Fischer et al., 2002). The concentration of amino acids in honeydew is relatively low (in the range of 3-20 nmol/ $\mu \mathrm{l}$ ), which is a growth-limiting factor. However, the overall nitrogen input (also from atmospheric sources) is sufficient for the development of plant-associated fungi: such as other oligotrophic fungi, they are well adapted to the plant biomass with wide $\mathrm{C} / \mathrm{N}$ ratios (Wainright et al., 1993 and references therein).

Massive colonization of black-pigmented ascomycete fungi ("black fungi", Dematiaceae) has been frequently observed in conjunction with honeydew coverings of surfaces (e.g. Crozier, 1981; Gerson, 1975). On leaves of affected plants, colonization is referred to as sooty mold Sooty mold is also a common disease on plane and linden trees (Hughes, 1976). Among other genera, also Aureobasidium species have been described for the normal phyllosphere as well as for sooty mold. Aureobasidium is not just a plantassociated ascomycete. Members of this genus, as well as the detected Sarcinomyces, frequently occur on rock and dimension stone surfaces (Simonovicova et al., 2004; Wollenzien et al., 1997). Organisms of this group have been identified as deteriorative rock-dwelling agents on natural and dimension stone (Gorbushina et al., 1993; Gorbushina and Krumbein, 2000). The black pigmentation is attributed to the ultraviolet-protective melanin (Bell and Wheeler, 1986). 

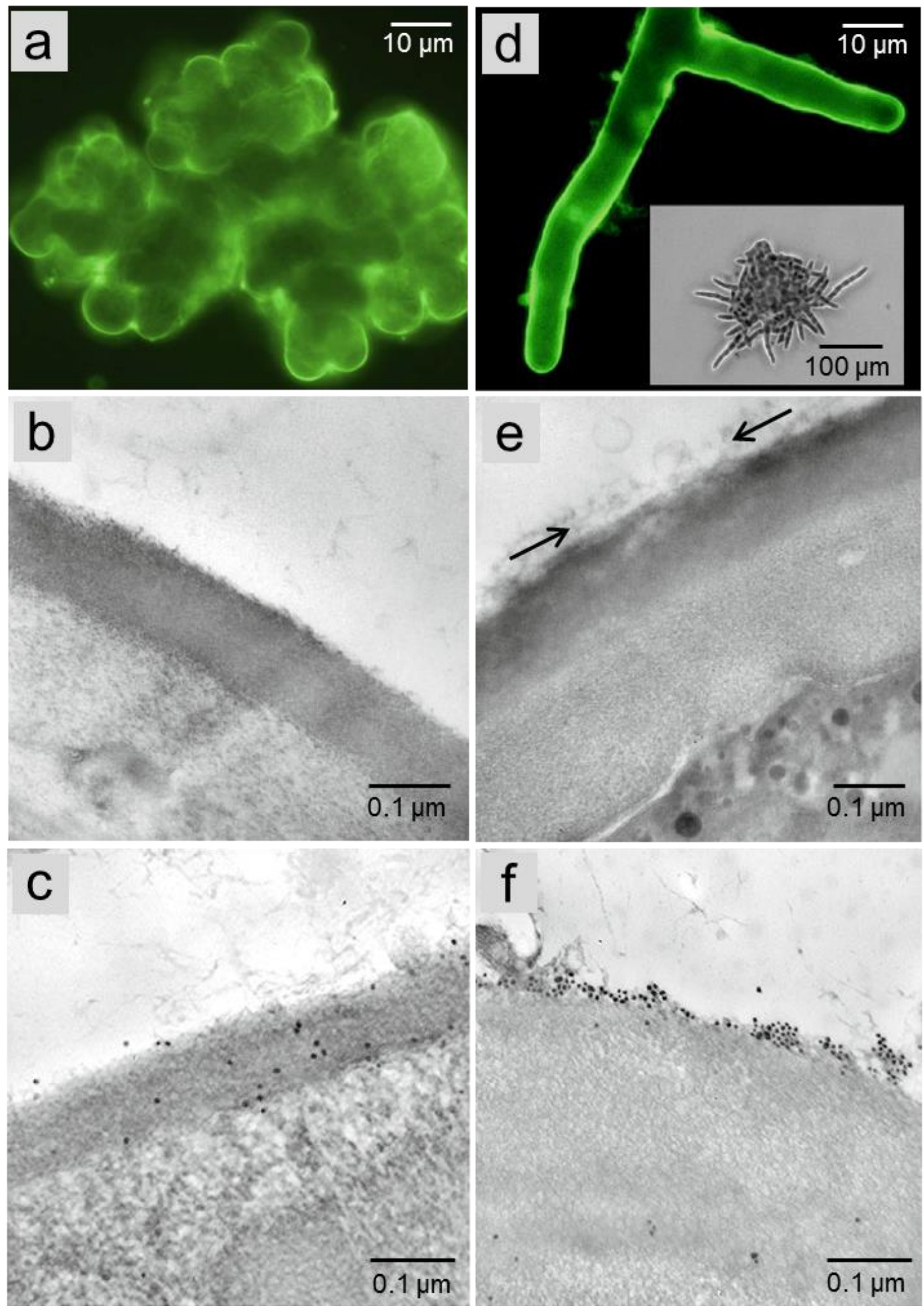

Fig. 4. Light and electron microscopy of lectin-labeled cells. (a) Fluorescence light microscopy of a Con A-FITC- labeled Apatococcus aggregate. (b) Ultrathin section of an Apatococcus cell wall. (c) Con A- gold labeled ultrathin section of an Apatococcus cell wall. Dark dots represent the colloidal gold marker. (d) Fluorescence light microscopy of Con A-FITC- labeled Prasiolopsis filaments. The inset shows a typical aggregate (phase contrast image). (e) Ultrathin section of a Prasiolopsis cell wall. The thin exopolysaccharide layer is marked by arrows. (f) Con A gold-labeled ultrathin section of a Prasiolopsis cell wall. 
In fungi, melanin is synthesized via different pathways, frequently from acetate via 1,8-dihy-droxynaphthalene as intermediate. The resulting phenolic polymer is deposited in- or outside the fungal cell wall (Bartnicki-Garcia, 1968). Hence, the dark stain is difficult to handle. Though superficial soiling, even black gypsum crusts on top of a surface are removable with mild chemical or biological agents (e.g. Polo et al., 2010), the organisms and stains may also penetrate the genuine marble surface (cf. Fig. 1e). When these cell wall remnants cannot be removed mechanically, or by application of mild detergents, rather harsh chemical treatment, e.g. with hydrogen peroxide as strong oxidant, is necessary to destroy the melanin (Korytowski and Sarna, 1990).

According to the clone library data, the group of plant-associated ascomycetes dominates over the rock-inhabiting genera. Though even sequencing clone libraries to saturation (which was not done here) does not reflect the real species diversity exactly (Jeon et al., 2008), we find in our case study a clear tendency for the presence of "allochthonous", not genuinely rock-inhabiting fungi. The organisms grow in the honeydew cover on the marble sculpture, whereas the "autochthonous" organisms do not benefit from the honeydew in the same way. In contrast, the algal species of the genus Stichococcus are typical colonizers of stone surfaces (cf. e.g. Michailyuk, 2008). It is noticeable that, though the algae are photoautotrophic, they may also benefit from external organic nutrients, especially from sucrose (e.g. Samejima and Myers, 1958).

Growth enhancement by carbohydrates has also been shown for Stichococcus mirabilis (Mattox and Bold, 1962). This may be one reason for the abundance of this algal species in a biofilm dominated by diverse fungi. Generally, the most abundant algal species were small unicellular morphotypes, known as pioneer organisms (e.g. Garty, 1992; Bellinzoni et al., 2003). Besides these organisms, others must be present in very low numbers of individuals, as a "seed bank" inside the biofilm (Table 3). Hence, their sequences were not present in the clone libraries, derived from environmental DNA. They will become important when environmental conditions change (which is, in fact, the case during enrichment of organisms from biofilm samples in a liquid culture). Some species may even not be detected in clone libraries of enrichment cultures, such as, in our example, Prasiolopsis sp., a green alga that could be obtained in unialgal culture. Prasiolopsis is a peculiar subaerial alga living on rock or tree bark with multiseriate filamentous or pseudoparenchymatous thalli (Karsten et al., 2005). Branched filaments are well adapted to those environments where tiny paths and small cavities, as well as impassable (crystalline) particles form a more or less solid substratum (e.g. Ritz and Young, 2004). 

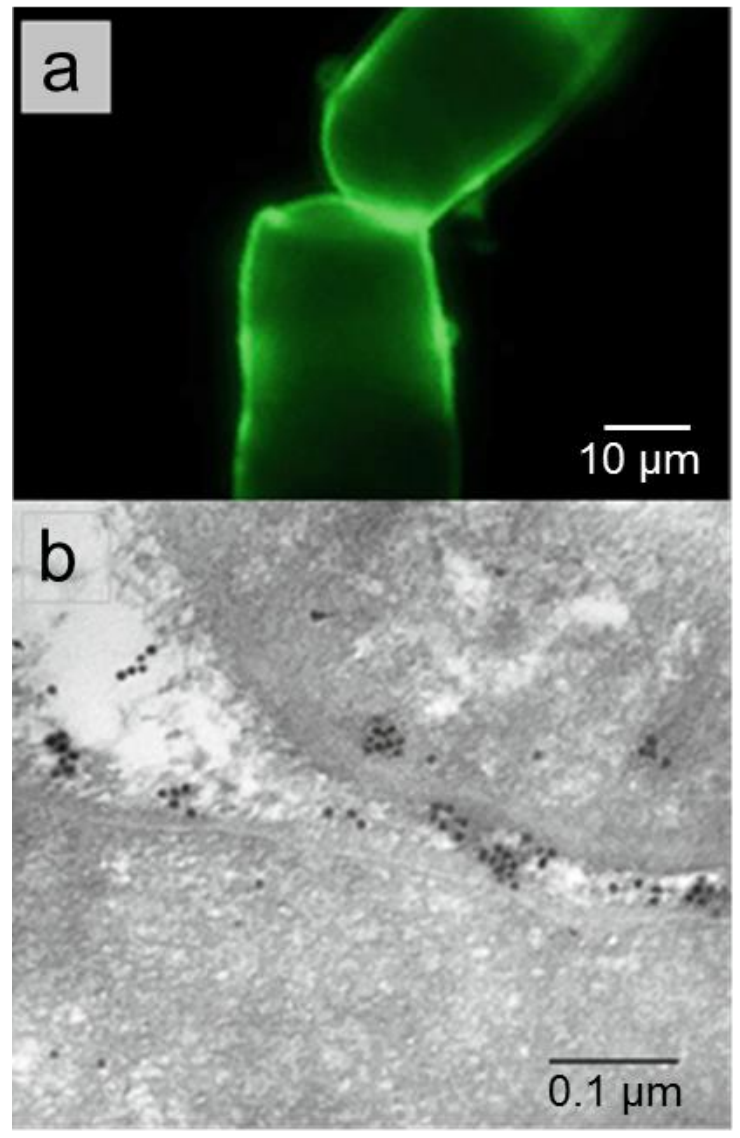

Fig. 5. Agglutination of Prasiolopsis filaments. (a) Fluorescence light microscopy of two attached filaments. (b) The same situation as depicted in a visualized by electron microscopy. Two attached filaments agglutinate via a thin exopolysaccharide layer, labeled with the Con A-gold maker.

Moreover, the algal exopolysaccharides (EP) facilitate the attachment to a surface as well as agglutination of organisms to each other. Up to now, mainly thick algal EP layers in aquatic biofilms have been described (see Sutherland, 2001 for review), where green algae and cyanobacteria are covered with a thick polysaccharide layer. It is also known that EP stabilizes terrestrial (soil) biofilms such as microbiotic soil crusts (Hoppert et al., 2004b; Bowker et al., 2008). The role of EP on dry, solid surfaces is much less known, though it is obvious that the organisms also produce these extracellular polymers. For detection of specific oligosaccharides in EP, marker techniques based on the binding of lectins to certain oligosaccharides stretches are used. The lectin concanavalin A binds to oligomannose-type $\mathrm{N}$-glycans. These motifs are common in cell wall polysaccharides and especially in EP of a variety of organisms, including cyanobacteria and eukaryotic algae (Mehta and Vaidya, 1978; Tien et al., 2005).

The Apatococcus strain does not show a layer adjacent to the cell wall, though the rigid wall itself exhibits a dispersed labeling (Fig. 4c). Heteropolysaccharides of different proportions are common in algal cell walls (Takeda and Hirokawa, 1984; Okuda, 2002) and can also be expected for Apatococcus. Prasiolopsis, in contrast, forms a thin layer of 
just several tens of $\mathrm{nm}$ in thickness, distinctively labeled with the concanavalin A-lectin (Fig. 4e, f). Compared with other EP layers from eukaryotic algae (e.g. Leppard, 1995), Prasiolopsis exhibits even in the hydrated state only a thin EPS coating. This layer may not have more than a gluing function. Up to now, there are no data concerning the interaction between the filaments and a material surface, but it is obvious that single filaments agglutinate via the thin EP layer (Fig. 5). This may be an important feature for the formation of an interwoven meshwork of branched filaments.

\section{Conclusion}

In our case study, we examined the microbial diversity on a monument contaminated by honeydew. Remarkably, typical rock-inhabiting fungi appear to be less relevant than plantinhabiting fungal microorganisms. Less contaminated areas of the sculpture exhibited typical green algal biofilms. Among the algae, unicellular Stichococcus-, Chloroidium- and Apatococcus-related strains were dominant in environmental samples and in enrichment cultures. Other algae, like Prasiolopsis, could also be isolated.

These results show the high relevance of an external carbon source (honeydew) for surface colonization by ascomycete fungi and, hence, formation of a dark-stained biofilm layer. The dark surface stain can only be avoided by removal of the carbon source, e.g. the honeydew, which may be achieved by suitable pest control. Also, an appropriate shaping of the canopy may lead, in this case, to an effect: parts of the sculptures are presently positioned in a way that they are placed rather under the periphery of the tree canopies. Thinning of the crown may not completely prevent, but reduce, the impact of downdripping honeydew.

\section{Acknowledgments}

The support of Mrs Ruth Hauer (Denkmalschutzamt Hamburg) during the field work is gratefully acknowledged. 


\section{References}

Abliz, P., Fukushima, K., Takizawa, K. and Nishimura, K. (2004) Identification of pathogenic dematiaceous fungi and related taxa based on large subunit ribosomal DNA D1/D2 domain sequence analysis. FEMS Immunol Med Microbiol 40: 41-49.

Adams, A.E., MacKenzie, W.S. and Guilford, C. (1984) Atlas of sedimentary rocks under the microscope. Longman Publ. Group, New York.

Ascaso, C., Wierzchos, J. and Castello, R. (1998) Study of the biogenic weathering of calcareous litharenite stones caused by lichen and endolithic microorganisms. Int Biodeterior Biodegradation 42: 29-38.

Bartnicki-Garcia, S. (1968) Cell wall chemistry, morphogenesis and taxonomy of fungi. Annu Rev Microbiol 22: 87-108.

Bell, A.A. and Wheeler, M.H. (1986) Biosynthesis and functions of fungal melanins. Annu Rev Phytopathol 24: 411-451.

Bellinzoni, A.M., Caneva, G. and Ricci, S. (2003) Ecological trends in travertine colonisation by pioneer algae and plant communities. Int. Biodeterior Biodegradation 51: 203-210.

Bowker, M.A.G., Koch, W., Belnap, J. and Johnson, N.C. (2008) Nutrient availability affects pigment production but not growth in lichens of biological soil crusts. Soil Biol Biochem 40: 2819-2826.

Cooke, W.B. (1961) A taxonomic study in the "black yeasts". Mycopathologia 17: 1-43.

Crous, P.W., Denman, S., Taylor, J.E., Swart, L. and Palm, M.E. (2004) Cultivation and diseases of Proteaceae: Leucadendron, Leucospermum and Protea. CBS Biodiv Ser 2: 1-226.

Crozier, L. (1981) Beech honeydew: forest produce. New Zeal J Forest 26: 200-209.

Darienko, T., Gustavs, L., Mudimu, O., Rad Menendez, C., Schumann, R., et al. (2010) Chloroidium, a common terrestrial coccoid green alga previously assigned to Chlorella (Trebouxiophyceae, Chlorophyta). Eur J Phycol 45: 1469-4433.

Finlay, B.J. and Esteban, G.F. (2004) Ubiquitous dispersal of free-living microorganisms. In Bull, A.T. (ed) Microbial diversity and bioprospecting. ASM Press, Washington, pp. 216-224.

Fischer, M.K., Völkl, W., Schopf, R. and Hoffmann, K.H. (2002) Age-specific patterns in honeydew production and honeydew composition in the aphid Metopeurum fuscoviride: implications for ant-attendance. J Insect Physiol 48: 319-326.

Friedl, T. (1996) Evolution of the polyphyletic genus Pleurastrum (Chlorophyta): inference from nuclear-encoded ribosomal DNA sequences and motile cell ultrastructure. Phycologia 35: 456-469.

Garty, J. (1992) The postfire recovery of rock-inhabiting algae, microfungi and lichens. Can J Bot 70: $310-312$.

Gerson, U. (1975) A soft scale as an urban pest. Isr J Entomol 10: 25-28.

Gorbushina, A.A. (2007) Life on the rocks. Environ Microbiol 9: 613-631.

Gorbushina, A.A. and Krumbein, W.E. (2000) Rock dwelling fungal communities: diversity of life styles and colony structure. In Seckbach, J. (ed) Journey to diverse microbial worlds. Kluwer, Amsterdam, pp. 317-334.

Gorbushina, A.A., Krumbein, W.E., Hamman, C.H., Panina, L., Soukharjevski, S. and Wollenzien, U. (1993) Role of black fungi in colour change and biodeterioration of antique marbles. Geomicrobiol J 11: 205-221.

Hamby, R.K., Sim, L.E. and Zimmer, E.A. (1988) Direct RNA sequencing techniques for work with higher plants. Plant Mol Biol Reporter 6: 179-197. 
Hedlund, B.P. and Staley, J.T. (2004) Microbial endemism and biogeography. In Bull, A.T. (ed) Microbial diversity and bioprospecting. ASM Press, Washington, pp. 225-231.

Hoppert, M. and Holzenburg, A. (1998) Electron microscopy in microbiology. Bios Scientific Publ, London.

Hoppert, M., Flies, C., Pohl, W., Günzl, B. and Schneider, J. (2004a) Colonization strategies of lithobiontic organisms on carbonate rocks. Environ Geol 46: 4212-4428.

Hoppert, M., Reimer, R., Kemmling, A., Schröder, A., Günzl, B. and Heinken, T. (2004b) Structure and reactivity of a biological soil crust from a xeric sandy soil in Central Europe. Geomicrobiol J 21: 183-191.

Hughes, S.J. (1976) Sooty molds. Mycologia 68: 693-820.

Jasalavich, C.A., Ostrofsky, A. and Jellison, J. (2000) Detection and identification of decay fungi in spruce wood by restriction fragment length polymorphism analysis of amplified genes encoding rRNA. Appl Environ Microbiol 66: 4725-4734.

Jeon, S., Bunge, J., Leslin, C., Stoeck, T., Hong, S. and Epstein, S.S. (2008) Environmental rRNA inventories miss over half of protistan diversity. BMC Microbiol 8: 222.

Kämper, M., Vetterkind, S., Berker, R. and Hoppert, M. (2004) Methods for in situ detection and characterization of extracellular polymers in biofilms by electron microscopy. $J$ Microbiol Meth 57: 55-64.

Karsten, U., Friedl, T., Schumann, R., Hoyer, K. and Lembcke, S. (2005) Mycosporine-like amino acids and phylogenies in green algae: Prasiola and its relatives from the Trebouxiophyceae (Chlorophyta). J Phycol 41: 557-566.

Kemmling, A., Kämper, M., Flies, C., Schieweck, O. and Hoppert, M. (2004) Biofilms and extracellular matrices on geomaterials. Environ Geol 46: 429-435.

Korytowski, W. and Sarna, T. (1990) Bleaching of melanin pigments. J Biol Chem 265: 12410-12416.

Leppard, G.G. (1995) The characterization of algal and microbial mucilages and their aggregates in aquatic ecosystems. Sci Total Environ 165: 103-131.

Macedo, M.F., Miller, A.Z., Dionisio, A. and Saiz-Jimenez, C. (2009) Biodiversity of cyanobacteria and green algae on monuments in the Mediterranean Basin: an overview. Microbiology 155: 3476-3490.

Martiny, J.B., Bohannan, B.J., Brown, J.H., Colwell, R.K., Fuhrman, J.A., et al. (2006) Microbial biogeography: putting microorganisms on the map. Nat Rev Microbiol 4: 102-112.

Mattox, K. and Bold, H.C. (1962) Phycological studies III. The taxonomy of certain ulotricacean algae. Univ Texas Publ No 6222, Austin.

Mehta, V.B. and Vaidya, B.S. (1978) Cellular and extracellular polysaccharides of the blue-green alga Nostoc. J Exp Bot 29: 1423-1430.

Meusnier, I., Singer, G.A.C., Landry, J.F., Hickey, D.A., Hebert, P.D.N. and Hajibabaei, M. (2008) A universal DNA mini-barcode for biodiversity analysis. BMC Genomics 9: 214.

Michailyuk, T.I. (2008) Terrestrial lithophilic algae in a granite canyon of the Teteriv River (Ukraine). Biologia 63: 824-830.

Okuda, K. (2002) Structure and phylogeny of cell coverings. J Plant Res 115: 283-288.

Phillips, A.J.L., Alves, A., Pennycook, S.R., Johnston, P.R., Ramaley, A., et al. (2008) Resolving the phylogenetic and taxonomic status of dark-spored teleomorph genera in the Botryosphaeriaceae. Persoonia 21: 29-55.

Polo, A., Cappitelli, F., Brusetti, L., Principi, P., Villa, F., et al. (2010) Feasibility of removing surface deposits on stone using biological and chemical remediation methods. Microb Ecol 60: $1-14$. 
Ritz, K. and Young, I.M. (2004) Interactions between soil structure and fungi. Mycologist 18: 52-59.

Roth, J., Bendayan, M., Carlemalm, E., Villiger, W. and Garavito, M. (1981) Enhancement of structural preservation and immunocytochemical staining in low temperature embedded pancreatic tissue. J Histochem Cytochem 29: 663-671.

Samejima, H. and Myers, J. (1958) On the heterotrophic growth of Chlorella pyrenoidosa. J Gen Microbiol 18: 107-117.

Schlösser, U.G. (1994) Sammlung von Algenkulturen at the University of Göttingen; catalogue of strains 1994. Bot Acta 107: 113-186.

Simonovicova, A., Godyova, M. and Svec, J. (2004) Airborne and soil microfungi as contaminants of stone in a hypogean cemetery. Int Biodeterior Biodegradation 54: 7-11.

Suryanarayanan, T.S., Ravishankar, J.P., Venkatesan, G. and Murali, T.S. (2004) Characterization of the melanin pigment of a cosmopolitan fungal endophyte. Mycol Res 108: 974-978.

Sutherland, I.W. (2001) Biofilm exopolysaccharides: a strong and sticky framework. Microbiology 147: 3-9.

Takeda, H. and Hirokawa, T. (1984) Studies on the cell wall of Chlorella V. Comparison of the cell wall chemical compositions in strains of Chlorella ellipsoidea. Plant Cell Physiol 25: 287-295.

Tien, C.J., Sigee, D.C. and White, K.N. (2005) Characterization of surface sugars on algal cells with fluorescein isothiocyanate-conjugated lectins. Protoplasma 225: 225-233.

Tsuneda, S., Aikawa, H., Hayashi, H., Yuasa, A. and Hirata, A. (2003) Extracellular polymeric substances responsible for bacterial adhesion onto solid surface. FEMS Microbiol Lett 223: 287-292.

Wainright, M., Ali, T.A. and Barakh, F. (1993) A review of the role of oligotrophic microorganisms in biodeterioration. Int Biodeterior Biodegradation 31: 1-13.

Warscheid, T. and Braams, J. (2000) Biodeterioration of stone: a review. Int Biodeterior Biodegradation 46: 343-368.

White, T.J., Bruns, T., Lee, S. and Talylor, J. (1990) Amplification and direct sequencing of fungal ribosomal RNA genes for phylogenetics. PCR protocols: a guide to methods and applications, pp. 315-322.

Wollenzien, U., de Hog, G.S., Krumbein, W. and Uijthof, J.M.J. (1997) Sarcinomyces petricola, a new microcolonial fungus from marble in the Mediterranean basin. Antonie van Leeuwenhoek 71: 281-288.

Zuo, R., Kus, E., Mansfeld, F. and Wood, T.K. (2005) The importance of live biofilms in corrosion protection. Corros Sci 47: 279-287. 


\section{Chapter 4:}

\section{Biodiversity of green phototrophic biofilms on artificial hard surfaces: a case study of aero-terrestrial algae in an urban environment using molecular approaches}

Christine Hallmann ${ }^{1}$, Michael Hoppert ${ }^{2,3}$, Opayi Mudimu ${ }^{1,4}$ and Thomas Friedl ${ }^{1,3}$ Manuscript to be resubmitted to Journal of Phycology

\footnotetext{
${ }^{1}$ Albrecht-von-Haller-Institute for Plant Sciences, Department of Experimental Phycology and Culture Collection of Algae, Georg-August-University, Untere Karspüle 2, 37073 Göttingen, Germany

${ }^{2}$ Institute for Microbiology and Genetics, Georg-August-University, Grisebachstraße 8, 37077 Göttingen, Germany

${ }^{3}$ Courant Research Center Geobiology, Georg-August-University, Goldschmidtstraße 3, 37077 Göttingen, Germany

${ }^{4}$ Present address: Plant Cell Physiology and Biotechnology, Botanical Institute, Christian Alberts University Kiel, Am Botanischen Garten 1-9, 24118 Kiel, Germany
}

Author contributions to the work:

Performed the experiments: $\mathrm{CH}$.

Analyzed data: $\mathrm{CH}$.

Wrote the paper: $\mathrm{CH}$, TF, $\mathrm{MH}$.

Conceived and designed the experiments: TF, OM, $\mathrm{CH}$. 


\begin{abstract}
Air-exposed green algae dominated biofilms on artificial hard substrates of urban environments represent an extreme habitat with respect to ever diminishing moisture coupled with strong fluctuations in temperature and PAR/UV irradiation. In Middle Europe they are common leading to undesired optical effects and accelerated biocorrosion of house facades, concrete walls and outdoor plastic objects. In a case study $18 \mathrm{~S}$ rRNA gene cloning/sequencing directly from the biofilms of eleven urban sites with various substrates revealed the prevalence of at least two distinct Operational Taxonomic Units (OTUs) or species of Apatococcus, three OTUs of Trebouxia and several microfungi, but no sequence counterparts for the additional morphotypes visible by microscopy of the biofilms were recovered. Also the phylogenetically distinct Desmococcus was not detected. For one study site, the polyethylene surface of a compost waste container, six more OTUs from five genera of Trebouxiophyceae as well as Klebsormidium were recovered when crude cultures were established to suppress growth of Apatococcus in favor of other species. Species so far reported only from Antarctica, Coenochloris signiensis and Pabia signiensis, or the tropics, Heveochlorella roystonensis, were detected in agreement with a world-wide distribution of the areo-terrestrial green algae as well as representatives of a new genus within the Watanabea-clade of Trebouxiophyceae. In addition, isolates established from the exemplar site exhibited structures probably facilitating adhesion and/or serving to protect the cells from drought. The genetic diversity of the biofilms contrasted their morphological uniformity; both may be the results of constraints effective in these extreme habitats.
\end{abstract}

Keywords: biofilm, extreme habitat, aero-terrestrial microalgae, Apatococcus, Desmococcus, Trebouxiophyceae. 


\section{Introduction}

In many urban areas in Middle Europe green phototrophic biofilms, dominated by green algae, colonize various types of substrates such as artificial building material (e.g. roof tiles, house facades, concrete wall, natural building stone), glass, metal, or plastic surfaces (e.g. glass roofs, street signs, waste containers) (Rindi, 2007; Karsten et al., 2007) which may also comprise a variety of mosses, fungi, lichens and bacteria (Gorbushina, 2007; Hallmann et al., 2015). Several hazards may be caused by the green algal biofilms on surfaces and, therefore, to study their biodiversity may be a first essential prerequisite to avoid the appearance of these biofilms. Biofilms lead to biocorrosion of material which is mainly driven by the excretion of organic acids and, hence, dissolution and complexation of calcium and magnesium ions (Welton et al., 2003; Karsten et al., 2005a). Also the biodeterioration due to biofilms of synthetic polymers, like epoxy resin applied as material for statues or for restoration applications, has recently been described (Cappitelli and Sorlini, 2008; Pangallo et al., 2014). The extent of the biocorrosion may depend on the algal life style, e.g. endolithic or epilithic growth (Hoppert et al., 2005; Horath and Bachofen, 2009), and, thus the composition of the algal community on a surface. Algal biofilms contribute to staining and soiling of the surface due to the production of red (caused by carotenoids) and green (chlorophylls) pigments and, thus, may led to undesired staining of air-exposed surfaces in an urban environment, e.g. house facades. The moisture regimen of facades strongly influences the establishment and growth of algal biofilms. In the past few years prolonged frost-free periods in winter promoted growth of aerophytic microalgae on artificial hard substrate surfaces in the Northern hemisphere. Frequently, also heat insulation of facades may cause a moisture regime which in addition promotes the establishment of the green algal biofilms (Karsten et al., 2005a).

In terrestrial habitats, green algae are among the most widespread eukaryotes (Darienko and Hoffmann, 2003; Rindi, 2011) and have already been recognized since the beginning of systematic research on algae (e.g. Agardh, 1824; for further references see Gärtner, 1994; Rindi, 2007). Aerophytic algae, i.e., algae which are dispersed by airflows, exhibit a variety of adaptations to their often extreme habitats. Dry periods, with temperatures on air-exposed surfaces in summer reaching up to $50{ }^{\circ} \mathrm{C}$ and higher and in winter below $0{ }^{\circ} \mathrm{C}$, require an adaptation of the algae mainly against desiccation. These adaptations may be manifested in highly thickened cell walls (e.g. the Apatococcus/Desmococcus morphotype and Klebsormidium spp.) or gelatinous sheaths 
formed by extracellular polymeric substances (EPS), e.g. in Coccomyxa (Karsten et al., 2005a; Holzinger and Karsten, 2013; Karsten et al., 2014). These structures may enable the green algal cells to store water for a certain time period and help to withstand high osmotic stress during desiccation. The accumulation of EPS as a protection against desiccation has already been reported (Shepherd and Beilby, 1999; Hoppert, 2003). Equally important are mechanisms protecting against high radiation, such as the accumulation of carotenoids and the formation of MAAs (mycosporine-like amino acids; Karsten et al., 2005b). Moreover, resting stages such as spores persist for years (Karsten et al., 2005a). In addition, also the chemical properties of the substratum substantially influences the settlement of specific algae (Darienko and Hoffmann, 2003; Rindi, 2007).

Members of various green alga genera, e.g. Apatococcus, Chlorella, Desmococcus, Klebsormidium, Stichococcus and Trebouxia are known as the most common representatives of aerophytic microalgae (Gärtner, 1994; Karsten et al., 2005a; Rindi et al., 2010). In spite of these general findings, knowledge on the algal diversity of the green algal biofilms is still in its infancy (Karsten et al., 2005a; Rindi, 2007). Up to now, the green biofilms have mostly been studied by microscopy, i.e. recognition of certain morphotypes. Only a few have been isolated and cultured (Darienko and Hoffmann, 2003; Uher, 2008; Khaybullina et al., 2010; Neustupa and Štifterová, 2013). However, most green algal species cannot be correctly identified by microscopy of the biofilm because their diagnostic features may appear only in culture and are hard to recognize for the nonspecialist. In addition, some biofilm algae may be difficult to isolate into culture. Therefore, the study of molecular characters is required, i.e. to identify the biofilm organisms using DNA sequence comparisons. The taxonomic composition of other terrestrial microalgal communities, e.g. Biological Soil Crusts, rock and building stone surfaces have been investigated using molecular phylogenetic markers (Lewis and Lewis, 2005; Horath and Bachofen, 2009; Büdel et al., 2009; Cuzman et al., 2010; Hallmann et al., 2013a). Though only a fraction of the algal diversity may be detected by culturing of samples, algal taxa may be enriched that are represented by only few individuals in the original samples - which may otherwise remain undetectable even with molecular techniques.

In an attempt to study the algal diversity of green phototrophic biofilms using 18S rRNA gene sequence comparisons we took biofilm samples from eleven localities representing various substrates within the urban environment of the city of Göttingen, Germany (Table 1). Due to relatively high moisture with frequent rainfalls and cool 
average air temperatures over the whole year green algal dominated biofilms are well developed on various air-exposed artificial substrates at different heights within the city of Göttingen. Microscopy of the biofilm samples revealed the dominance of the common Apatococcus/Desmococccus morphotype together with Trebouxia spp. over much less abundant smaller round or ovoid cells with a Chlorella- or Coccomyxa-like appearance and sometimes also round green algal cells covered by mucilage. Because the cultureindependent approach of PCR amplification, cloning and sequencing directly from DNA extracts of the biofilms revealed a just very poor diversity of the biofilms, i.e. representatives of Apatococcus and Trebouxia, we selected one locality as an example to study the biofilm algal community in more detail, i.e. also using crude (enrichment) cultures and green algal isolates. The latter efforts revealed a diversity of eleven molecular Operational Taxonomic Units (OTUs) or species from at least six genera of Trebouxiophyceae (Chlorophyta) apart from Klebsormidium.

\section{Materials and methods}

Green phototrophic biofilms from eleven sites with air-exposed surfaces of various artificial substrates were collected within the city limits of Göttingen, Germany, during the year 2006 (Table 1). The biofilms were openly exposed to the environment and situated at least at height of approximately $1.5 \mathrm{~m}$ above ground in a horizontal position. Only site MA was covered by vegetation at about $20 \mathrm{~cm}$ above ground and, therefore, shaded and with more moisture than the other sites. The biofilm samples were scraped off with a sterile scalpel and stored in $2 \mathrm{ml}$ reaction tubes. One site, a polyethylene surface of a compost waste container (GOG, Fig. 1a, b), was selected as an exemplar site to study the algal composition of the biofilm also by crude cultures. For them small portions of the biofilm samples were suspended into a glass tube with $10 \mathrm{ml}$ liquid MIEB $_{12}$ medium (http://www.uni-goettingen.de/de/184982.html). For isolation of microalgae a small amount of the biofilm sample was spread onto MIEB $_{12}$ agar plates. The crude cultures and agar plates were incubated at $18{ }^{\circ} \mathrm{C}$ on a $14: 10$ hour light:dark cycle at $25 \mu \mathrm{mol}$ photons $\mathrm{m}^{-2} \mathrm{~s}^{-1}$ of white fluorescent light for 4 weeks. From agar plates colonies were selected and purified by repeated transferring on fresh agar media until unialgal cultures were obtained. The isolates were then maintained on agar slants. Representative isolates were accessioned by the Sammlung von Algenkulturen der Universität Göttingen (SAG) under the strain numbers SAG 2359, SAG 2373, SAG 2374 and SAG 2375 (Table 2). 


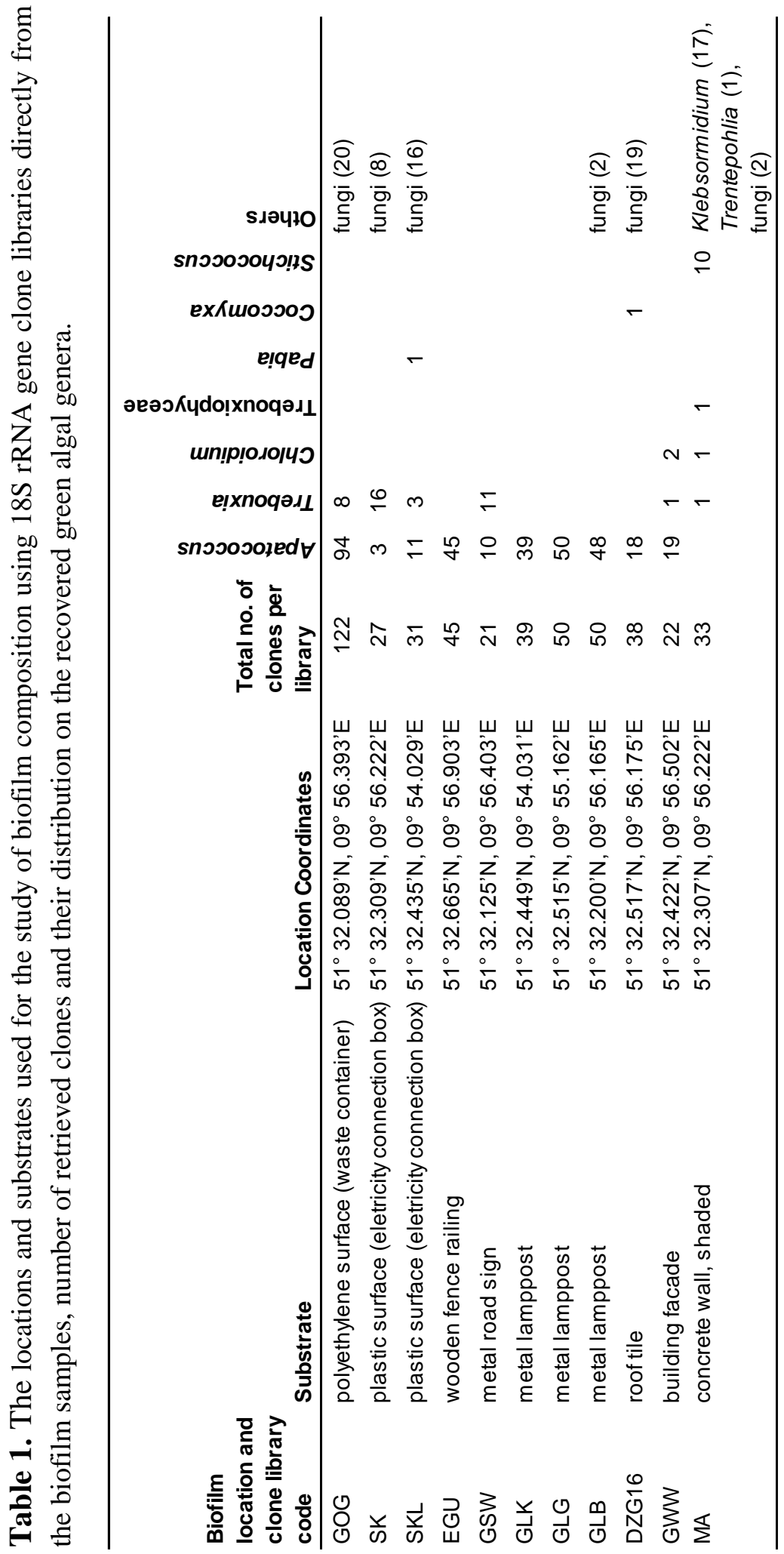




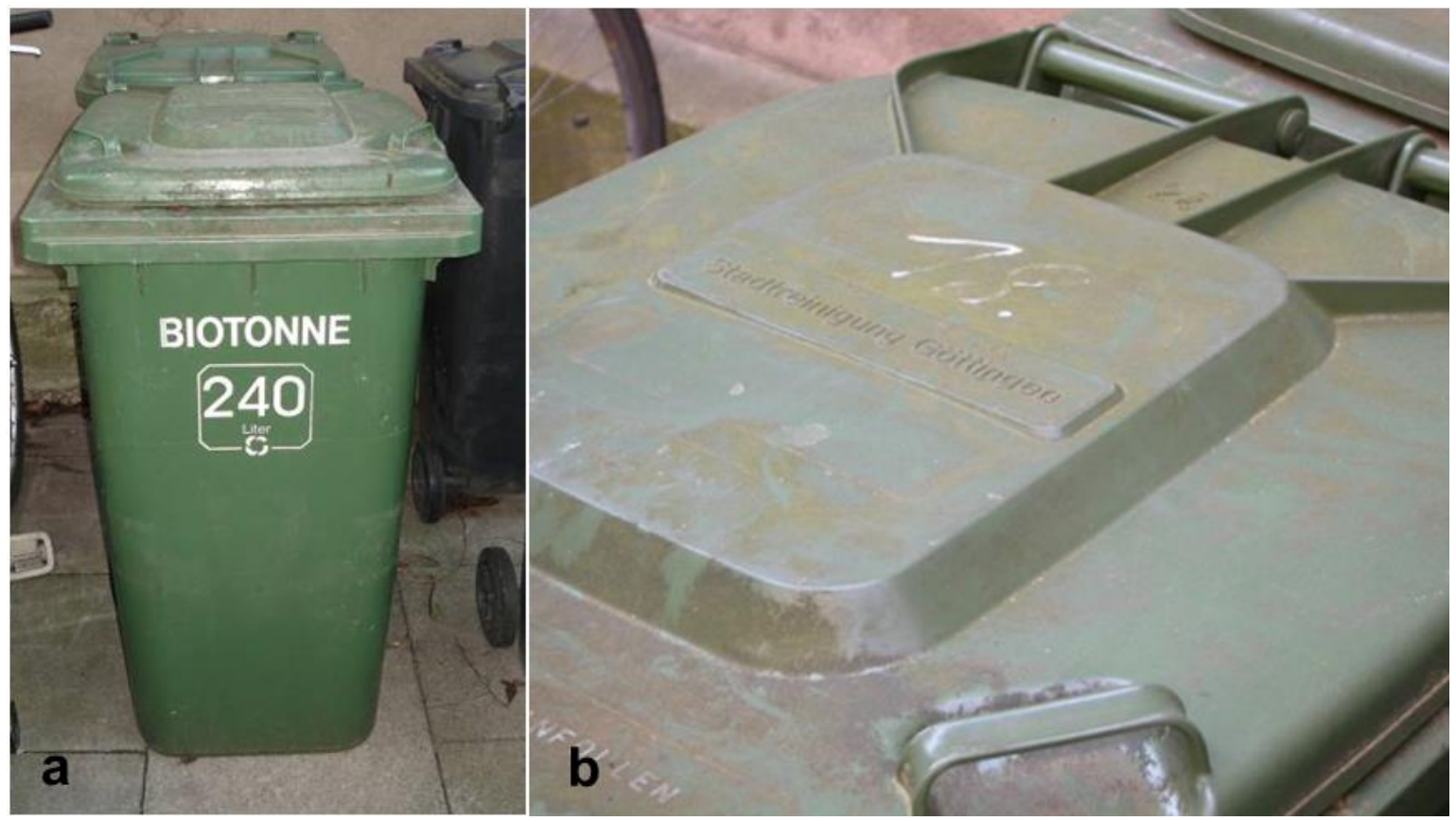

Fig. 1. Study site of an air-exposed phototrophic green biofilm (exemplar site GOG). (a) polyethylene compost waste container (b) biofilm on the surface of the waste container lid.

\section{DNA extraction, PCR amplification, cloning and sequencing.}

Genomic DNA was extracted from the biofilm samples, the GOG liquid crude culture and isolates. Two different methods were used for cell disruption before DNA preparation. For the cell disruption by shaking in a Mini-BeadBeater (Biospec, Barlesville, OK, USA) samples were divided into two fractions for different bead beating times. Equivalent amounts of $120-200 \mu \mathrm{m}$ and $425-600 \mu \mathrm{m}$ diameter acid washed glass beads (SigmaAldrich, ST. Louis, MO, USA) were added to $2 \mathrm{ml}$ reaction tubes containing the samples which were vortexed briefly. The samples were treated in the bead beater once for $30 \mathrm{~s}$ and once for $50 \mathrm{~s}$ at $5.000 \mathrm{rpm}$. The biofilm samples were also disrupted by repeated freezethawing, i.e. samples frozen in liquid nitrogen were ground with a micropestle in $1.5 \mathrm{ml}$ reaction tubes placed in aluminium blocks, pre-cooled in liquid nitrogen and then thawn. DNA was extracted with the Invisorb ${ }^{\circledR}$ Spin Plant Mini Kit (Stratec Molecular, Berlin, Germany), following the manufacturer's instructions. Quality of the DNA after extraction was checked on a $1 \%(\mathrm{w} / \mathrm{v})$ agarose gel. Isolated DNA was stored at $-20{ }^{\circ} \mathrm{C}$ until further processing.

Eukaryote specific primer pairs NS1 (White et al., 1990) and 18L (Hamby et al., 1988) and NS1/LR1850 (Friedl, 1996) were used for the amplification of rRNA genes. The primer set NS1/18L amplifies the 18S rRNA gene region only, approximately $1800 \mathrm{bp}$ 
length, used for the biofilm sample. The primer set NS1/LR1850 amplifies the 18S rRNA gene, internal transcribed spacer 1 (ITS1), 5.8S rRNA gene, ITS2 and partial 26S rRNA gene regions, approximately $2300 \mathrm{bp}$ length, used for biofilm sample, crude culture and isolates. About 10-100 ng of the extracted DNA were used as template. The amplification reaction mixture $(50 \mu \mathrm{l})$ contained each $\mathrm{dNTP}$ at a concentration of $0.1 \mathrm{mM}, 5 \mu \mathrm{l}$ of $10 \mathrm{x}$ reaction buffer, $2 \mathrm{mM} \mathrm{MgCl}_{2}$, each primer at a concentration of $0.2 \mu \mathrm{M}, 2 \mathrm{U}$ of Taq DNA polymerase (Bioline, Luckenwalde, Germany) and $4 \%(\mathrm{v} / \mathrm{v})$ dimethyl sulfoxide (DMSO)-solution. PCR was performed in a PTC 200 thermocycler (MJ Research, Waltham, MA, USA) using the following program for the primer set NS1/18L: initial denaturation at $95{ }^{\circ} \mathrm{C}$ for $5 \mathrm{~min}$, followed by 33 cycles of denaturation at $94{ }^{\circ} \mathrm{C}$ for $1 \mathrm{~min}$, annealing at $52{ }^{\circ} \mathrm{C}$ for $45 \mathrm{~s}$, extension at $72{ }^{\circ} \mathrm{C}$ for $3 \mathrm{~min}$ and final extension at $72{ }^{\circ} \mathrm{C}$ for $7 \mathrm{~min}$. For the primer set NS1/LR1850, the following program was used: initial denaturation at $95{ }^{\circ} \mathrm{C}$ for $5 \mathrm{~min}$, followed by 33 cycles of denaturation at $94{ }^{\circ} \mathrm{C}$ for $40 \mathrm{~s}$, annealing at $52{ }^{\circ} \mathrm{C}$ for $90 \mathrm{~s}$, extension at $72{ }^{\circ} \mathrm{C}$ for $90 \mathrm{~s}$, followed by 6 cycles of denaturation at $94{ }^{\circ} \mathrm{C}$ and final extension at $72{ }^{\circ} \mathrm{C}$ for $2 \mathrm{~min}$. The PCR products were purified using the Invisorb ${ }^{\mathrm{R}}$ Spin PCRapid Kit (Stratec Molecular). Aliquots of $2 \mu \mathrm{l}$ of purified amplicons were analysed by electrophoresis on a $1 \%(\mathrm{w} / \mathrm{v})$ agarose gel.

Cloning was carried out with the TOPO TA cloning kit (Invitrogen, Carlsbad, CA, USA) as described in Hallmann et al. 2013a. About 50 positive clones were cultivated overnight in LidBac reaction tubes (Qiagen, Hilden, Germany) with $1 \mathrm{ml}$ LB medium containing $100 \mu \mathrm{g}$ ampicillin. Plasmid DNA was purified with the NucleoSpin-Plasmid kit (Macherey and Nagel, Düren, Germany) and stored at $-20^{\circ} \mathrm{C}$. Sequencing reactions were conducted with the Dye Terminator Cycle Sequencing v3.1 kit (Applied Biosystems, Darmstadt, Germany) and an ABI Prism 3100 (Applied Biosystems) automated sequencer. All clones were sequenced with the 18S rRNA gene standard sequencing primers either 895R (Hallmann et al., 2013a) or 34F (5' GTCTCAAAGATTAAGCCATGC 3') which yielded partial sequences of about $700 \mathrm{nts}$ and included the hypervariable regions V2-V4. The sequences were edited using SeqAssem (Hepperle, 2004).

\section{DNA sequence and phylogenetic analyses.}

Sequences shorter than $420 \mathrm{bp}$ without introns were excluded from further analysis. The sequences were compared with similar sequences of reference organisms by performing a BLASTn search at NCBI (Altschul, 1990; http://www.ncbi.nlm.nih.gov/). About 550 next relative sequences were imported into the ARB program (Ludwig et al., 2004; 
www.arb-home.de), additional to internal sequence references. To determine the first phylogenetic affiliation the partial sequences were aligned with the homologous eukaryotic $18 \mathrm{~S}$ rRNA gene sequences by using the automatic alignment tool of the ARB program package. Potential chimeras were checked by Bellerophon (Huber et al., 2004), the first and the last $300 \mathrm{bp}$ of the sequence were compared with similar rRNA gene sequences in NCBI and putative chimeras were excluded from the dataset. Rarefaction curves and OTUs with $\geq 99 \%$ similarity were calculated with MOTHUR (Schloss et al., 2009).

One up to four sequences of each OTU were selected and sequenced completely with standard sequencing primers. From isolates full length of the18S rRNA gene and the ITS region were sequenced. The sequences obtained in this study and internal sequence references were deposited in GenBank under the following accession numbers: JX169825 - JX169846 and KM116459 - KM116466. The alignment was performed using MAFFT version 6 (Katoh and Toh, 2008), small corrections were done by eye, using BioEdit alignment editor (Hall, 1999). The alignment included 109 sequences and 1794 positions (677 variable/485 parsimony informative sites).

Phylogenies were constructed by using the maximum likelihood (ML) method by RAxML (Stamatakis et al., 2008), using the GTR $+\Gamma+\mathrm{I}$ model with 100 replicates and with Bayesian methods (Huelsenbeck and Ronquist, 2001). Four Markov chains and three million generations sampling every 100 generations were applied, using the GTR $+\Gamma+\mathrm{I}$ model. Phylogenetic trees were viewed with FIGTREE (http://tree.bio.ed.ac.uk/software/figtree/).

Pairwise sequence similarities calculated from p-distances for representative clone and isolate sequences in comparison with reference sequences were computed with the program MEGA6 (Tamura et al., 2013).

\section{Microscopy}

For fluorescence light microscopy, the cells were double-stained with concanavalin A, coupled to fluorescein isothiocyanate (FITC; Sigma-Aldrich). The dye was applied in $50 \mathrm{mM}$ potassium phosphate buffer, supplemented with $0.01 \mathrm{mM}$ magnesium chloride and $0.01 \mathrm{mM}$ calcium chloride at a dilution of $1 / 1000$ of the original stock solution. The sample was inspected under a fluorescence light microscope (Axioscope, Zeiss, Göttingen, Germany; excitation wavelength $495 \mathrm{~nm}$, emission wavelength $517 \mathrm{~nm}$, Zeiss filter set 09). For staining of the EPS, samples on microscopy slides were covered with drops of indian ink (Pelikan, Hannover, Germany) or $1 \%$ methylene blue (Merck, Darmstadt, Germany) prior to light microscopy. 
For transmission electron microscopy (TEM), cells were harvested by short centrifugation at $10.000 \mathrm{rpm}$, resuspended in $50 \mathrm{mM}$ potassium phosphate buffer, chemically fixed in $0.5 \%(\mathrm{w} / \mathrm{v})$ formaldehyde and $0.3 \%(\mathrm{w} / \mathrm{v})$ glutardialdehyde solution for $90 \mathrm{~min}$ at $0{ }^{\circ} \mathrm{C}$, dehydrated in a graded methanol series and embedded in Spurr resin (Spurr, 1969; Hoppert and Holzenburg, 1998). Resin sections of 80-100 nm in thickness were cut with glass knives. Finally, the sections were stained with $0.5 \%(\mathrm{w} / \mathrm{v})$ phosphotungstic acid, $\mathrm{pH}$ 7.0, for three minutes. Electron microscopy was performed in a Zeiss EM 902 transmission electron microscope (Zeiss SMT, Oberkochen, Germany), equipped with a $1 \mathrm{~K}$ digital camera, at $80 \mathrm{kV}$ acceleration voltage and at calibrated magnifications.

\section{Results}

\section{Biofilm clone libraries}

The 18S rRNA gene clones from the studied green phototrophic biofilms revealed the dominance of Apatococcus. Apatococcus sequences were the only green algal sequences retrieved from the biofilms of four localities irrespective of the substratum (wood, EGU; metal, GLB, GLG, GLK; Table 1). Clones representing Apatococcus were dominant in the clone libraries established for three more localities with stone or plastic surfaces (DZG16, GOG, SKL). There, Trebouxia was the $2^{\text {nd }}$ most abundant green alga and/or a third algal genus, Coccomyxa (DZG16), Chloroidium (GWW), Pabia (SKL) was retrieved by just one or two clones each. Trebouxia was equally dominant as Apatococcus in one sample (GSW) and at another locality (SK) Trebouxia was even the most dominant alga. The ten Apatococcus biofilms were at open and dry localities, i.e. they were not covered by vegetation and stayed humid only during and shortly after rainfalls. Apatococcus clones were absent in a clone library from a single locality which was less dry and sun-exposed than the other localities (MA, a humid concrete wall shaded by vegetation). At the latter locality 29 clones even represented green algae not retrieved from the other study sites (Table 1).

Microscopic observations of the ten Apatococcus-dominated biofilms always revealed green algal morphotypes besides the cell packages of Apatococcus, i.e. round or ovoid cells with a Chlorella- or Coccomyxa-like appearance and sometimes also round green algal cells covered by mucilage which may be assigned to Radiococcaceae following traditional green algal systematics (Ettl and Gärtner, 1995; Kostikov et al., 2002). However, algae 
corresponding to these morphotypes were hardly retrieved from the clone libraries of the Apatococcus-dominated biofilms (Table 1). To test whether a larger algal diversity is present but simply cannot be detected adequately due to the dominance of Apatococcus and Trebouxia in these biofilms, we investigated crude cultures from a single locality using the same cloning/sequencing approach. It appeared that in the crude cultures growth of Apatococcus was somehow suppressed, i.e. it grew much slower than other terrestrial green algae.

\section{Biofilm algae from cultures}

We selected locality GOG because there the presence of Chlorella-, Coccomyxa and Radiococcaceae morphotypes was obvious in microscopy of the biofilms even without culturing. Microscopy of the GOG biofilm samples showed the dominance of Apatococcus cell packages and Trebouxia cells over inconspicuous, Chlorella-like or radiococcacean green algal cells (Fig. 2a). In addition to green algae, various filamentous fungi could be discerned (Fig. 2a), but no other algae or cyanobacteria. The crude cultures, i.e. after incubation of the biofilm material in liquid culture media for about four weeks, revealed a different picture. As expected, the Apatococcus cell packages were almost absent, but colonies of spherical cells with mucilage, Pabia morphotype, and long filaments of Klebsormidium had appeared, together with autospores packages-forming Trebouxia spp., numerous Chlorella- and Coccomyxa-like green algal cells (Fig. 2b). In addition, green algae of the Chloroidium morphotype were present.

The 18S rRNA gene clone library from the crude (enrichment) cultures revealed 83 green algal clones, but in contrast to the biofilm library no fungal clones were detected. We used a $99 \%$ threshold to group the partial sequences obtained for the algal clones into OTUs. Rarefaction curves revealed a nearly full coverage of the crude culture library while almost a plateau for the biofilm clone library was found (Fig. 3). With both clone libraries a total of twelve green algal OTUs was detected and, as expected, both libraries were rather different in their OTU composition (Table 2). While just five green algal OTUs were recovered in the GOG biofilm library, nine were detected in the GOG crude culture library (Table 2). Interestingly, both libraries shared only two green algal OTUs, i.e. Apatococcus OTU 1 and Trebouxia OTU 10. Chloroidium OTU 8 was most dominant in the crude culture library (43 clones; Table 2). 

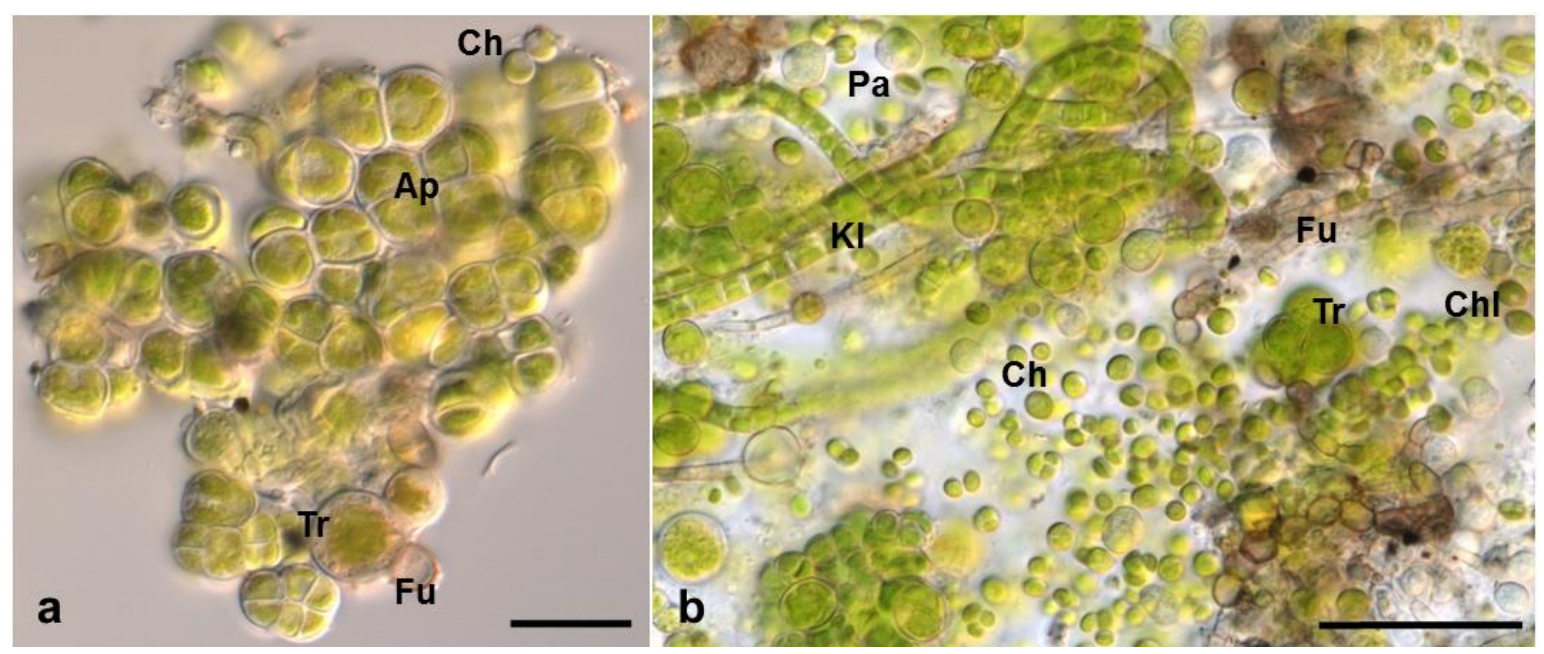

Fig. 2. Microscopy of the green biofilm at site GOG and crude culture developed from the same biofilm. (a) Biofilm sample with green algal morphotypes (Ap, Apatococcus; Ch, Chlorella-like; $\mathrm{Tr}$, Trebouxia) and fungal hyphae (Fu). Scale bar, $20 \mu \mathrm{m}$ (b) Crude culture with coccoid green algal morphotypes (Ch, Chlorella-like; Chl, Chloroidium; Pa, Pabia; Tr, Trebouxia), filaments of Klebsormidium (Kl) and fungi (Fu). Scale bar, $50 \mu \mathrm{m}$.

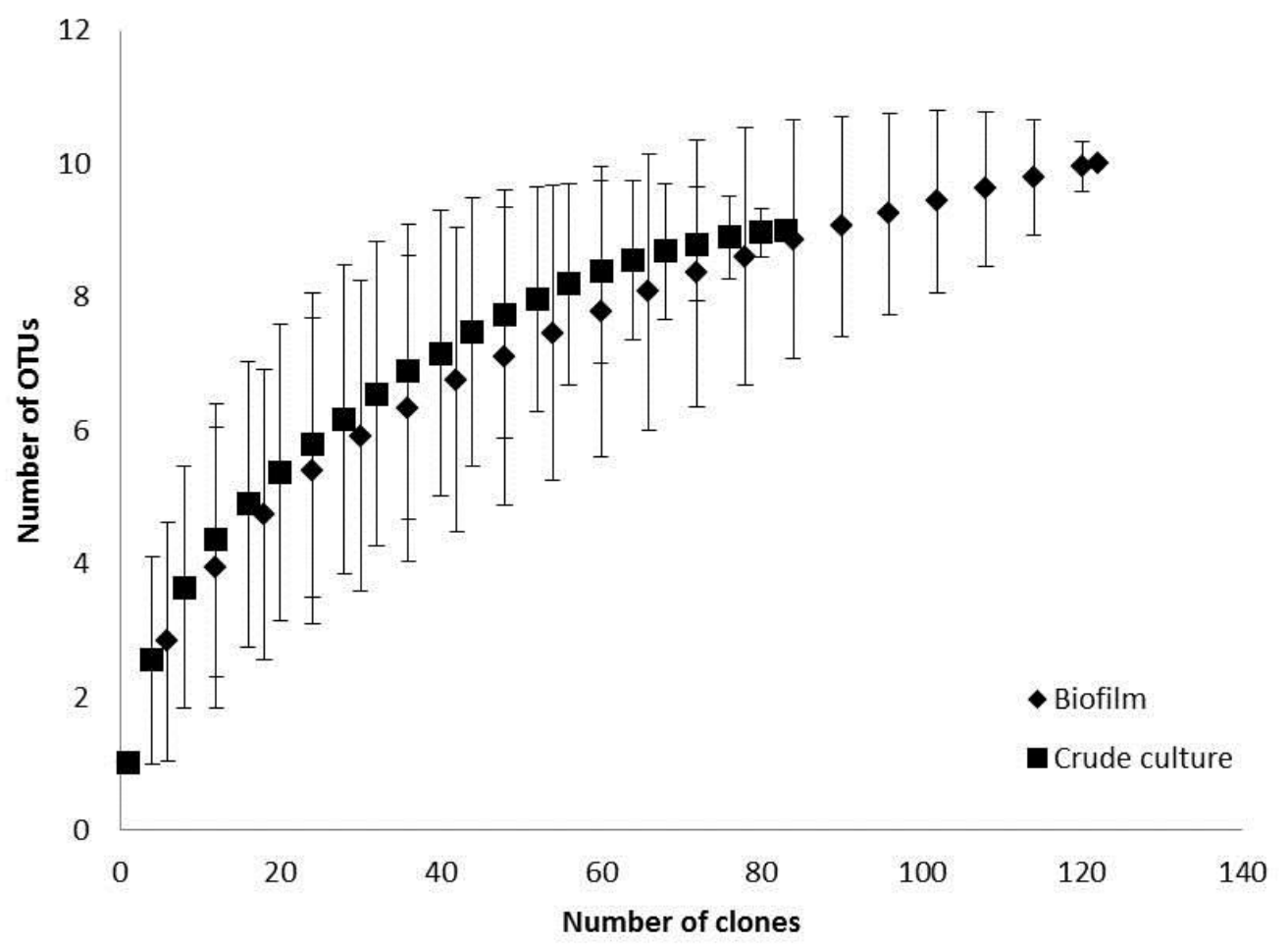

Fig. 3. Rarefaction curves for the $18 \mathrm{~S}$ rRNA gene clone libraries established from the biofilm material and the crude culture of site GOG. 
For a more reliable identification of the recovered green algae, for each OTU at least one almost full 18S rRNA gene sequence was determined. Using BLASTn the next closest neighboring available sequences (range of $99 \%$ to $100 \%$ from pairwise sequence similarities with the clones calculated from p-distances, see Table 2) were retrieved. In addition, five green algal strains, isolated from similar artificial substrates of urban environments as the GOG biofilm and available from the SAG culture collection, were sequenced and added to the data set of almost full 18S rRNA gene sequences (accession nos. KM116459 - KM116461, KM116463 and KM116465). From the latter data set of almost full 18S rRNA gene sequences OTUs (99\% sequence similarity threshold) were determined and a selection of sequences for each OTU was used for the phylogenetic analyses with a set of additional reference sequences (Table 2).

The biofilm algae were distributed on five distant groups (clades) of the Trebouxiophyceae (Fig. 4). For Apatococcus two OTUs were revealed which formed two clearly separated lineages in the $18 \mathrm{~S}$ rRNA gene phylogeny; it is tempting to suspect both represent two distinct species (Fig. 4). OTU 1 included A. lobatus SAG 2037 which, because no authentic strain for the species is available, may be used as a reliable reference for the species. The strain has morphologically been well characterized as strain ASIB G177 in Gärtner and Ingolić (1989) and compared with the iconotype (Petersen, 1928). Strain SAG 2359 which we isolated from the GOG biofilm represented the same OTU and also exhibited the same morphology as A. lobatus SAG 2037 (Fig. 5a). Both strains shared $99.9 \%$ pairwise sequence similarity with each other (Table 1), i.e. were different only in a single sequence position of the $18 \mathrm{~S}$ rRNA gene region V4.

For Apatococcus OTU 2 four almost full 18S rRNA gene sequences were determined and they had rather high similarities (99.6\% to $100 \%)$ with another reference strain, Apatococcus SAG 2151 (Table 2). For Trebouxia three OTUs were detected and they represented three independent lineages within the monophyletic clade representing the genus and, therefore, may represent three distinct species. OTU 5 was a close relative with the authentic strain of $T$. impressa, whereas OTUs 9 and 10 were closer related to the authentic strain of T. asymmetrica (Friedl and Gärtner, 1988) and a reference strain for T. arboricola (Gärtner, 1985). 


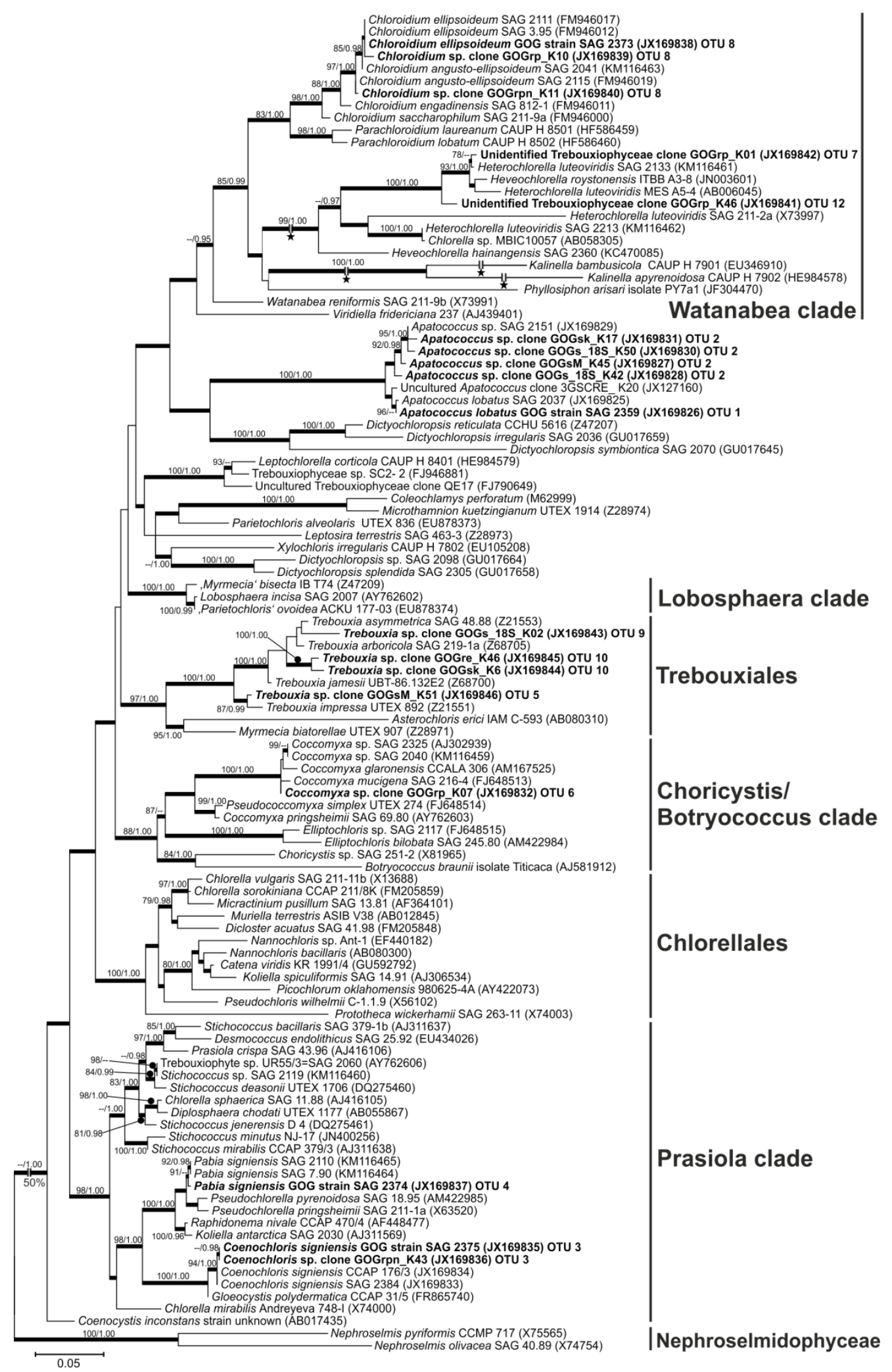

Fig. 4. Maximum-likelihood (ML) phylogeny of 18S rRNA gene sequences obtained from green biofilms using clone libraries and four isolates of the GOG exemplar site and other members of the Trebouxiophyceae, with members of Nephroselmidophyceae as outgroup taxa. Thick lines mark those internal branches which were received in both ML and Bayesian analyses (BI). Numbers at nodes correspond to ML bootstrap / BI posterior probabilities. Values only > $75 \%$ (bootstrap) or $>95 \%$ (posterior probabilities) are recorded. Asterisks mark those branches which were reduced to $50 \%$ in lengths for the graphic. 


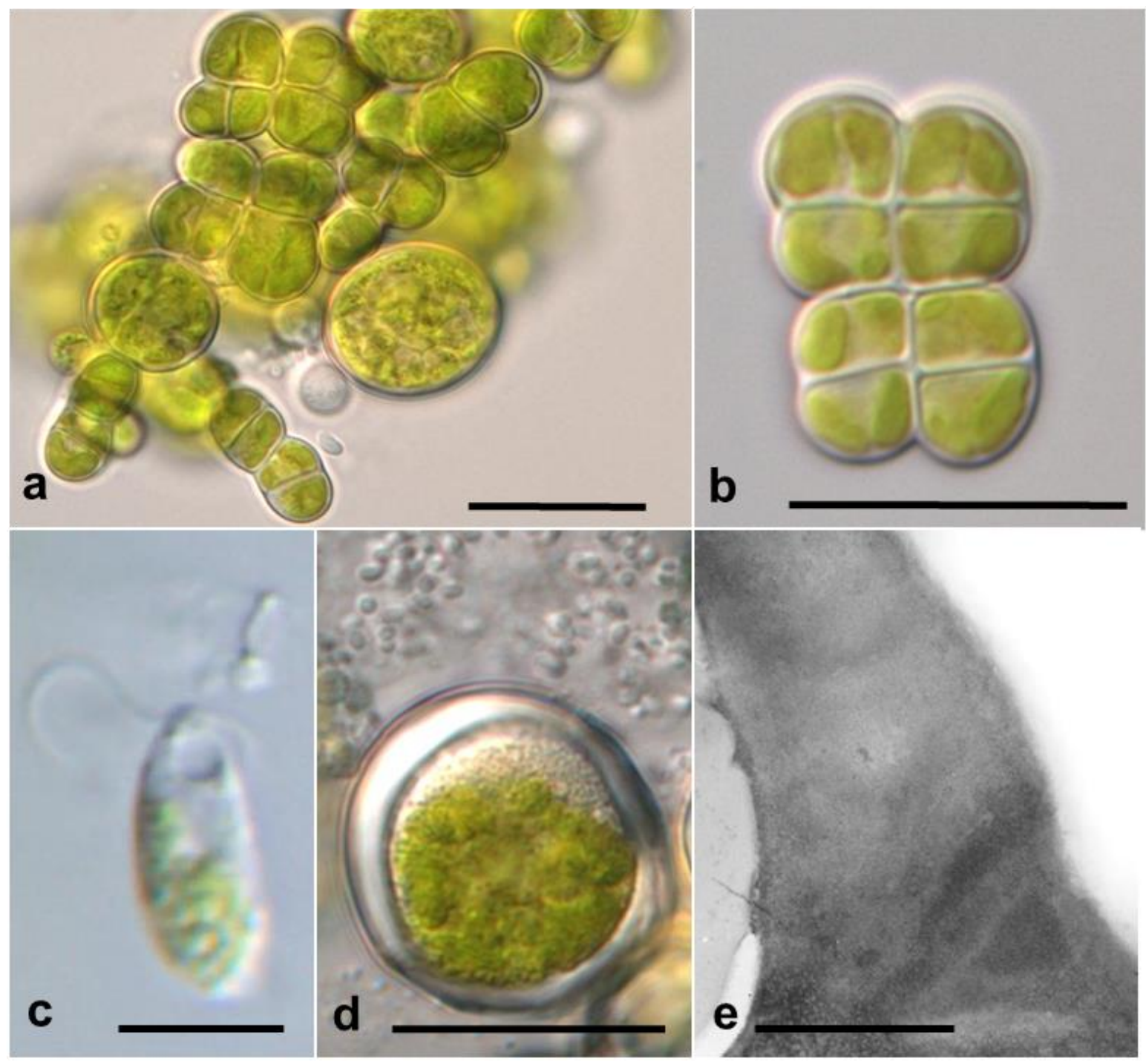

Fig. 5. Morphology of isolate Apatococcus lobatus SAG 2359 developed from the GOG study site. (a) Vegetative cells of various sizes. (b) Cell package. (c) Zoospore with two flagella and apical vacuole. (d) Cell with very thick wall of an old culture. (e) TEM detail of cell walls of two neighboring autospores. Scale bar, $0.5 \mu \mathrm{m}$ (e) or $5 \mu \mathrm{m}$ (c) or $20 \mu \mathrm{m}$ (a, b, d). 


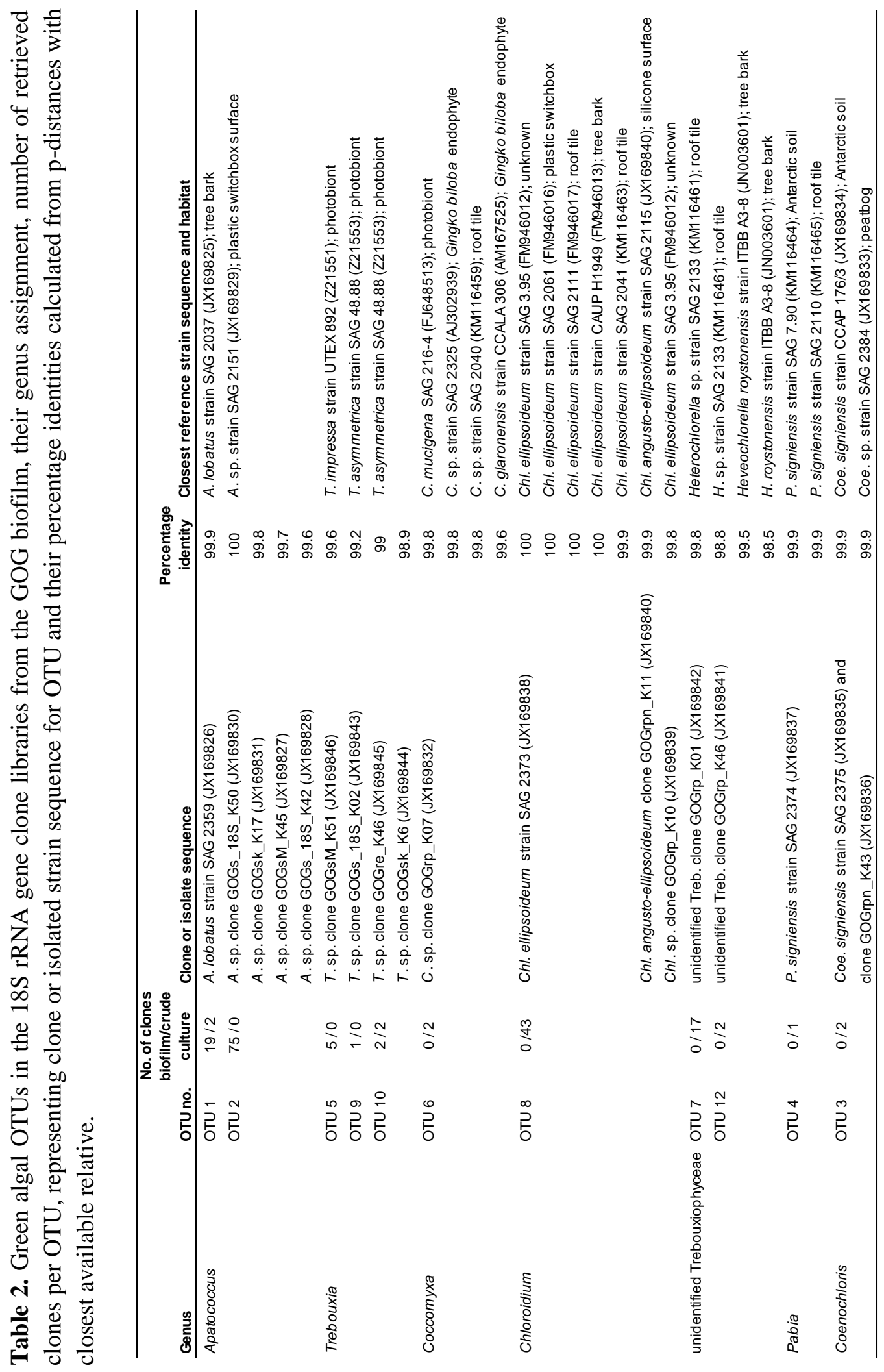


Six more OTUs, assigned to at least five different genera of Trebouxiophyceae, were retrieved only from the crude cultures. OTU 6 Coccomyxa sp. was represented as a wellsupported monophyletic lineage in the 18S rRNA gene phylogeny (Fig. 4). It included the authentic strain of $C$. mucigena SAG 216-4 which has been isolated from a lichen as well as several unidentified strains of Coccomyxa isolated from different terrestrial habitats, i.e. a roof tile (SAG 2040) and as an endophyte in Gingko biloba tissue (SAG 2325). Interestingly, the Coccomyxa was paraphyletic with Pseudococcomyxa within the Choricystis/Botryococcus-clade of the 18S rRNA gene phylogeny (Fig. 4).

Three more OTUs represented three independent lineages of the Watanabea-clade. OTU 8, represented by two clones and strain SAG 2373 isolated from the GOG biofilm, also included reference strains for species of Chloroidium, i.e. Chl. ellipsoideum SAG 3.95 (authentic strain) and Chl. angusto-ellipsoidea SAG 2115 (epitype strain; Darienko et al., 2010). Strain SAG 2373 exhibited $100 \%$ 18S rRNA gene sequence identity with strain SAG 3.95 and also had only a single sequence position different in the ITS2 rRNA gene with the latter strain. Therefore, strain SAG 2373 was assigned to Chl. ellipsoideum (Table 2). Strain SAG 2373 exhibited also very high 18S and ITS2 rRNA gene sequence similarities (100\% and $99.9 \%$ ) with strains isolated from similar habitats, i.e. an airexposed plastic surface in an urban environment (SAG 2061), a roof tile from a building in the close vicinity of GOG (SAG 2111), but also from tree bark (CAUP H 1949). There was even a $100 \%$ ITS 2 rRNA gene sequence identity with a strain isolated from a freshwater pond in Japan, SAG 2140. Clone GOGrpn_K11 (JX169840) from the crude culture library had $99.9 \%$ 18S rRNA gene sequence similarity with the epitype strain of C. angustoellipsoideum SAG 2115 which was isolated from a similar urban habitat in the close vicinity of GOG, but $99.7 \%$ with Chl. ellipsoideum SAG 3.95 and, therefore, was assigned to the former species. Clone K10 (JX169839) had genetic similarities with the C. angustoellipsoideum and Chl. ellipsoideum reference strains shorter than $99.9 \%(99.5 \%$ and $99.8 \%$ ) and, therefore, may represent an independent species of Chloroidium.

The crude culture clones representing OTU 7 and OTU 12 were within a wellsupported monophyletic lineage within the Watanabea-clade of the 18S rRNA gene phylogeny which also included strains assigned to Heterochlorella luteoviridis and Heveochlorella roystonensis (Fig. 4). Because the authentic strain of $H$. luteoviridis SAG 211-2a was not included into this lineage and rather represented an independent lineage of the Watanabea-clade, the lineage may not represent $H$. luteoviridis. Heterochlorella is paraphyletic with Heveochlorella in the 18S rRNA gene phylogenies, i.e. the authentic 
strain of the type of Heveochlorella, $H$. hainangensis, and the strain representing $H$. roystonensis did not form a monophyletic lineage either, but were separated from each other on rather distant lineages within the Watanabea-clade (Fig. 4). Therefore, no species and generic assignments are yet possible for OTU 7 and OTU 12 and we refer them to "unidentified Trebouxiophyceae" (Tables 1 and 2) here. Based on 18S rRNA gene genetic distances and phylogenetic relationships, their closest relatives were strains isolated from a roof tile, SAG 2133, and from tree bark, $H$. roystonensis, as well as a strain of unknown origin (MES A5-4).

OTU 3 and OTU 4 represented two independent lineages within the distant Prasiolaclade of Trebouxiophyceae (Fig. 4). They were related to species which form spherical cells with mucilage which in traditional green algal systematics were assigned to the family Radiococcaceae (Kostikov et al., 2002). Strain SAG 2374 (OTU 4) isolated from the study site exhibited this morphotype (Fig. 6a). It had a $18 \mathrm{~S}$ rRNA gene sequence similarity of $99.9 \%$, corresponding to two positions different in the $18 \mathrm{~S}$ rRNA gene V4 region, with strain Pabia signiensis SAG 7.90 which is the authentic strain of the type species of the genus (Friedl and O'Kelly, 2002) and, therefore, is assigned to this species. Interestingly, strain SAG 7.90 has been isolated from soil in Antarctica (isolated by PA Broady, 1979).
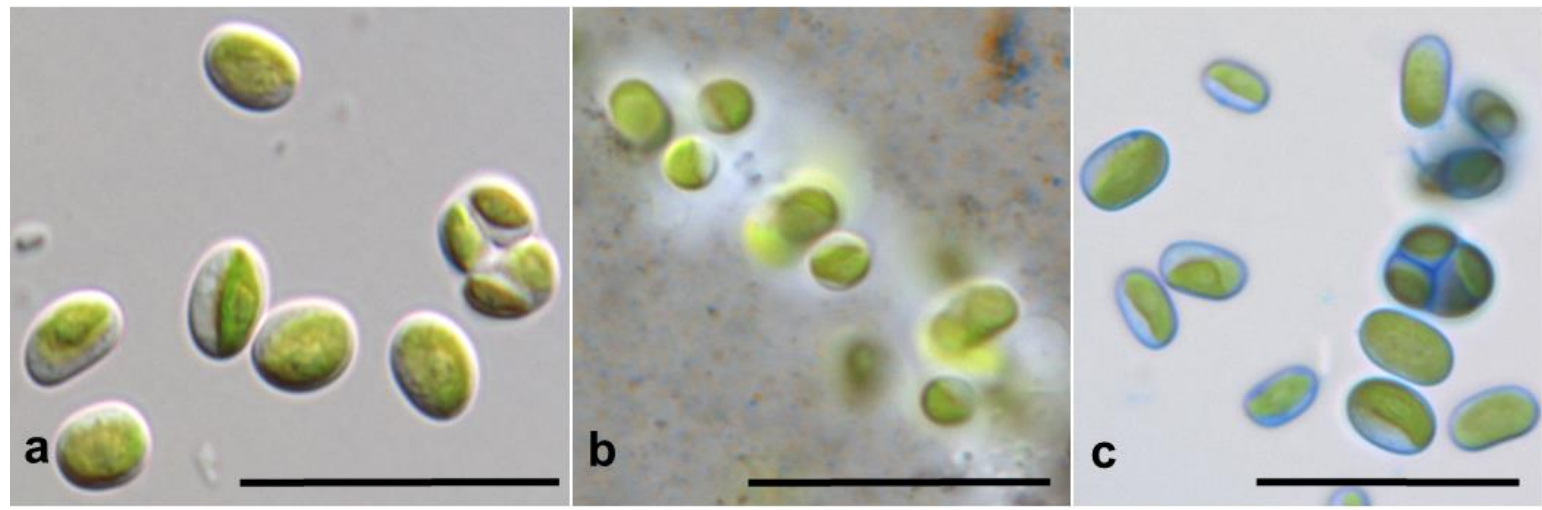

Fig. 6. Morphology of isolate Pabia signiensis SAG 2374 developed from the GOG study site. (a) Vegetative cells and autosporangia. (b) Mucilage after negative staining with indian ink. (c) Vegetative cells after staining with methylene blue. Scale bars, $20 \mu \mathrm{m}$. 
Strain SAG 2374 had the same high 18S rRNA gene similarity with strain SAG 2110 which has been isolated from a roof tile of a building in the close vicinity of GOG. At the ITS2 rRNA gene level, strain SAG 2374 had eight and nine sequence positions different with strains SAG 7.90 and SAG 2210. OTU 3 was represented by two identical 18S rRNA gene sequences which were from an isolate from GOG, SAG 2375, and a crude culture clone (Table 2; Fig. 4). Both had $99.9 \%$ pairwise 18S rRNA gene sequence similarity, corresponding to a single sequence difference in the V4 region with the authentic strain of the Coenochloris signiensis CCAP 176/3 and, therefore, the OTU was assigned to this species. Again, also the reference strain CCAP 176/3 has been isolated from Antarctica (by PA Broady, 1973; www.ccap.ac.uk). Strain SAG 2375 shared a $99.9 \%$ sequence similarity with so far unidentified strain SAG 2384 and, therefore, also the latter strain is assigned to Coe. signiensis here. At the level of ITS2 rRNA gene sequences, there were 18 differences between strains SAG 2375 and SAG 2384. An environmental unidentified clone from a glacier forefield in the Alps (sequence JX435389) was with just 10 ITS2 sequence differences the closest relative with strain SAG 2375.

\section{Microscopy of biofilm isolates}

Unialgal cultures from the GOG biofilm could be established for four OTUs (Table 2). Strain A. lobatus SAG 2359 formed packages of thick-walled cells which were about 9-11 $\mu \mathrm{m}$ in diameter, autosporangia (cell packages) were up to $20 \mu \mathrm{m}$ in size (Fig. 5a, b).

The formation of zoospores in cultures of about two weeks old was also frequently observed, despite zoospore formation in Apatococcus has been reported only rarely so far (e.g. Gärtner and Ingolić, 1989). The zoospores were 6-7 $\mu \mathrm{m}$ in length, with two flagella and an apical vacuole, but without a stigma (Fig. 5c). Vegetative cells were covered by remnants of sporangial walls or were rather thick which was particularly frequently seen in old cultures (Fig. 5d). Transmission electron microscopy (TEM) depicted thick cell walls of about $1 \mu \mathrm{m}$ (Fig. 5e).

Two strains represented the Radiococcaceae morphotype and were characterized by conspicuous formation of mucilage on agar plates, i.e. P. signiensis SAG 2374 (Fig. 6) and Coe. signiensis SAG 2375 (Fig. 7). SAG 2374 formed mostly ellipsoidal cells of 3-6 $\mu \mathrm{m}$, chloroplasts containing a pyrenoid (Fig. 6a). The vegetative cells of SAG 2375 were ellipsoidal when young, later becoming spherical and were 3.5-12 $\mu \mathrm{m}$ in diameter (Fig. 7). The chloroplast was band-shaped with a pyrenoid (Fig. 7a). They formed 2-4 ellipsoidal autospores per cell, the cell division was oblique. 


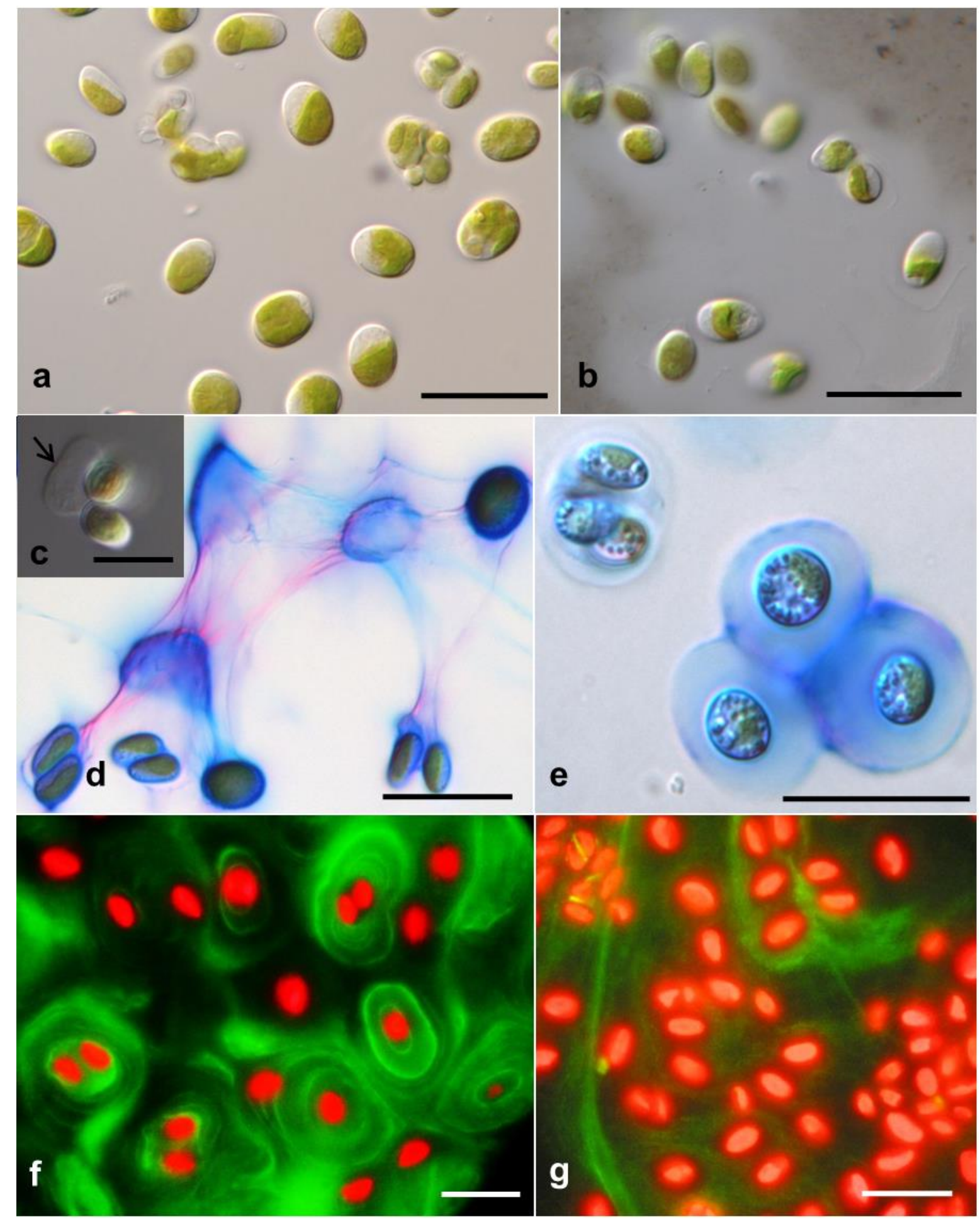

Fig. 7. Morphology of isolate Coenochloris signiensis SAG 2375 developed from the GOG study site. (a) Vegetative cells with smooth chloroplasts. (b) Mucilage after negative staining with indian ink. (c) Remnants of mother cell walls (arrow). (d) Vegetative cells with mucilage in young culture after staining with methylene blue. (e) Vegetative cells with mucilage in an old culture after staining with methylene blue. (f) Xenic culture, cells forming mucilage capsules. Green, Concanavalin A FITC conjugated stain; Red, autofluorescence of chlorophyll. (g) Axenic culture with loose mucilage. Green, Concanavalin A FITC conjugated stain; Red, autofluorescence of chlorophyll. Scale bar $5 \mu \mathrm{m}$ (c) or $20 \mu \mathrm{m}$ (a, b, d-g). 
Remnants of sporangal walls sticked to vegetative cells were often observed (Fig. 7c). Both isolates produced exopolymer matrices on agar plates, although the $P$. signiensis SAG 2374 matrix appeared to be thinner and less rigid (Fig. 6b, c) than that of the Coe. signiensis SAG 2375 matrix (Fig. 7b-e). The latter could be identified as an exopolysaccharide (EPS), since Concanavalin A staining was positive (Fig. 7f, g). By this way, also concentric layers of different fluorescent intensities could be observed in older and xenic cultures (Fig. 7g), which are also typical for rigid exopolymer matrices. Interestingly, this feature could not be observed in axenic culture (Fig. 7f). Strain Chl. ellipsoideum SAG 2373 showed ellipsoidal cells, 4-9 $\mu \mathrm{m}$ in diameter, with lobed chloroplasts containing a pyrenoid (Fig. 8). The strain exhibited no special cell wall features as depicted by TEM (Fig. 8b, c).
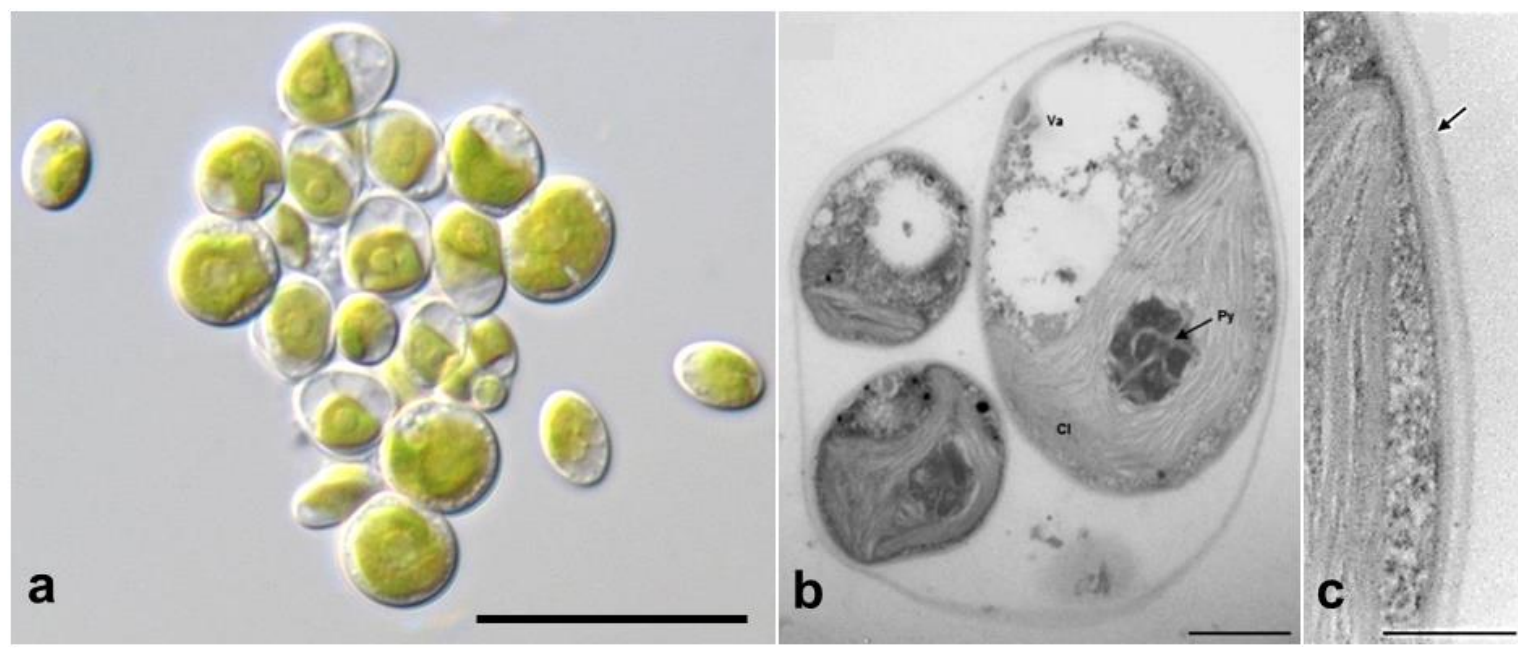

Fig. 8. Morphology of isolate Chloroidium ellipsoideum SAG 2373 developed from the GOG study site. (a) Vegetative cells and autosporangia. (b) TEM section of autosporangium. Cl, chloroplast; Py, pyrenoid; Va, vacuole. (c) TEM detail of thin cell wall of the autosporangium (arrow), close up of image (b). Scale bar, $0.5 \mu \mathrm{m}$ (b, c) or $20 \mu \mathrm{m}$ (a). 


\section{Discussion}

Our study focused on eleven sites providing air-exposed surfaces of various artificial substrates for green phototrophic biofilms, ten sites were open dry air- and sun exposed higher than $1.5 \mathrm{~m}$ above the ground. These sites represent a particular type of green algal dominated biofilms, common in urban areas of Middle Europe, allowing a case study in order to assess the algal diversity of these biofilms, despite the number of investigated sites was still small and the study sites were within short distances of a single mid-sized town. All green biofilms were dominated by cell packages-forming green algae, which in previous works have been assigned to "Apatococcus and/or Desmococcus" or the Pleurococcetum community of aeroterrestrial green algae (e.g. Rindi, 2007). Our study using 18S rRNA gene clone libraries established from the dry biofilms without culturing clearly showed the biofilms being dominated by Apatococcus with Trebouxia as the second most abundant green algae, whereas Desmococcus was not detected. Although difficult to distinguish by microscopy (e.g. Gärtner, 1994; Lüttge and Büdel, 2010; Rindi, 2011), both genera are phylogenetically clearly separated from each other within the Trebouxiophyceae. Apatococcus forms a lineage by its own, i.e. there is no support for a closer relationship with another lineage of Trebouxiophyceae, although in some analyses a sister-group relationship with species of Dictyochloropsis and even the Watanabea-clade has been resolved, but without support in significance tests (Fig. 4; Hallmann et al., 2013a, 2013b; Neustupa et al., 2013). The analyses here substantiate this phylogenetic position with eight almost full 18S rRNA gene sequences from Apatococcus strains/clones of various origins. In contrast, strains of Desmococcus assume a position within the Prasiolaclade (Fig. 4; Mikhailyuk et al., 2008; Hallmann et al., 2013a).

The dominating Apatococcus in the dry sun-exposed biofilms is not just a single species, A. lobatus (Gärtner and Ingolić, 1989), but may consist of several species of Apatococcus which can be separated by the 18S and ITS2 rRNA gene sequence analyses. Two OTUs representing two distinct species of Apatococcus were retrieved from the GOG site with the biofilm clone libraries and they form two distinct lineages in the 18S rRNA gene phylogenies (Fig. 4). Partial 18S rRNA gene sequences identical to those from both Apatococcus OTUs at GOG were retrieved from five other studied sites (DZG16, SKL, GSW, GLG and GLB), three of the sites (DZG16, GLG and GLB) exhibited even another additional type of Apatococcus partial sequence. Only from three sites (EGU, GWW and SK) just a single Apatococcus sequence type, corresponding neither to OTU 1 nor OTU 2 
were retrieved. The two OTUs of Apatococcus discriminated in the biofilm study here correspond to an earlier finding (Hallmann et al., 2013b).

Similarly, also three OTUs or species of Trebouxia were recovered from the GOG biofilm clone libraries (Table 1) and, as far as the sequence comparisons with the reference sequences for these OTUs (Table 2) allows at least two of them were found at two other study sites as well, SK and GWS. For identification of the Trebouxia OTUs to species level the 18S rRNA gene sequence comparisons may, however, not be sufficient and ITS rRNA gene sequences be required, also because there is a large number of ITS rRNA gene sequences for the various species of Trebouxia available (e.g. Ruprecht et al., 2014). Apart from species of Apatocococcus and Trebouxia various filamentous fungi were recovered from the biofilm clone libraries of the sun-exposed sites in relatively high abundances. These fungi may live embedded together with the green algae in an exopolymeric matrix produced by the biofilm organisms.

Several fungi detected here may occur as lichen mycobionts, e.g. close relatives of Heterodea muelleri were retrieved (Wedin et al., 2000). Therefore, young inconspicuous initial stages of lichens or small lichen propagules consisting of both symbionts may have introduced the Trebouxia species (OTUs) into the biofilms although no detectable lichen thalli were found at the sampling sites. The Trebouxia cells in the biofilms might not have necessarily been free-living (Ahmadjian, 1988). Trebouxia has already been frequently described in terrestrial habitats, even when identifiable lichens were absent (e.g. Gärtner, 1994; Macedo et al., 2009). Also other microfungi not known as lichen-forming were detected, i.e. the Hyphozyma-related clones may represent free-living yeast-like hyphomycetes (De Hoog and Smith, 1986). The GOG biofilm clone library revealed a high abundance of the ascomycete Glyphium elatum which is known to develop peculiar black ascomata on tree bark, but has also been reported from chemically treated marble surfaces (Cappitelli et al., 2007). Although the biodegradability of high density polyethylene (HDPE), the substrate at the GOG site, by molds has been reported (Albertsson et al., 1978), it is more likely that the Glyphium-related fungi detected in the green biofilms use the green algae as a more convenient substrate. The relatively high number of retrieved Glyphium clones also makes it rather unlikely that our sample taken from GOG was just contaminated by allochthonous Glyphium mycelia.

The presence of just a few organisms but in relatively high abundances as observed for the studied biofilms may indicate an extreme habitat with life conditions favorable to only a small selection of algae. Also, the substrate surfaces at all our study sites have been 
exposed for a long time, i.e. since several years, to the environment and, therefore, the biofilm may not consist of just transient "pioneer" colonizers. For example, the substrate of our exemplar study site, GOG, represents a chemically inert material, i.e. high density polyethylene (HDPE), which is rather hydrophobic, with a slightly negative water contact angle (Vogler, 1998). HDPE is a very abundant plastic material out of which numerous different products such as bins, tubes, signboards or street furniture which all can frequently be covered by green phototrophic biofilms are manufactured. HDPE provides a smooth, inert surface, which may be less favorable for colonization than natural surfaces such as stone or tree bark. Water on dry plastic material is less available since it does not penetrate the surface via small pores and ducts like on tree bark or natural stone. Although liquid water after rainfall provides a thin water film which may cover the biofilm on a horizontal face for even a longer time period than on a porous surface, no moisture from underlying material will be available to the biofilm. HDPE shows a low biodegradability (Fontanella et al., 2010) presenting a "neutral" substrate to adhering organisms without providing minerals and trace ions but also being non-toxic.

In concordance with regarding the exemplar site GOG as well as the other studied sites as extreme habitats is that two species, Coenochloris signiensis and Pabia signiensis, so far reported from the very harsh climate of Antarctica, have been found as colonizers of the sun-exposed dry biofilms (Tables 1,2 ).

Our isolates established from the exemplar site GOG may exhibit some features which may be regarded as particular adaptation to their extreme habitat. The formation of thick cell walls of Apatococcus as seen by microscopy of the studied biofilms or in old cultures (e.g. the isolate from GOG, SAG 2359) may serve as an adaption to desiccation concurrent with high temperature amplitudes and UV-irradiation (Karsten et al., 2005a).

The isolates of Coenochloris signiensis and Pabia signiensis from GOG, SAG 2375 and SAG 2374, produced exopolymer matrices that appear to be functional in rather hydrated conditions on agar plates and in liquid cultures. However, no indication for a protective function of the EPS could be found upon drying and UV-irradiation, a feature that has been described for typical aeroterrestrial algae and cyanobacteria with rigid capsules (Wynn-Williams et al., 1997; Kemmling et al., 2004). In an aqueous habitat (or on a fully hydrated substratum like agar), the EPS may act as an adhesive between cells and mediate the attachment to the substrate. Induction of exopolysaccharide formation in bacterial biofilms has been observed frequently, e.g. by quorum sensing (e.g. Sakuragi and Kolter, 2007). For eukaryotes, the phenomenon has so far mostly been described only for 
the interaction between symbiotic nitrogen-fixing bacteria and higher plants (e.g. Marketon et al., 2003), but one example for the secretion of EPS upon co-culturing with distinct $E$. coli strains has been described for the diatom Phaeodactylum tricornutum (Bruckner et al., 2011). Chloroidium isolate SAG 2373 had no visible adaptive structures to extreme environments, i.e. neither thick cell walls nor mucilage was observed. However, an unusual constitutive carbohydrate composition including the presence of polyols, e.g. ribitol, has been reported for Chloroidium strains and considered as effective stress metabolites (Darienko et al., 2010; Gustavs et al., 2011).

Six OTUs or species from at least five genera of Trebouxiophyceae were recovered exclusively in the clone library developed from crude cultures of the biofilm from the exemplar site GOG (Table 2). Though it may be expected that microbial diversity changes upon culturing, this feature has hitherto rarely been described for algae (Guillou et al., 2004; Miller et al., 2008; Hallmann et al., 2011). Various green algae, also those not from air-exposed habitats, can form drought-resistant dormant stages (Lennon and Jones, 2011) and could have been detected by our culture approach. However, except for Coenochloris signiensis, representatives of the other four genera were also retrieved from the biofilm libraries without culturing (Table 1). This together with the fact that all species detected in the crude culture clone library are common species of air-exposed habitats evidences that they do not represent just a small "seed bank" (Lennon and Jones, 2011; Hallmann et al., 2013a) of diverse algae which were just drifted onto the biofilm surfaces without actually being active members within the biofilms. In addition, four of the species found in crude culture have their closest relatives with isolates from habitats similar to the study sites (SAG 2040, SAG 2041, SAG 2110, SAG 2115 and SAG 2133; Table 2, Fig. 4). That these species were absent or mostly found with a single clone in the biofilm libraries without culturing may be simply due to that the Apatococcus/Trebouxia DNA was so abundant in the biofilm extractions that DNA of almost no other algae could become amplified. We experienced that establishing cultures of Apatococcus using standard methods was less successful than for most other terrestrial green algae and, therefore, the development of Apatococcus may have been suppressed in the liquid crude cultures, at the same time favoring the development of the other green algae already present in the biofilm. Also, the number of sequenced clones per biofilm library (21-102; Table 1) may still have been not sufficient to detect other green algae although the rarefaction analysis of the GOG biofilm clones indicated almost full coverage of the library (Fig. 3). Fungi could not be retrieved 
from liquid crude cultures. Though also oligotrophic fungi may be present as saprophytes in algal cultures, liquid cultures are less favorable for fungal growth.

Probably due to constraints of the extreme habitat the biofilm green algae exhibited a high degree of morphological uniformity which, however, belied a variety of distinct genotypes or species which cannot be discerned by microscopy of the biofilms. Similarly to Apatococcus and Trebouxia, our sequence analyses of the crude cultures from exemplar site GOG revealed at least two species, C. ellipsoideum and C. angusto-ellipsoideum, cooccuring in the same biofilm. Species of Chloroidium are rather common in aeroterrestrial habitats (Darienko et al., 2010) with previously being reported from light microscopic studies of biofilms as a single species, "Chlorella trebouxioides" (e.g. Lüttge and Büdel, 2010).

The unidentified trebouxiophyte of the Watanabea-clade (previously assigned to Heterochlorella, see below) from GOG was present in two lineages (OTUs) and also our isolates of Coenochloris signiensis and Pabia signiensis from GOG were different at the rRNA gene level from previous isolates of the same species (Table 2). This "cryptic" (genetic) diversity may also be an adaptive feature of the algal community to the extreme biofilm habitat. Finally, the finding of genetic diversity in both the latter species is not in concordance with the classical tenet which says "Everything is everywhere, but, the environment selects" (Baas Becking, 1934; De Wit and Bouvier, 2006), but congruent with a similar finding of the same terrestrial microalgae species being distributed in Antarctica and temperate regions, but present as different "subpopulations" which previously has been reported for the Xanthophyceae (Stramenopiles, Rybalka et al., 2009, 2013).

Despite the biodiversity of green algae in the studied biofilms may have been low, i.e. no more than 11 OTUs or species of Trebouxiophyceae (Chlorophyta) were revealed in our study, also species or even genera so far not represented in molecular-phylogenetic analyses or even representing so far undescribed new taxa were found. OTUs 7 and 12 may represent two distinct species of a still undescribed genus, OTU 12 even a species at least so far not recovered in molecular phylogenetic analyses. OTU 7 may correspond to Heveochlorella roystonensis, together with other strains isolated from terrestrial habitats previously assigned to $H$. luteoviridis, because of their very close relatedness in the $18 \mathrm{~S}$ rRNA gene phylogenies (Fig. 4; Table 2). However, H. roystonenis is not only distantly related within the Watanabea-clade to the type of Heterochlorella, Het. luteoviridis with SAG 211-2a as authentic strain, but also to the type of Heveochlorella which is H. hainangensis (Fig. 4; Zhang et al., 2008). The species needs to be transferred to another 
genus. The finding of very close relatives of $H$. roystonenis in the exemplar GOG biofilm again supports a world-wide distribution of terrestrial green algae (Hodač et al., 2012); H. roystonenis has been reported only from tropical China so far (Ma et al., 2013).

The still unidentified species of Coccomyxa from the biofilms with no named closer related strain available yet, represented by our OTU 10 and two isolates from similar habitats, strains SAG 2040 and SAG 2325, was found as a close relative with lichen photobionts in the 18S rRNA gene phylogenies. Coccomyxa in its present circumscription was revealed not as a monophyletic lineage; rather it was separated into two phylogenetically distinct but related monophyletic lineages (Fig. 4). Zoller and Lutzoni (2002) showed that there are two distinct lineages of Coccomyxa, one including lichen photobionts and the other with only free-living non-symbiotic species. It is also likely that Coccomyxa OTU 10 was introduced by lichen propagules or initial stages, similar to the species of Trebouxia recovered from the studied biofilms.

\section{Acknowledgements}

This work was supported by grants from Deutsche Forschungsgemeinschaft to T. F. and Ulf Karsten (DFG FR 905/14-1). We thank Ilse Kunkel for purification of isolates obtained in this study, Maike Lorenz for valuable comments and the deposition of cultures to the SAG culture collection as well as Imke Lang and Elke Zufall-Roth for provision of reference sequences. We are indebted to Tatyana Darienko for helpful comments and interpretation of light microscopy.

\section{References}

Agardh, C.A. (1824) Systema Algarum. Lundae Literis Berlingianis, Lund.

Albertsson, A.C., Bándhidi, Z.G. and Beyer-Ericsson, L.L. (1978) Biodegradation of synthetic polymers. III. The liberation of ${ }^{14} \mathrm{CO}_{2}$ by molds like Fusarium redolens from ${ }^{14} \mathrm{C}$-labeled pulverized high-density polyethylene. J Appl Polym Sci 22: 3435-3447.

Altschul, S.F., Gish, W., Meyers, E.W. and Lipman, D.J. (1990) Basic local alignment search tool. J Mol Biol 215: 403-410.

Ahmadjian, V. (1988) The lichen alga Trebouxia: does it occur free-living? Plant Syst Evol 158: 243-247.

Baas Becking, L.G.M. (1934) Geobiologie of inleiding tot de milieukunde. The Hague, the Netherlands: W.P. Van Stockum and Zoon (in Dutch).

Büdel, B., Darienko, T., Deutschewitz, K., Dojani, S., Friedl, T., et al. (2009) Southern African Biological Soil Crusts are ubiquitous and highly diverse in drylands, being restricted by rainfall frequency. Microb Ecol 57: 229-47. 
Bruckner, C.G., Rehm, C., Grossart, H.P. and Kroth, P.G. (2011) Growth and release of extracellular organic compounds by benthic diatoms depend on interactions with bacteria. Environ Microbiol 13: 1052-1063.

Cappitelli, F., Nosanchuk, J.D., Casadevall, A., Tomiolo, L., Bruscetti, L., et al. (2007) Synthetic consolidants attacked by melanin-producing fungi: Case study of the biodeterioration of Milan (Italy) cathedral marble treated with acrylics. Appl Environ Microbiol 73: 271-277.

Cappitelli, F. and Sorlini, C. (2008) Microorganisms attack synthetic polymers in items representing our cultural heritage. Appl Environ Microbiol 74: 564-569.

Cuzman, O.A., Ventura, S., Sili, C., Mascalchi, C., Turchetti, T., et al. (2010) Biodiversity of phototrophic biofilms dwelling on monumental fountains. Microb Ecol 60: 81-95.

Darienko, T. and Hoffmann, L. (2003) Algal growth on cultural monuments in Ukraine. Biologia 58: $587-587$.

Darienko, T., Gustavs, L., Mudimu, O., Menendez, C.R., Schumann, R., et al. (2010) Chloroidium, a common terrestrial coccoid green alga previously assigned to Chlorella (Trebouxiophyceae, Chlorophyta). Eur J Phycol 45: 79-95.

De Hoog, G.S. and Smith, M.T.H. (1986) Key to the species of Hyphozyma (yeast-like Hyphomycetes) and description of $H$. roseonigra sp. nov. Antonie van Leeuwenhoek 52: 39-44.

De Wit, R. and Bouvier, T. (2006) 'Everything is everywhere, but, the environment selects'; what did Baas Becking and Beijerinck really say? Environ Microbiol 8: 755-758.

Ettl, H. and Gärtner, G. (1995) Syllabus der Boden-, Luft und Flechtenalgen. Gustav Fischer Verlag, Stuttgart.

Fontanella, S., Bonhomme, S., Koutny, M., Husarova, L., Brusson, J.M., et al. (2010) Comparison of the biodegradability of various polyethylene films containing pro-oxidant additives. Polym Degrad Stab 95: 1011-1021.

Friedl, T. and Gärtner, G. (1988) Trebouxia (Pleurastrales, Chlorophyta) as a phycobiont in the lichen genus Diploschistes. Arch Protistenkd 135: 147-158.

Friedl, T. (1996) Evolution of the polyphyletic genus Pleurastrum (Chlorophyta): inference from nuclear-encoded ribosomal DNA sequences and motile cell ultrastructure. Phycologia 35: 456-469.

Friedl, T. and O'Kelly, C.J. (2002) Phylogenetic relationships of green algae assigned to the genus Planophila (Chlorophyta): evidence from 18S rDNA sequence data and ultrastructure. Eur $J$ Phycol 37: 373-384.

Gärtner, G. (1985) Die Gattung Trebouxia Puymaly (Chlorellales, Chlorophyceae). Arch Hydrobiol Suppl Algol Stud 41: 495-548.

Gärtner, G. and Ingolić, E. (1989) Ein Beitrag zur Kenntnis von Apatococcus lobatus (Chlorophyta, Chaetophorales, Leptosiroideae). Plant Syst Evol 164: 133-143.

Gärtner, G. (1994) Zur Taxonomie aerophiler grüner Algenanflüge an Baumrinden. Berichte des Naturwissenschaftlich-medizinischen Vereins in Innsbruck 81: 51-59.

Guillou, L., Eikrem, W., Chrétiennot-Dinet, M.J., Le Gall, F., Massana, R., et al. (2004) Diversity of picoplanktonic prasinophytes assessed by direct nuclear SSU rDNA sequencing of environmental samples and novel isolates retrieved from oceanic and coastal marine ecosystems. Protist 155: 193-214.

Gorbushina, A.A. (2007) Life on the rocks. Environ Microbiol 9: 1613-1631.

Gustavs, L., Görs, M. and Karsten, U. (2011) Polyol patterns in biofilm-forming aeroterrestrial green algae (trebouxiophyceae, Chlorophyta). J Phycol 47: 533-537.

Hall, T.A. (1999) BioEdit: a user-friendly biological sequence alignment editor and analysis program for Windows 95/98/NT. Nucl Acids Symp Ser 41: 95-98. 
Hallmann, C., Rüdrich, J., Enseleit, M., Friedl, T. and Hoppert, M. (2011) Microbial diversity on a marble monument: a case study. Environ Earth Sci 63: 1701-1711.

Hallmann, C., Stannek, L., Fritzlar, D., Hause-Reitner, D., Friedl, T. and Hoppert, M. (2013a) Molecular diversity of phototrophic biofilms on building stone. FEMS Microbiol Ecol 84: 355-372.

Hallmann, C., Wedekind, W., Hause-Reitner, D. and Hoppert, M. (2013b) Cryptogam covers on sepulchral monuments and re-colonization of a marble surface after cleaning. Environ Earth Sci 69: 1149-1160.

Hallmann, C., Friedenberger, H., Hause-Reitner, D. and Hoppert, M. (2015) Depth profiles of microbial colonization in sandstones. Geomicrobiol J 32: 365-379.

Hamby, R.K., Sims, L., Issel, L. and Zimmer, E. (1988) Direct ribosomal RNA sequencing: optimization of extraction and sequencing methods for work with higher plants. Plant Mol Biol Rep 6: 175-192.

Hepperle, D. (2004) SeqAssem®. A sequence analysis tool, counting assembler and trace data visualization tool for molecular sequences. Win32-Version. Distributed by the author via: http://www.seqeuntix.de.

Hodač, L., Hallmann, C, Rosenkranz, H., Faßhauer, F. and Friedl, T. (2012) Molecular evidence for the wide distribution of two lineages of terrestrial green algae (Chlorophyta) over tropics to temperate zone. ISRN Ecol 2012: 795924.

Holzinger, A. and Karsten, U. (2013) Desiccation stress and tolerance in green algae: consequences for ultrastructure, physiological, and molecular mechanisms. Front Plant Sci 4 article 327.

Hoppert, M. and Holzenburg, A. (1998) Electron Microscopy in Microbiology. Bios-Springer in association with the Royal Microscopical Society, Oxford, UK.

Hoppert, M. (2003) Microscopic techniques in biotechnology. Wiley-VCH, Weinheim, Germany.

Hoppert, M., König, S. and Hegermann, J. (2005) Mikroalgen auf Oberflächen von Baumaterialien. Zeitschrift der Deutschen Gesellschaft für Geowissenschaften 156: 93-101.

Horath, T. and Bachofen, R. (2009) Molecular characterization of an endolithic microbial community in dolomite rock in the central Alps (Switzerland). Microb Ecol 58: 290-306.

Huber, T., Faulkner, G. and Hugenholtz, P. (2004) Bellerophon; a program to detect chimeric sequences in multiple sequence alignments. Bioinformatics 20: 2317-2319.

Huelsenbeck, J.P. and Ronquist, F. (2001) MRBAYSE: Bayesian inference of phylogenetic trees. Bioinformatics 17: 754-755.

Katoh, K. and Toh, H. (2008) Recent developments in the MAFFT multiple sequence alignment program. Brief Bioinform 9: 286-298.

Karsten, U., Schumann, R., Häubner, N. and Friedl, T. (2005a) Lebensraum Fassade: Aeroterrestrische Mikroalgen. Biologie in unserer Zeit 1: 20-30.

Karsten, U., Friedl, T., Schumann, R., Hoyer, K. and Lembcke, S. (2005b) Mycosporine-like amino acids and phylogenies in green algae: Prasiola and its relatives from the Trebouxiophyceae (Chlorophyta). J Phycol 41: 557-566.

Karsten, U., Schumann, T. and Mostaert, A.S. (2007) Aeroterrestrial algae growing on man-made surfaces: What are their secrets of ecological success? In Seckbach, J. (ed) Algae and Cyanobacteria in Extreme Environments. Springer Verlag, Dordrecht, the Netherlands, pp. 583-597.

Karsten, U., Herburger, K. and Holzinger, A. (2014) Dehydration, temperature, and light tolerance in members of the aeroterrestrial green algal genus Interfilum (Streptophyta) from biogeographically different temperate soils. J Phycol 50: 804-816.

Kemmling, A., Kämper, M., Flies, C., Schieweck, O. and Hoppert, M. (2004) Biofilms and extracellular matrices on geomaterials. Environ Geol 46: 429-435. 
Khaybullina, L.S., Gaysina, L.A., Johansen, J R. and Krautová, M. (2010) Examination of the terrestrial algae of the Great Smoky Mountains National Park, USA. Fottea (Praha) 10: 201-215.

Kostikov, I., Darienko, T., Lukešová, A. and Hoffmann, L. (2002) Revision of the classification system of Radiococcaceae Fott ex Komárek (except the subfamily Dictyochlorelloideae) (Chlorophyta). Arch Hydrobiol Suppl Algol Stud 104: 23-58.

Lennon, J.T. and Jones, S.E. (2011) Microbial seed banks: the ecological and evolutionary implications of dormancy. Nat Rev Microbiol 9: 119-130.

Lewis, L.A. and Lewis, P.O. (2005) Unearthing the molecular phylodiversity of desert soil green algae (Chlorophyta). Syst Biol 54: 936-947.

Ludwig, W., Strunk, O., Westram, R., Richter, L., Meier, H., et al. (2004) ARB: a software environment for sequence data. Nucleic Acids Res 32: 1363-1371.

Lüttge, U. and Büdel, B. (2010) Resurrection kinetics of photosynthesis in desiccation-tolerant terrestrial green algae (Chlorophyta) on tree bark. Plant Biol (Stuttg) 12: 437-444.

Ma, S., Huss, V.A.R., Tan, D., Sun, D., Sun, X., et al. (2013) A novel species in the genus Heveochlorella (Trebouxiophyceae, Chlorophyta) witnesses the evolution from an epiphytic into an endophytic lifestyle in tree-dwelling green algae. Eur J Phycol 48: 2000-2009.

Macedo, M.F., Miller, A.Z., Dionísio, A. and Saiz-Jimenez, C. (2009) Biodiversity of cyanobacteria and green algae on monuments in the Mediterranean Basin: an overview. Microbiology 155: 3476-3490.

Marketon, M.M., Glenn, S.A., Eberhard, A. and Gonźalez, J.E. (2003) Quorum sensing controls exopolysaccharide production in Sinorhizobium meliloti. J Bacteriol 185: 325-331.

Mikhailyuk, T.I., Sluiman, H.J., Massalski, A., Mudimu, O., Demchenko, E.M., Kondratyuk, S.Y. and Friedl, T. (2008) New streptophyte green algae from terrestrial habitats and an assessment of the genus Interfilum (Klebsormidiophyceae, Streptophyta). J Phycol 44: 1586-1603.

Miller, A.Z., Laiz, L., Gonzalez, J.M., Dionísio, A., Macedo, M.F. and Saiz-Jimenez, C. (2008) Reproducing stone monument photosynthetic-based colonization under laboratory conditions. Sci Total Environ 405: 278-285.

Neustupa, J. and Štifterová, A. (2013) Distribution patterns of subaerial corticolous microalgae in two European regions. Plant Ecol Evol 146: 279-289.

Neustupa, J., Němcová, Y., Veselá, J., Steinová, J. and Škaloud, J. (2013) Parachloroidium gen. nov. (Trebouxiophyceae, Chlorophyta), a novel genus of coccoid green algae from subaerial corticolous biofilms. Phycologia 52: 411-421.

Pangallo, D., Bučková, M., Kraková, L., Puškárová, A., Šaková, N., et al. (2014) Biodeterioration of epoxy resin: a microbial survey through culture-independent and culture-dependent approaches. Environ Microbiol doi:10.1111/1462-2920.12523.

Petersen, J.B. (1928) The aërial algae of Iceland. In Rosenvinge, L.K. and Warming, E. (eds), The botany of Iceland. Vol. II. Part II. Wheldon and Wesley, Copenhagen and London, pp. $328-447$.

Rindi, F. (2007) Diversity, ecology and distribution of green algae and cyanobacteria in urban habitats. In Seckbach, J. (ed) Algae and Cyanobacteria in Extreme Environments. Springer Verlag, Dordrecht, the Netherlands, pp. 583-597.

Rindi, F., Allali, H.A., Lam, D.W. and López-Bautista, J.M. (2010) An overview of the biodiversity and biogeography of terrestrial green algae. In Rescigno, V. and Maletta, S. (eds) Biodiversity Hotspots. Nova Science Publishers, Hauppauge, New York, pp. 105-122.

Rindi, F. (2011) Terrestrial green algae: systematics, biogeography and expected responses to climate change. In Hodkinson T. R., Jones, M.B., Waldren, S. and Parnell, J.A.N. (eds) 
Climate Change, Ecology and Systematics. Cambridge University Press, Cambridge, pp. 201-227.

Ruprecht, U., Brunauer, G. and Türk, R. (2014) High photobiont diversity in the common European soil crust lichen Psora decipiens. Biodivers Conserv 23: 1771-1785.

Rybalka, N., Andersen, R.A., Kostikov, I., Mohr, K.I., Massalski, A., Olech, M. and Friedl, T. (2009) Testing for endemism, genotypic diversity and species concepts in Antarctic terrestrial microalgae of the Tribonemataceae (Stramenopiles, Xanthophyceae). Environ Microbiol 11: 554-565.

Rybalka, N., Wolf, M., Andersen, R.A. and Friedl, T. (2013) Congruence of chloroplast- and nuclear-encoded DNA sequence variations used to assess species boundaries in the soil microalga Heterococcus (Stramenopiles, Xanthophyceae). BMC Evol Biol 13: 1471-2148.

Sakuragi, Y. and Kolter, R. (2007) Quorum-sensing regulation of the biofilm matrix genes (pel) of Pseudomonas aeruginosa. J Bacteriol 189: 5383-5386.

Schloss, P.D., Westcott, S.L., Ryabin, T., Hall, J.R., Hartmann, M., et al. (2009) Introducing mothur: open-source, platform-independent, community-supported software for describing and comparing microbial communities. Appl Environ Microbiol 75: 7537-7541.

Shepherd, V.A. and Beilby, M.J. (1999) The effect of an extracellular mucilage on the response to osmotic shock in the charophyte alga Lamprothamnium papulosum. J. Membr Biol 170: 229-242.

Spurr, A.R. (1969) A low-viscosity epoxy resin embedding medium for electron microscopy. $J$ Ultrastruct Res 26: 31-43.

Stamatakis, A., Hoover, P. and Rougemont, J. (2008) A rapid bootstrap algorithm for the RAxML web servers. Syst Biol 57: 758-771.

Tamura, K., Stecher, G., Peterson, D., Filipski, A. and Kumar, S. (2013) MEGA6: Molecular Evolutionary Genetics Analysis version 6.0. Mol Biol Evol 30: 2725-2729.

Uher, B. (2008) Spatial distribution of cyanobacteria and algae from the tombstone in a historic cemetery in Bratislava, Slovakia. Fottea (Praha) 9: 81-92.

Vogler, E.A. (1998) Structure and reactivity of water at biomaterial surfaces. Adv Colloid Interface Sci 74: 69-117.

Wynn-Williams, D.D., Russell, N.C. and Edwards, H.G.M. (1997) Moisture and habitat structures as regulators for microalgal colonists in diverse Antarctic terrestrial habitats. In Lyons, W.B., Howard-Williams, C. and Hawes, I. (eds) Ecosystem processes in Antarctic ice-free landscapes, Balkema Publishers, Rotterdam, pp. 77-88.

Wedin, M., Döring, H. and Ekman, S. (2000) Molecular phylogeny of the lichen families Cladoniaceae, Sphaerophoraceae, and Stereocaulaceae (Lecanorales, Ascomycotina). Lichenologist 32: 171-187.

Welton, R.G., Cuthbert, S.J., McLean, R., Hursthouse, A. and Hughes, J. (2003) A preliminary study of the phycological degradation of natural stone masonry. Environ Geochem Health 25: 139-145.

White, T.J., Bruns, T., Lee, S. and Talylor, J. (1990) Amplification and direct sequencing of fungal ribosomal RNA genes for phylogenetics. PCR protocols: a guide to methods and applications, pp. 315-322.

Zhang, J., Huss, V.A.R., Sun, X., Chang, K. and Pang, D. (2008) Morphology and phylogenetic position of a trebouxiophycean green alga (Chlorophyta) growing on the rubber tree, Hevea brasiliensis, with the description of a new genus and species. Eur J Phycol 43: 185-193.

Zoller, S. and Lutzoni, F. (2002) Slow algae, fast fungi: exceptionally high nucleotide substitution rate differences between lichenized fungi Omphalina and their symbiotic green algae Coccomyxa. Mol Phylogenet Evol 29: 629-40. 


\title{
Chapter 5:
}

\section{Green algal communities from soil and tree bark in middle European forests: a molecular comparison}

\author{
Christine Hallmann ${ }^{1}$, Ladislav Hodač ${ }^{1}$, Fabian Faßhauer ${ }^{1}$, Michael Hoppert ${ }^{2,3}$ \\ and Thomas Friedl ${ }^{1,3}$
}

Manuscript

\footnotetext{
${ }^{1}$ Albrecht-von-Haller-Institute for Plant Sciences, Department of Experimental Phycology and Culture Collection of Algae, Georg-August-University, Untere Karspüle 2, 37073 Göttingen, Germany

${ }^{2}$ Institute for Microbiology and Genetics, Georg-August-University, Grisebachstraße 8, 37077 Göttingen, Germany

${ }^{3}$ Courant Research Center Geobiology, Georg-August-University, Goldschmidtstraße 3, 37077 Göttingen, Germany
}

Author contributions to the work:

Performed the experiments: $\mathrm{CH}$.

Analyzed data: $\mathrm{CH}$.

Statistical support (multivariate analysis): LH.

Contributed data of tree bark samples and analysis of these data: $\mathrm{FF}, \mathrm{CH}$.

Contributed data of cultures and analysis of these data: LH.

Wrote the paper: $\mathrm{CH}, \mathrm{TF}, \mathrm{LH}, \mathrm{MH}$.

Conceived and designed the experiments: TF, $\mathrm{CH}, \mathrm{LH}$. 


\begin{abstract}
The composition of green algal communities from soils and tree barks was determined using 18S rRNA gene sequence comparisons. The samples were collected from nine defined research plots of the German Biodiversity Exploratory Schwäbische Alb, representing three different management types of spruce and beech forests. Following a culture-independent approach (cloning and sequencing) which was complemented by culturing of green algae, a total of 62 operational taxonomic units (OTUs) were identified. In soil 37 OTUs representing the green algal class Trebouxiophyceae and 15 OTUs affiliated to Chlorophyceae were detected. Most abundant OTUs in soil belong to Desmococcus, Elliptochloris and a group of so far unidentified Prototheca-relatives, which were retrieved exclusively through cloning. On tree bark the algal diversity was lower with 26 OTUs representing only Trebouxiophyceae, out of which Apatococcus, Coccomyxa and Elliptochloris were the most frequent ones. The microhabitats in forest soils are more heterogeneous than tree bark surfaces which is congruent with the different molecular diversities in soil and on tree bark we found within the same plots.
\end{abstract}

Key words: green algae, soil, forest, tree bark, 18S rRNA gene, OTUs, cultureindependent. 


\section{Introduction}

Terrestrial green algae are important primary producers in soils and on tree bark and were suggested as potential bioindicators (Bérard et al., 2005; Freystein et al., 2008). Large part of microbial diversity resides in forest soils and epiphytic on tree bark (e.g. Will-Wolf et al., 2002; O'Brien et al., 2005; Roesch et al., 2007). However, the ecological relevance of microbial diversity in these terrestrial ecosystems is poorly understood, in particular for eukaryotic organisms. Though the importance of fungi with respect to the remediation of organic biomass in soil is well recognized and epiphytic fungi and lichens are well known as abundant cryptogams on tree bark (Barkman, 1958; Elbert et al., 2012), the ecological role of algae has not been addressed so far in temperate ecosystems. It is known that microalgae, besides cyanobacteria, lichens and mosses, are important primary producers in Antarctic terrestrial ecosystems (Bölter, 1992; Broady, 1996; Feng et al., 2010 and references therein). In arid and semi arid habitats, microbiotic soil crusts, dominated by eukaryotic algae and cyanobacteria, are highly important for soil fertilization and mechanical stability (Lewis and Lewis, 2005; Büdel et al., 2009; Řeháková et al., 2011). In temperate soil ecosystems, the role of algae may be less pronounced. Since vascular plants are the predominant primary producers in soil ecosystems, a major contribution of algae to soil organic matter may not be expected. However, their importance as producers of organic matter were seemingly underestimated, which serves as nutrient source for microorganisms and invertebrates and were consumed by roots of plants (Kabirov and Gaisina, 2009).

Green algae (Chlorophyta) comprise the most part of the algal diversity in soils (Metting, 1981; Hoffmann, 1989). They improve soil fertility and trap particles together with the other groups of eukaryotic algae known to be abundant from soils besides chlorophytes, e.g. the heterokont algae, xanthophytes, eustigmatophytes and diatoms, improve soil texture and nitrogen-fixing cyanobacteria (Shields and Durrell, 1964; Metting, 1981; Hoffmann, 1989; García-Pichel et al., 2001). Diversity assessments of microalgal communities from temperate forest soil and the comparison of forest soil algal communities of different localities have so far been achieved only by morphology (Lukešová and Hoffmann, 1996; Hoffmann et al., 2007; Novakovskaya and Patova, 2007, 2008; Khaybullina et al., 2010). Earlier studies revealed first top $5 \mathrm{~cm}$ soils rather diverse in microalgae and that the microalgal communities may be sensitive to changes of environmental factors and differences in algal communities in relation to land management 
were found (Hunt et al., 1979; Metting, 1981; Bérard et al., 2005). However, in these previous studies no cultures have been deposited in culture collections so that a comparison at the molecular genetic level and re-evaluation of the identification of algal taxa is not possible. Additionally comparisons of studies with traditional culturing approaches, based on morphological criteria, are difficult because of different identification strategies of authors and taxonomic uncertainties of floristic lists (Lukešová and Hoffmann, 1996; Neustupa and Škaloud, 2010).

As compared to soil algae, much less is known about algae on tree bark, which are often observed in Europe (Gärtner, 1994; López-Bautista et al., 2007; Freystein et al., 2008; Lüttge and Büdel, 2010; Hodač et al., 2012). Two types of tree bark covers can be noticed; while orchard tree barks were often reddish due to Trentepohliales, the bark of forest trees had often a green cover (Lüttge and Büdel, 2010). The most abundant algae on tree bark may be the cell package forming green alga Apatococcus, a member of Trebouxiophyceae (Gärtner and Ingolić, 1989; Gärtner, 1994; López-Bautista et al., 2007). The green biofilms comprise also other common trebouxiophyte genera, e.g. Trebouxia, Coccomyxa, Chloroidium and Stichococcus (Freystein et al., 2008; Lüttge and Büdel, 2010). They are also described as food source of microarthropods (Erdmann et al., 2007). Besides morphological studies of corticolous microalgae from tropical habitats (Neustupa and Škaloud, 2008, 2010; Kharkongor and Ramanujam, 2014), also temperate forests were investigated (Mikhailyuk, 1999; Neustupa and Štifterová, 2013). Most green algae found in soil and on tree bark are rather small and inconspicuous so that their identification remains uncertain given the high genetic diversity, e.g. for Chlorella-like algae (Rindi et al., 2010; Darienko et al., 2010).

Combined approaches of sequencing of isolates established from communities are still increasing (Lewis and Lewis, 2005; De Wever et al., 2009; Flechtner et al., 2013; Lin et al., 2013; Kulichová et al., 2014; Hodač et al., 2015). Culture-independent approaches with focus on eukaryotic green algal diversity, however, are still lacking. To our knowledge, only one contribution dealing explicitly with diversity of soil algae in a temperate region at the molecular level by cloning and sequencing are available (Bérard et al., 2005). No such studies have been performed for algae on tree barks and no comparison of tree bark algal communities to those in soil. The rRNA gene sequence comparisons provide a clear distinction of taxa independent of plesiomorphic variation and unambiguous reidentification of the genetically same species. The rRNA gene sequence analysis of environmental DNA allows the estimation of genetic diversity of algal communities. 
SSU rRNA gene is a commonly used marker molecule; it serves as the gold standard for prokaryotic diversity, but also for estimates of eukaryotic microbial diversity due to the tremendous extent of sequences available for almost all known groups of organisms and its suitability for phylogenetic analyses.

In this study the green algal communities of soil and tree bark from three different management types in spruce and beech forests were investigated and compared. Sampling sites were nine defined research plots of the German Biodiversity Exploratory Schwäbische Alb (Fischer et al., 2010).

Mainly a culture-independent approach was used, i.e. cloning and sequencing of $18 \mathrm{~S}$ rRNA genes from soil/tree bark DNA extracts. To achieve a maximum recovery of the green algal diversity in the soil, the same soil samples were also used for establishing cultures and the 18S rRNA gene sequences from both approaches were compared. The aim of the present study was to compare the green algal diversities from both habitats, soil and tree bark of the same research plots. This was to test the hypothesis that the diversities of both habitats may largely overlap with the tree bark species richness being lower compared to that of the soil because the latter habitat may be more harsh. In addition, the studied research plots represented three different types of forest management and provided different substrate trees. This allowed to test in as much different intensities of forest management (age class forest versus unmanaged forest) and different types of tree bark (beech versus spruce) influence the composition of green algal assemblages in soil and on tree bark.

\section{Material and Methods}

\section{Study site and sampling}

The soil and tree bark samples were collected from nine forest plots of the German Biodiversity Exploratory Schwäbische Alb (48 $\left.44^{\prime} \mathrm{N}, 9^{\circ} 39^{\prime} \mathrm{E}\right)$ in the low mountain ranges of South-western Germany in the state of Baden-Württemberg. The study sites were investigated within the large-scale and long-term project 'Biodiversity Exploratories' (www.biodiversity-exploratories.de; Fischer et al., 2010).

The studied nine plots represent three different forest and management types with three replicates of each type (Table 1). They included three spruce age class forests (plots AEW1, AEW2, AEW3), three beech age class forests (plots AEW4, AEW5, AEW6) and three unmanaged beech forests (plots AEW7, AEW8, AEW9). Both the spruce and beech 
age class forests represent managed sites. The investigated plots comprise Cambisol or Leptosol soil types (Table 1). The soil $\mathrm{pH}$ values varied in the spruce plots between 3.3 and 5.04, in the beech plots between 4.5 and 6.4 (for detailed measurements and further physical and geochemical characteristics see Nacke et al., 2011). The soil samples were taken from a given area of $20 \mathrm{~m}$ x $20 \mathrm{~m}$ from the A-horizons in April and May 2008 with a motor-driven soil column cylinder as described in Will et al., 2010. Samples of tree barks covered by a green biofilm were collected from spruce (Picea abies (L.) H. Karst) and beech (Fagus sylvatica L.; Table 1), at the same plots in July 2008. Biofilm samples were scraped off from tree bark at a height of about $1.5 \mathrm{~m}$ with a sterile scalpel and stored in $2 \mathrm{ml}$ reaction tubes.

Table 1. Sampling sites and numbers of the retrieved green algal OTUs from soil and tree bark of temperate forests.

\begin{tabular}{|c|c|c|c|c|c|c|c|}
\hline Sample & Coordinates & Management type & Substrate & $\begin{array}{l}\text { Tree/Soil } \\
\text { type }\end{array}$ & $\begin{array}{l}\text { Total no. of } \\
\text { sequences } \\
\text { (algal seq.) }\end{array}$ & $\begin{array}{l}\text { No. of } \\
\text { algal } \\
\text { OTUs }\end{array}$ & $\begin{array}{c}\text { Coverage* } \\
(\%)\end{array}$ \\
\hline \multirow{2}{*}{ AEW1 } & \multirow{2}{*}{$48^{\circ} 28^{\prime} \mathrm{N}, 9^{\circ} 20^{\prime} \mathrm{E}$} & \multirow{2}{*}{ Age class forest } & tree bark & Spruce & $7(5)$ & 5 & 0 \\
\hline & & & soil & Cambisol & $45(4)$ & 3 & 50 \\
\hline \multirow{2}{*}{ AEW2 } & \multirow{2}{*}{$48^{\circ} 22^{\prime} \mathrm{N}, 9^{\circ} 21^{\prime} \mathrm{E}$} & \multirow{2}{*}{ Age class forest } & tree bark & Spruce & $18(15)$ & 6 & 80 \\
\hline & & & soil & Leptosol & $102(61)$ & 16 & 93.4 \\
\hline \multirow{2}{*}{ AEW3 } & \multirow{2}{*}{$48^{\circ} 24^{\prime} \mathrm{N}, 9^{\circ} 21^{\prime} \mathrm{E}$} & \multirow{2}{*}{ Age class forest } & tree bark & Spruce & $21(18)$ & 8 & 72.2 \\
\hline & & & soil & Cambisol & $37(33)$ & 7 & 90.9 \\
\hline \multirow{2}{*}{ AEW4 } & \multirow{2}{*}{$48^{\circ} 23^{\prime} \mathrm{N}, 9^{\circ} 14^{\prime} \mathrm{E}$} & \multirow{2}{*}{ Age class forest } & tree bark & Beech & NA & NA & NA \\
\hline & & & soil & Cambisol & $51(38)$ & 10 & 94.7 \\
\hline \multirow{2}{*}{ AEW5 } & \multirow{2}{*}{$48^{\circ} 25^{\prime} \mathrm{N}, 9^{\circ} 24^{\prime} \mathrm{E}$} & \multirow{2}{*}{ Age class forest } & tree bark & Beech & $31(29)$ & 4 & 89.7 \\
\hline & & & soil & Cambisol & $38(36)$ & 5 & 97.2 \\
\hline \multirow{2}{*}{ AEW6 } & \multirow{2}{*}{$48^{\circ} 23^{\prime} \mathrm{N}, 9^{\circ} 26^{\prime} \mathrm{E}$} & \multirow{2}{*}{ Age class forest } & tree bark & Beech & $27(21)$ & 9 & 81.0 \\
\hline & & & soil & Cambisol & $38(30)$ & 13 & 73.3 \\
\hline \multirow{2}{*}{ AEW7 } & \multirow{2}{*}{$48^{\circ} 23^{\prime} \mathrm{N}, 9^{\circ} 15^{\prime} \mathrm{E}$} & \multirow{2}{*}{ Unmanaged forest } & tree bark & Beech & $125(111)$ & 11 & 98.2 \\
\hline & & & soil & Leptosol & $39(38)$ & 4 & 100 \\
\hline \multirow{2}{*}{ AEW8 } & \multirow{2}{*}{$48^{\circ} 22^{\prime} \mathrm{N}, 9^{\circ} 22^{\prime} \mathrm{E}$} & \multirow{2}{*}{ Unmanaged forest } & tree bark & Beech & $35(33)$ & 7 & 87.9 \\
\hline & & & soil & Cambisol & $56(56)$ & 7 & 94.6 \\
\hline \multirow{2}{*}{ AEW9 } & \multirow{2}{*}{$48^{\circ} 22^{\prime} \mathrm{N}, 9^{\circ} 24^{\prime} \mathrm{E}$} & \multirow{2}{*}{ Unmanaged forest } & tree bark & Beech & $21(18)$ & 7 & 88.9 \\
\hline & & & soil & Leptosol & $34(29)$ & 3 & 100 \\
\hline
\end{tabular}

*after GOOD: [1-(n/N)] x 100

$\mathrm{n}=$ number of OTUs represented by just one clone, $\mathrm{N}=$ total number of clones

$\mathrm{NA}=$ data not available 


\section{Isolation and microscopy}

In order to obtain cultures of green algae one gram of fresh soil material was spread onto plates with agarized (1.5\%) 3NBBM+V culture medium (Starr and Zeikus, 1987) and kept at $18{ }^{\circ} \mathrm{C}$ under a light:dark regime of $14: 10 \mathrm{hrs}$ at a light intensity of about $25 \mu \mathrm{E}$ from white fluorescent bulbs. After three to six weeks algal colonies appeared and selected colonies were repeatedly transferred onto new plates until the cultures were unialgal by microscopy. The isolated algae were kept as stock cultures on agar slants $(1.5 \%)$ with the same culture medium and under the same growth conditions. Representative isolates were accessioned by the Culture Collection of Algae (SAG; Friedl and Lorenz, 2012) under the strain numbers SAG 2476 - SAG 2483 after phylogenetic analyses. Microscopic observations were accomplished with an Olympus BX60 microscope (Tokyo, Japan) with Nomarski DIC optics with a ColorView III camera (Soft Imaging System, Münster, Germany) attached and micrographs were processed using the Cell^ ${ }^{\wedge} \mathrm{image}$ software (Soft Imaging System, Münster, Germany).

\section{DNA extraction, PCR amplification, cloning and sequencing}

The MoBio PowerSoil DNA isolation Kit (MoBio Laboratories Inc. Carlsbad, CA, USA) was used to extract the genomic DNA from soil samples, i.e. about $10 \mathrm{~g}$ of soil from each sample (Will et al., 2010). The Invisorb ${ }^{\circledR}$ Spin Plant Mini Kit (Stratec Molecular, Berlin, Germany) was used for DNA extraction of tree bark biofilm samples and cultures after the cells were disrupted by beating with glass beads (Hallmann et al., 2013a). Extraction results were evaluated after electrophoresis on a $1 \%(\mathrm{w} / \mathrm{v})$ agarose gel. Isolated DNA was stored at $-20{ }^{\circ} \mathrm{C}$ until further processing. For soil and tree bark samples PCR amplification of $18 \mathrm{~S}$ rRNA genes were conducted in two rounds, first amplified using the eukaryotic specific primers 20F (Hallmann et al., 2013a) and 18L (Hamby et al., 1988) followed by a second amplification with the primers 20F and CH1750R (Hallmann et al., 2013a) which preferentially amplify Chlorophyta rRNA genes. PCR conditions were as described previously (Hallmann et al., 2013a). For algal isolates PCR was conducted directly with the primer pair $20 \mathrm{~F}$ and $\mathrm{CH} 1750 \mathrm{R}$, using 35 PCR cycles. Aliquots of $2 \mu \mathrm{l}$ of the PCR products were analysed by electrophoresis on a $1 \%(\mathrm{w} / \mathrm{v})$ agarose gel. After purification using the Invisorb ${ }^{\circledR}$ Spin PCRapid Kit (Stratec Molecular, Berlin, Germany) the PCR products were cloned using the TOPO ${ }^{\circledR}$ TA cloning kit (Life Technologies, Carlsbad, CA, USA) with TOP 10 chemically competent one Shot $^{\circledR}$ Escherichia coli cells (Life Technologies, Carlsbad, CA, USA). Positive white clones (blue/white screening), grown 
on LB agar plates containing $0.1 \%$ ampicillin and $0.2 \% \mathrm{X}$-Gal at $37{ }^{\circ} \mathrm{C}$ overnight, were checked for the presence of an insert by vector-specific primers M13F/M13R (Life Technologies, Carlsbad, CA, USA). Positive clones were cultivated overnight in $2 \mathrm{ml}$ reaction tubes with $1 \mathrm{ml}$ LB medium containing $100 \mu \mathrm{g}$ ampicillin. The plasmid purification kit (Stratec Molecular, Berlin, Germany) was used for plasmid DNA extraction and purification followed by cycle sequencing reaction with the standard sequencing primer 895R (Hallmann et al., 2013a) which yielded partial sequences of about 700 nucleotides (nts) and included the hypervariable regions V2-V4. Purified PCR products from pure cultures were directly used for sequencing. The cycle sequencing reactions were done with the Big Dye Terminator Cycle Sequencing kit v3.1 (Applied Biosystems, Foster city, USA) and the reactions were separated on an ABI Prism 3100 (Applied Biosystems, Foster city, USA) automated sequencer.

\section{Sequence and phylogenetic analyses}

The sequences were edited and assembled into contigs using the programme SeqAssem (Hepperle, 2004). Vector sequence was removed and all sequences shorter than $400 \mathrm{bp}$ were excluded from further analyses. The sequences were compared with similar sequences of reference organisms by performing BLASTn searches at NCBI (Altschul et al., 1990, http://www.ncbi.nlm.nih.gov/). Next relative sequences were imported into the ARB program (Ludwig et al., 2004; www.arb-home.de), additional to internal sequence references. To determine the first phylogenetic affiliation the partial sequences were aligned with the homologous eukaryotic 18S rRNA gene sequences by using the automatic alignment tools of the ARB program package. Non-algal sequences were excluded from further analysis. Potential chimeras were examined by Bellerophon (Huber et al., 2004); in addition, the first and the last $300 \mathrm{bp}$ of putative chimeras were compared with similar rRNA gene sequences in NCBI. Chimeric sequences were excluded from the data set. Operational taxonomic units (OTUs), defined at $\geq 98 \%$ sequence similarity (Hallmann et al., 2013a and references therein), were calculated with MOTHUR version 1.13.0 (Schloss et al., 2009). One up to three representative 18S rRNA gene sequences of almost each OTU obtained from environmental preparations and from isolates was sequenced in full length.

The coverage values of the clone libraries were calculated according to Good's formula (Good, 1953), $\mathrm{C}=(1-\mathrm{n} / \mathrm{N}) \times 100$ ( $\mathrm{C}$ is the percentage of coverage of the library, $\mathrm{n}$ the number of singletons and $\mathrm{N}$ the total number of clones). A representative selection of 
partial and full sequences obtained in this study was deposited in GenBank under the following accession numbers, KP081318 - KP081408. The alignment for phylogenetic analysis was performed using MAFFT version 6 (Katoh and Toh, 2008), alignment was checked for misaligned positions by eye, using BioEdit alignment editor (Hall, 1999). The alignment comprised 194 sequences from the Chlorophyta, i.e. representatives of both classes Trebouxiophyceae and Chlorophyceae, and was 1902 positions (948 variable/698 parsimony informative sites) long. Phylogenies were constructed with the maximum likelihood (ML) method using RAxML (Stamatakis et al., 2008), using the GTR $+\Gamma+\mathrm{I}$ model with 100 replicates. In addition, Bayesian methods were employed with MrBayes 3.2.1 (Huelsenbeck and Ronquist, 2001). Four Markov chains and two million generations sampling every 100 generations were applied, using the GTR $+\Gamma+\mathrm{I}$ model. For calculating pairwise sequence similarities (p-distances) between clone/isolate and reference sequences the program MEGA6 (Tamura et al., 2013) was used.

\section{Statistical analyses}

The overall similarities of clone libraries from soils (labelled AEW-B) and those from tree barks (labelled AEW-R) were compared based on the presence/absence matrix of the OTU occurrence. In order to identify clusters of OTUs occurring at similar sampling plots, Principal components analysis (PCA) was conducted with the same dataset. A data subset representing clone libraries only from tree barks (AEW-R) was further analysed for similarities between spruce and beech samples with PCA. All statistical analyses were computed with the program PAST 2.17c (Hammer et al., 2001).

\section{Results}

From nine research forest sites of the Exploratory Schwäbische Alb a total of 725 partial $18 \mathrm{~S}$ rRNA gene sequences were retrieved. Non-algal sequences were excluded from further analysis. Altogether there were 575 sequences representing various green algae from a total of 17 clone libraries obtained from soils (nine) and tree barks (eight) (Table 1). The majority of the sequences (325) represented green algae from soil; 250 were obtained from tree bark samples. The coverage values for each clone library reached an average about $81.9 \%$ (Table 1); combined across all samples the coverage was almost saturated with $96.6 \%$ for soil and with $98.4 \%$ for tree bark. The clone sequences (from soil and tree bark) were distributed on 52 OTUs. In addition, 20 morphologically different isolates were 
obtained from soil and six from tree bark samples, sequence analyses of them revealed a total of 17 different OTUs.

\section{Soil algal diversity}

The clone libraries of the nine soil samples consisted of 42 OTUs in total. According to the phylogenetic analyses, these OTUs belonged either to the green algal classes Trebouxiophyceae or to Chlorophyceae (Fig. 1 and Fig. 2). Overall $90 \%$ of the clones represented Trebouxiophyceae comprising 30 OTUs, while $10 \%$ belong to Chlorophyceae, comprising 12 OTUs (Table 2). The soil algal richness of the sampling sites varied from three (AEW1 and AEW9) to 16 OTUs (AEW2). The number of OTUs varied between sampling sites of different forest management types. Samples of the age class forests exhibited higher numbers of OTUs, with 22 (spruce; AEW1-3) and 24 OTUs (beech; AEW4-6) than the unmanaged beech forests AEW7-9 which had just about half the number (11) of OTUs (Fig. 3, Table 2). Similarly, for the managed forest plot groups seven and eight OTUs just for the Chlorophyceae were recovered, whereas for the unmanaged plot group just a single chlorophycean OTU was recovered in the soil samples.

The most frequently recovered soil OTU was Elliptochloris OTU 10, found in five out of the nine samples, representing $4.3 \%$ of the total number of soil clones. Also discovered in high abundances were Desmococcus, Prototheca-relative OTU 26 and OTU 29 in four samples and Apatococcus OTU 03, Elliptochloris OTU 13 and Prototheca-relative OTU 28, which occurred in three samples. Three of the most abundant OTUs, the Protothecarelatives (OTUs 26, 28 and 29), represented more than $47 \%$ of all clones retrieved from soil (Table 2). Further seven OTUs (16.7\%) occurred in two sampling sites, whereas 28 OTUs $(66.7 \%)$ existed in one sample.

Fig. 1. Phylogenetic tree of Trebouxiophyceae and Chlorophyceae based on 18S rRNA gene sequences with two members of Nephroselmidophyceae as outgroup taxa using maximum likelihood method (ML). The portion of the tree representing the Trebouxiophyceae is shown. Thick lines indicate internal nodes that received significant statistical support in both, maximum likelihood and Bayesian analyses (i.e. $>75 \%$ bootstrap value with ML and >0.95 Bayesian posterior probabilities). Highlighted sequences (blue) represent full 18S rRNA gene sequences obtained in this study. Sequences in bold indicate representative sequences for a certain of OTUs. An asterisk indicates an OTU represented by the next available reference sequence (see Table S1). Filled circles: OTU from tree bark, empty circles: OTU from soil samples. 

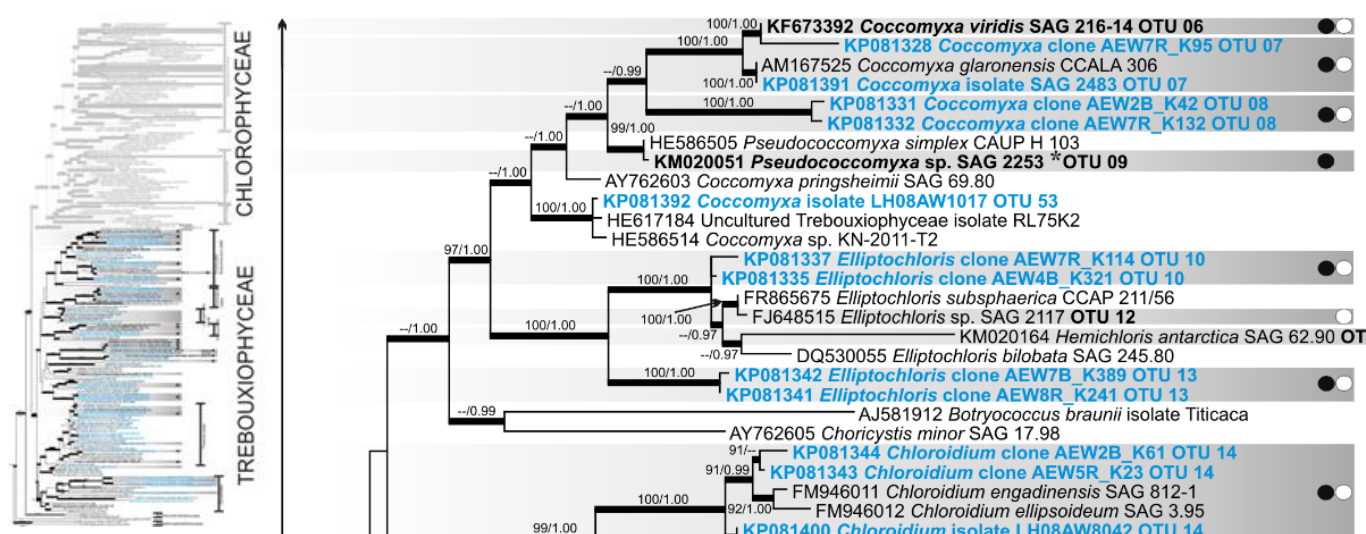
clone AEWTR

- AY762603 Coccomyxa pringsheimii SAG 69.80

1.1.00 [ KP081392 Coccomyxa isolate LH08AW1017 OTU 53

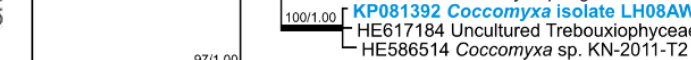

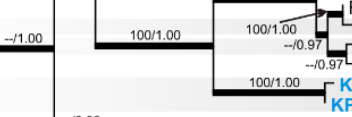
L - FR

\section{KP081337 Elliptoch}

ris clone AEW7 P081337 Elliptochloris clone AEW7R K114 OTU
81335 Elliptochloris clone AEW4B K321 OTU 10
R865675 Elliptochloris subsphaerica CCAP 211/56
FJ648515 Elliptochloris sp. SAG 2117 OTU 12

DQ530055 Elliptochloris bilobata SAG 245.80 K081342 Elliptochloris clone AEW7B_K389 OTU 13 AJ581912 Botryococcus braunii isolate Titicaca

KP Choricystis minor SAG 17.98

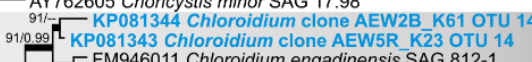

9211.00 FM946011 Chloroidium engadinensis SAG 812-1
FM946012 Chloroidium ellipsoideum SAG 3.95
KP 081400 Chloroidium isolate LH08AW8042 OTU 14

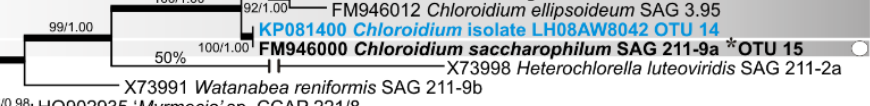

50\% ${ }^{10011.00} \mathrm{FM946000}$ Chloroidium saccharophilum SAG 211-9a *OTU 15 $\mathrm{X}$.

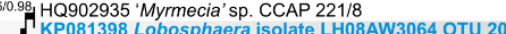

980.99 [' EU878372 'Parietochloris' cohaerens UTEX 1707

AY762602 Lobosphaera incisa SAG 2007

AY762602 'Mrrmecia' bisecta IB T74

10011.00 EU123942 Trebouxia aggregata SAG 219-1d OTU 21 9710.99
10011.00
Z687000 Trebouxia jamesii UBT-86.132E2 * OTU 22
Z21551 Trebouxia impressa UTEX 892 OTU 24 KP081355 Trebouxia clone AEW6B_K207 OTU 23
KP081356 Trebouxia clone AEW7R_K112 OTU 23

10 Asterochloris erici IAM C-593 OTU 25

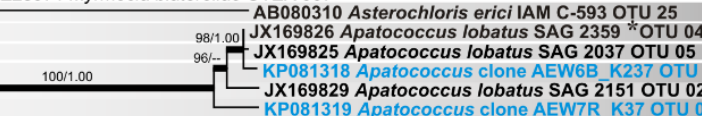

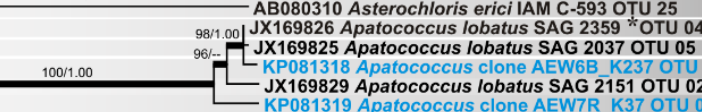

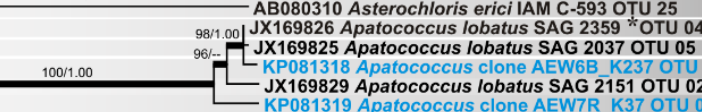
GU017659 Dictyochloropsis irregula

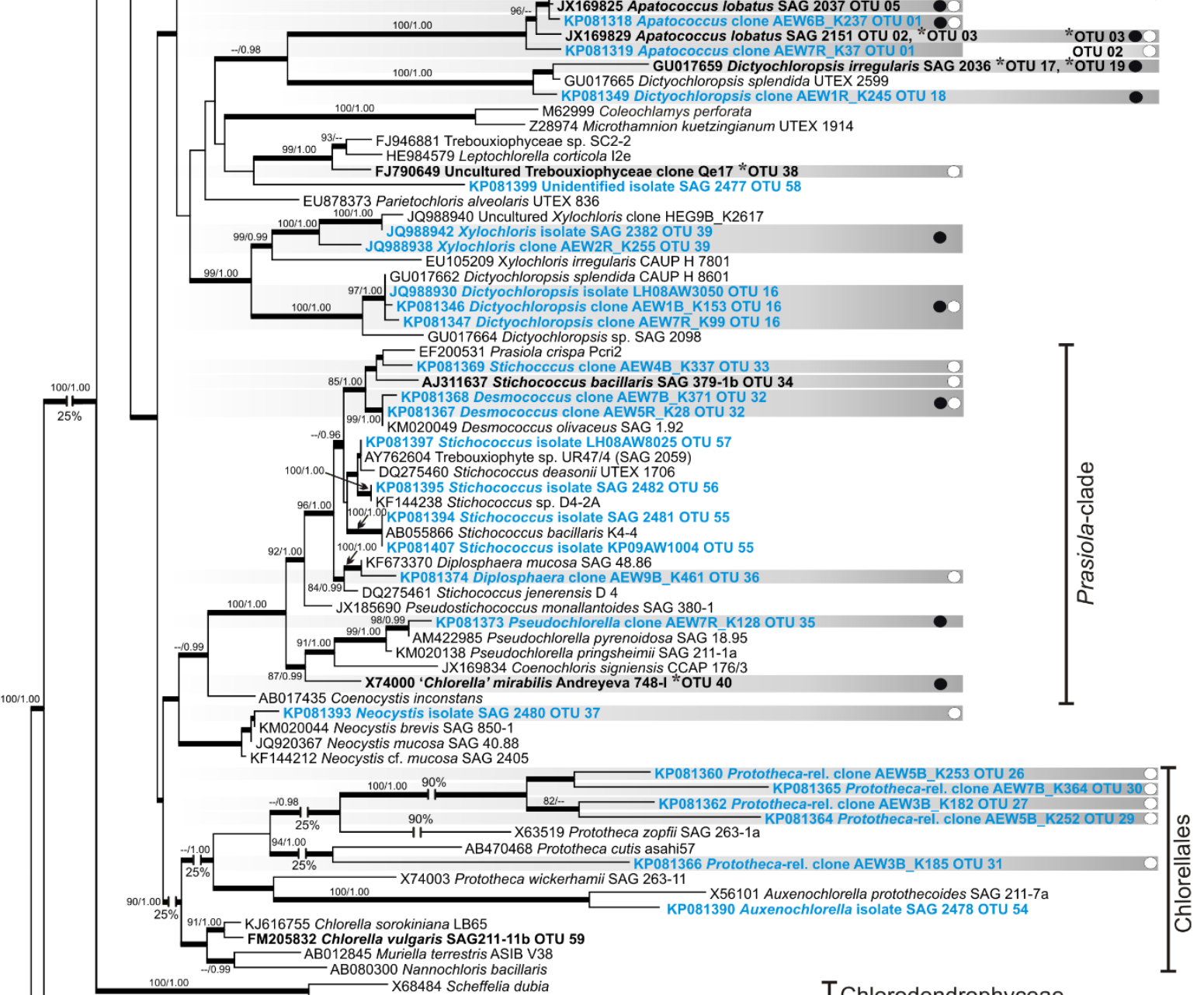
AB080300 Nannochloris bacillaris 


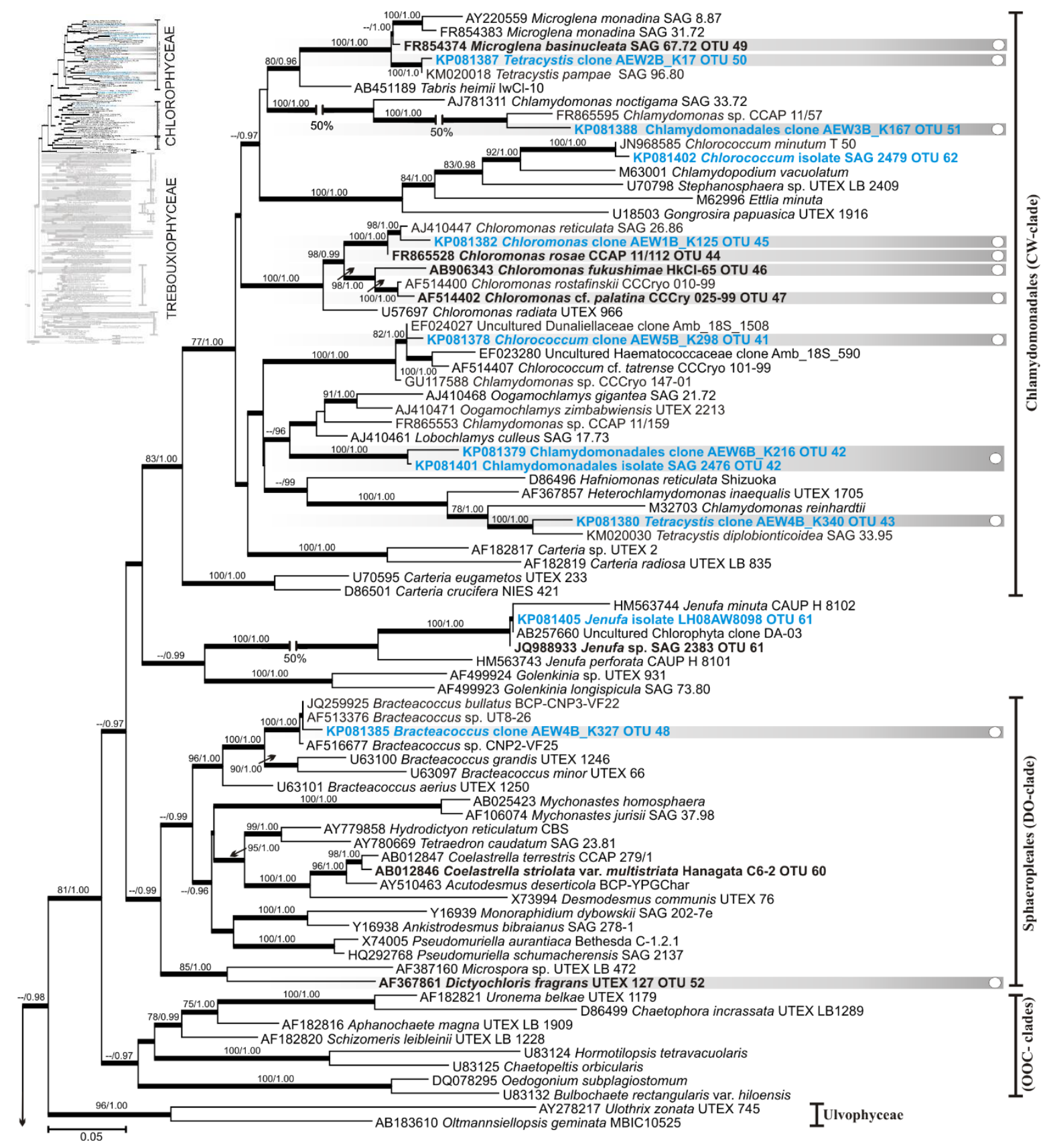

Fig. 2. Phylogenetic tree of Trebouxiophyceae and Chlorophyceae based on 18S rRNA gene sequences with two members of Nephroselmidophyceae as outgroup taxa using maximum likelihood method (ML). The portion of the tree representing the Chlorophyceae is shown. Thick lines indicate internal nodes that received significant statistical support in both, maximum likelihood and Bayesian analyses (i.e. $>75 \%$ bootstrap value with ML and >0.95 Bayesian posterior probabilities). Highlighted sequences (blue) represent full 18S rRNA gene sequences obtained in this study. Sequences in bold indicate representative sequences for a certain of OTUs. Filled circles: OTU from tree bark, empty circles: OTU from soil samples. 
Table 2. Distribution of 52 green algal OTUs in the $18 \mathrm{~S}$ rRNA gene clone libraries from the soil and tree bark of temperate forests. The OTUs belong to the green algal classes of Trebouxiophyceae and Chlorophyceae. An asterisk indicates an isolate is available for this OTU.

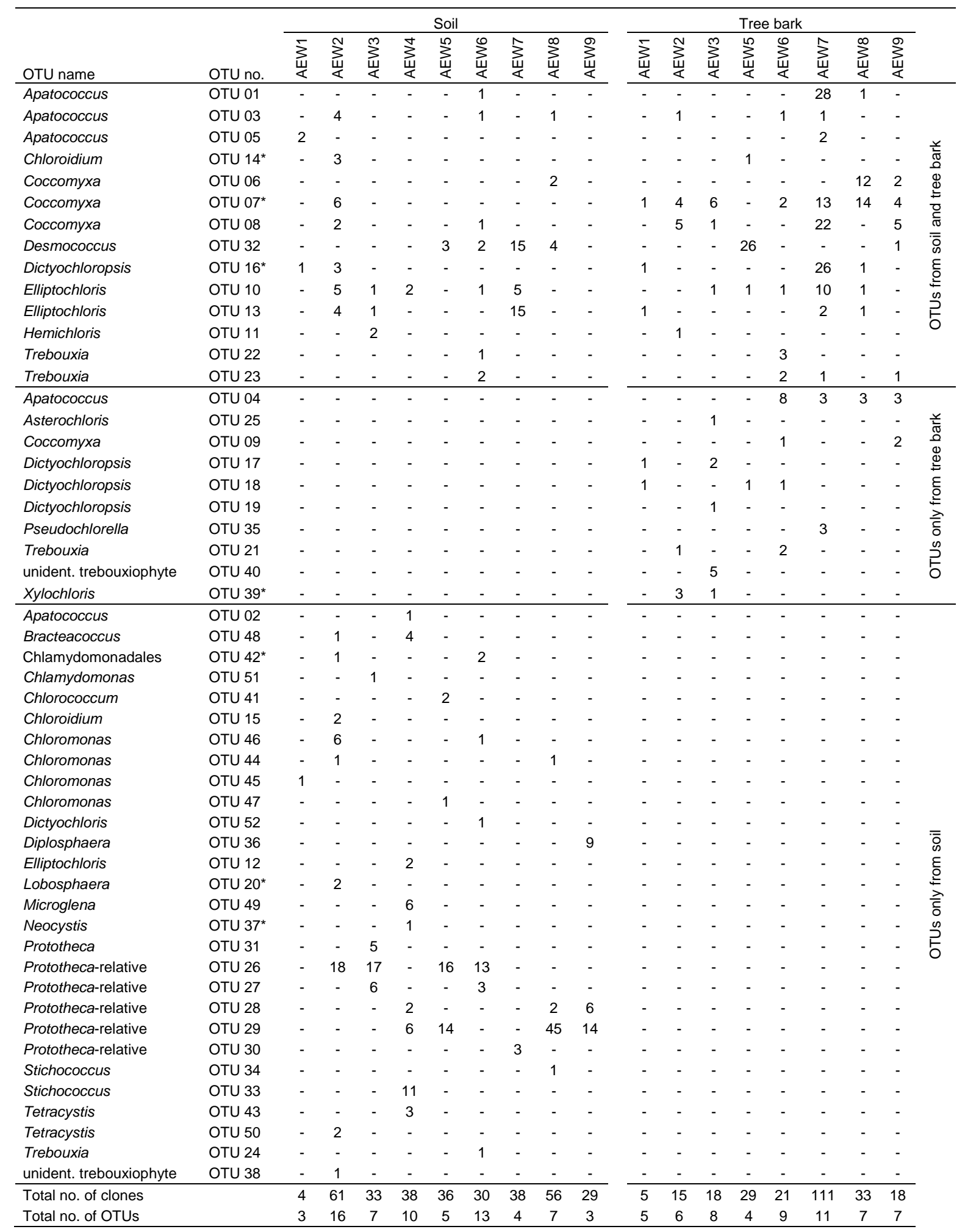




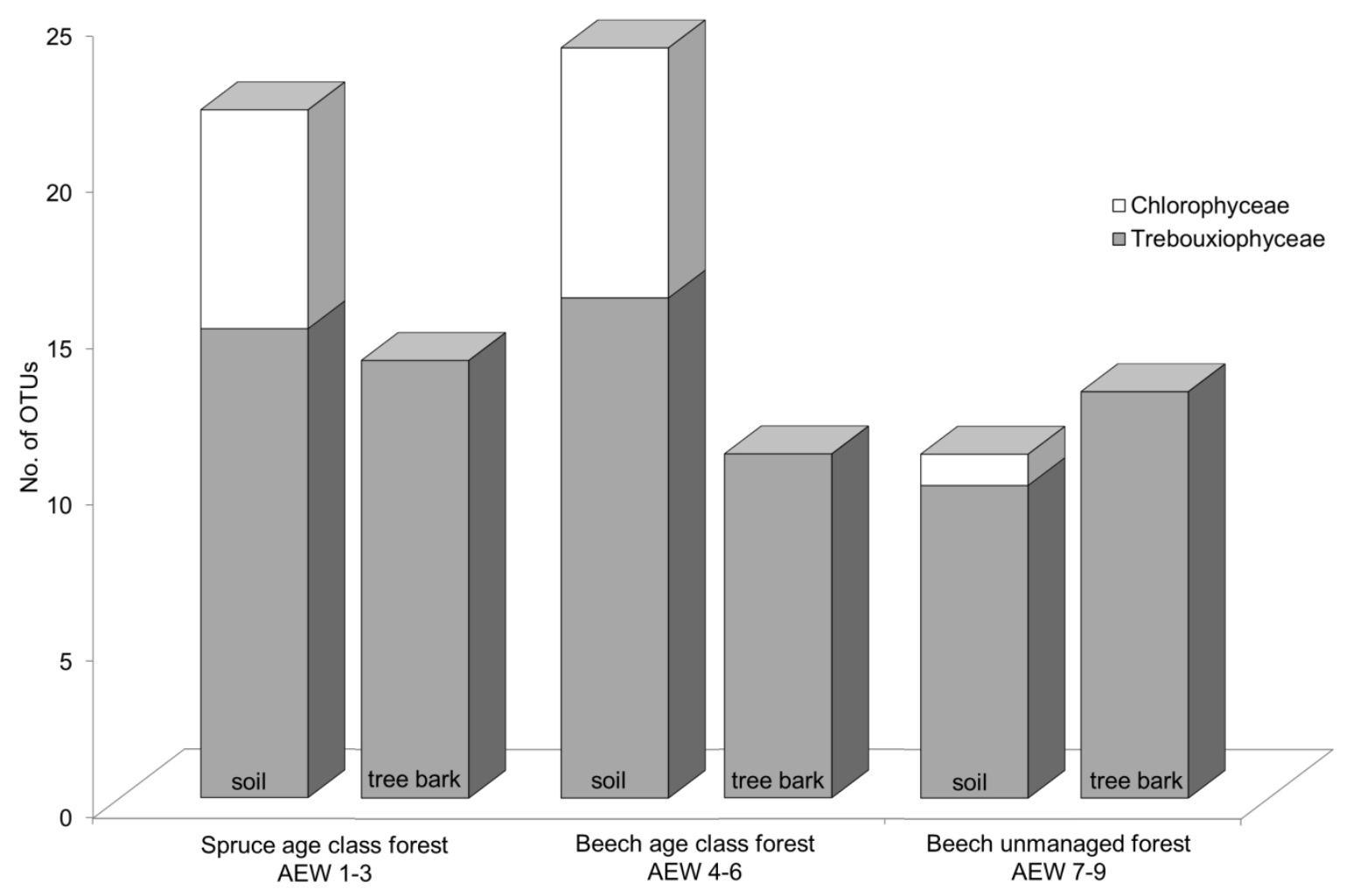

Fig. 3. Distribution of 52 green algal OTUs in the $18 \mathrm{~S}$ rRNA gene clone libraries from the soil and tree bark at different forest management types.

Culturing increased the number of OTUs recovered from the soil by 20 cultures (16 different OTUs), i.e. to a total of 52 OTUs (Table 3). With the cultures, there were seven additional OTUs from the Trebouxiophyceae and three OTUs for the Chlorophyceae which exclusively were recovered by the cultures, but not by the culture-independent cloning approach. Both approaches overlapped in no more than six OTUs (12\% of all recovered OTUs), whereas 36 OTUs (69\%) were exclusively retrieved by the culture-independent approach (Table 2).

Five trebouxiophycean OTUs (OTUs 07, 14, 16, 20, and 37) were concordantly detected by both approaches and exhibited partially a higher inner phylogenetic diversity. The sequences representing OTU 16 (including that of isolate LH08AW3050) had high similarities of 99.9-100\% with Dictyochloropsis splendida (reference sequence JQ988930) and, therefore, were identified as this species. Isolate LH08AW3050 was also characterized by a morphology characteristic for that species, i.e. spherical cells with a rich and finely lobed chloroplast without a visible pyrenoid (Fig. 4a). Similarly, sequences 
representing OTU 14 had high sequence similarities of 99.1-99.3\% with the authentic strain of Chloroidium saccharophilum, SAG 211-9a. The isolate LH08AW8042 from that OTU had even a sequence $100 \%$ identical with SAG 211-9a and, therefore, was representing that species. Similarly, the isolate representing OTU 07 (strain SAG 2483) had a $100 \%$ identical sequence with reference sequence AM167525 representing Coccomyxa glaronensis. The full clone sequence representative for this OTU (AEW7R_K95) had $99 \%$ sequence similarity with the authentic strain of $C$. viridis, SAG 216-14. Therefore, OTU 07 may represent even several species of Coccomyxa. Correspondingly, the OTU 20 isolate (LH08AW3064) shared $100 \%$ sequence identity with strain CCAP 221/8 assigned to 'Myrmecia' sp., whereas the representative full clone sequence (clone AEW2B_K6) was $99.9 \%$ identical with the corresponding sequence of the authentic strain of 'M.' bisecta SAG 2043. Most likely, OTU 20 represented several species of 'Myrmecia'. The isolate LH08AW3064 exhibited spherical cells with one bandshaped chloroplast without a pyrenoid (Fig. 4b) which are typical features of Lobosphaeralike green algae. The isolate for OTU 37 (strain SAG 2480) shared $99.9 \%$ sequence identity with the authentic strain of Neocystis brevis SAG 850-1, whereas the representative partial clone sequence for this OTU shared just $98.9 \%$ sequence similarity with isolate SAG 2480.

Seven trebouxiophycean OTUs (OTU 39, OTUs 53-58) were retrieved exclusively by cultures (Table 3). The isolates affiliated to Coccomyxa OTU 53 and Stichococcus OTU 55/OTU 56/OTU 57 exhibited high similarities (99.9 \% to $100 \%$ ) to sequences available in GenBank (Fig. 1, Table S1). The Stichococcus isolate SAG 2482, representing OTU 56, exhibited a typical Stichococcus morphology with rod-shaped cells with a single band-shaped chloroplast (Fig. 4c). The Auxenochlorella isolate SAG 2478 (KP081390) of OTU 54 had a $99.9 \%$ sequence similarity with a lichen photobiont strain (AM260449) assigned to this genus. The phylogenetic analyses showed isolate SAG 2478 being a close relative to the authentic strain of $A$. protothecoides SAG 211-7a (Fig. 1). The isolate SAG 2478 exhibited a rather simple morphology, spherical Chlorella-like cells, under culture conditions without visible photosynthetic pigments (Fig. 4d). SAG 2382 was within the same OTU 39 as representative fully sequenced clone AEW2R_K255 and reference sequence EU105209 for Xylochloris irregularis, the type of the genus Xylochloris. Therefore, OTU 39 represents Xylochloris. However, the genetic distances of the former two sequences with that of $X$. irregularis as seen in the phylogenetic analyses (Fig. 1) makes it questionable, whether both sequences belong to $X$. irregularis. 
Table 3. Green algal isolates retrieved from soil and tree bark of temperate forests. The 17 OTUs belong to the green algal classes of Trebouxiophyceae and Chlorophyceae. An asterisk indicates clones available for this OTU.

\begin{tabular}{|c|c|c|c|c|c|}
\hline OTU Name & OTU No. & Isolate & Acc. No. & Plot & Substrate \\
\hline \multicolumn{6}{|l|}{ Trebouxiophyceae } \\
\hline Auxenochlorella & OTU 54 & SAG 2478 & KP081390 & AEW4 & soil \\
\hline \multirow[t]{2}{*}{ Chlorella } & OTU 59 & KP09AW8003 & KP081408 & AEW8 & tree bark \\
\hline & & KP09AW8002 & - & AEW8 & tree bark \\
\hline Chloroidium & OTU $14^{*}$ & LH08AW8042 & KP081400 & AEW8 & soil \\
\hline \multirow[t]{2}{*}{ Coccomyxa } & OTU $07^{*}$ & SAG 2483 & KP081391 & AEW8 & soil \\
\hline & OTU 53 & LH08AW 1017 & KP081392 & AEW10 & soil \\
\hline \multirow[t]{2}{*}{ Dictyochloropsis } & OTU $16^{*}$ & LH08AW3050 & JQ988930 & AEW3 & soil \\
\hline & & SAG 2305 & GU017658 & AEW3 & tree bark \\
\hline Lobosphaera & OTU 20* & LH08AW3064 & KP081398 & AEW3 & soil \\
\hline Neocystis & OTU $37^{*}$ & SAG 2480 & KP081393 & AEW8 & soil \\
\hline \multirow[t]{7}{*}{ Stichococcus } & OTU 55 & SAG 2481 & KP081394 & AEW8 & soil \\
\hline & & KP09AW1004 & KP081407 & AEW10 & tree bark \\
\hline & & KP09AW1006 & - & AEW10 & tree bark \\
\hline & & KP09AW1001 & - & AEW10 & tree bark \\
\hline & OTU 56 & SAG 2482 & KP081395 & AEW8 & soil \\
\hline & & LH08AW8104 & KP081396 & AEW8 & soil \\
\hline & OTU 57 & LH08AW8025 & KP081397 & AEW8 & soil \\
\hline unident. trebouxiophyte & OTU 58 & SAG 2477 & KP081399 & AEW3 & soil \\
\hline Xylochloris & OTU 39* & SAG 2382 & JQ988942 & AEW7 & soil \\
\hline \multicolumn{6}{|l|}{ Chlorophyceae } \\
\hline Chlamydomonadales & OTU $42^{*}$ & SAG 2476 & KP081401 & AEW1 & soil \\
\hline \multirow[t]{3}{*}{ Chlorococcum } & OTU 62 & SAG 2479 & KP081402 & AEW5 & soil \\
\hline & & LH08AW5111 & KP081403 & AEW5 & soil \\
\hline & & LH08AW5107 & KP081404 & AEW5 & soil \\
\hline Coelastrella & OTU 60 & LH08AW4118 & KP081406 & AEW4 & soil \\
\hline \multirow[t]{2}{*}{ Jenufa } & OTU 61 & LH08AW8098 & KP081405 & AEW8 & soil \\
\hline & & SAG 2383 & JQ988933 & AEW8 & soil \\
\hline
\end{tabular}

Rather, both our OTU 39 sequence from soils of the AEW plots may represent two additional species of Xylochloris. Four more trebouxiophycean OTUs were recovered exclusively by cultured isolates, i.e. OTUs 55, 56, 57, and 58 (Tables 3 and S1). The former three exhibited Stichococcus-like morphological features (e.g. OTU 56; Fig. 4c) and were also close relatives with reference strains representing various lineages of Stichococcus which appeared as a paraphyletic assemblage within the Prasiola-clade of Trebouxiophyceae (Fig. 1). Strain SAG 2477 (OTU 58) represented an independent lineage within the Trebouxiophyceae. It was somehow closer related to the Leptochlorellaclade, but there was no statistical support for this relationship (Fig. 1). 

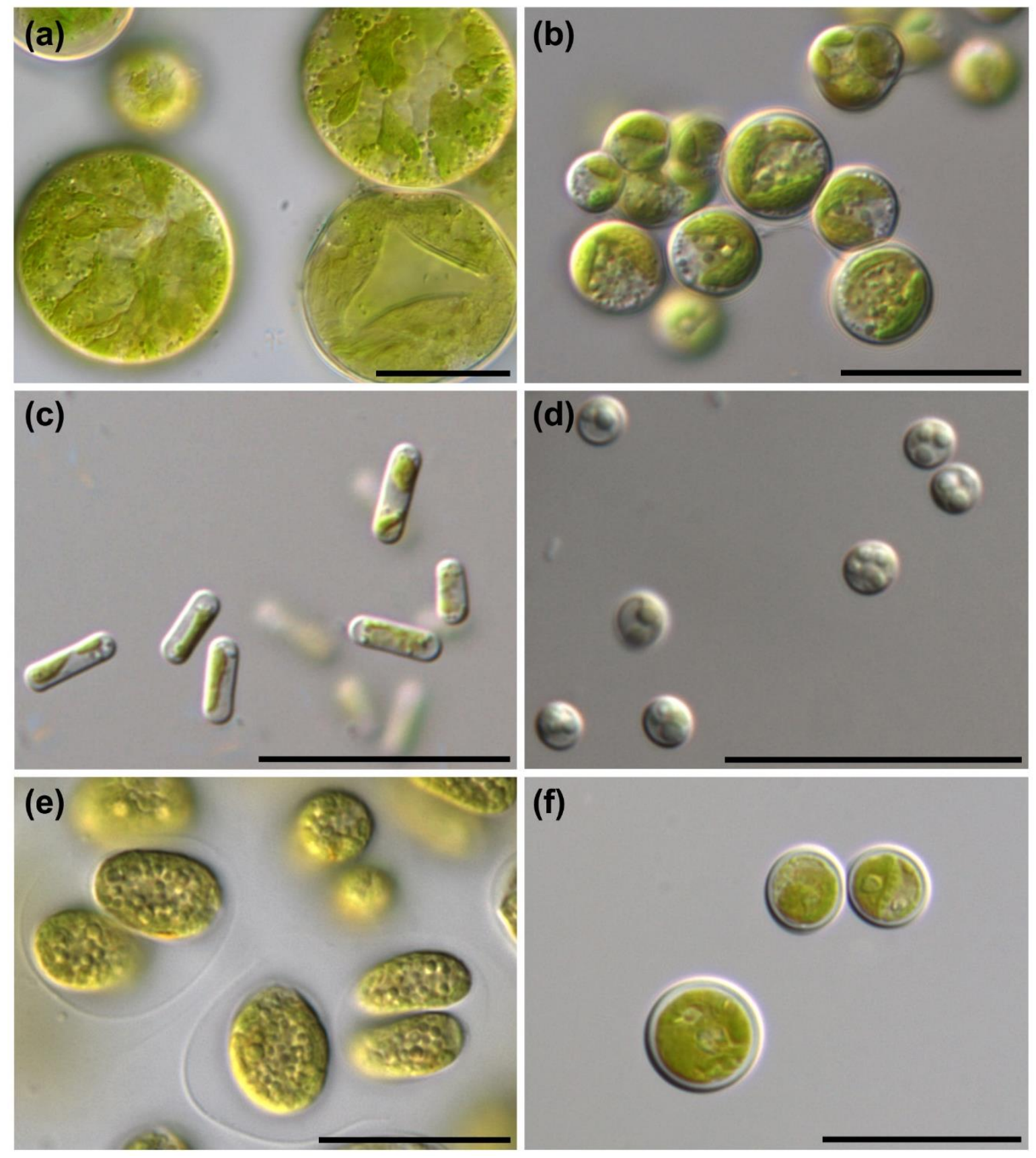

Fig. 4. Photomicrographs of cultured isolates. (a) - (d) Trebouxiophyceae, (e) - (f) Chlorophyceae. (a) Dictyochloropsis sp. LH08AW3050 (OTU 16); (b) 'Myrmecia' sp. isolate LH08AW3064 (OTU 20); (c) Stichococcus sp. isolate SAG 2482 (OTU 56); (d) Auxenochlorella sp. isolate SAG 2478 (OTU 54); (e) Chlamydomonadales sp./Oogamochlamydinia clade isolate SAG 2476 (OTU 42); (f) Chlorococcum cf. minutum isolate SAG 2479 (OTU 62). Scale bars, $20 \mu \mathrm{m}$. 
Only one member of the class Chlorophyceae was found by both culturing and cloning. The OTU 42 comprising isolate SAG 2476 and clone AEW6B_K216, was phylogenetically affiliated to Chlamydomonadales sp. /Oogamochlamydinia clade and exhibited a distinct linage without known close relatives (Fig. 2). The isolate has characteristic monadoid morphology with elliptic cells with two flagella, one cup-shaped chloroplast (without pyrenoid) and stigma (Fig. 4e). Three more chlorophycean OTUs (OTUs 60, 61, and 62) were detected exclusively with cultures from soils of plots AEW4, AEW 8 and AEW 5 (Tables 3, S1; Fig. 4f). The OTUs 60 and 61 may represent species of Coelastrella and Jenufa, respectively (Fig. 2; Hodač et al., 2012). OTU 62 has a Chlorococcum-like morphology (Fig. 4f), but Chlorococcum appears as a polyphyletic assemblage in molecular phylogenies (Fig. 2) and, therefore, the correct assignment of strain SAG 2479 remains unclear at present.

\section{Tree bark algal diversity}

From the tree bark samples, collected from two different host trees (Picea abies and Fagus sylvatica), a total of 24 OTUs were recovered through cloning. All OTUs detected in these samples were affiliated to Trebouxiophyceae, no Chlorophyceae were observed (Table 2, Table S1). The most frequent OTU detected on tree bark was Coccomyxa OTU 07, which occurred in seven out of eight samples and represented $17.6 \%$ of the retrieved tree bark clones. Additionally observed in high abundances was Elliptochloris OTU 10 in five samples and Coccomyxa OTU 08 and Apatococcus OTU 04 in four. Twelve OTUs were found twice or more times and eight OTUs were recovered only a single time (Table 2). The highest species/OTU richness of tree bark samples was detected in the plots AEW7 and AEW6 (11 and nine OTUs), both host trees were beech, while lowest species/OTU richness were investigated in AEW1 (spruce) and AEW5 (beech) with five and four OTUs.

No correlation between species/OTU richness on tree barks and forest management types was found (Fig. 3). The number of OTUs retrieved from the different management types were almost the same, from age class forests 14 (spruce) and 11 OTUs (beech) were recovered, from unmanaged beech forests a total of 13 OTUs were retrieved (Fig. 3). Modest differences between OTU richness of spruce (exclusively six OTUs) and beech tree bark (exclusively ten OTUs) were obvious, whereas $33 \%$ (eight OTUs) were common to both host tree species. A separate PCA ordination focusing solely on tree bark samples illustrated dissimilarity in OTU composition of spruce (AEWR1 to AEW3) and beech 
(AEWR5 to AEW9) forest samples (Fig. 5). Here, Dictyochloropsis OTU 19, Asterochloris OTU 25 and Chlorella mirabilis relative OTU 40 were detected predominantly on spruce tree barks, whereas, for example, Trebouxia OTU 23 or Apatococcus OTU 04 occurred more frequently on beech tree barks.

Six isolates were retrieved from tree bark samples (Table 3). The isolate SAG 2305 Dictyochloropsis splendida (GU017658), isolated from spruce tree bark, belonged to the same OTU 16, which was found as an isolate and as clones in soil samples. Another three isolates from spruce tree bark were represented by partial sequences and affiliated to Stichococcus OTU 55, isolated from soil samples as well. Finally, two isolates belonged to OTU 59, with high similarity (99.8 \%) to FM205832 Chlorella vulgaris strain SAG 211-11b (isolated from beech tree bark).

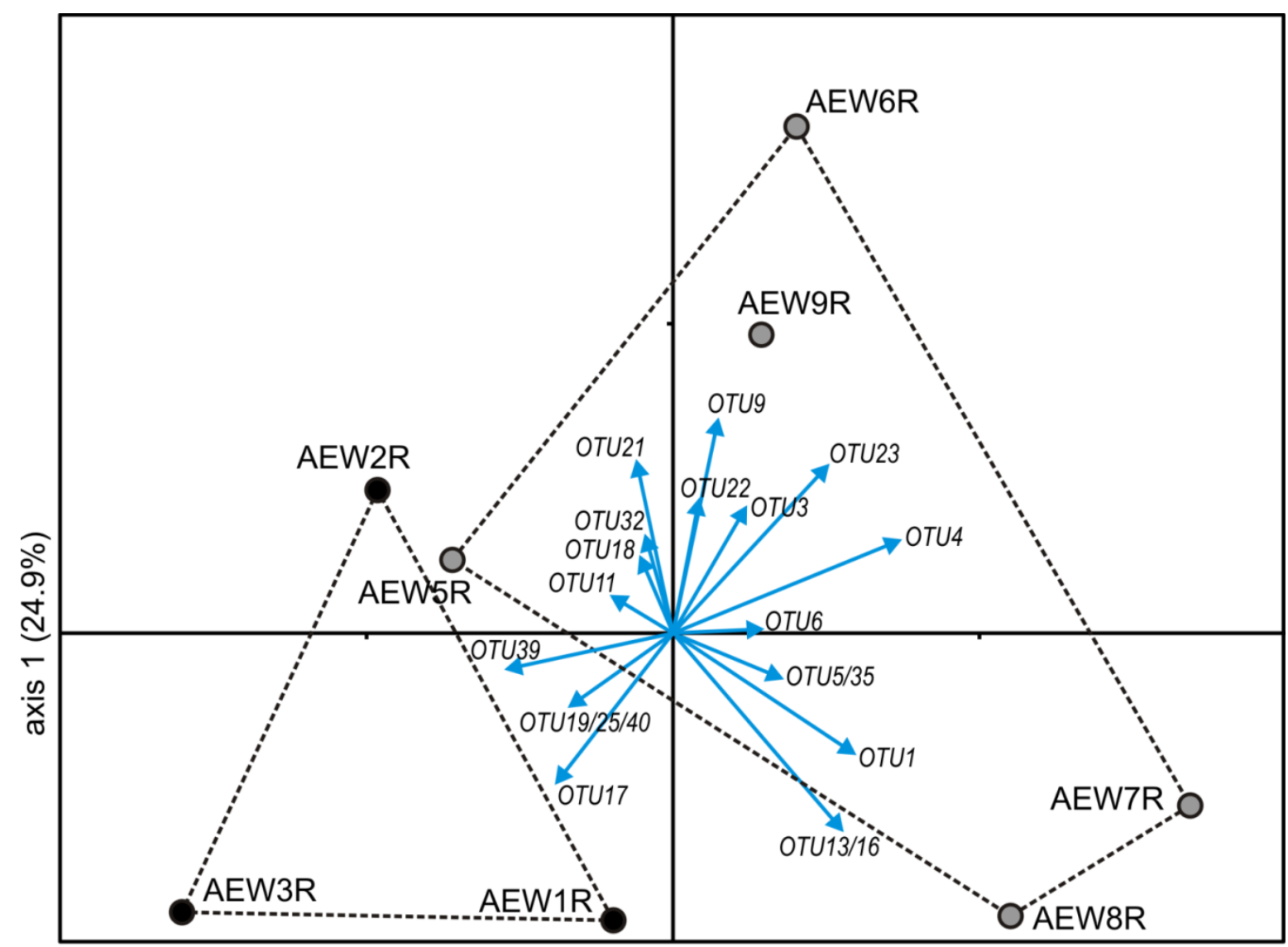

axis $2(19.9 \%)$

Fig. 5. Principal Components Analysis (PCA). Ordination diagram showing trebouxiophyte OTUs (blue arrows) which are responsible for the main differences between tree-bark samples from spruce (black dots) and beech (grey dots) forests. For the species/genus assignments of the OTUs see Table 2 . 


\section{Comparison of tree bark algal diversity with that of soil algae}

The clone libraries from tree bark samples exhibited lower green algal OTU diversity compared to those from soils. A total of ten OTUs (19\%) were exclusively retrieved from tree bark, 28 OTUs (54\%) were exclusively detected in soil (16 trebouxiophycean OTUs and 12 chlorophycean OTUs), whereas 14 OTUs $(27 \%)$ were shared by both habitats (Table 2). The species/OTU richness indicated no major differences between the habitats; the number of OTUs of tree barks samples varied from four to 11 OTUs with an average of 7.1 OTUs and from three to 16 OTUs with an average of 7.6 OTUs for the soil samples (Table 2). In addition to the OTUs affiliated to Chlorophyceae, also some OTUs represented Trebouxiophyceae exhibited habitat preferences. The PCA ordination depicted those trebouxiophycean OTUs which occurred preferentially either in soil or in tree bark samples (Fig. 6). As example, Coccomyxca OTU 07, Coccomyxa OTU 08 and

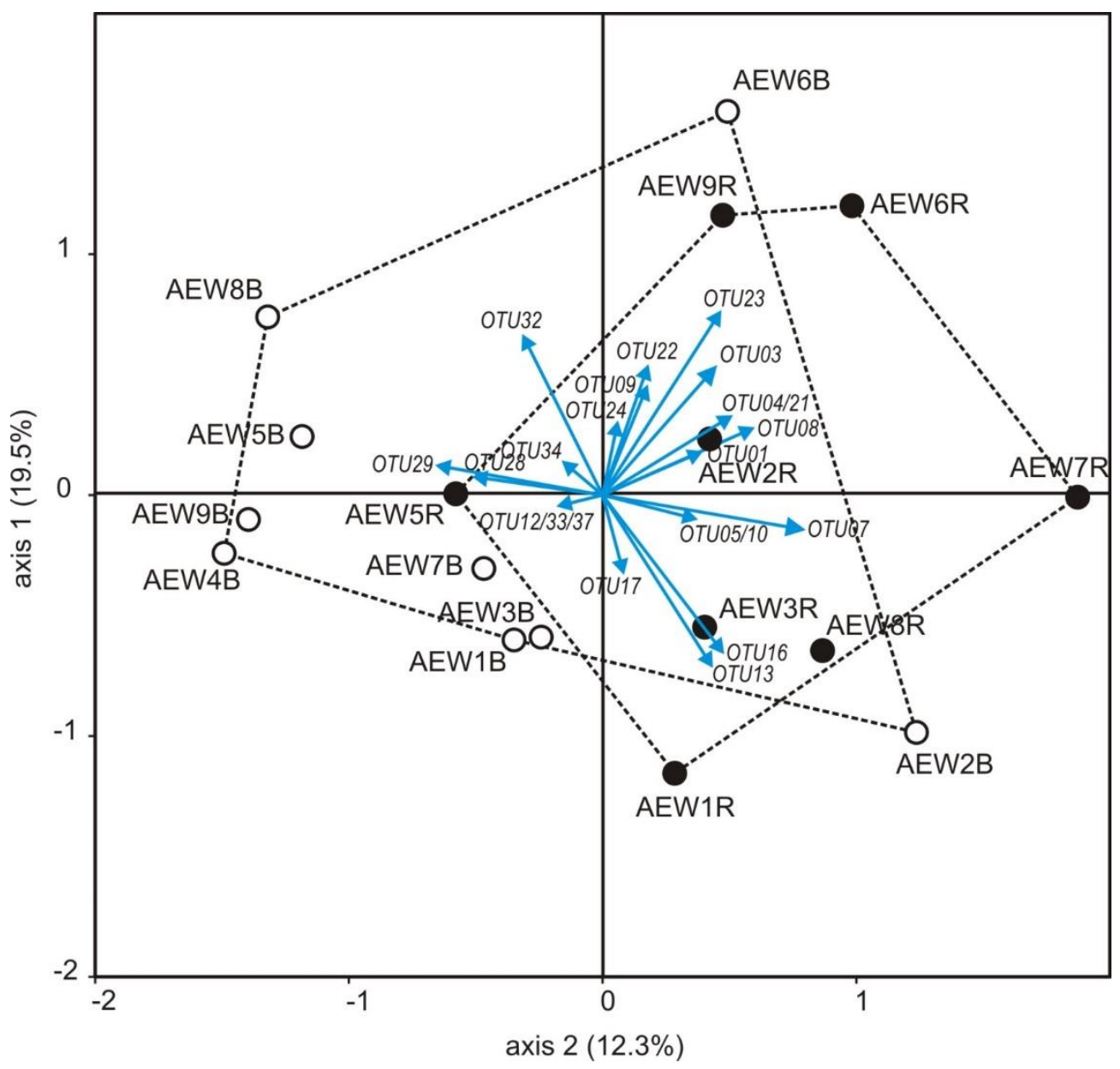

Fig. 6. Principal Components Analysis (PCA). Ordination diagram showing trebouxiophyte OTUs (blue arrows) which correspond to the main differences between soil ("B", white dots) and treebark ("R", black dots) plots. For the species/genus assignments of the OTUs see Table 2. 
Trebouxia OTU 23 represented taxa occurring preferentially on tree barks, whereas the Desmococcus OTU 32 occurred more frequently in soils. Clear habitat preferences were shown by Prototheca-relative OTUs 26, 27, 28 and 29, which were detected two to four times in high clone numbers from soil, but not a single time from tree bark and Apatococcus OTU 04 which was recovered four times from tree bark, but not a single time from soil.

\section{Discussion}

In this study the green algal communities from soil and tree bark samples from nine research plots of temperate forests in Germany were investigated through a cultureindependent approach and 18S rRNA gene sequence comparisons. The soil samples were additionally analysed by a traditional culturing approach and a few isolates were obtained from tree bark. So far culture-independent approaches including eukaryotic phototrophs from soil were predominantly performed for extreme environments like soils from Antarctic, fumaroles, Himalaya and glacier forefront (Lawley et al., 2004; Costello et al., 2009; Schmidt et al., 2011; Frey et al., 2013). Here we present the first molecular survey on green algae from temperate forests in Central Europe.

\section{Culture-independent and culture-dependent approach}

For the culture-independent approach and the sequencing of cultures the PCR primer CH1750R was used that preferentially amplifies 18S rRNA genes from green algae (Hallmann et al., 2013a) in order to enrich the clone libraries, especially of soil samples, with green algal sequences. Clone libraries from soil samples with standard PCR primer combinations which generally amplify eukaryotic 18S rRNA genes (e.g. primer 20F/18L) yielded various sequences from other soil organisms, e.g. fungi, alveolates and nematodes, and these were even dominating over corresponding green algal sequences. In the majority of the established clone libraries green algal 18S rRNA gene sequences were predominant, except for sample AEW1 a large fraction of a Dileptus-like ciliate 18S rRNA gene sequence (98 \% blast similarity with Dileptus sp.; acc. no. AF029764) was retrieved (Table 1). Probably this ciliate was so abundant in AEW1 that it masked the green algae present there. In addition, members of Klebsormidiophyceae and the ulvophyte Trentepohlia were not amplified, whilst microscopic observation of soil and tree bark 
samples recovered also algae of other groups like Klebsormidium sp. (Streptophyta) and Xanthophyceae (Stramenopiles).

For the soil samples we used two approaches, culture-independent rRNA gene cloning/sequencing and sequencing of unialgal cultures developed from the same samples. This allows comparing the algal diversities recovered by both approaches. The cloning approach revealed a higher OTU diversity (42 OTUs) like the culture-based approach (16 OTUs), as expected. Many studies have shown that sequencing of SSU rRNA genes and culture-independent approaches resulted in much higher diversity (e.g. López-García et al., 2001; Moon-van der Staay et al., 2001; Scheckenbach et al., 2010; Lara et al., 2011). Only six OTUs (11.5\% of all detected) were shared by both approaches. Interestingly, these OTUs occurred only in small clone numbers (1-6 clones per OTU). Remarkably no isolate was obtained from the most abundant OTUs retrieved by the cloning approach, i.e. seven OTUs occurred in three up to five samples with relatively high clone numbers from 9 to 69 . The different results of samples analyzed by a combination of culture-independent and dependent methods, were often observed (Norris and Castenholz, 2005; Vaz-Moreira et al., 2011; Bazin et al., 2014). Culture-based approaches often favor ubiquitous algae and suppress specialists, also very rare species and non-cultivable algae were not captured (Hoffmann, 1989; Neustupa and Škaloud, 2010).

\section{Diversity of OTUs}

The majority of OTUs belonged to the green algal class Trebouxiophyceae and was distributed over five well known distinct clades and various single lineages, representing predominantly aerophytic or soil algae (Friedl and Rybalka, 2012).

The most abundant OTU, Elliptochloris OTU 10, found in ten samples (Table 2), exhibited no preference towards tree bark or soil and shared $99.3 \%$ to $99.8 \%$ pairwise sequence similarities, calculated from p-distances (Table S1), to Elliptochloris subsphaerica FR865675 isolated from Antarctic soils. E. subsphaerica were also observed on tree bark (Ettl and Gärtner, 1995; Freystein et al., 2008). The other Elliptochloris OTU, OTU 13, was also without preference towards tree bark or soil because it was recovered from three samples of each habitat (Table 2). The representative clone sequences exhibited only $97.2 \%$ to reference sequence E. subsphaerica FR865675. In the phylogenetic tree (Fig. 1) reference strains for all so far known species of Elliptochloris were included, but the OTU 13 did not match any of them. Therefore, Elliptochloris OTU 13 may represent a still undescribed new species of Elliptochloris. As well Apatococcus OTU 03 indicated no 
preference towards tree bark or soil (found in three samples of each habitat). However Apatococcus OTU 04 exhibited a clear preference towards tree bark and was not retrieved from soil. The OTUs affiliated to Apatococcus exhibited high similarities (99.1\% to $99.9 \%$ ) to reference strains SAG 2037, SAG 2359 and SAG 2151 (JX169825, JX169826, JX169829), isolated from green biofilms collected from tree bark and plastic surfaces. Apatococcus was also observed in soil (Ettl and Gärtner, 1995), but this cannot be clearly validated since no Apatococcus strains isolated from soil were available (two strains mentioned in Gärtner and Ingolić, 1989 were misidentified, see e.g. sequence KM020045). Characteristic tree bark algae were Coccomyxa sp., Dictyochloropsis-related and Trebouxia sp. because they were found at more plots on tree bark than in the soil. The representative clone sequence for OTU 07, indicated $99 \%$ similarity to the authentic strain Coccomyxa viridis SAG 216-14 (KF673392), whereas the representative sequence for OTU 08 AEW7R_K132 showed just $97.5 \%$ and $97.4 \%$ similarities to Pseudococcomyxa (HE586505, KM020051). The OTU Coccomyxa-related (OTU 08) was nested within a clade representing strains of Coccomyxa and Pseudococcomyxa; it may represent a species of one of these genera that has not been sequenced so far or a new undescribed species (Fig. 1). OTU 16 was shared by all approaches and was retrieved from tree bark and soil; it is assigned to Dictyochloropsis splendida. Interestingly, the genus Dictyochloropsis appeared as a paraphyletic assemblage, i.e. D. splendida was not closer related to other species of the same genus (Fig. 1). For OTUs, observed in the clone libraries only in one sample, it remained unclear whether they had a habitat preference or not. The OTU affiliated to Desmococcus olivaceus (99.8\% and $100 \%$ similarity) could be denoted as a characteristic soil alga because it was retrieved in more samples from soil than from tree bark. Desmococcus is well known from tree bark, stone and soil (Gärtner and Ingolić, 2003). The trebouxiophycean OTU 38 as represented by clone AEW2B_K3 (partial sequence KP081376) was a close relative to Leptochlorella corticola (Fig. 1). The reference strain for L. corticola (sequence HE984579) was, however, not within the same OTU 38. Therefore, identification of the OTU still remains unclear; it may represent another yet undescribed species of Leptochlorella. Interestingly, the representative clone was next related to a sequence of a green algal clone recovered from the hypolithic habitat in Tibet (sequence FJ790649; Wong et al., 2010) which, however, shared only $97.9 \%$ similarity with our clone AEW2B_K3 (Table S1). OTU 20 was represented by one isolate (LH08AW3064) and a full length sequence of clone AEW2B_K6 (Fig. 1), next related to 'Myrmecia' sp. CCAP 221/8 (HQ902935) and 'Myrmecia' bisecta IB T74 (Z47209). This 
OTU included as well the reference strains 'Parietochloris' cohaerens UTEX 1707 (EU878372) and Lobosphaera incisa SAG 2007 (AY762602), the only authentic strain of a genus within this clade. Since of the distant position of L. incisa to the 'true' Myrmecia spp., see Myrmecia biatorella, closely related to Trebouxia spp. (Friedl, 1995; Karsten et al., 2005), our sequences could be probably assigned to Lobosphaera (Fig. 1).

No closer affiliation to any known green algal genera could be found for the five trebouxiophycean OTUs Prototheca-relative (OTU 26 to 31). Blast searches revealed just $80 \%$ to $84 \%$ similarities to representatives of Chlorellales or $93 \%$ to $\mathrm{AB} 470468$ Prototheca cutis. The phylogenetic analysis assigned these sequences within in Chlorellales clade, they had a sister group-relationship with P. zopfii, P. cutis and Auxenochlorella protothecoides, but were separated by long internal branches from the latter three (Fig. 1). Whereas Prototheca-relatives OTU 26 to 30 were closer related to $P$. zopfii X63519, OTU 31 was somehow closer related to P. cutis AB470468. Interestingly the most abundant OTUs in soil, Prototheca-relative OTU 26 to 31, were neither retrieved from tree bark nor could an isolate be established. These OTUs were next related to the heterotrophic genus Prototheca (including A. protothecoides) which is characterized by an accelerated mutation rate of its $18 \mathrm{~S}$ rRNA gene, which is indicated by unusually long branches. This is especially obvious for P. zopfii (Huss et al., 1999). Prototheca species are non-photosynthetic, known as pathogens but also described in soil (Roesler and Hensel, 2003; Ueno et al., 2003). It is likely to assume that the Prototheca-relative OTUs were important soil algae and were up to now retrieved by culturing.

The OTUs assigned to Chlorophyceae were distributed on Chlamydomonadales and Sphaeropleales. Most likely, the chlamydomonadalean OTUs (obtained exclusively from soil samples) represent flagellated taxa like Chlamydomonas or Chloromonas.

\section{Green algal communities in soils and on tree barks}

Altogether the soil algal communities exhibited a higher diversity than the communities on tree bark. This may be explained by that soil represents a more heterogeneous habitat, with trickles and small water pits. However in the tree bark samples no chlorophycean OTUs were detected. A similar finding has been reported for tree bark samples in Slovenia and Italy (Kulichová et al., 2014) as well as for sun-exposed stone substrates (Hallmann et al., 2013a, 2013b). Previous studies observed a few findings of Chlorophyceae on tree bark, but mainly resting stages like palmelloid phases of Chlamydomonas (Gärtner, 1994). Light, humidity, temperature, availability of nutrients, and $\mathrm{pH}$ seem to be the most important 
environmental factors that influence soil algal communities (Metting, 1981; Hoffmann, 1989). Based on the factors humidity and light it is conceivable to obtain exclusively in soil Chlorophyceae with motile members like Chlamydomonas and Chloromonas, described as typical algae in temperate forest soils (Neustupa, 2001 and references therein), and members of presumably non-photosynthetic Trebouxiophyceae (Prototheca-relative OTUs).

Epiphytic substrates as tree bark are less humid and dry over longer periods (arid) than soil (Hoffmann, 1989). Therefore, members of Trebouxiophyceae which exhibit various adaptions to desiccation like mucilage (e.g. Coccomyxa), thick cell walls (e.g. Apatococcus) and stress metabolites like polyols, may have more competitive advantages on tree bark (Gustavs et al., 2011; Holzinger and Karsten, 2013). The PCA analysis (Fig. 6) indicated an obvious overlap between tree bark and soil algal communities (altogether ten trebouxiophycean OTUs). Two of the most common OTUs on tree bark, Elliptochloris OTU 10 and Apatococcus OTU 03, were found almost equally frequent in the soil as well. A few OTUs which have clear preference to tree bark were also found in the soil, but mostly with less frequency there, e.g. Coccomyxa OTU 07 and OTU 08, (Table 2) Conversely, Desmococcus was retrieved from the soil of four sampling sites, but observed on tree bark only in two samples. The occurrence of Trebouxiophyceae in soil could be explained by lichens which grow on the soil surface and on tree bark as well, e.g. photobionts like Dictyochloropsis, Elliptochloris, Myrmecia and Pseudococcomyxa (Hoffmann et al., 2007; Khaybullina et al., 2010). In addition, dispersal by wind and rain water may transport biofilm algae from tree bark into soil.

\section{Trends with respect to forest type}

The green algal communities indicated some tendencies with respect to different host species trees and forest types. The PCA analysis (Fig. 5) exhibited differences between the algal composition on tree bark of spruce and beech trees. Additionally, less OTU richness in samples of spruce bark could be observed, i.e. an average of 6.3 different OTUs in sample from spruce (three samples) and 7.6 OTUs from beech (five samples) tree bark. These findings could be explained by different structures/microhabitats of tree bark, like roughness (Lüttge and Büdel, 2010), water availability or light (UV irradiance). The tendency of less OTU richness of needle-leaved tree barks compared to those of broadleaved were already observed but exhibited low significance (Kulichová et al., 2014). 
The soil algal communities exhibited no obvious differences in OTU richness between beech and spruce forest, i.e. a total of 22 OTUs were detected in soil of spruce forests and 24 OTUs in beech. However, former studies observed in soils of needle-leaved forests a lower diversity and abundance of soil algae than in broadleaved forest, presumably because they are highly acidic and nutrient-poor (Lukešová and Hoffmann, 1996; Neustupa, 2001, and references therein; Novakovskaya and Patova, 2008). Some OTUs indicated preferences to sampling sites of different management types. Remarkably one of the most abundant OTUs, Prototheca-relative OTU 26, was not discovered in the unmanaged beech samples, while it was present in spruce and beech age class forests. OTUs with preference to beech forest were represented by Prototheca-relative OTU 29 and Desmococcus, which were not retrieved from spruce forest samples.

Obvious differences in the OTU composition between the soil types, Leptosol (AEW2, AEW7 and AEW9) and Cambisol, could not be observed. Interestingly, the OTU richness of unmanaged forest sampling sites was the lowest one, especially of chlorophycean OTUs One can expect there the specialist taxa. On the other hand the age class forest sites were higher diverse and there generalists could be supposed. A former study observed less algal density in old forest soils compared to deforested soils, it could be related to low light intensity due to high litter and cover (Lukešová and Hoffmann, 1996). Our findings may also explained by low light or water capability. 


\section{Acknowledgements}

We thank Heiko Nacke, Christiane Fischer and Rolf Daniel for providing DNA-extracts from soil samples, Maike Lorenz for valuable comments and the deposition of cultures to the SAG culture collection as well as Kristin Pahlmann for provision of sequences. We thank the managers of the three Exploratories, Swen Renner, Sonja Gockel, Kerstin Wiesner, and Martin Gorke for their work in maintaining the plot and project infrastructure; Simone Pfeiffer and Christiane Fischer giving support through the central office, Michael Owonibi for managing the central data base, and Markus Fischer, Eduard Linsenmair, Dominik Hessenmöller, Jens Nieschulze, Daniel Prati, Ingo Schöning, François Buscot, Ernst-Detlef Schulze, Wolfgang W. Weisser and the late Elisabeth Kalko for their role in setting up the Biodiversity Exploratories project. The work has been (partly) funded by the DFG Priority Program 1374 "Infrastructure-BiodiversityExploratories" (DFG FR 905/16-1). Field work permits were issued by the responsible state environmental offices of Baden-Württemberg, Thüringen, and Brandenburg (according to $\S 72 \mathrm{BbgNatSchG).}$

\section{References}

Altschul, S.F., Gish, W., Meyers, E.W. and Lipman, D.J. (1990) Basic local alignment search tool. J Mol Biol 215: 403-410.

Barkman, J.J. (1958) Phytosociology and ecology of cryptogamic epiphytes. Van Gorkum and Company. Assen, Netherlands.

Bazin, P., Jouenne, F., Friedl, T., Deton-Cabanillas, A.F., Le Roy, B., et al. (2014) Phytoplankton diversity and community composition along the estuarine gradient of a temperate macrotidal ecosystem: Combined morphological and molecular approaches. PLoS ONE 9: e94110.

Bérard, A., Dorigo, U., Humbert, J.F. and Martin-Laurent, F. (2005) Microalgae community structure analysis based on $18 \mathrm{~S}$ rDNA amplification from DNA extracted directly from soil as a potential soil bioindicator. Agron Sustain Dev 25: 285-291.

Bölter, M. (1992) Environmental conditions and microbiological properties from soils and lichens from Antarctica (Casey Station, Wilkes Land). Polar Biol 11: 591-599.

Broady, P.A. (1996) Diversity, distribution and dispersal of Antarctic terrestrial algae. Biodivers Conserv 5: 1307-1335.

Büdel, B., Darienko, T., Deutschewitz, K., Dojani, S., Friedl, T., Mohr, K.I., Salisch, M., Reisser, W. and Weber, B. (2009) Southern African biological soil crusts are ubiquitous and highly diverse in drylands, being restricted by rainfall frequency. Microb Ecol 57: 229-247.

Costello, E.K., Halloy, S.R.P., Reed, S.C., Sowell, P. and Schmidt, S.K. (2009) Fumarolesupported islands of biodiversity within a hyperarid, high-elevation landscape on Socompa Volcano, Puna de Atacama, Andes. Appl Environ Microbiol 75: 735-747. 
Darienko, T., Gustavs, L., Mudimu, O., Rad Menendez, C., Schumann, R., Karsten, U., Friedl, T. and Pröschold, T. (2010) Chloroidium, a common terrestrial coccoid green alga previously assigned to Chlorella (Trebouxiophyceae, Chlorophyta). Eur J Phycol 45: 1469-4433.

De Wever, A., Leliaert, F., Verleyen, E., Vanormelingen, P., Van der Gucht, K., Hodgson, D.A., Sabbe, K. and Vyverman, W. (2009) Hidden levels of phylodiversity in Antarctic green algae: further evidence for the existence of glacial refugia. Proc Biol Sci 276: 3591-3599.

Elbert, W., Weber, B., Burrows, S., Steinkamp, J., Büdel, B., Andreae, M.O. and Pöschl, U. (2012) Contribution of cryptogamic covers to the global cycles of carbon and nitrogen. Nat Geosci 5 : 459-462.

Erdmann, G., Otte, V., Langel, R., Scheu, S. and Maraun, M. (2007) The trophic structure of barkliving oribatid mite communities analysed with stable isotopes $(15 \mathrm{~N} ; 13 \mathrm{C})$ indicates strong niche differentiation. Exp Appl Acarol 41: 1-10.

Ettl, H. and Gärtner, G. (1995) Syllabus der Boden-, Luft- und Flechtenalgen. Gustav Fischer, Stuttgart.

Feng, X., Simpson, A.J. and Gregorich, E.G. (2010) Chemical characterization of microbialdominated soil organic matter in the Garwood Valley, Antarctica. Geochim Cosmochim Acta 74: 6485-6498.

Fischer, M., Bossdorf, O., Gockel, S., Hänsel, F., Hemp, A., et al. (2010) Implementing large-scale and long-term functional biodiversity research: The Biodiversity Exploratories. Basic Appl Ecol 11: 473-485.

Flechtner, V.R., Pietrasiak, N. and Lewis, L.A. (2013) Newly revealed diversity of eukaryotic algae from wilderness areas of Joshua Tree National Park (JTNP). Monogr West N Am Nat 6: 43-63.

Frey, B., Bühler, L., Schmutz, S., Zumsteg, A. and Furrer, G. (2013) Molecular characterization of phototrophic microorganisms in the forefield of a receding glacier in the Swiss Alps. Environ Res Lett 8: 015033.

Freystein, K., Salisch, M. and Reißer, W. (2008) Algal biofilms on tree bark to monitor airborne pollutants. Biologia 63: 866-872.

Friedl, T. (1995) Inferring taxonomic positions and testing genus level assignments in coccoid green lichen algae: A phylogenetic analysis of $18 \mathrm{~S}$ ribosomal RNA sequences from Dictyochloropsis reticulate and from members of the genus Myrmecia (Chlorophyta, Trebouxiophyceae cl. nov.). J Phycol 31: 632-639.

Friedl, T. and Rybalka, N. (2012) Systematics of the green algae: A brief introduction to the current status. In Lüttge, U., Beyschlag, W., Francis, D. and Cushman, J. (eds) Progress in Botany No. 73. Springer, Heidelberg, pp. 259-280.

Friedl, T. and Lorenz, M. (2012) The Culture Collection of Algae at Göttingen University (SAG): A biological resource for biotechnological and biodiversity research. Proced Environ Sci 15: 110-117.

García-Pichel, F., López-Cortés, A. and Nübel, U. (2001) Phylogenetic and morphological diversity of cyanobacteria in soil desert crusts from the Colorado Plateau. Appl Environ Microbiol 67: 1902-1910.

Gärtner, G. and Ingolić, E. (1989) Ein Beitrag zur Kenntnis von Apatococcus lobatus (Chlorophyta, Chaetophorales, Leptosiroideae). Plant Syst Evol 164: 133-143.

Gärtner, G. (1994) Zur Taxonomie aerophiler grüner Algenanflüge an Baumrinden. Ber nat-med Verein Innsbruck 81: 51-59.

Gärtner, G. and Ingolić, E. (2003) Further studies on Desmococcus Brand emend. Vischer (Chlorophyta, Trebouxiophyceae) and a new species Desmococcus spinocystis sp. nov. from soil. Biologia (Bratislava) 58: 517-523. 
Good, I.J. (1953) The population frequencies of species and the estimation of population parameters. Biometrika 40: 237-264.

Gustavs, L., Görs, M. and Karsten, U. (2011) Polyol patterns in biofilm-forming aeroterrestrial green algae (Trebouxiophyceae, Chlorophyta). J Phycol 47: 533-537.

Hall, T.A. (1999) BioEdit: a user-friendly biological sequence alignment editor and analysis program for Windows 95/98/NT. Nucleic Acids Symp Ser (Oxf) 41: 95-98.

Hallmann, C., Stannek, L., Fritzlar, D., Hause-Reitner, D., Friedl, T. and Hoppert, M. (2013a) Molecular diversity of phototrophic biofilms on building stone. FEMS Microbiol Ecol 84: 355-372.

Hallmann, C., Wedekind, W., Hause-Reitner, D. and Hoppert, M. (2013b) Cryptogam covers on sepulchral monuments and re-colonization of a marble surface after cleaning. Environ Earth Sci 69: 1149-1160.

Hamby, R.K., Sim, L.E., Issel, L.E. and Zimmer, E.A. (1988) Direct RNA sequencing optimization of extraction and sequencing techniques for work with higher plants. Pl Mol Biol Rep 6: 179-197.

Hammer, Ø., Harper, D.A.T. and Ryan, P.D. (2001) PAST: Paleontological Statistics Software Package for education and data analysis. Palaeontol Electronica 4.

Hepperle, D. (2004) SeqAssem $\odot$. A sequence analysis tool, counting assembler and trace data visualization tool for molecular sequences. Win32-Version. Distributed by the author via: http://www.seqeuntix.de.

Hodač, L., Hallmann, C., Rosenkranz, H., Faßhauer, F. and Friedl, T. (2012) Molecular evidence for the wide distribution of two lineages of terrestrial green algae (Chlorophyta) over tropics to temperate zone. ISRN Ecol 2012: 795924.

Hodač, L., Brinkmann, N., Mohr, K.I., Arp, G., Hallmann, C., Ramm, J., Spitzer, K. and Friedl, T. (2015) Diversity of microscopic green algae (Chlorophyta) in calcifying biofilms of two karstic streams in Germany. Geomicrobiol J 32: 275-290.

Hoffmann, L. (1989) Algae of terrestrial habitats. Bot Rev 55: 77-105.

Hoffmann, L., Ector, L. and Kostikov, I. (2007) Algae flora from limed and unlimed forest soils in the Adrenne (Belgium). Syst Geogr Pl 77: 15-90.

Holzinger, A. and Karsten, U. (2013) Desiccation stress and tolerance in green algae: consequences for ultrastructure, physiological, and molecular mechanisms. Front Plant Sci 4 article 327.

Huber, T., Faulkner, G. and Hugenholtz, P. (2004) Bellerophon; a program to detect chimeric sequences in multiple sequence alignments. Bioinformatics 20: 2317-2319.

Huelsenbeck, J.P. and Ronquist, F. (2001) MrBayes: Bayesian inference of phylogenetic trees. Bioinformatics 17: 754-755.

Hunt, M.E., Floyd, G.L. and Stout, B.B. (1979) Soil algae in field and forest environments. Ecology 60: 362-375.

Huss, V.A.R., Frank, C., Hartmann, E.C., Hirmer, M., Kloboucek, A., Seidel, B.M., Wenzeler, P. and Kessler, E. (1999) Biochemical taxonomy and molecular phylogeny of the genus Chlorella sensu lato (Chlorophyta). J Phycol 35: 587-598.

Kabirov, R.R. and Gaisina, L.A. (2009) Parameters of the productivity of soil algae in terrestrial ecosystems. Eur Soil Sci 42: 1374-1379.

Karsten, U., Friedl, T., Schumann, R., Hoyer, K. and Lembcke, S. (2005) Mycosporine-like amino acids and phylogenies in green algae: Prasiola and its relatives from the Trebouxiophyceae (Chlorophyta). J Phycol 41: 557-566.

Katoh, T. and Toh, H. (2008) Recent developments in the MAFFT multiple sequence alignment program. Brief Bioinform 9: 286-298. 
Kharkongor, D. and Ramanujam, P. (2014) Diversity and species composition of subaerial algal communities in forested areas of Meghalaya, India. International Journal of Biodiversity Volume 2014, Article ID 456202.

Khaybullina, L.S., Gaysina, L.A., Johansen, J.R. and Krautová, M. (2010) Examination of terrestrial algae of the great smoky mountains national park, USA. Fottea 10: 201-215.

Kulichová, J., Škaloud, P. and Neustupa, J. (2014) Molecular diversity of green corticolous microalgae from two sub-Mediterranean European localities. Eur J Phycol 49: 345-355.

Lara, E., Mitchell, E.A., Moreira, D. and López-García, P. (2011) Highly diverse and seasonally dynamic protist community in a pristine peat bog. Protist 162: 14-32.

Lawley, B., Ripley, S., Bridge, P. and Convey, P. (2004) Molecular analysis of geographic patterns of eukaryotic diversity in Antarctic soils. Appl Environ Microbiol 70: 5963-5972.

Lewis, L.A. and Lewis, P.O. (2005) Unearthing the molecular phylodiversity of desert soil green algae (Chlorophyta). Syst Biol 54: 936-947.

Lin, C.S., Chou, T.L. and Wu, J.T. (2013) Biodiversity of soil algae in the farmlands of midTaiwan. Bot Stud 54: 41.

López-García, P., Rodríguez-Valera, F., Pedrós-Alió, C. and Moreira, D. (2001) Unexpected diversity of small eukaryotes in deep-sea Antarctic plankton. Nature 409: 603-607.

López-Bautista, J.M., Rindi, F. and Casamatta, D. (2007) The systematics of subaerial algae. In Seckbach, J. (ed) Algae and Cyanobacteria in Extreme Environments. Springer Verlag, Dordrecht, the Netherlands, pp. 599-617.

Ludwig, W., Strunk, O., Westram, R., Richter, L., Meier, H., et al. (2004) ARB: a software environment for sequence data. Nucl Acids Res 32: 1363-1371.

Lukešová, A. and Hoffmann, L. (1996) Soil algae from acid rain impacted forest areas of Krusne hory Mts. 1. Algal communities. Vegetatio 125: 123-136.

Lüttge, U. and Büdel, B. (2010) Resurrection kinetics of photosynthesis in desiccation-tolerant terrestrial green algae (Chlorophyta) on tree bark. Plant Biol 12: 437-444.

Metting, B. (1981) The systematics and ecology of soil algae. Bot Rev 47: 195-312.

Mikhailyuk, T.I. (1999) Eusubaerial algae of kaniv nature reserve (Ukraine). Ukrainskii Botanicheskii Zhurnal 56: 507-513.

Moon-van der Staay, S.Y., De Wachter, R. and Vaulot, D. (2001) Oceanic 18S rDNA sequences from picoplankton reveal unsuspected eukaryotic diversity. Nature 409: 607-610.

Nacke, H., Thürmer, A., Wollherr, A., Will, C., Hodac, L., Herold, N., Schöning, I., Schrumpf, M. and Daniel, R. (2011) Pyrosequencing-based assessment of bacterial community structure along different management types in German forest and grassland soils. PLOS ONE 6: e17000.

Neustupa, J. (2001) Soil algae from marlstone-substratum based biotopes, Czech Republic park Džbán (Central Bohemia, Czech Republic) with special attention to the natural treeless localities. Algol Stud 101: 109-120.

Neustupa, J. and Škaloud, P. (2008) Diversity of subaerial algae and cyanobacteria on tree bark in tropical mountain habitats. Biologia 63: 806-812.

Neustupa, J. and Škaloud, P. (2010) Diversity of subaerial algae and cyanobacteria growing on bark and wood in the lowland tropical forests of Singapore. Plant Ecol Evol 143: 51-62.

Neustupa, J. and Štifterová, A. (2013) Distribution patterns of subaerial corticolous microalgae in two European regions. Plant Ecol Evol 146: 279-289.

Norris, T.B. and Castenholz, R.W. (2006) Endolithic photosynthetic communities within ancient and recent travertine deposits in Yellowstone National Park. FEMS Microbiol Ecol 57: 470-483.

Novakovskaya, I.V. and Patova, E.N. (2007) Changes in soil algal communities in spruce phytocenoses under the influence of aerotechnogenic pollution. Eur Soil Sci 40: 576-582. 
Novakovskaya, I.V. and Patova, E.N. (2008) Green algae in spruce forests in the north-east of European Russia. Biologia 63: 836-842.

O'Brien, H.E., Parrent, J.L., Jackson, J.A., Moncalvo, J.M. and Vilgalys, R. (2005) Fungal community analysis by large-scale sequencing of environmental samples. Appl Environ Microbiol 71: 5544-5550.

Řeháková, K., Chlumská, Z. and Doležal, J. (2011) Soil cyanobacterial and microalgal diversity in dry mountains of Ladakh, NW Himalaya, as related to site, altitude, and vegetation. Microb Ecol 62: 337- 346.

Rindi, F., Allali, H.A., Lam, D.W. and López-Bautista, J.M. (2010) An overview of the biodiversity and biogeography of terrestrial green algae. In Rescigno, V. and Maletta, S. (eds) Biodiversity Hotspots. Nova Science Publishers, Hauppauge, New York, pp. 105-122.

Roesch, L.F.W., Fulthorpe, R.R., Riva, A., Casella, G., Hadwin, A.K.M., et al. (2007) Pyrosequencing enumerates and contrasts soil microbial diversity. ISME J 1: 283-290.

Roesler, U. and Hensel, A. (2003) Longitudinal analysis of Prototheca zopfii-specific immune responses: Correlation with disease progression and carriage in dairy cows. J Clin Microbiol 41: 1181-1186.

Scheckenbach, F., Hausmann, K., Wylezich, C., Weitere, M. and Arndt, H. (2010) Large-scale patterns in biodiversity of microbial eukaryotes from the abyssal sea floor. PNAS 107: 115-120.

Schloss, P.D., Westcott, S.L., Ryabin, T., Hall, J.R., Hartmann, M., et al. (2009) Introducing mothur: open-source, platform-independent, community-supported software for describing and comparing microbial communities. Appl Environ Microbiol 75: 7537-7541.

Schmidt, S.K., Lynch, R.C., King, A.J., Karki, D., Robeson, M.S., Nagy, L., Williams, M.W., Mitter, M.S. and Freeman, K.R. (2011) Phylogeography of microbial phototrophs in the dry valleys of the high Himalayas and Antarctica. Proc R Soc B 278: 702-708.

Shields, L.M. and Durrell, L.W. (1964) Algae in relation to soil fertility. Bot Rev 30: 92-128.

Stamatakis, A., Hoover, P. and Rougement, J. (2008) A rapid bootstrap algorithm for the RAxML web-servers. Syst Biol 75: 758-771.

Starr, R.C. and Zeikus, J.A. (1987) UTEX-The Culture Collection of Algae at the University of Texas at Austin. J Phycol 23 (suppl.): 1-47.

Tamura, K., Stecher, G., Peterson, D., Filipinski, A. and Kumar, S. (2013) MEGA6: Molecular Evolutionary Genetics Analysis version 6.0. Mol Biol Evol 30: 2725-2729.

Ueno, R., Urano, N. and Suzuki, M. (2003) Phylogeny of the non-photosynthetic green micro-algal genus Prototheca (Trebouxiophyceae, Chlorophyta) and related taxa inferred from SSU and LSU ribosomal DNA partial sequence data. FEMS Microbiol Lett 223: 275-280.

Vaz-Moreira, I., Egas, C., Nunes, O.C. and Manaia, C.M. (2011) Culture dependent and cultureindependent diversity surveys target different bacteria: a case study in a freshwater sample. Antonie Van Leeuwenhoek 100: 245-257.

Will, C., Thürmer, A., Wollherr, A., Nacke, H., Herold, N., Schrumpf, M., Gutknecht, J., Wubet, T., Buscot, F. and Daniel, R. (2010) Horizon-specific bacterial community composition of German grassland soils as revealed by pyrosequencing-based analysis of 16S rRNA genes. Appl Environ Microb 76: 6751-6759.

Will-Wolf, S., Esseen, P.A. and Neitlich, P. (2002) Monitoring biodiversity and ecosystem function: forests. In Nimis, P.L., Scheidegger, C. and Wolseley, P. (eds) Monitoring with lichens-monitoring lichens, vol. 7, no. 4. Kluwer Academic Publishers, Dordrecht, The Netherlands, pp. 203-222.

Wong, F.K., Lacap, D.C., Lau, M.C., Aitchison, J.C., Cowan, D.A. and Pointing, S.B. (2010) Hypolithic microbial community of quartz pavement in the high-altitude tundra of central Tibet. Microb Ecol 60: 730-739. 


\section{Supplementary Material chapter 5}

Table S1. Green algal OTUs recovered from soil and tree bark, their genus assignment, representing clone or isolated strain $18 \mathrm{~S}$ rRNA gene sequence for OTU and their percentage identities calculated from p-distances with closest available relative. An asterisk mark representative full-length sequences in phylogenetic analysis. A ' $\mathrm{P}$ ' indicates representative partial sequences (588-866 nts long). 


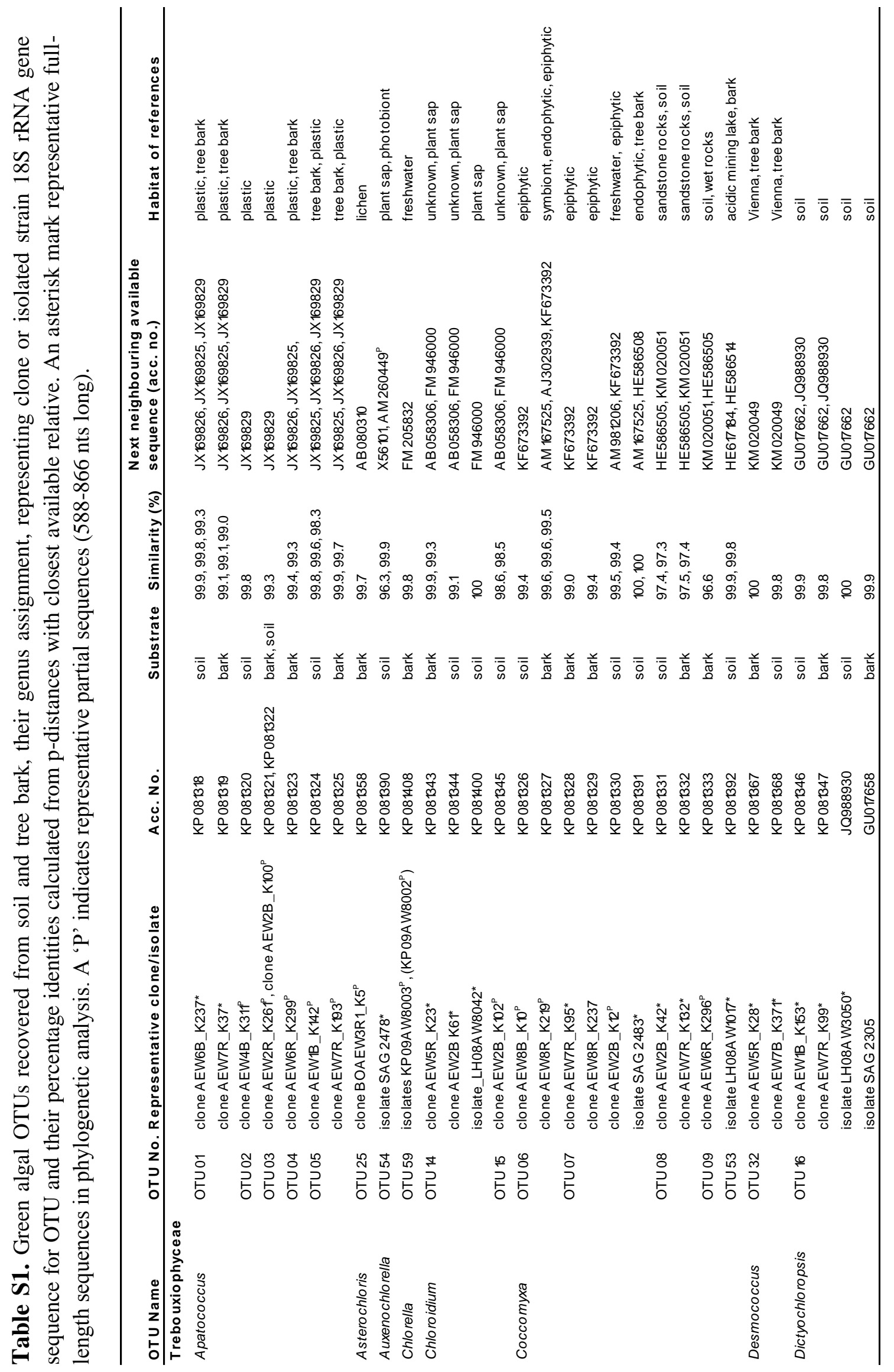




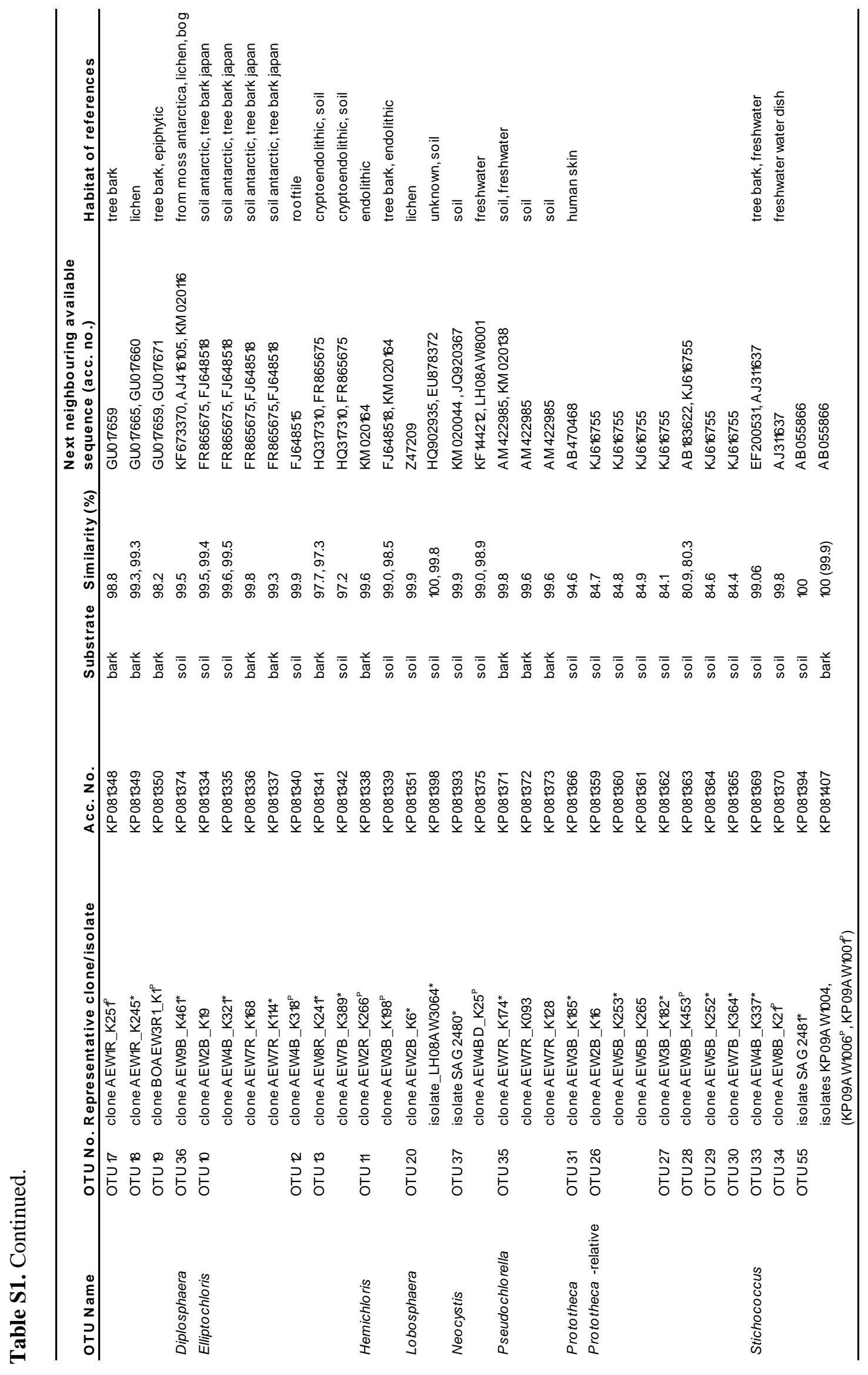




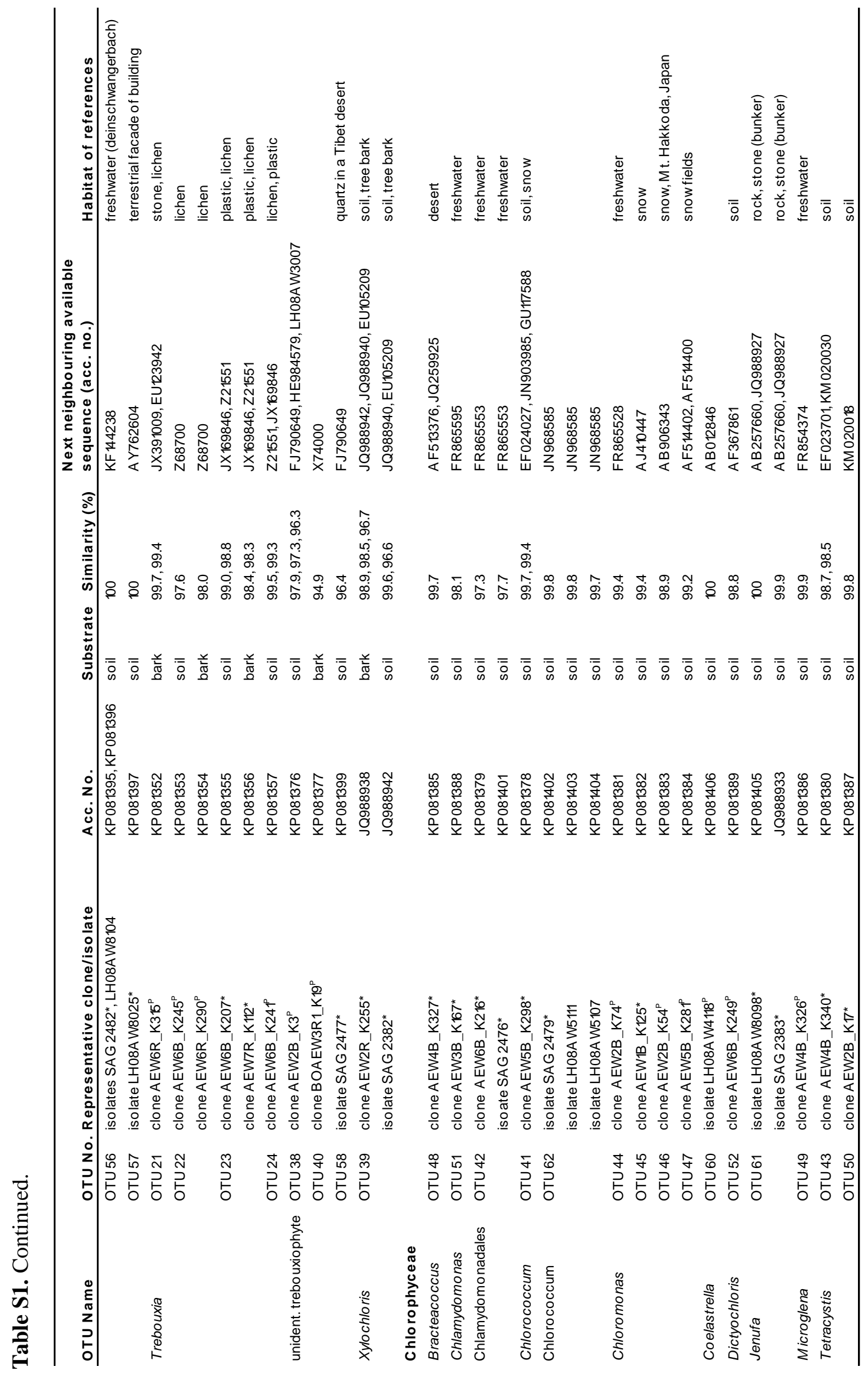




\title{
Chapter 6:
}

\section{Diversity of green algae in grassland and forest soils under different management types - a culture-independent approach}

Christine Hallmann, Ladislav Hodač and Thomas Friedl

\author{
Manuscript
}

Department of Experimental Phycology and Culture Collection of Algae (SAG), Albrecht- von-Haller-Institute for Plant Sciences, Georg-August-University,

Göttingen, Germany

Author contributions to the work:

Performed the experiments: $\mathrm{CH}$.

Analyzed data: $\mathrm{CH}$.

Statistical support (multivariate analysis): $\mathrm{LH}$.

Wrote the paper: $\mathrm{CH}, \mathrm{TF}$.

Conceived and designed the experiments: TF, $\mathrm{CH}$. 


\section{Abstract}

The diversity of soil algae from 57 defined research plots of three German regions, Schwäbische Alb, Schorfheide-Chorin and Hainich-Dün, were investigated using a cultureindependent cloning and sequencing approach. The taxonomic composition of green algal communities and their changes in relation to region identity, different land-use types and different management regimes and intensities were determined. For the molecular phylogenetic identification 18S rRNA gene clone libraries were established directly from 27 grassland and 30 forest soils. A total of 145 operational taxonomic units (OTUs) was recovered, representing mainly the green algal classes Trebouxiophyceae and Chlorophyceae. Multivariate statistics pointed out significantly different green algal composition in grassland and forest soils, best explained by soil $\mathrm{pH}$. Grassland soils exhibited a higher diverse community than forest soils. The most widely distributed OTUs, with particular dominance in grassland, were affiliated to Chloroidium, Stichococcus, Muriella, Tetracystis and Bracteacoccus, whereas OTUs related to Apatococcus, Desmococcus and Prototheca-relatives were dominant or exclusively discovered in forest soils. In relation to management types and intensities, soils in unmanaged forest sites indicated markedly less OTU richness than in managed age class forests. However, this was not evident for the grassland plots. The soil algal community structure exhibited also differences between forest types. Whereas beech and spruce forest soils were dominated by Trebouxiophyceae, in pine forest soils Chlorophyceae were mainly retrieved. In addition a seasonal comparison of selected grassland and forest plots was performed. The algal communities within one sampling site indicated more similar structures and seasonal variations have no significant effect.

Keywords: green algae, soil, land-use, environmental sample, cloning, 18S rRNA gene. 


\section{Introduction}

Soil habitats are most important non-aqueous ecosystems for algal communities; they are present in relatively large amounts in the top soil layer (Shields and Durrell, 1964; Ruble and Davis, 1988; Wöhler et al., 1988; Zenova et al., 1995; Kabirov and Gaisina, 2009). Soil algae comprise eukaryotic representatives like green algae, diatoms, xanthophytes and eustigmatophytes and prokaryotes like cyanobacteria (Metting, 1981; Starks et al., 1981; Hoffmann, 1989). They have beneficial functions in soil, e.g. provide organic matter as food source, perform nitrogen fixation, and interact with higher plants (Metting, 1981; Starks et al., 1981). These phototrophic communities are among the first organisms colonizing bare soils or disturbed sites and promote soil stability and constitute waterstable aggregates to prevent erosion (Johansen, 1993; Büdel et al., 2014). Environmental factors which influence algae growth and community structures in soil are light, moisture, temperature, availability of nutrients, $\mathrm{pH}$ and soil type (Shields and Durrell, 1964; Metting, 1981; Tester and Morris, 1987; Hoffmann, 1989).

Since soil algae are prevalent in topsoil, they are among the first soil organisms exposed to environmental changes and hence integrate environmental and seasonal changes over relatively short periods of time (Bérard et al., 2005). Soil algae are especially sensitive towards soil solution chemistry and thus are promising as potential bioindicators for soil quality (Bérard et al., 2004, 2005; Zancan et al., 2006). Algae are influenced by synthetic pesticides and pollutants; as well the supply rate of $\mathrm{N}$ and $\mathrm{P}$ strongly affects the growth of algae (Metting, 1981; Smith et al., 1999; Temraleeva et al., 2011). However, despite the vital ecological and physiological importance and numerous studies on soil algae (e.g. Shields and Durrell, 1964; Metting, 1981; Starks et al., 1981; Lukešová, 2001; Hoffmann et al., 2007; Bakieva et al., 2012), it is still difficult to draw general conclusions on the diversity of the flora and their influence on ecosystem functions (Zancan et al., 2006). The latter authors studied changes in algal communities in different agroecosystems treated by tillage and pesticides. They mainly concluded that the structure of soil algal communities was obviously affected more by land-use intensities rather than physicochemical parameters of the soil. Their estimates of mean abundances were based on colony counts in algal cultures which did not allow discriminating at the genus and species levels. Most studies on soil algae, especially related to land-use, have been based on morphological observations. Molecular approaches are still increasing (Hallmann et al., in prep. and references therein), up to now there are merely case studies or the overall 
eukaryotic community going not into further detail (Bérard et al., 2005; Lentendu et al., 2014). In the present study the green algal communities in German grassland and forest soils were investigated by a culture-independent approach. In this large scale study $18 \mathrm{~S}$ rRNA gene sequence comparison and phylogenetic methods lead to a reliable and unambiguous re-identification on soil algae. Here we present the taxonomic composition of soil algal communities and their changes in relation to region identity, different land-use types and different management intensities, whereas to take into account the physicochemical parameters of soil.

\section{Material and Methods}

\section{Sampling site, sampling, soil properties, cultivation}

This study was conducted within the large-scale and long-term project 'Biodiversity Exploratories' (www.biodiversity-exploratories.de). The soil samples were collected from three areas in Germany: the UNESCO Biosphere Reserve Schwäbische Alb (AEG, grassland; AEW, forest), a limestone middle mountain range area in South-western Germany, the Hainich-Dün region including the National Park Hainich (HEG, HEW) in central Germany and the UNESCO Biosphere Reserve Schorfheide-Chorin (SEG, SEW), a glacial landscape in North-eastern Germany (Fischer et al., 2010). The Exploratory Schorfheide-Chorin represents with an annual precipitation of 500-600 nm and an annual average temperature of $8-8.5{ }^{\circ} \mathrm{C}$ the driest and warmest region of the three research sites followed by the Hainich-Dün region (500-800 nm and 6.5-8 ${ }^{\circ} \mathrm{C}$ ) and Schwäbische Alb (700-1000 nm and 6-7 ${ }^{\circ} \mathrm{C}$; Fischer et al., 2010). The samples were taken from each region from nine grassland and nine forest plots (except Hainich-Dün with 12 forest plots). Both land-use types comprised different management types and land-use intensities, with triplicates of each management type (Table 1 and 2, Fischer et al., 2010). The sampling was conducted through a joint effort in April and May 2008. In each plot five soil cores were taken from a given area of $20 \mathrm{~m}$ x $20 \mathrm{~m}$ by a motor-driven soil column cylinder and samples of the same plot and the same soil horizon were pooled (for details see Will et al., 2010). For this study 57 samples from the A-horizon (up to $10 \mathrm{~cm}$ ) were taken for further analysis and one sample from the B-horizon (plot HEG7). Soil characteristics like pH, organic carbon (OC) and total nitrogen (TN) content were taken from Nacke et al. (2011) and the project database BExIS, measurements were described in Will et al. (2010). Data for total phosphorus (TP) and measurements are described in Alt et al. (2011). 


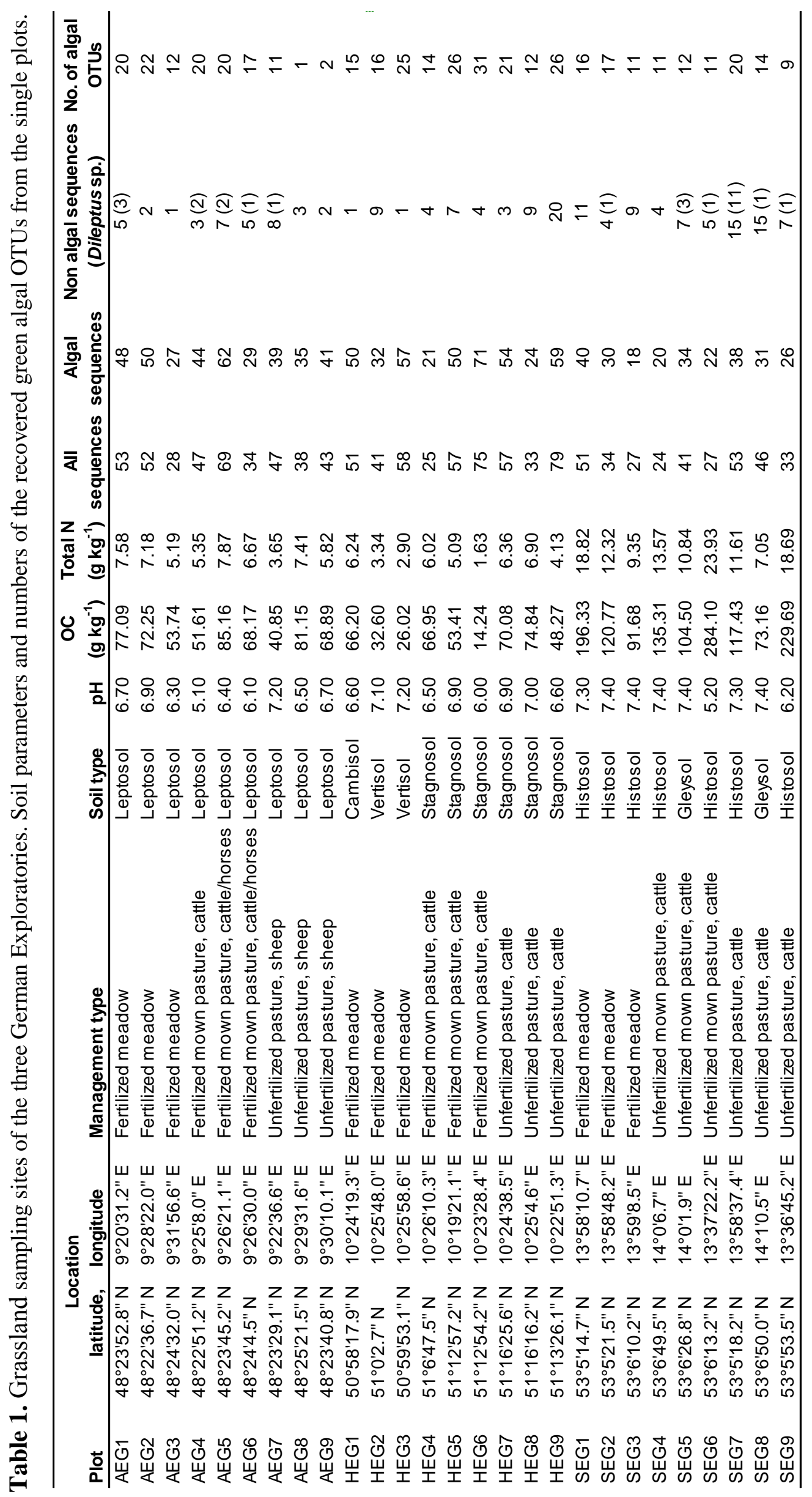




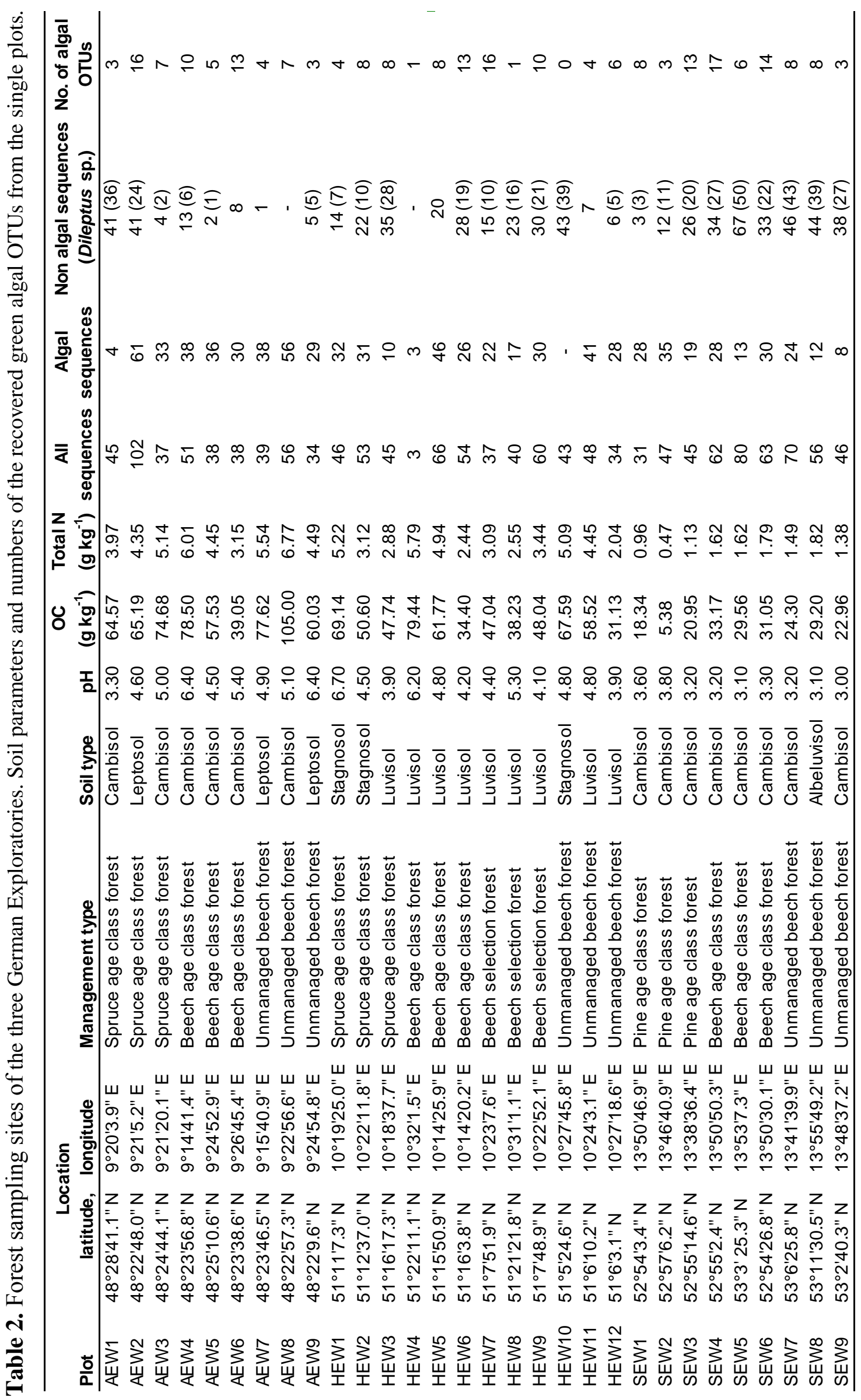


Values for land-use intensity, LUI, were taken from project database BExIS (Fischer et al., 2010) and described in Blüthgen et al. (2012). Additionally 15 soil samples were collected of three selected grassland (HEG7, HEG8 and HEG9) and four forest plots (HEW3, HEW4, HEW5 and HEW10) in the Hainich-Dün area in September 2010 (samples labeled with an S, e.g. HEG7S) and March 2011 (samples labeled with a W, e.g. HEG7W; Table 6). From each plot three samples were taken in the given area of $20 \mathrm{~m}$ x $20 \mathrm{~m}$ (North-east, South-west and from the center) from the upper $0-3 \mathrm{~cm}$. The three samples from the same plot were pooled to mitigate differences, litter and roots were removed. In addition, of a single plot, HEG7 (March 2011), three individual samples within the same plot, NE, SW and the center, were not mixed, but investigated individually (North-east labeled HEG7NOW; center labeled HEG7MW; South-west labeled HEG7SWW). From two samples (HEG7W and HEW3W, both taken in March 2011) enrichment cultures in liquid media were established (see Hodač et al., in prep.).

\section{DNA extraction, PCR amplification, cloning and sequencing}

Genomic DNA from approximately $10 \mathrm{~g}$ of soil samples were extracted with the MoBio PowerSoil DNA isolation Kit (MoBio Laboratories Inc. Carlsbad, CA) according to the manufacturer's instructions. For further details and DNA extraction of enrichment cultures see Hallmann et al., 2013a and Hallmann et al., in prep.). Extraction results were evaluated after electrophoresis on a $1 \%(\mathrm{w} / \mathrm{v})$ agarose gel. Isolated DNA was stored at $-20{ }^{\circ} \mathrm{C}$ until further processing. For PCR 18S rRNA genes were first amplified using eukaryotic specific primers 20F and 18L (Hallmann et al., 2013a; Hamby et al., 1988) followed by a second amplification (semi- nested PCR) with the primers $20 \mathrm{~F}$ and the green algae preferring primer CH1750R (Hallmann et al., 2013a). PCR conditions were as described previously (Hallmann et al., 2013a). In a further approach instead of the reverse primer CH1750R the green algal preferring primer 1650Rmod (5' TCACCAGCACAYYCAAT $3^{\prime}$ ) under previously described conditions were used. All PCR products were purified using the Invisorb DNA CleanUp Kit (STRATEC Molecular). Aliquots of $2 \mu 1$ of the purified amplicons were analysed by electrophoresis on a $1 \%(\mathrm{w} / \mathrm{v})$ agarose gel.

Cloning was carried out with the TOPO TA cloning kit (Invitrogen, Carlsbad, CA) with TOP 10 chemically competent One Shot Escherichia coli cells (Invitrogen), as supplied by the manufacturer. In the plasmid blue/white screening, white E. coli colonies containing correct DNA insertions were further identified by direct amplification of the inserted DNA fragment with a vector-specific primer set M13F/M13R (Invitrogen). 
Positive clones were cultivated overnight in $2 \mathrm{ml}$ reaction tubes with $1 \mathrm{ml} \mathrm{LB}$ medium containing $100 \mu \mathrm{g}$ ampicillin. Plasmid DNA was purified with the Invisorb Spin Plasmid Mini Two kit (STRATEC Molecular) and stored at $-20{ }^{\circ} \mathrm{C}$. Sequencing reactions were performed with the Dye Terminator Cycle Sequencing v3.1 kit (Applied Biosystems, Darmstadt, Germany) and an ABI Prism 3100 (Applied Biosystems) automated sequencer. All eukaryotic clones were sequenced with the $18 \mathrm{~S}$ standard sequencing primer $895 \mathrm{R}$, resulting in partial sequences, including the hypervariable regions V2-V4 (Hallmann et al., 2013a).

\section{Phylogenetic and statistical analysis}

The sequences were edited and assembled using SeqAssem (Hepperle, 2004). Sequences shorter than $400 \mathrm{bp}$ were excluded from further analysis. The remaining sequences were compared with available sequences in NCBI by BLASTN (Altschul et al., 1990; http://www.ncbi.nlm.nih.gov/). Non-algal sequences were excluded from further analysis. Next relative sequences were imported into the ARB program (Ludwig et al., 2004; http://www.arb-home.de) to determine preliminary phylogenetic affiliations. Potential chimeras were checked by Bellerophon (Huber et al., 2004); in addition, the first and the last $300 \mathrm{bp}$ of putative chimeras were compared with similar rRNA gene sequences in NCBI. Chimeric sequences were excluded from the data set. Rarefaction curves and operational taxonomic units (OTUs) were calculated with MOTHUR version 1.13.0 (Schloss et al., 2009). OTUs were defined on the basis of $\geq 98 \%$ sequence similarity (Hallmann et al., 2013a). Representative sequences of almost each OTU were selected and sequenced over almost entire length ( $\geq 1639 \mathrm{bp}$ ) with standard sequencing primers for phylogenetic analysis. For phylogenetic analyses, two alignments of almost full length 18S rRNA gene sequences were performed using MAFFT, version 6 (Katoh and Toh, 2008). The alignment of Trebouxiophyceae included 164 sequences and 1821 positions (892 variables, 619 parsimony informative positions), the dataset of Chlorophyceae contained 167 sequences and 1798 positions (848 variable, 593 parsimony informative). Complete rRNA gene sequences were subjected to phylogenetic analyses using the maximum likelihood (ML) method by RAxML (Stamatakis et al., 2008), in conjunction with the $\mathrm{GTR}+\Gamma+\mathrm{I}$ model with 100 bootstrap replicates. In addition, Bayesian posterior probabilities (MB) were calculated with MrBayes 3.2.2 (Huelsenbeck and Ronquist, 2001). Two parallel Markov chain Monte Carlo (MCMC) runs for two million generations each 
with one cold and three heated chains were conducted using the GTR $+\Gamma+\mathrm{I}$ model, with trees sampled every 100 generations.

The overall similarity of clone libraries from grassland and forest soils was compared based on a presence/absence matrix of the OTU occurrence. The binary matrix was used for Canonical Correspondence Analysis (CCA). To correlate the green algal OTUs with soil properties Spearman's rank correlation were computed. In order to identify clusters of OTU occurring at similar sampling plots, we conducted Principal Components Analysis (PCA) of two data subsets representing clone libraries from grassland and forest sites. To assess sampling and seasonal effects of the OTUs a Detrended Correspondence Analysis (DCA) were accomplished of a selected dataset (Table 6). All statistical analyses were computed with the program PAST 2.17c (Hammer et al., 2001).

\section{Results and Discussion}

\section{Overall diversity and richness}

For this study samples from topsoil (A-horizon) were collected from 27 grassland and 30 forest sites from three regions in Germany, Schorfheide-Chorin, Hainich-Dün and Schwäbische Alb, representing a north-south gradient. Both land-use types comprise different management types and intensities like fertilized and intensely managed grasslands to unfertilized grazed pastures and spruce or pine managed age class forests to unmanaged beech forests (Tables 1 and 2).

Using a culture-independent cloning and sequencing approach a total of 1860 green algal 18S rRNA gene sequences were analysed after quality and chimera check. A number of 145 green algal OTUs were recovered based on $98 \%$ sequence similarity. To determine the clone library coverage for the algal sequences, rarefaction curves were calculated for grassland and forest sites of each Exploratory (Fig. 1a and b). The curves for the grassland samples reached nearly full coverage, whereas the forest samples were not saturated. The OTU richness of the single sampling sites differed between one and 31 green algal OTUs (Table 1 and 2). Except for one forest plot (HEW10), out of 43 sequences no green algal sequence could be retrieved. The green algal (Chlorophyta) preferring primer (CH1750R) resulted also in non-algal sequences. For sample HEW10 a high fraction (39 sequences) of an alveolate-related 18S rRNA gene sequence, a representative full length clone (1573 nucleotides) exhibited $97 \%$ blast similarity to Dileptus microstoma HM581676, was retrieved. Dileptids are ciliates known from terrestrial habitats like soil and leaf litter 
(Vd'ačný and Foissner, 2008). Presumably this ciliate was abundant at this sampling site and masked the green algae there. Altogether $71.3 \%$ of the non-algal sequences at all forest sites belonged to this Dileptus related sequences, this high abundance resulted also in less green algal sequences for these sites, however, only $15.8 \%$ of the non-algal sequences in grassland soils were affiliated to this ciliate.

The retrieved 145 OTUs were distributed over the green algal classes Chlorophyceae (71 OTUs), Trebouxiophyceae (70 OTUs), Ulvophyceae (3 OTUs) and Pedinophyceae (1 OTU). The largest amount of sequences belonged to the Trebouxiophyceae $(66.5 \%)$, $32.2 \%$ of all retrieved sequences belonged to Chlorophyceae, while a small fraction of $1.3 \%$ of the clones were affiliated to Ulvophyceae and Pedinophyceae (Table 3). The molecular approach enabled the identification of the soil algae down to the generic or even species level. Therefore a representative full length sequence of almost each OTU was established for the phylogenetic analysis or the next available relative sequence (as determined from BLAST queries) was used (Table 4). According to the phylogenetic analysis the trebouxiophycean OTUs were distributed over the Chlorellales (including e.g. the Chlorella-, Marvania-, Auxenochlorella- and Protoheca-clade, Fig. 2), the Choricystis/Botryococcus-clade, including species of Coccomyxa and Elliptochloris, the Prasiola-, Trebouxia- and the Watanabea-clades sensu Leliaert et al. (2012) and Friedl and Rybalka (2012) and several independent single lineages (Fig. 2). The Trebouxiophyceae comprises mainly terrestrial species, adapted to drier habitats like soil/desert and air exposed substrates, furthermore lichen symbionts and freshwater species (Friedl and Büdel, 2008; Friedl and Rybalka, 2012; Hallmann et al., 2013a; Fučíková et al., 2014).

The chlorophycean OTUs were phylogenetically (Fig. 3) mainly distributed over Chlamydomonadales (motile representatives with flagella) and Sphaeropleales (includes also non-motile algae) and a few representatives of Chaetopeltidales and Chaetophorales, including also freshwater and terrestrial species (Lewis and McCourt, 2004; Friedl and Rybalka, 2012). The class of Ulvophyceae includes species from marine, freshwater and terrestrial habitats, the latter were distributed in lineages like Ulotrichales and Scotinophaerales (Friedl and O'Kelly, 2002; Friedl and Rybalka, 2012; Škaloud et al., 2013). The one retrieved relative of Pedinophyceae, OTU 142 was closely related to Pedinomonas minor, was also known from soil (Ettl and Gärtner, 1995).

Most groups and genera identified at the here described sampling sites were wellknown from temperate soil habitats like e.g. Bracteacoccus, Chlamydomonas, members of Chlorellales, Chlorococcum, Chloromonas, Coccomyxa, Elliptochloris, Leptosira, 
Myrmecia, Stichococcus, and Tetracystis (e.g. Reisigl, 1964; Metting, 1981; Ettl and Gärtner, 1995; Lukešová and Hoffmann, 1996; Lukešová, 2001; Neustupa and Škaloud, 2004; Zancan et al., 2006; Hoffmann et al., 2007; Khaybullina et al., 2010; Bakieva et al., 2012). A few of the detected OTUs, but with less clone numbers, were so far identified from the Tropics, Antarctica or deserts e.g. Leptochlorella, Xerochlorella and Xylochloris (Němcová et al., 2011; Hodač et al., 2012; Neustupa et al., 2013; Fučíková et al., 2014). Some of the here retrieved OTUs could not be further identified because of taxonomic problems and several of the OTUs may represent still new undescribed species or even new genera e.g. Prototheca relative OTUs 31-36, Chlorellales relative OTUs 43, 46 and 49 (Fig. 2). In a parallel approach the same 57 soil samples were analysed after classical enrichment of soil algae in liquid media and establishment of isolates (Hodač et al., in prep). The microscopic evaluation and sequencing of the obtained isolates allowed a reliable description of new species.

The occurrence of the OTUs were distributed as follows, $4.1 \%$ of the OTUs were retrieved frequently from more than 15 sampling sites out of 56, 15.2\% were found at 9-14 sites, $46.2 \%$ at $2-8$ sites and $34.5 \%$ of the OTUs were recovered only at a single sampling site, these 50 OTUs included 32 singleton OTUs (Table 3). Six OTUs were frequently received and presented in relatively high sequence numbers (Table 3 ). The most abundant OTU across all samples was Chloroidium OTU 15, phylogenetically affiliated to Chloroidium saccharophilum, detected in 25 of 56 plots and representing with $7.8 \%$ the most frequent algal sequences (Fig. 2, Table 4). The genus Chloroidium, in earlier studies assigned to Chlorella, is widespread in different kinds of substrates like in freshwater and terrestrial, including soil (Lukešová and Hoffmann, 1996; Zancan et al., 2006; Darienko et al., 2010). OTUs which were as well recovered in high frequency were phylogenetically assigned to: Stichococcus minutus OTU 54 (21/56 plots), Muriella sp. OTU 42 and Tetracystis vinatzeri OTU 118 each found at 17 plots and Tetracystis sp. OTU 84 and Bracteacoccus minor OTU 107, both occurred at 15 plots (Table 3, Table 4, Fig. 2, Fig. 3). 


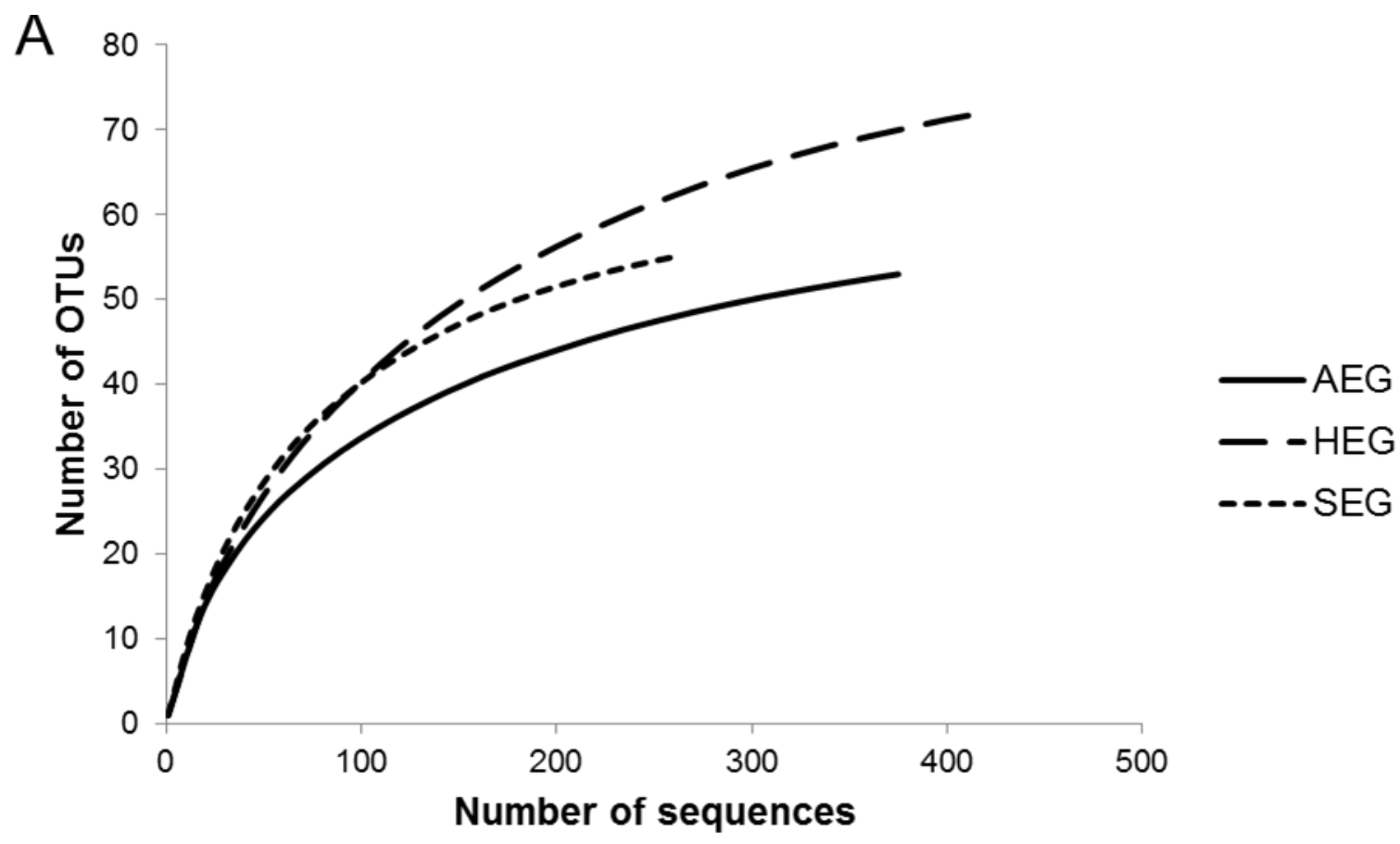

B

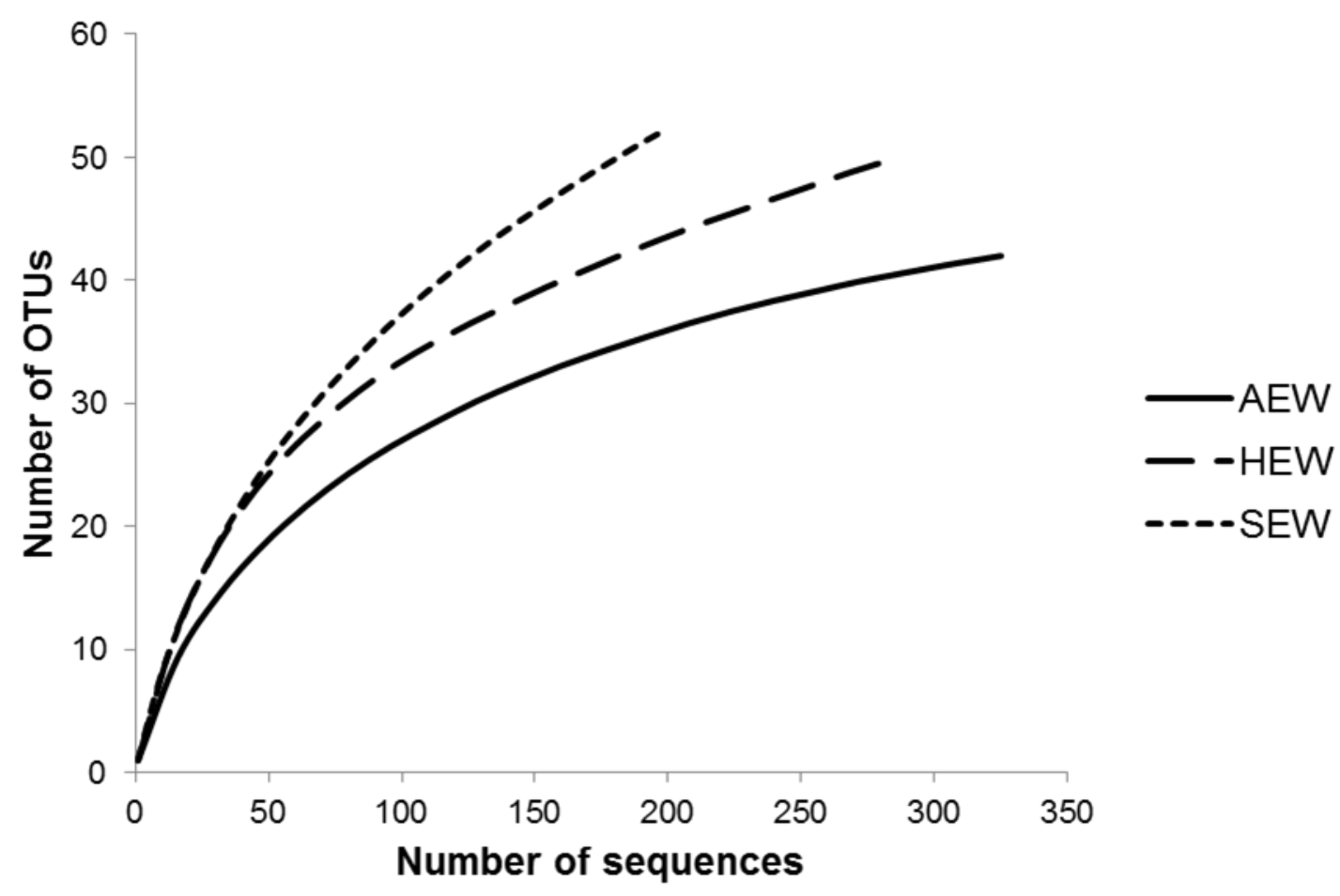

Fig. 1. Rarefaction curves determined for $18 \mathrm{~S}$ rRNA gene clone libraries. The OTUs include the green algal sequences from (A) grassland and from (B) forest soil samples of the three German research sites Schwäbische Alb (AEG, AEW), Hainich-Dün (HEG, HEW) and Schorfheide-Chorin (SEG, SEW). 


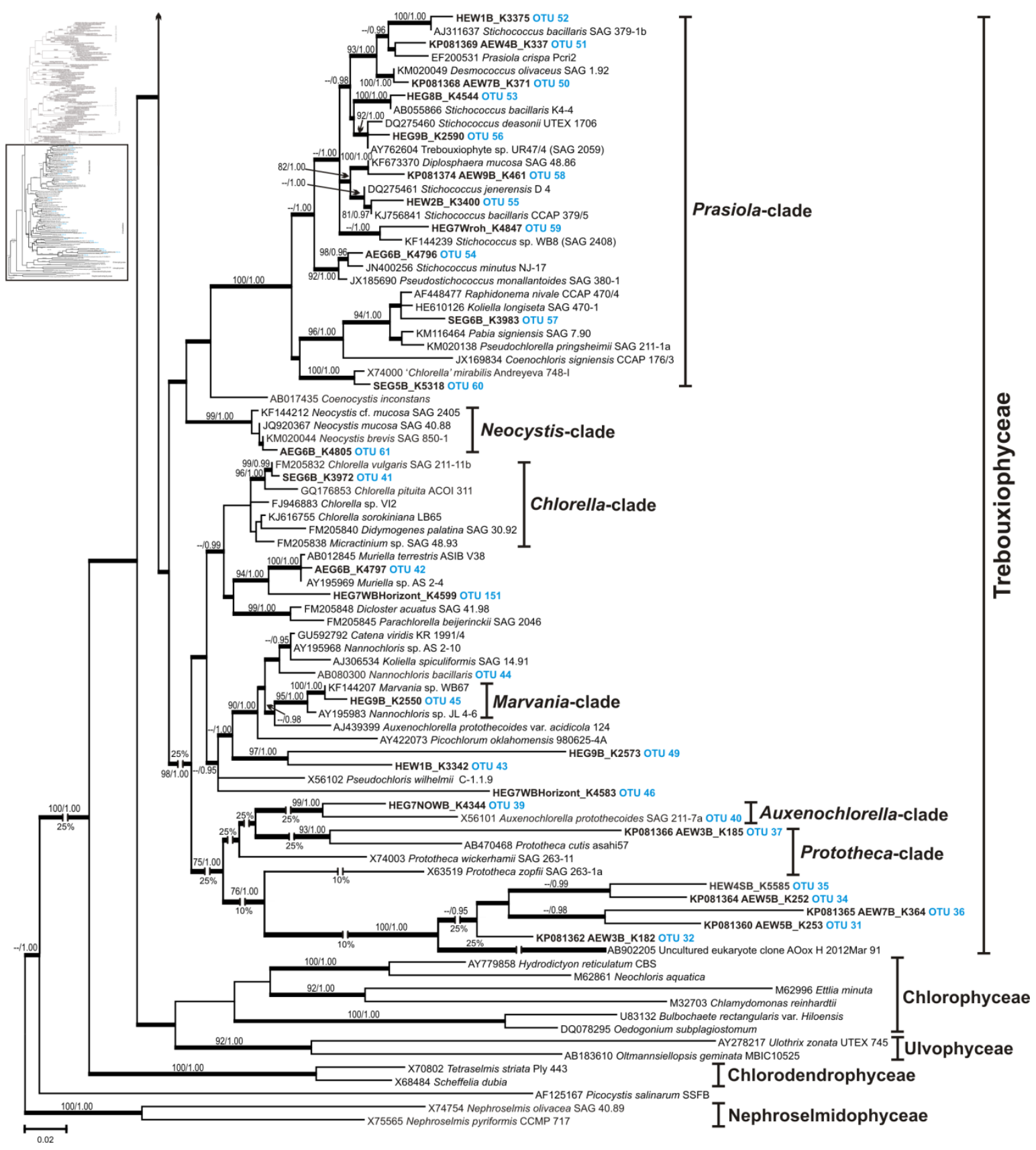

Fig. 2. Maximum likelihood tree (RAxML) of Trebouxiophyceae based on $18 \mathrm{~S}$ rRNA gene sequences from German grassland and forest soils with two members of Nephroselmidophyceae as outgroup taxa. Sequences in bold represent full 18S rRNA gene sequences of this study, blue labels mark representatives of the recovered OTUs. Thick lines indicate internal nodes that were received in maximum likelihood and Bayesian trees. Support values given as ML (Maximum Likelihood; $>75 \%$ bootstrap values) /MB (MrBayes; >0.95 Bayesian posterior probabilities). 


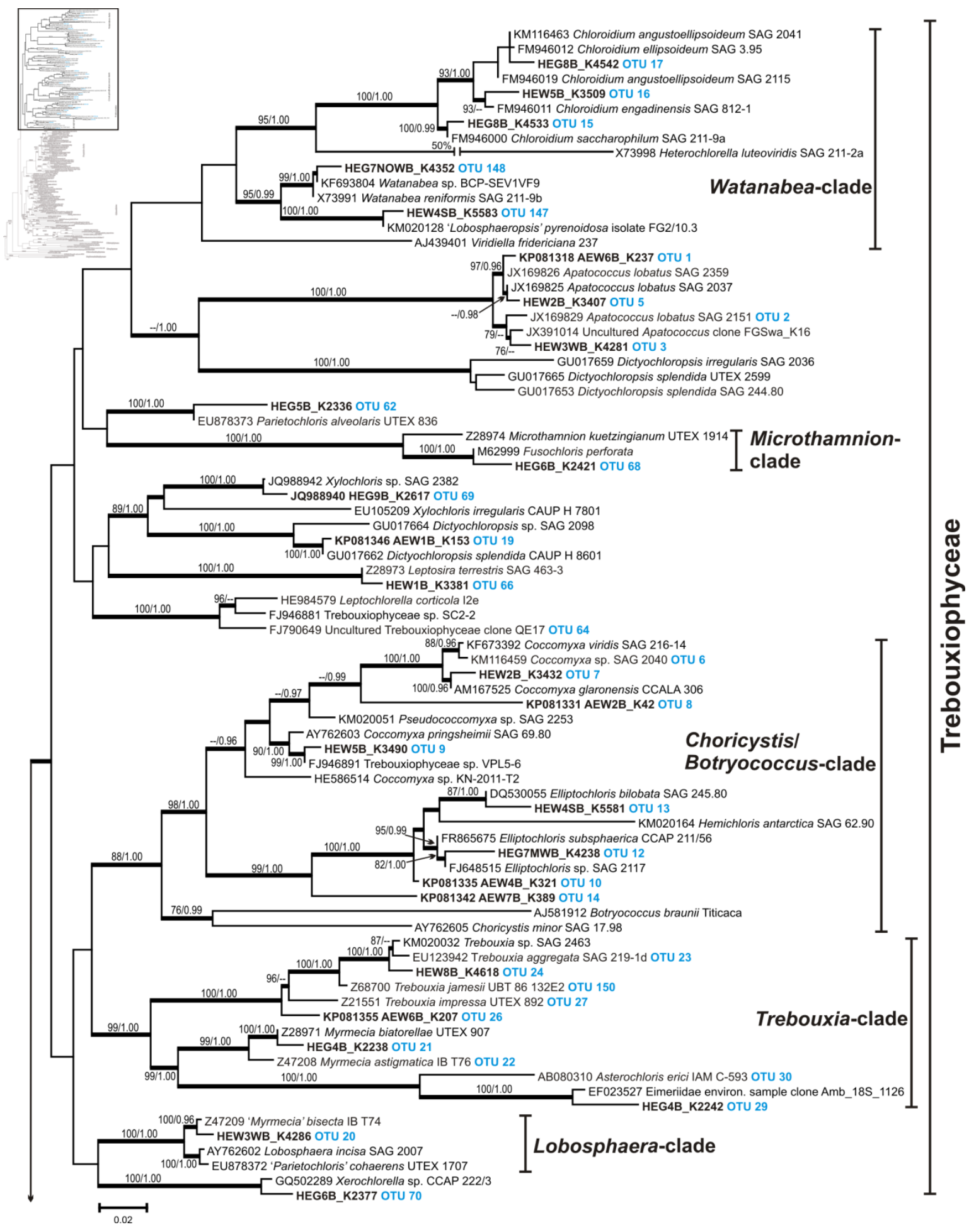

Fig. 2. Continued. 


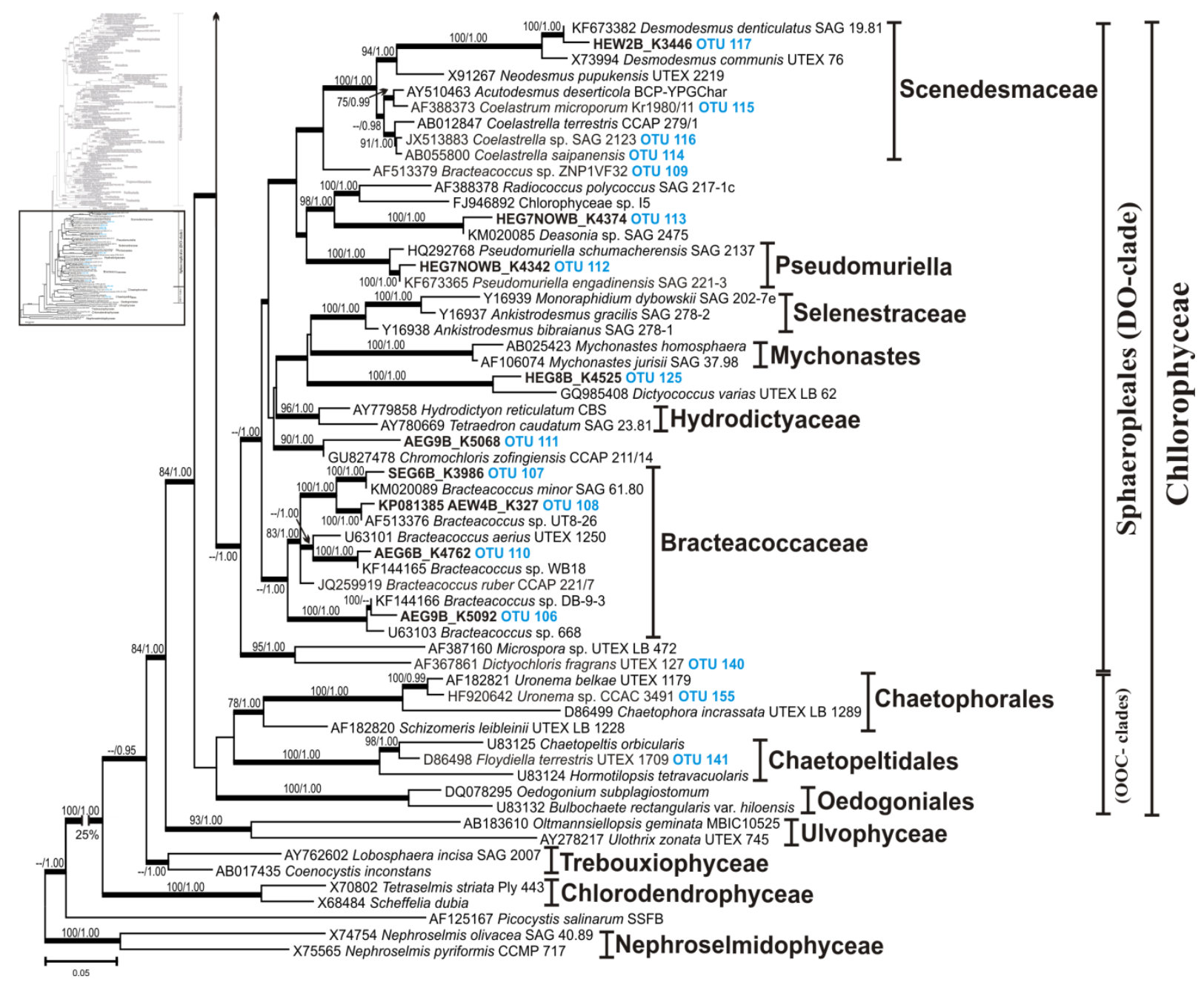

Fig. 3. Maximum likelihood tree (RAxML) of Chlorophyceae based on 18S rRNA gene sequences from German grassland and forest soils with two members of Nephroselmidophyceae as outgroup taxa. Sequences in bold represent full 18S rRNA gene sequences of this study, blue labels mark representatives of the recovered OTUs. Thick lines indicate internal nodes that were received in maximum likelihood and Bayesian trees. Support values given as ML (Maximum Likelihood; $>75 \%$ bootstrap values) /MB (MrBayes; >0.95 Bayesian posterior probabilities). 


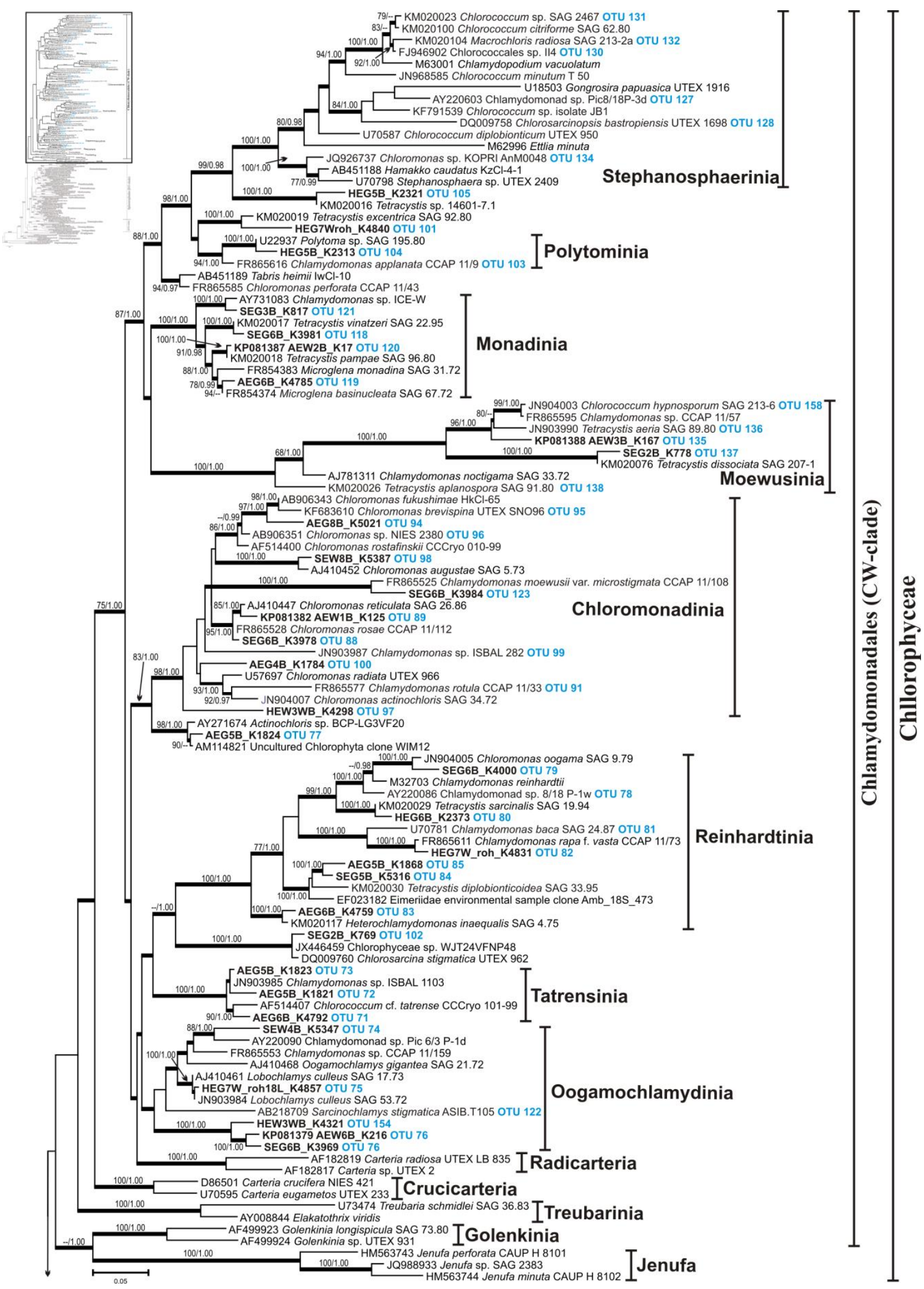

Fig. 3. Continued. 
Table 3. Distribution of 145 green algal OTUs in the $18 \mathrm{~S}$ rRNA gene clone libraries from 27 grassland and 30 forest soils of the three German research sites. Numbers indicated frequencies of plots where the OTUs were recovered. The OTUs belong to the green algal classes of Trebouxiophyceae, Chlorophyceae, Ulvophyceae and Pedinophyceae.

\begin{tabular}{|c|c|c|c|c|c|c|c|c|}
\hline \multirow[b]{2}{*}{ OTU name } & \multirow[b]{2}{*}{ OTU no. } & \multicolumn{3}{|c|}{ grassland plots } & \multicolumn{3}{|c|}{ forest plots } & \multirow[b]{2}{*}{$\begin{array}{l}\text { total no. of } \\
\text { sequences }\end{array}$} \\
\hline & & $\begin{array}{l}\text { AEG } \\
(9)\end{array}$ & $\begin{array}{l}\text { HEG } \\
(9)\end{array}$ & $\begin{array}{l}\text { SEG } \\
(9)\end{array}$ & $\begin{array}{l}\text { AEW } \\
\text { (9) }\end{array}$ & $\begin{array}{r}\text { HEW } \\
(12)\end{array}$ & $\begin{array}{c}\text { SEW } \\
(9)\end{array}$ & \\
\hline \multicolumn{9}{|l|}{ Trebouxiophyceae } \\
\hline \multirow[t]{5}{*}{ Apatococcus } & OTU 1 & - & - & - & 1 & 1 & - & 3 \\
\hline & OTU 2 & - & - & - & 1 & 1 & 1 & 4 \\
\hline & OTU 3 & - & - & - & 3 & 2 & 3 & 14 \\
\hline & OTU 4 & - & - & - & - & - & 1 & 8 \\
\hline & OTU 5 & - & - & - & 1 & 1 & 1 & 9 \\
\hline \multirow[t]{2}{*}{ Asterochloris } & OTU 29 & - & 3 & - & - & - & 1 & 6 \\
\hline & OTU 30 & - & 1 & - & - & - & - & 4 \\
\hline \multirow[t]{2}{*}{ Auxenochlorella } & OTU 39 & 3 & 1 & - & - & - & 2 & 8 \\
\hline & OTU 40 & 5 & 2 & 5 & - & 1 & - & 30 \\
\hline Chlorella & OTU 41 & 1 & 4 & 4 & - & - & - & 14 \\
\hline \multirow[t]{3}{*}{ Chlorellales relative } & OTU 43 & 1 & 2 & - & - & 1 & - & 12 \\
\hline & OTU 46 & - & 2 & 1 & - & - & - & 4 \\
\hline & OTU 49 & 1 & 4 & - & - & - & - & 6 \\
\hline 'Chlorella' mirabilis & OTU 60 & 1 & - & 2 & - & - & - & 5 \\
\hline \multirow[t]{4}{*}{ Chloroidium } & OTU 15 & 7 & 8 & 5 & 1 & 2 & 2 & 146 \\
\hline & OTU 16 & 3 & 6 & 1 & 1 & 1 & 1 & 52 \\
\hline & OTU 17 & 3 & 7 & 2 & - & - & 1 & 44 \\
\hline & OTU 18 & - & 1 & - & - & - & - & 1 \\
\hline \multirow[t]{4}{*}{ Coccomyxa } & OTU 6 & - & - & - & 1 & 3 & 1 & 12 \\
\hline & OTU 7 & - & 1 & - & 1 & 2 & 2 & 17 \\
\hline & OTU 8 & - & - & - & 2 & - & 2 & 5 \\
\hline & OTU 9 & 1 & 3 & 1 & - & 2 & 1 & 13 \\
\hline Desmococcus & OTU 50 & - & 1 & - & 4 & 3 & 3 & 57 \\
\hline Dictyochloropsis & OTU 19 & - & - & - & 2 & 3 & - & 11 \\
\hline Diplosphaera & OTU 58 & 1 & 3 & 1 & 1 & 1 & 1 & 19 \\
\hline \multirow[t]{5}{*}{ Elliptochloris } & OTU 10 & - & - & - & 5 & 1 & 5 & 22 \\
\hline & OTU 11 & - & - & - & 1 & 1 & 1 & 5 \\
\hline & OTU 12 & 3 & 3 & - & 1 & - & 2 & 17 \\
\hline & OTU 13 & - & 1 & - & - & - & - & 2 \\
\hline & OTU 14 & - & - & - & 3 & - & - & 20 \\
\hline Fuscochloris & OTU 68 & - & 4 & - & - & - & - & 8 \\
\hline Helicosporidium relative & OTU 38 & - & - & - & - & 1 & - & 1 \\
\hline Koliella & OTU 57 & 3 & 2 & 6 & - & - & - & 36 \\
\hline Leptochlorella & OTU 64 & - & - & - & 1 & - & - & 1 \\
\hline \multirow[t]{2}{*}{ Leptosira } & OTU 66 & 1 & 8 & 2 & - & 1 & - & 46 \\
\hline & OTU 67 & - & 2 & - & - & - & - & 2 \\
\hline Lobosphaera & OTU 20 & 2 & 3 & - & 1 & 1 & 2 & 20 \\
\hline
\end{tabular}


Table 3. Continued.

\begin{tabular}{|c|c|c|c|c|c|c|c|c|}
\hline \multirow[b]{2}{*}{ OTU name } & \multirow[b]{2}{*}{ OTU no. } & \multicolumn{3}{|c|}{ grassland plots } & \multicolumn{3}{|c|}{ forest plots } & \multirow[b]{2}{*}{$\begin{array}{l}\text { total no. of } \\
\text { sequences }\end{array}$} \\
\hline & & $\begin{array}{c}\text { AEG } \\
(9)\end{array}$ & $\begin{array}{c}\text { HEG } \\
(9)\end{array}$ & $\begin{array}{c}\text { SEG } \\
(9)\end{array}$ & $\begin{array}{c}\text { AEW } \\
(9)\end{array}$ & $\begin{array}{r}\text { HEW } \\
(12)\end{array}$ & $\begin{array}{c}\text { SEW } \\
(9)\end{array}$ & \\
\hline Marvania & OTU 45 & 3 & 4 & 2 & - & 1 & - & 16 \\
\hline Muriella & OTU 42 & 6 & 9 & 1 & - & 1 & - & 50 \\
\hline \multirow[t]{2}{*}{ Myrmecia } & OTU 21 & 1 & 2 & - & - & - & - & 3 \\
\hline & OTU 22 & 1 & - & - & - & - & - & 1 \\
\hline Nannochloris & OTU 44 & - & 2 & - & - & - & - & 2 \\
\hline Neocystis & OTU 61 & 4 & 1 & - & 1 & 2 & 1 & 14 \\
\hline Parietochloris & OTU 62 & - & 1 & - & - & 2 & - & 5 \\
\hline Prasiola & OTU 51 & 3 & - & - & 1 & - & - & 19 \\
\hline Prototheca & OTU 37 & - & - & - & 1 & 1 & - & 6 \\
\hline \multirow[t]{6}{*}{ Prototheca relative } & OTU 31 & - & - & - & 4 & 3 & - & 88 \\
\hline & OTU 32 & - & - & - & 2 & 3 & - & 23 \\
\hline & OTU 33 & - & - & - & 3 & - & - & 10 \\
\hline & OTU 34 & - & - & - & 4 & 4 & 4 & 143 \\
\hline & OTU 35 & - & - & - & - & 1 & - & 1 \\
\hline & OTU 36 & - & - & - & 1 & - & - & 3 \\
\hline \multirow[t]{6}{*}{ Stichococcus } & OTU 52 & 2 & 2 & 3 & 1 & 2 & 2 & 31 \\
\hline & OTU 53 & 2 & 2 & - & - & 2 & - & 12 \\
\hline & OTU 54 & 6 & 8 & 4 & - & 2 & 1 & 50 \\
\hline & OTU 55 & - & 4 & 3 & - & 2 & - & 17 \\
\hline & OTU 56 & 1 & 1 & 1 & - & - & 1 & 8 \\
\hline & OTU 59 & - & 1 & - & - & - & - & 1 \\
\hline \multirow[t]{6}{*}{ Trebouxia } & OTU 23 & - & - & 1 & - & - & - & 1 \\
\hline & OTU 24 & - & - & - & - & 2 & 3 & 27 \\
\hline & OTU 25 & - & - & - & 1 & - & - & 1 \\
\hline & OTU 26 & - & - & - & 1 & - & - & 2 \\
\hline & OTU 27 & - & - & - & 1 & 1 & - & 4 \\
\hline & OTU 28 & - & - & - & - & 1 & - & 1 \\
\hline \multirow[t]{4}{*}{ Unidentified trebouxiophyte } & OTU 47 & - & - & - & - & - & 1 & 1 \\
\hline & OTU 48 & - & 1 & - & - & - & - & 2 \\
\hline & OTU 63 & 1 & - & - & - & - & - & 1 \\
\hline & OTU 65 & - & 1 & - & - & - & - & 1 \\
\hline Xerochlorella & OTU 70 & 1 & 3 & - & - & - & - & 6 \\
\hline Xylochloris & OTU 69 & 2 & 1 & - & - & - & - & 3 \\
\hline \multicolumn{9}{|l|}{ Chlorophyceae } \\
\hline Actinochloris & OTU 77 & 1 & - & 1 & - & - & 1 & 4 \\
\hline \multirow[t]{5}{*}{ Bracteacoccus } & OTU 106 & 2 & 5 & - & - & - & 1 & 28 \\
\hline & OTU 107 & 6 & 4 & 4 & - & - & 1 & 21 \\
\hline & OTU 108 & 2 & 2 & 3 & 2 & 1 & 2 & 23 \\
\hline & OTU 109 & - & 1 & - & - & - & - & 2 \\
\hline & OTU 110 & 3 & 2 & 2 & - & - & - & 13 \\
\hline \multirow[t]{3}{*}{ Chlamydomonas } & OTU 72 & 1 & - & - & - & 1 & - & 4 \\
\hline & OTU 73 & 1 & 3 & - & - & - & 1 & 9 \\
\hline & OTU 78 & - & - & - & - & 1 & - & 1 \\
\hline
\end{tabular}


Table 3. Continued.

\begin{tabular}{|c|c|c|c|c|c|c|c|c|}
\hline \multirow[b]{2}{*}{ OTU name } & \multirow[b]{2}{*}{ OTU no. } & \multicolumn{3}{|c|}{ grassland plots } & \multicolumn{3}{|c|}{ forest plots } & \multirow[b]{2}{*}{$\begin{array}{l}\text { total no. of } \\
\text { sequences }\end{array}$} \\
\hline & & $\begin{array}{c}\text { AEG } \\
(9) \\
\end{array}$ & $\begin{array}{c}\text { HEG } \\
(9) \\
\end{array}$ & $\begin{array}{c}\text { SEG } \\
(9)\end{array}$ & $\begin{array}{c}\text { AEW } \\
(9)\end{array}$ & $\begin{array}{r}\text { HEW } \\
(12) \\
\end{array}$ & $\begin{array}{c}\text { SEW } \\
(9)\end{array}$ & \\
\hline & OTU 81 & - & 1 & - & - & - & - & 2 \\
\hline & OTU 82 & - & - & 2 & - & - & - & 5 \\
\hline & OTU 91 & - & - & - & - & - & 1 & 3 \\
\hline & OTU 99 & - & - & - & - & - & 1 & 1 \\
\hline & OTU 103 & - & - & 2 & - & - & - & 7 \\
\hline & OTU 121 & - & - & 1 & - & - & - & 2 \\
\hline & OTU 123 & - & - & 1 & - & - & - & 2 \\
\hline & OTU 124 & - & 1 & - & - & - & - & 1 \\
\hline & OTU 135 & - & - & - & 1 & - & 2 & 5 \\
\hline \multirow[t]{3}{*}{ Chlorococcum } & OTU 71 & 4 & 1 & - & 1 & - & 3 & 19 \\
\hline & OTU 127 & 1 & - & 1 & - & - & - & 2 \\
\hline & OTU 131 & - & 2 & 2 & - & 1 & - & 10 \\
\hline \multirow[t]{10}{*}{ Chloromonas } & OTU 79 & - & - & 1 & - & - & - & 1 \\
\hline & OTU 88 & 2 & 1 & 4 & 2 & 1 & 3 & 26 \\
\hline & OTU 89 & - & - & - & 1 & - & - & 1 \\
\hline & OTU 90 & - & - & - & - & - & 1 & 7 \\
\hline & OTU 94 & 1 & 1 & - & 2 & 1 & 1 & 46 \\
\hline & OTU 95 & - & - & - & - & 1 & 2 & 4 \\
\hline & OTU 96 & - & - & - & 1 & - & 1 & 2 \\
\hline & OTU 98 & - & 3 & - & - & - & 1 & 7 \\
\hline & OTU 100 & 1 & - & 2 & - & - & - & 3 \\
\hline & OTU 134 & - & - & - & - & 3 & 1 & 12 \\
\hline Chlorosarcina & OTU 102 & - & - & 5 & - & - & - & 13 \\
\hline Chlorosarcinopsis & OTU 128 & - & - & 1 & - & - & - & 1 \\
\hline Chromochloris & OTU 111 & 1 & - & - & - & - & - & 24 \\
\hline Coelastrella & OTU 114 & 4 & 6 & 1 & - & - & - & 23 \\
\hline \multirow[t]{2}{*}{ Coelastrum } & OTU 115 & - & 1 & - & - & - & - & 1 \\
\hline & OTU 116 & - & 1 & - & - & - & - & 2 \\
\hline Deasonia & OTU 113 & - & 2 & - & - & - & - & 2 \\
\hline Desmodesmus & OTU 117 & - & - & - & - & 1 & - & 11 \\
\hline Dictyochloris & OTU 140 & 2 & - & - & 1 & - & - & 3 \\
\hline Dictyococcus & OTU 125 & 1 & 4 & 3 & - & 1 & - & 17 \\
\hline Floydiella & OTU 141 & - & - & 1 & - & - & - & 1 \\
\hline Heterochlamydomonas & OTU 83 & 2 & 1 & 7 & - & 3 & - & 24 \\
\hline Lobochlamys & OTU 75 & - & - & 2 & - & - & - & 3 \\
\hline \multirow[t]{2}{*}{ Macrochloris } & OTU 130 & - & 1 & 2 & - & - & - & 4 \\
\hline & OTU 132 & - & - & 2 & - & - & - & 2 \\
\hline Microglena & OTU 119 & 5 & 2 & 2 & 1 & 2 & - & 45 \\
\hline \multirow[t]{2}{*}{ Oogamochlamydinia } & OTU 74 & - & - & - & - & - & 1 & 1 \\
\hline & OTU 76 & - & - & 1 & 2 & - & 1 & 11 \\
\hline Polytoma & OTU 104 & - & 1 & - & - & - & - & 2 \\
\hline Pseudomuriella & OTU 112 & 1 & 1 & - & - & - & - & 3 \\
\hline Sarcinochlamys & OTU 122 & - & - & - & - & - & 1 & 1 \\
\hline
\end{tabular}


Table 3. Continued.

\begin{tabular}{|c|c|c|c|c|c|c|c|c|}
\hline \multirow[b]{2}{*}{ OTU name } & \multirow[b]{2}{*}{ OTU no. } & \multicolumn{3}{|c|}{ grassland plots } & \multicolumn{3}{|c|}{ forest plots } & \multirow[b]{2}{*}{$\begin{array}{l}\text { total no. of } \\
\text { sequences }\end{array}$} \\
\hline & & $\begin{array}{l}\text { AEG } \\
(9)\end{array}$ & $\begin{array}{c}\text { HEG } \\
(9) \\
\end{array}$ & $\begin{array}{l}\text { SEG } \\
(9)\end{array}$ & $\begin{array}{c}\text { AEW } \\
(9)\end{array}$ & $\begin{array}{r}\text { HEW } \\
(12) \\
\end{array}$ & $\begin{array}{c}\text { SEW } \\
(9)\end{array}$ & \\
\hline \multirow[t]{11}{*}{ Tetracystis } & OTU 80 & - & 1 & - & - & - & - & 1 \\
\hline & OTU 84 & 3 & 4 & 7 & 1 & - & - & 32 \\
\hline & OTU 85 & 1 & - & - & - & - & 2 & 9 \\
\hline & OTU 86 & - & 1 & - & - & - & - & 1 \\
\hline & OTU 101 & 1 & - & 1 & - & - & - & 5 \\
\hline & OTU 105 & - & 3 & 1 & - & - & - & 7 \\
\hline & OTU 118 & 6 & 7 & 3 & - & 1 & - & 50 \\
\hline & OTU 120 & 1 & 2 & - & 1 & 1 & - & 7 \\
\hline & OTU 136 & - & - & - & - & - & 1 & 1 \\
\hline & OTU 137 & - & - & 2 & - & - & - & 3 \\
\hline & OTU 138 & - & 1 & 1 & - & - & - & 3 \\
\hline \multirow[t]{8}{*}{ Unidentified Chlorophyceae } & OTU 87 & - & - & 1 & - & - & - & 1 \\
\hline & OTU 92 & - & - & - & - & - & 1 & 1 \\
\hline & OTU 93 & - & - & - & - & - & 1 & 2 \\
\hline & OTU 97 & - & - & - & - & - & 1 & 1 \\
\hline & OTU 126 & - & - & - & - & 1 & - & 1 \\
\hline & OTU 129 & - & - & - & - & - & 1 & 1 \\
\hline & OTU 133 & - & - & 1 & - & - & - & 4 \\
\hline & OTU 139 & - & - & 1 & - & - & - & 1 \\
\hline \multicolumn{9}{|l|}{ Pedinopyhceae } \\
\hline Pedinomonas & OTU 142 & - & - & 1 & - & - & - & 1 \\
\hline \multicolumn{9}{|l|}{ Ulvophyceae } \\
\hline Chlorochytrium & OTU 143 & - & 1 & 1 & - & - & - & 5 \\
\hline Scotinosphaera & OTU 144 & - & 2 & 1 & - & - & - & 5 \\
\hline Pseudendocloniopsis & OTU 145 & 3 & 2 & 2 & - & - & 1 & 14 \\
\hline
\end{tabular}


Table 4. Blast identities of representative sequences of the green algal OTUs in the 18S rRNA gene clone libraries from the grassland and forest soils. An asterisk indicates a partial sequence ( $\geq 506 \mathrm{bp}$ ).

\begin{tabular}{|c|c|c|c|c|c|}
\hline OTU name & OTU no. & $\begin{array}{l}\text { Representative clone } \\
\text { (Acc. no.) }\end{array}$ & Closest reference sequence & Acc. no. & $\begin{array}{c}\text { Blast } \\
\text { similatity }\end{array}$ \\
\hline \multicolumn{6}{|l|}{ Trebouxiophyceae } \\
\hline \multirow{4}{*}{ Apatococcus } & 2 & SEW4B_K1276* & Apatococcus lobatus strain SAG 2151 & JX169829 & $99 \%$ \\
\hline & 3 & HEW3WB_K4281 & Uncultured Apatococcus clone FGSwa_K16 & JX391014 & $99 \%$ \\
\hline & 4 & SEW7B_K1417* & Apatococcus lobatus strain SAG 2359 & JX169826 & $99 \%$ \\
\hline & 146 & HEW3WB_K4325* & Uncultured Apatococcus clone FGSwa_K16 & JX391014 & $99 \%$ \\
\hline \multirow[t]{2}{*}{ Asterochloris } & 30 & HEG3B_K2223* & Asterochloris erici strain IAM C-593 & AB080310 & $99 \%$ \\
\hline & 29 & HEG4B_K2242 & Eimeriidae environmental clone Amb_18S_1126 & EF023527 & $99 \%$ \\
\hline \multirow[t]{2}{*}{ Auxenochlorella } & 40 & AEG3B_K1692* & Auxenochlorella protothecoides strain SAG $211-7$ a & X56101 & $99 \%$ \\
\hline & 39 & HEG7NOWB_K4344 & Auxenochlorella protothecoides strain SAG $211-7$ a & X56101 & $97 \%$ \\
\hline \multirow{2}{*}{ Chlorellales relative } & 49 & HEG9B_K2573 & Micractinium sp. strain SAG 48.93 & FM205838 & $95 \%$ \\
\hline & & & Nannochloris sp. isolate AS 2-10 & AY195968 & $95 \%$ \\
\hline 'Chlorella' mirabilis & 60 & SEG5B_K5318 & 'Chlorella' mirabilis strain Andreyeva 748-I & $X 74000$ & $99 \%$ \\
\hline \multirow[t]{4}{*}{ Chloroidium } & 15 & HEG8B_K4533 & Chloroidium saccharophilum strain SAG 211-9a & FM946000 & $99 \%$ \\
\hline & 16 & HEW5B_K3509 & Chloroidium angustoellipsoideum strain SAG 2115 & FM946019 & $99 \%$ \\
\hline & 17 & HEG8B_K4542 & Chloroidium angustoellipsoideum strain SAG 2041 & KM116463 & $99 \%$ \\
\hline & 18 & HEG7B_K2505* & Chloroidium angustoellipsoideum strain SAG 2041 & KM116463 & $98 \%$ \\
\hline \multirow[t]{3}{*}{ Coccomyxa } & 6 & HEW9B_K3122* & Coccomyxa sp. strain SAG 2040 & KM116459 & $99 \%$ \\
\hline & 7 & HEW2B_K3432 & Coccomyxa glaronensis strain CCALA 306 & AM167525 & $99 \%$ \\
\hline & 9 & HEW5B_K3490 & Trebouxiophyceae sp. strain VPL5-6 & FJ946891 & $99 \%$ \\
\hline Dictyochloropsis & 19 & AEW1B_K153 (KP081346) & Dictyochloropsis splendida strain CAUP H8601 & GU017662 & $99 \%$ \\
\hline \multirow[t]{2}{*}{ Diplosphaera } & 58 & AEW9B_K461 (KP081374) & Diplosphaera sp. strain SAG 49.86 & KM020116 & $99 \%$ \\
\hline & & & Diplosphaera mucosa strain SAG 48.86 & KF673370 & $99 \%$ \\
\hline \multirow[t]{5}{*}{ Elliptochloris } & 10 & AEW4B_K321 (KP081335) & Elliptochloris subsphaerica strain CCAP 211/56 & FR865675 & $99 \%$ \\
\hline & 11 & HEW3B_K5207* & Elliptochloris subsphaerica strain SAG 2202 & FJ648518 & $99 \%$ \\
\hline & 12 & HEG7MWB_K4238 & Elliptochloris sp. strain SAG 2117 & FJ648515 & $99 \%$ \\
\hline & 13 & HEW4SB_K5581 & Elliptochloris bilobata strain SAG 245.80 & DQ530055 & $99 \%$ \\
\hline & 14 & AEW7B_K389 (KP081342) & Elliptochloris subsphaerica strain CCAP 211/56 & FR865675 & $97 \%$ \\
\hline Fuscochloris & 68 & HEG6B_K2421 & 'Characium' perforatum & M62999 & $99 \%$ \\
\hline Helicosporidium relative & 38 & HEW2B_K3394* & Helicosporidium sp. & JN869301 & $89 \%$ \\
\hline \multirow[t]{2}{*}{ Koliella } & 57 & SEG6B_K3983 & Koliella longiseta strain SAG 470-1 & HE610126 & $99 \%$ \\
\hline & & & Raphidonema nivale strain CCAP 470/4 & AF448477 & $99 \%$ \\
\hline \multirow[t]{2}{*}{ Leptochlorella } & 64 & AEW2B_K3 (KP081376)* & Uncultured Trebouxiophyceae clone QE17 & FJ790649 & $98 \%$ \\
\hline & 153 & HEW3Wroh18L_K4936* & Leptochlorella corticola strain $\mathrm{I} 2 \mathrm{e}$ & HE984579 & $97 \%$ \\
\hline \multirow[t]{2}{*}{ Leptosira } & 66 & HEW1B_K3381 & Leptosira terrestris strain SAG 463-3 & Z28973 & $99 \%$ \\
\hline & 67 & HEG3B_K2234* & Leptosira terrestris strain SAG $463-3$ & Z28973 & $97 \%$ \\
\hline Lobosphaera/Myrmecia & 20 & HEW3WB_K4286 & 'Myrmecia' bisecta strain IB T74 & Z47209 & $99 \%$ \\
\hline \multirow[t]{2}{*}{ Marvania } & 45 & HEG9B_K2550 & Marvania sp. isolate WB67 & KF144207 & $99 \%$ \\
\hline & & & Nannochloris sp. isolate JL 4-6 & AY195983 & $99 \%$ \\
\hline Muriella & 42 & AEG6B_K4797 & Muriella sp. strain AS 2-4 & AY195969 & $99 \%$ \\
\hline
\end{tabular}


Table 4. Continued.

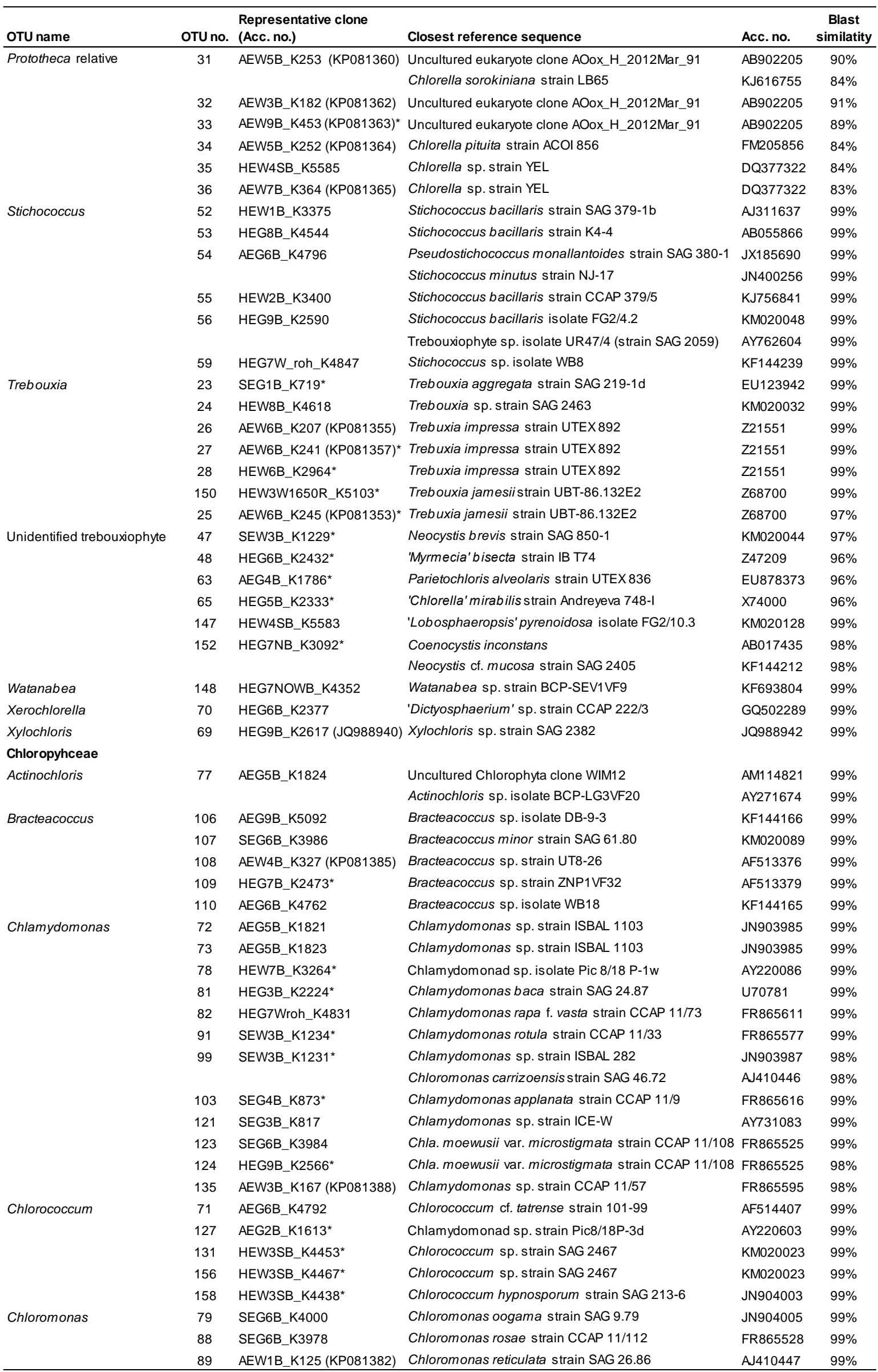


Table 4. Continued.

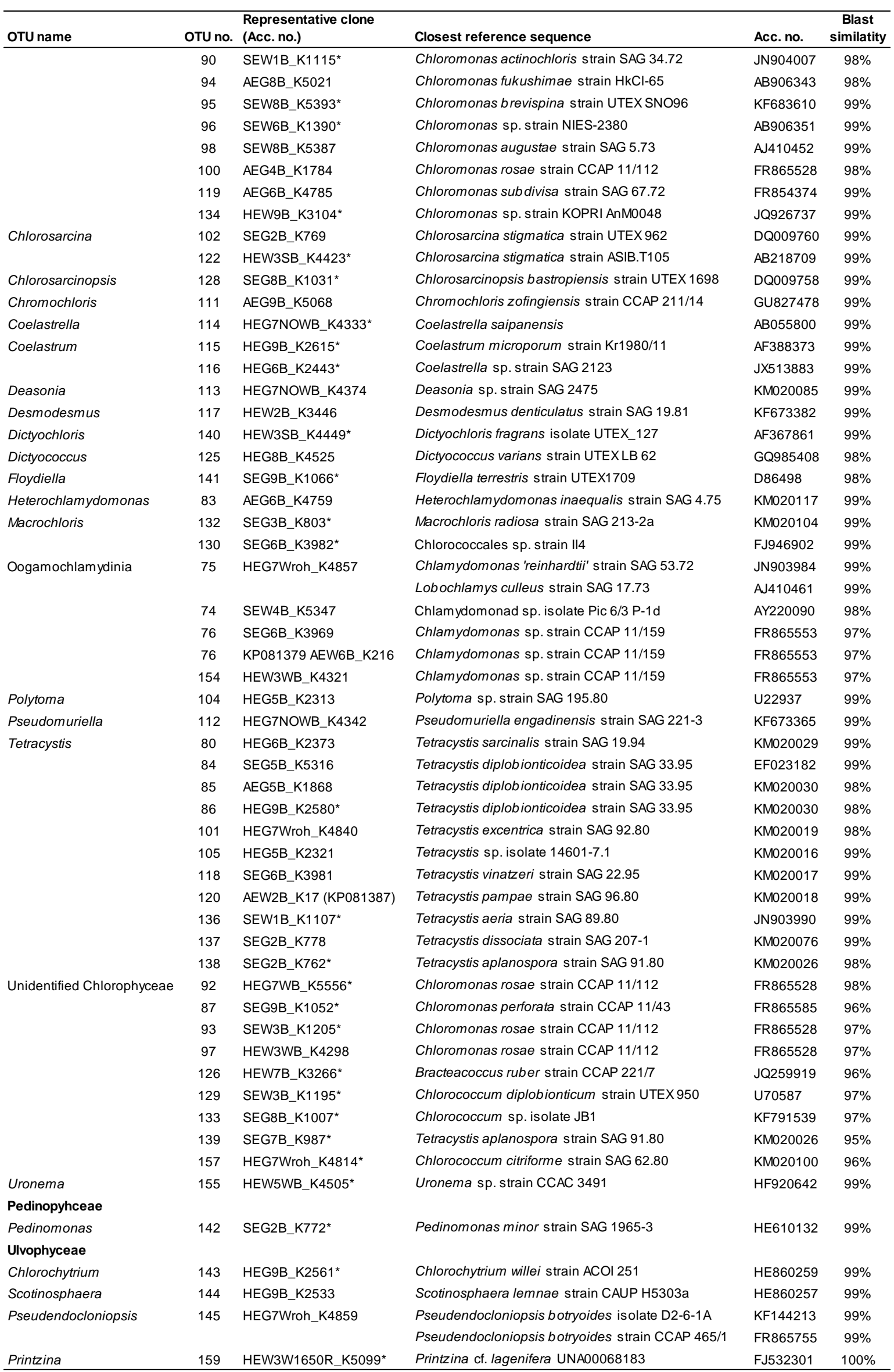




\section{Overall diversity in the study regions}

Altogether for the Exploratory Hainich-Dün 704 clones were retrieved, for the Schwäbische Alb 700 and for the region Schorfheide-Chorin 456 clones were recovered. With 95 OTUs and an average of 13.3 OTUs for each plot, the Hainich-Dün region turned out to be the most diverse Exploratory, followed by Schorfheide-Chorin with 93 OTUs (an average of 11.2 OTUs) and Schwäbische Alb with the lowest diversity of 79 OTUs (an average of 10.7 OTUs). Hainich-Dün region and Schwäbische Alb exhibited plots with highest OTU richness. Five of the most diverse plots with 21-31 OTUs were located in Hainich-Dün, four plots representing 20-22 OTUs in Schwäbische Alb, whereas in the Schorfheide-Chorin region only one plot with 20 OTUs was found. Overall the three Exploratories shared 42 OTUs (29\%), OTUs exclusively retrieved in the regions Schorfheide-Chorin, Hainich-Dün and Schwäbische Alb yielded in 19.3\%, $17.2 \%$ and $8.3 \%$. Compared to OTU richness the region Hainich-Dün and Schwäbische Alb indicated the highest similarity, sharing 57 OTUs, while compared to Schorfheide-Chorin the region Hainich-Dün exhibited 55 OTUs and Schwäbische Alb only 52 OTUs. Soils differed with respect to type, $\mathrm{pH}$, total organic carbon and total nitrogen content (Table 1 and 2). Whereas the Hainich-Dün region and Schwäbische Alb were predominated by soils with higher clay content, Schorfheide-Chorin was dominated by sandy soils. Since clayey soils retain more water than the quickly drying sandy soils, tendencies of wider algal distribution in clay than in lighter or sandy soils were reported (Shields and Durrell, 1964; Lukešová and Hoffmann, 1996).

The Principal Components Analysis (PCA) showed that differences in the composition of green algae between the three Exploratories are more obvious in grassland (Fig. 4) than in forest soils (Fig. 5). The green algal communities in grassland plots of Hainich-Dün region and Schwäbische Alb were more similar with each other, whereas those from the Schorfheide-Chorin Exploratory were more dissimilar from the former two. However, this was not evident at the forest plots (Fig. 5). Though these analyses indicated some tendencies, because low explanatory validation of the total variance was obtained (axis were supported between $9 \%$ and $14 \%$ ).

With respect to soil algal communities the green algal class Trebouxiophyceae were dominant in the Hainich-Dün region and Schwäbische Alb with 56 and 50 OTUs, while 36 and 28 OTUs were affiliated to Chlorophyceae. However in Schorfheide-Chorin most OTUs (53) belonged to Chlorophyceae and even 36 OTUs were assigned to Trebouxiophyceae. This finding was particularly evident for the grassland soils. 
Chlorophyceae dominated here in all but one (SEG5) plot. Accordingly, the number of trebouxiophycean OTUs was much lower compared to the grassland sites of the other region; 33 OTUs Chlorophyceae and 18 OTUs Trebouxiophyceae were obtained (Table 5). In the Canonical Correspondence Analysis (CCA) the OTU composition of the Schorfheide-Chorin grassland samples exhibited a gradient which correspond to total nitrogen (TN) and organic carbon (OC), here the sampling sites SEG5 and SEG8 showed the greatest differences in OTU composition to SEG6 and SEG9 (Fig. 6).

The Exploratory Schorfheide-Chorin, with many wetlands, is situated at the lowest altitude with 3-140 $\mathrm{m}$ a.s.l. of the three investigated regions (Fischer et al., 2010). In the grassland plots of Schorfheide-Chorin occur two different soil types, sandy mineral soil (Gleysol) at the sampling sites SEG5 and SEG8 and drained peat soil (Histosol) with high OC and TN concentrations (Table 1). The drained peat soils were affected by a varying groundwater table, also showed by high Ellenberg values for soil moisture, and in winter and early spring these sites were often flooded (Müller et al., 2012; Herold et al., 2014). The moist to flooded grassland soils in Schorfheide-Chorin were dominated by Chlorophyceae, this class inhabiting many motile species, e.g. like Heterochlamydomonas OTU 83 at seven out of nine SEG sites or Chloromonas OTU 88 in four and the Chlamydomonas OTUs 82, 103, 121, 123 exclusively found at these grassland sites, this condition was more comfortable for motile algae (Hunt et al., 1979). At these sampling sites the number of trebouxiophycean OTUs were lower than in the other regions, most aerophytic algae belonged Trebouxiophyceae and seem to be more adapted to dryer habitats like e.g. building stone and tree bark (Karsten et al., 2007; Hallmann et al., 2013a, 2013b; Kulichová et al., 2014).

Table 5. Distribution of the retrieved green algal OTUs (numbers of OTUs) from grassland (AEG, HEG, SEG) and forest soils (AEW, HEW, SEW) of the three German research sites with respect to the green algal classes.

\begin{tabular}{lccccccccc}
\hline & \multicolumn{2}{c}{ Schwäbische Alb } & & \multicolumn{2}{c}{ Hainich-Dün } & & \multicolumn{2}{c}{ Schorfheide-Chorin } \\
\cline { 2 - 3 } Green algal class & AEG & AEW & & HEG & HEW & & SEG & SEW \\
\hline Trebouxiophyceae & 28 & 30 & & 39 & 35 & & 18 & 26 \\
Chlorophyceae & 24 & 12 & & 30 & 15 & & 33 & 25 \\
Ulvophyceae & 1 & - & & 3 & - & & 3 & 1 \\
Pedinophyceae & - & - & & - & - & & 1 & - \\
\hline Summary & 53 & 42 & & 72 & 50 & & 55 & 52 \\
\hline
\end{tabular}




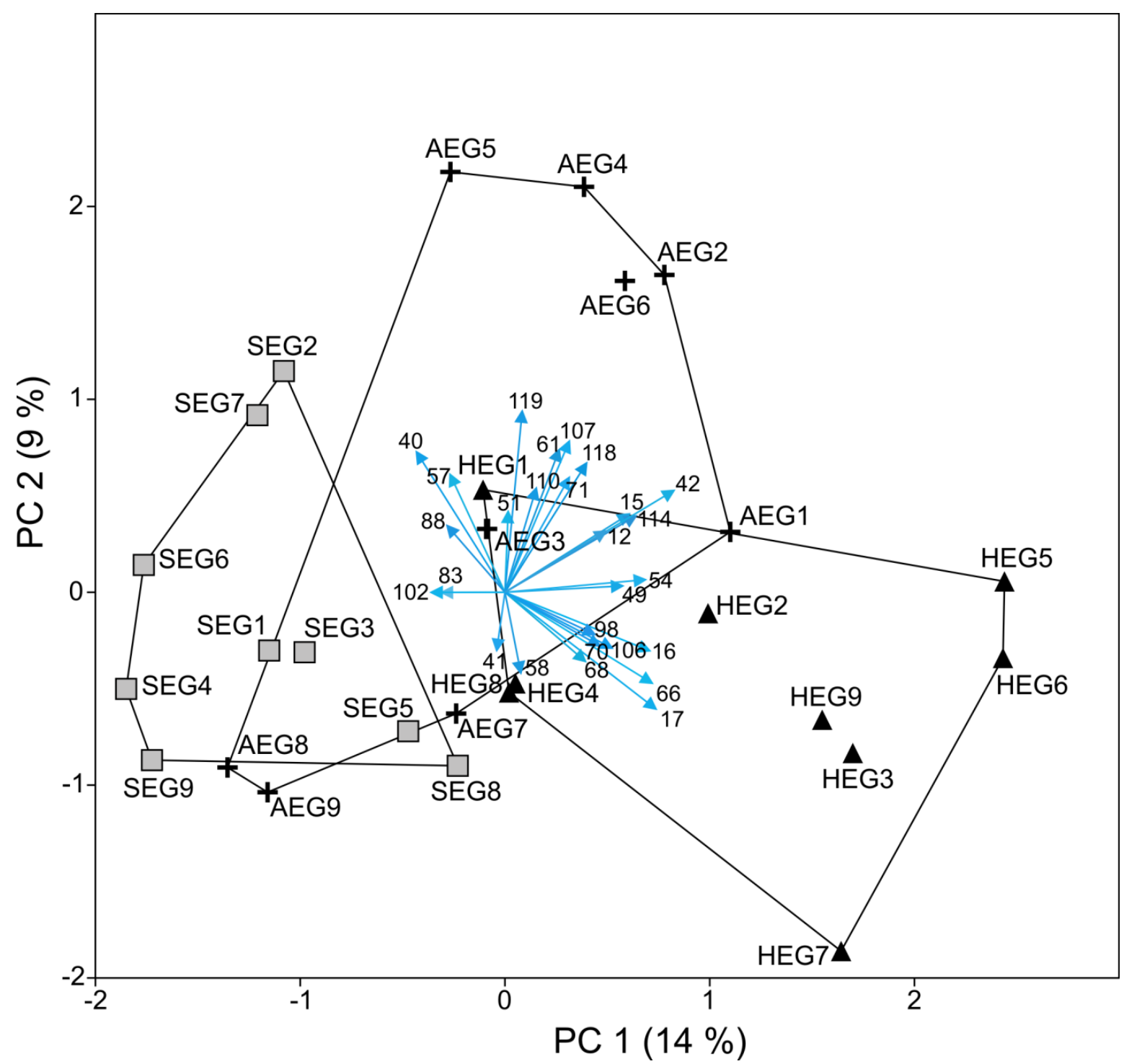

Fig. 4. The Principal Components Analysis (PCA) indicates green algal OTUs (blue arrows) which are responsible for the main differences between grassland soils of the three German research sites. Squares: Schorfheide-Chorin; triangle: Hainich-Dün; cross: Schwäbische Alb. For the species/genus assignments of the OTUs see Table 4. 


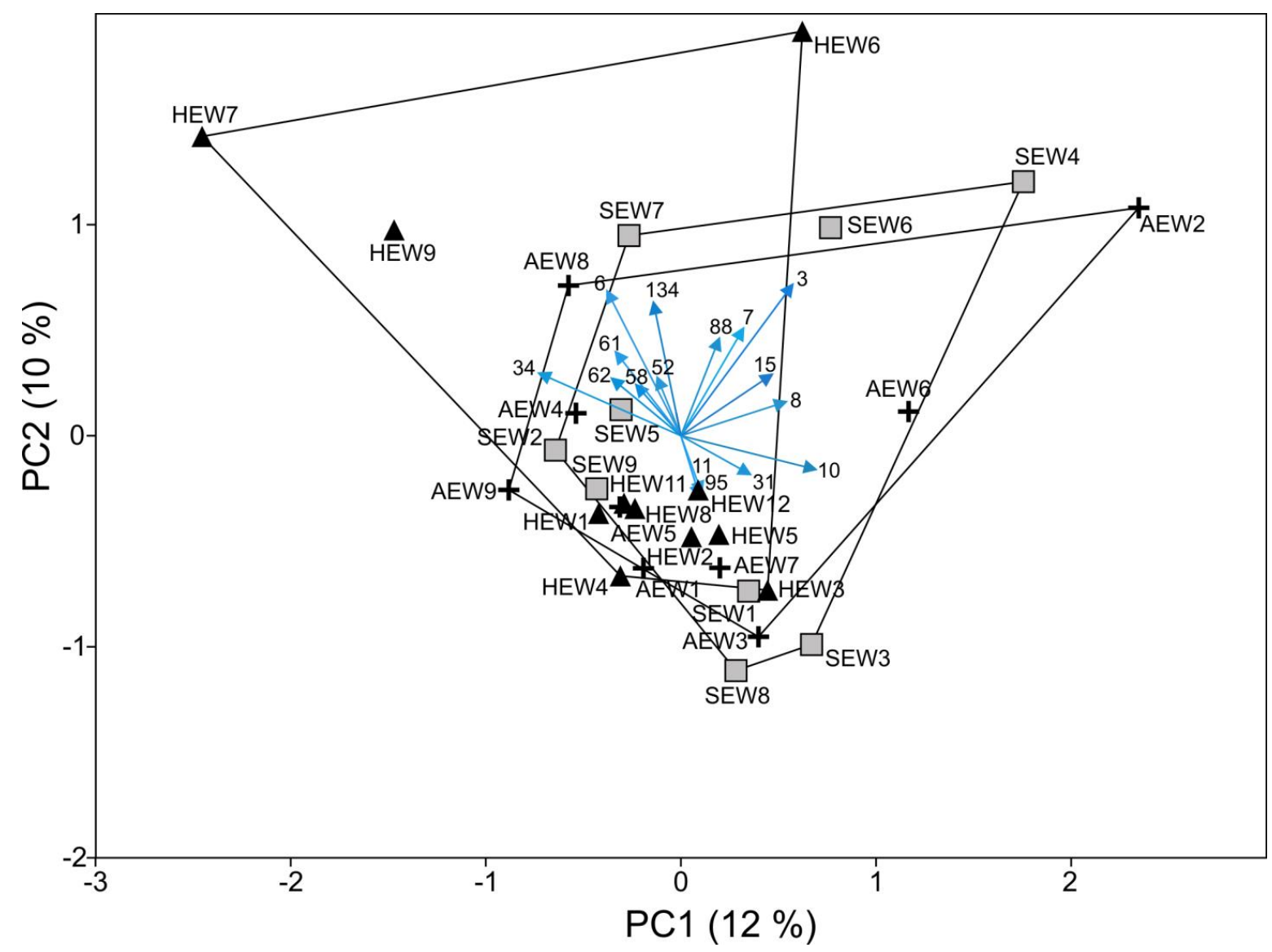

Fig. 5. The Principal Components Analysis (PCA) showing green algal OTUs (blue arrows) which correspond to the main differences between forest soils of the three German research sites. Squares: Schorfheide-Chorin; triangle: Hainich-Dün; cross: Schwäbische Alb. For the species/genus assignments of the OTUs see Table 4.

\section{Differences between land-use type (grassland and forest)}

Overall the green algal community of grassland and forest soils exhibited significant differences in OTU richness and composition. In grassland soils a total of 101 OTUs were recovered, dominated by chlorophycean OTUs (53), followed by Trebouxiophyceae (44 OTUs), Ulvophyceae (three OTUs) and the one singleton OTU assigned to Pedinophyceae (Table 3). However in forest soils (89 OTUs) Trebouxiophyceae dominated (50 OTUs), 38 OTUs belonged to Chlorophyceae and one OTU represented Ulvophyceae. To be precise, in 15 out of the 27 grassland plots OTUs mainly assigned to Trebouxiophyceae were retrieved, whereas at 12 sites more chlorophycean OTUs were retrieved, including at eight sites of Schorfheide-Chorin (Table 3). In forest soils the majority of OTUs belonged to Trebouxiophyceae, in 26 of 30 sampling sites, especially in Hainich-Dün and Schwäbische Alb (Table 5). The grassland soils exhibited an obvious higher OTU richness than the forest soils. In grassland soils an average of 16 OTUs per 
plot was recovered while in forest soils a much lower diversity was found with an average of 7.8 OTUs. Ten sampling sites in grassland soils exhibited more than 20 OTUs; the maximum was 31 OTUs, thus in forest soils nine plots showed more than 10 OTUs; the maximum was a number of 17 OTUs (Table 1 and 2). It is noticeable that about 11 OTUs were recovered from more than 10 grassland sites, whereas only three OTUs occurred at more than 10 forest sites.

The Canonical Correspondence Analysis CCA (Fig. 6) demonstrated the 56 sampling sites and the distribution due to their OTU composition and the parameter $\mathrm{pH}, \mathrm{TN}$ and OC. The CCA indicated a clear differentiation between grassland and forest soil algal communities, except of the two sampling sites AEG8 and AEG9 (Fig. 6, Table 3). Beside different factors $\mathrm{pH}$ values may best explain the difference between both land-use types at the level of soil algal communities. The $\mathrm{pH}$ values in grassland soils range from 5.10-7.40, while $\mathrm{pH}$ of forest soils vary from 3.00-6.70, the forest soils of Schorfheide-Chorin indicated acidic soils with the lowest $\mathrm{pH}$ values 3.00-3.80 (Table 2). In the CCA (Fig. 6) the data of the $\mathrm{X}$-axis were significantly correlated to $\mathrm{pH}(\mathrm{p} \leq 0.001)$. Additionally to $\mathrm{pH}$, TN and OC also total phosphorus (TP) were tested (data not shown); TP was significantly correlated $(\mathrm{p} \leq 0.001)$ with $\mathrm{pH}$. The difference of algal composition in grassland and forest soils and the influence of $\mathrm{pH}$ on soil alga communities have been shown in previous studies, thus cyanobacteria were preferably in neutral and alkaline soils and therefore less common in forest soils, whereas green algae occur also in acidic soils (Shields and Durell, 1964; Metting, 1981; Hoffmann, 1989; Lukešová and Hoffmann, 1996; Neustupa, 2001). Additionally light radiation may cause the difference between communities in grassland and in forest soils (Hunt et al., 1979).

The grassland and forest soils exhibited different green algal compositions, a total of 46 OTUs $(31.7 \%)$ were shared by both land-use types (Table 3 ). Forty-four OTUs were exclusively retrieved from forest soils e.g. the Apatococcus OTUs 1-5, the Protothecarelative OTUs 31-36, Elliptochloris OTU 10 and Dictyochloropsis OTU 19 whereas a larger number of OTUs (55) were recovered only in grassland soils, e.g. Chlorella OTU 41 (phylogenetically assigned to Chlorella vulgaris, Fig. 2), Coelastrella OTU 144 and Koliella/Raphidonema OTU 57 (Table 3). Green algal OTUs with frequent occurrence and obvious preference to grassland soils were: Auxenochlorella OTU 40 (phylogenetically assigned to Auxenochlorella protothecoides, Fig. 2) Bracteacoccus OTU 107, the Chloroidium OTUs 15-17, Heterochlamydomonas OTU 83, Leptosira OTU 66, Muriella OTU 42, Stichococcus OTU 54 and the Tetracystis OTUs 84 and 118. Overall the 
members of Chlorellales, except the Prototheca-relative OTUs, Stichococcus, Sphaeropleales, like Bracteacoccus, seem to prefer grassland soils, as well the recovered OTUs assigned to Ulvophyceae. The latter comprise the three OTUs Chlorochytrium OTU 143, Pseudendocloniopsis OTU 145 and Scotinosphaera OTU 144 described from freshwater and terrestrial habitats (Table 4, Friedl and O'Kelly, 2002; Škaloud et al., 2013). Algae with an evidently preference to forest were Desmococcus OTU 10 and OTUs assigned to Coccomyxa and Trebouxia.

Previous studies reported that the algal communities of grassland and forest soils were different, whereas forest soils were less diverse (Metting, 1981; Lukešová, 2001; Neustupa, 2001; Novakovskaya and Patova, 2008). Whereas members of Trebouxiophyceae occurred only in slightly higher amount in grassland soils, except of Schorfheide-Chorin, they clearly predominated in forest soils of Schwäbische Alb and Hainich-Dün Exploratory (Table 5). The recovered OTUs like Apatococcus, Chloroidium, Coccomyxa, Desmococcus, Dictyochloropsis, Elliptochloris and Trebouxia are well known aerophytic algae on tree bark and/or lichen symbionts (Ettl and Gärtner, 1995; Freystein et al., 2008; Lüttge and Büdel, 2010; Dal Grande et al., 2014; Hallmann et al., in prep.). Apatococcus is among the most widely distributed tree bark algae (Gärtner, 1994) and was exclusively retrieved from the forest soils. Thus it is conceivable that this tree bark alga occurs mainly aerophytic and was washed by rain water from tree bark into the soil. The same may apply to e.g. Coccomxya, Dictyochloropsis, Desmococcus and Trebouxia, whereas Coccomyxa was found characteristic for acidic soils (Shields and Durrell, 1964). However the OTUs assigned to Chloroidium occurred preferably in grassland soil and was also described in soil habitats (Darienko et al., 2010). The Prototheca-relative OTUs 31-36 were the most abundant OTUs in forest soils and represented $33.2 \%$ of all clones retrieved from the forest samples. The phylogenetic analysis and Blast search revealed no closer relation to a known green algal genus and represented a distinct group within the Chlorellales (Fig. 2). The phylogenetic analysis revealed a sister-group relationship to the non-photosynthetic genus Prototheca, known from various habitats e.g. soil and brackish water and includes parasitic/pathogenic members (Figueroa-Martinez et al., 2015) The next related sequence presented an environmental clone, AOox_H_2012Mar_91 (Acc. No. AB902205), retrieved from a sample of activated sludge treating municipal sewage from Japan (Matsunaga et al., 2014), but with modest blast similarity (Table 4). The exclusive occurrence in forest soils could be explained by low light tolerance or low $\mathrm{pH}$. 


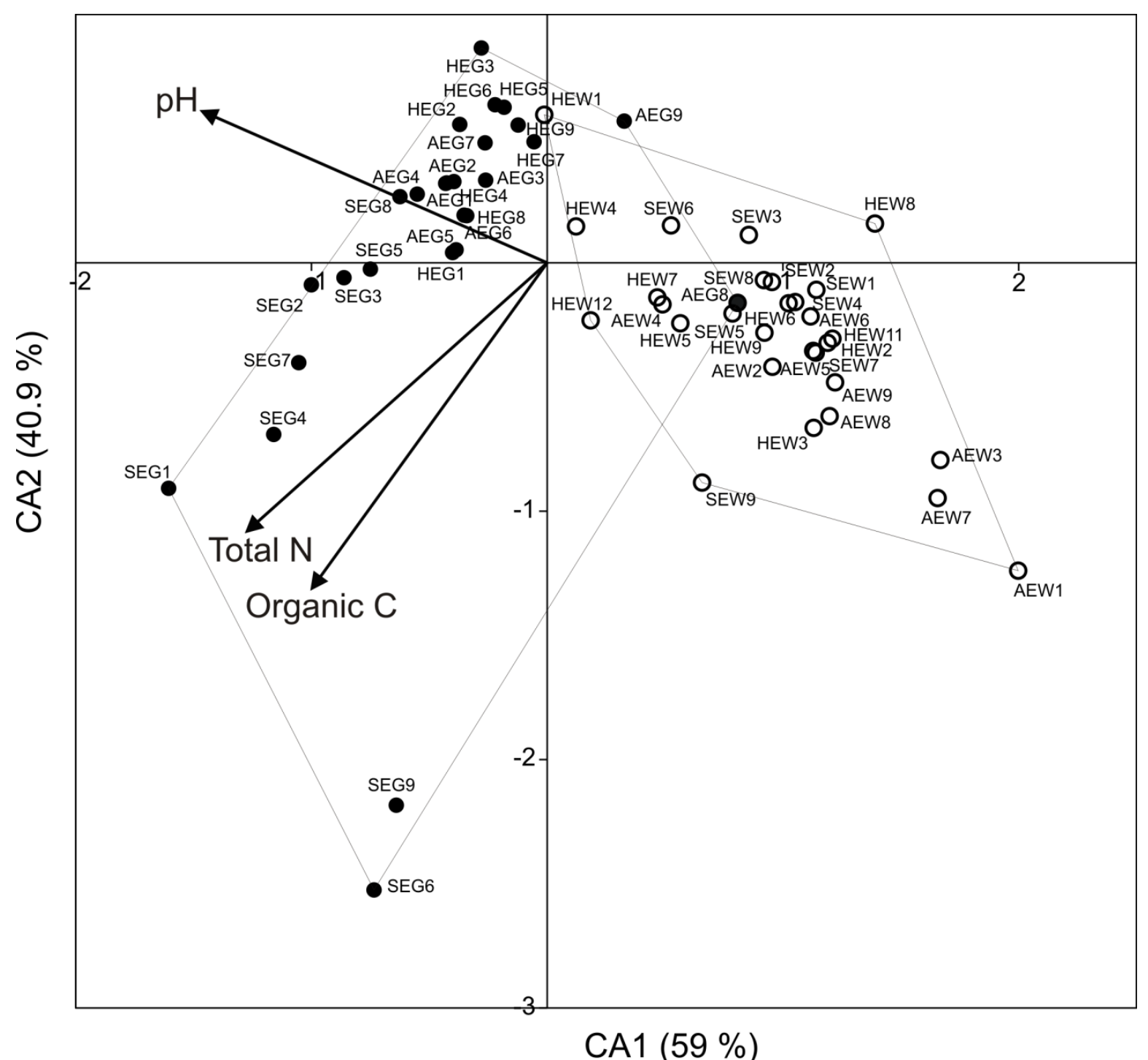

Fig. 6. Canonical Correspondence Analysis (CCA). The ordination diagram showing the grouping of forest (white dots) and grassland (black dots) soil samples in relation to environmental variables (the both canonical axis are significant on the 0.05 level). The analysis was based on a presence/absence matrix of the green algal OTUs.

\section{Management intensities}

Three categories of management intensities have been defined for the Biodiversity Exploratories. At the grassland sites were intensively managed meadows (Plot numbers 1-3), managed mown pastures with cattle, sheep or horses as grazers (Plot numbers 4-6) and extensive treated pastures with grazers (Plot numbers 7-9; Table 1 and 2). The managed grassland sites were treated with $\mathrm{N}$ fertilization, with a maximum of $140 \mathrm{~kg} \mathrm{~N}$ $\mathrm{ha}^{-1} \mathrm{yr}^{-1}$ in the Hainich-Dün plots HEG2 and HEG3 (Herold et al., 2014).

The intensively managed grassland sites showed an almost similar OTU richness to the intermediary managed sites with an average of 11.1 OTUs and 11.9 OTUs of each plot, 
the extensive treated sites exhibited less diversity with an average of 9.7 OTUs per plot (Fig. 7). In the grassland soils no obvious trend of management intensity of the green alga OTU richness were found. In Schorfheide-Chorin the OTU richness were slightly less at the intermediate managed sites than at the other management intensities, in Hainich-Dün the highest diversity were discovered at the intermediate managed sites, while fewest numbers of OTUs were found at the intensively treated plots. However, at two extensive managed sites in the Schwäbische Alb a very low diversity was obvious: AEG8 exhibited only one OTU, Chloromonas OTU 94, with a high number of sequences (35) and AEG9 showed two OTUs with both in a large amount of sequences, Bracteacoccus OTU 106 (17 clones) and Chromochloris OTU 111 (24 clones), thus OTU 111 occurred exclusively at this site.

The green algal composition revealed no clear gradients to management intensities (CCA; Fig. 6). For each grassland soils a quantitative index of land-use intensity (LUI) was established, quantified as the combined variation of the intensity of fertilization, mowing frequency and intensity of grazing (Blüthgen et al., 2012). The green algal OTUs indicated no significant correlation to LUI (analysis not shown). Allan et al. (2014) demonstrated that multidiversity notably of aboveground organisms decreased with increasing LUI, while belowground groups were less sensitive.

Here the grassland sampling sites with high land-use intensity were treated mainly by mowing up to three times in a year and with $\mathrm{N}$ fertilization, while in other studies higher amounts of fertilizers was reported, thus probably no clear trend could be observed (Herold et al., 2014). A former study observed higher cell counts and more genera of soil algae in a newly plowed field compared to an older field (Hunt et al., 1979). Disturbed fields may represent an area open for colonization e.g. by diaspores of airborne algae (Brown et al., 1964; Hunt et al., 1979), this could explain a slightly higher OTU richness in managed grassland sites. Other authors reported algal diversity was found to be greater in the undisturbed sites and disturbance, like tillage and pesticides, had strong effect on the composition and density of algal communities, with cyanobacteria being particularly sensitive to disturbance (Zancan et al., 2006). As well diversity of algal communities in forest and non-forest soils were affected by soil pollutions e.g. lead, coal mines or aerotechnogenic pollutions and less species were observed compared to undisturbed regions (Novakovskaya and Patova, 2007; Patova and Dorokhova, 2008; Temraleeva et al., 2011). 
Three categories of forest management intensities were determined, intensively managed spruce or pine age class forest (Plot numbers 1-3), managed beech age class forest (Plot numbers 4-6) and beech selection forest in Hainich-Dün (Plot number HEW7-9) and unmanaged beech forest (Plot number 7-9 and HEW10-12). The OTU richness of green algae indicated at the forest sites of the three regions the same trend. The intermediate managed forest sites exhibited the largest green algal diversities in all three Exploratories (Fig. 7), with an average of 8 OTUs per sampling site of this management intensity, lower diversities were detected in the intensively treated plots with an average of 7.1 OTUs. Interestingly, the lowest diversity was revealed in the unmanaged forest sites with only the half number of OTUs compared to the managed forest sites (an average of 4.1 OTUs).

The unmanaged forest sites were 130 up to 189 years old with well-developed understory vegetation and low light at the ground. Less algal diversity and density in undisturbed forest soils could be explained by high cover of litter and understory and low light intensity at the ground (Hunt et al., 1979; Lukešová and Hoffmann, 1996; Lukešová, 2001). The intensively managed forest sites were coniferous forest and exhibited little less soil algal diversity than in the managed beech forest sites. Differences in algal composition between coniferous and deciduous forest soils were observed earlier, communities of coniferous forest soils were described as less diversified (Neustupa, 2001). At all forest sites of the three Exploratories OTUs affiliated to Trebouxiophyceae dominated, except at the three pine forest sites in Schorfheide-Chorin (SEW1, SEW2 and SEW3). Interestingly ten out of 14 chlorophycean OTUs found at these sites were exclusively recovered in these pine forest soils, while only one trebouxiophyte OTU out of nine were exclusively found at these sites. In Schorfheide-Chorin sandy soils are commonly associated with pine forests, furthermore these three sites showed the lowest values of OC and TN. Land-use, and soil type may correlate and hence both parameters together affect biodiversity (Fischer et al., 2010). However, higher plants also have a significant influence on the soil algal composition (Bakieva et al., 2012). Effects of management intensities on the green algal diversity in soils remain still unclear and are different to separate from physico-chemical parameters of soil. 

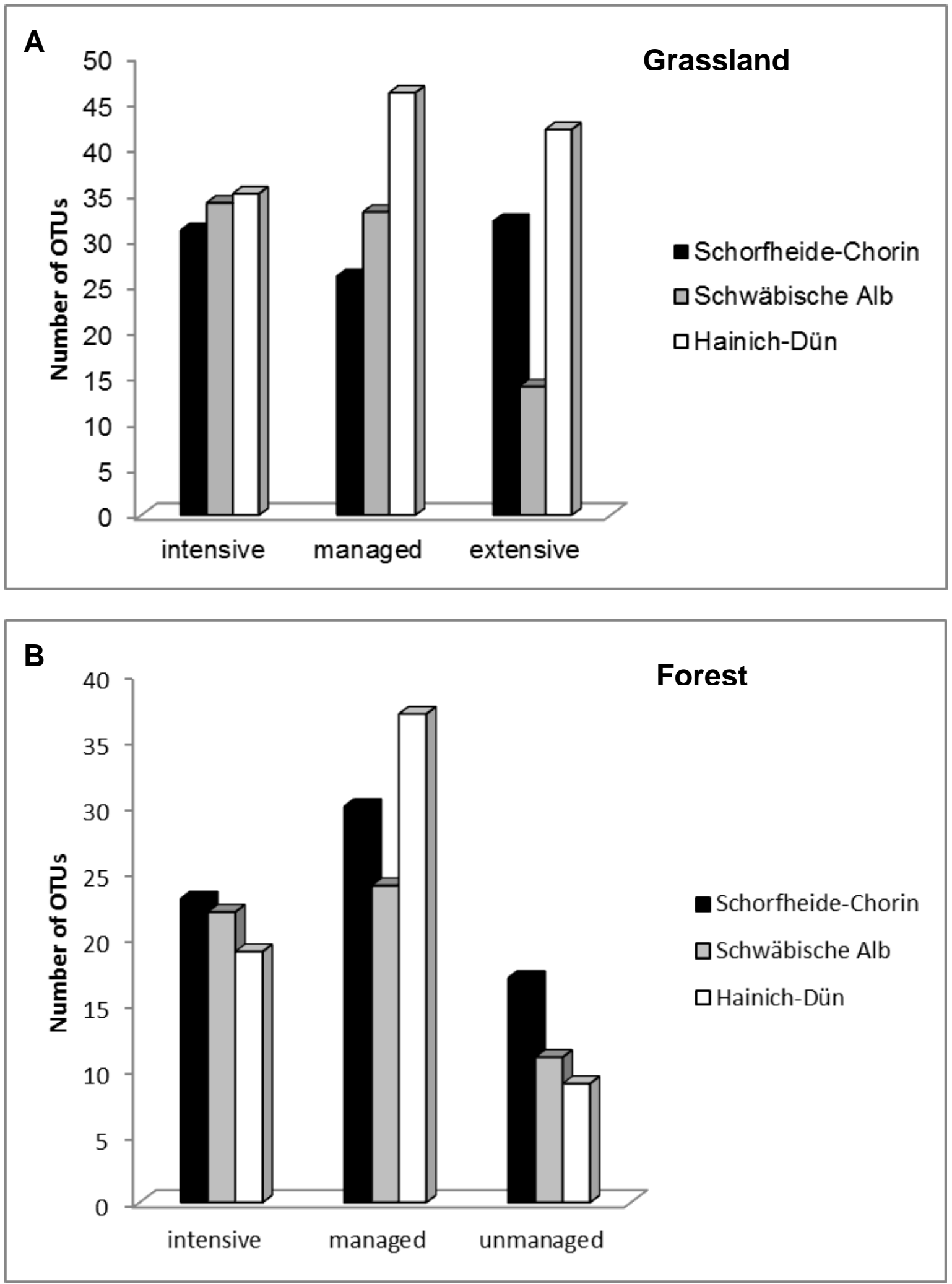

Fig. 7. Distribution of the green algal OTUs in (A) grassland and (B) forest soils of the three German Exploratories. Both land-use types comprised three different management intensities, intensive, managed and extensive/unmanaged. 


\section{Sampling effects and seasonal comparison}

For a more detailed investigation of the green algal composition in the grassland and forest soils seven plots were selected. From the three grassland plots (HEG7, HEG8 and HEG9) and four forest plots (HEW3, HEW4, HEW5 and HEW10) samples were taken in September 2010 and March 2011, in addition to those from 2008 (Table 6). The topsoil of 0-3 cm was collected; the samples were treated similarly to those 57 samples of the joint effort in spring 2008 (0-10 cm soil depth). Additionally, the March 2011 samples from HEG7 and HEW3 were treated with different methods e.g. using diverse PCR primer combinations and cloning of an enrichment culture obtained from these soil samples. These different efforts were compared to the corresponding samples from spring 2008 with the focus on seasonal comparison, sampling effects, like soil depth and different sampling points at one plot, different treatments of one sampling site to cover the almost complete green algal diversity.

A total of 612 sequences was retrieved from the new sampling effort, altogether 92 OTUs were recovered and 14 OTUs were exclusively found by these approaches (OTU number 146 to 159; Table 4, Table 7). The soil samples taken in September 2010 and March 2011 were treated like the samples from the joint effort and exhibited overall the same trends compared to the samples from 2008. The grassland soils were again found more diverse (eight to 24 OTUs per sample) than the forest soils (six to 14 OTUs per sample) and in the majority of the samples trebouxiophycean OTUs dominated. Additionally same preferences of some OTUs could be observed e.g. Prototheca-relative OTUs were preferentially in forest soils, while Muriella OTU 42 and Stichococcus OTU 54 were recorded mainly from grassland soils (Table 7).

The triplicates within one plot, taken in spring 2008, September 2010 and March 2011, exhibited differences in OTU richness and composition; about $9.7 \%$ to $37.5 \%$ of OTUs were shared at least twice at one plot, whereas sample HEW3 showed the greatest heterogeneity (Table 7). Nevertheless the Detrended Correspondence Analysis (DCA) indicated that the algal communities within one sampling site were more similar and seasonal variations have no significant effect (Fig. 8). Again the algal composition revealed a clear separation of grassland and forest soils, except the forest sample from March 2011 HEW3W. Furthermore the DCA indicated that the green algal composition obtained from the mixed samples from 2008 representing the grassland and forest soils as well. 


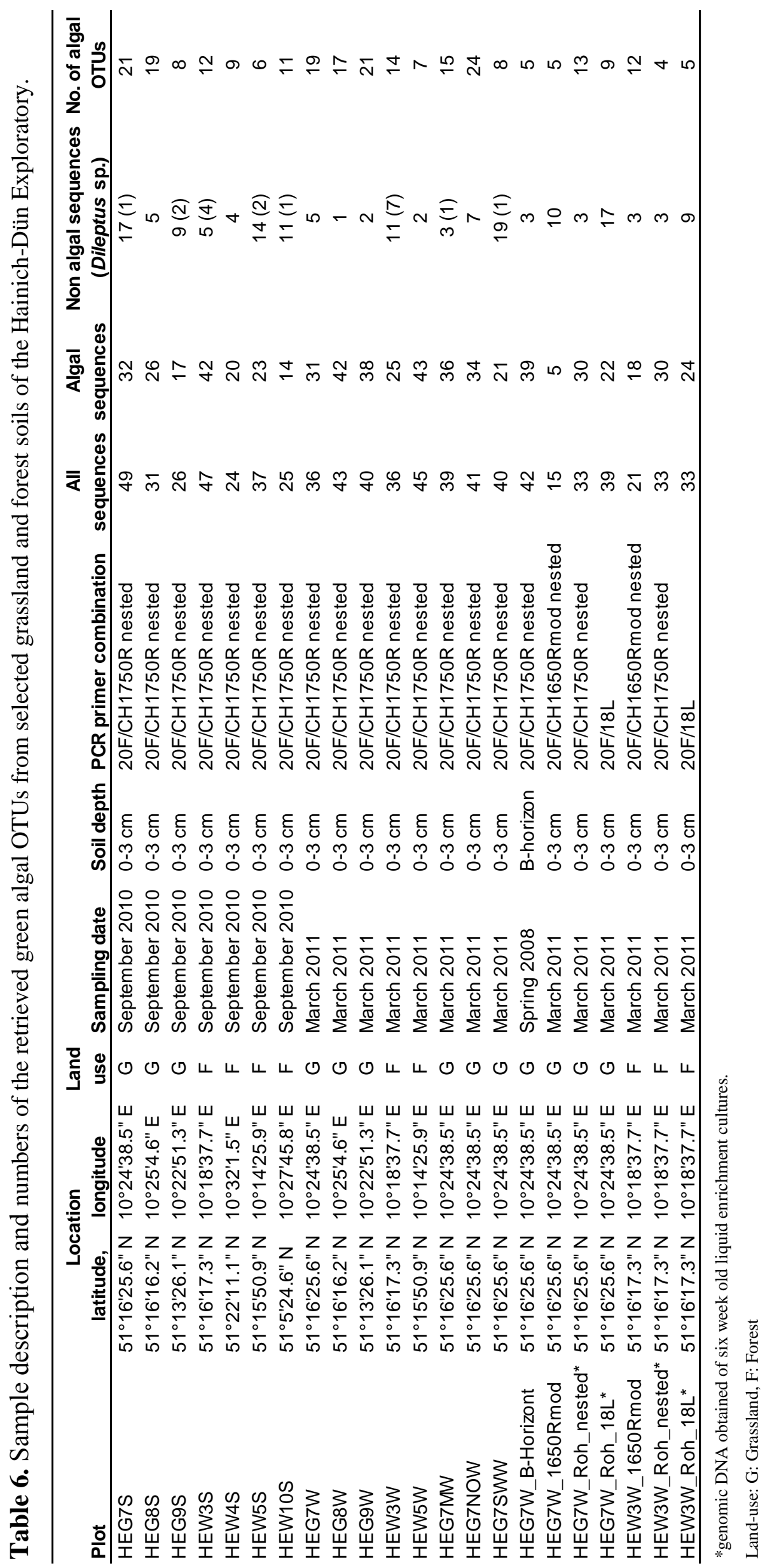


Spatial heterogeneity was also investigated at one plot, four samples of the grassland plot HEG7 (NO, SW, the center and the mixed sample, all obtained in March 2011) were analyzed separately (Fig. 8). Altogether 41 OTUs were recovered; the number of the retrieved OTUs varied from eight to 24 OTUs per sample and about 19 OTUs (46.3\%) were shared and discovered in more than two samples. Nevertheless the DCA illustrated similarity in OTU composition at different sampling points within the same plot (Fig. 8).

Seasonal changes in cell counts of soil algae have often been reported (Shields and Durrell, 1964; Metting, 1981; Shimmel and Darley, 1985), whereas in temperate regions a change in soil algal communities is less obvious and more likely due to changing light intensities affected by canopy and leaf litter (Hunt et al., 1979; Johansen et al., 1993; Zancan et al., 2006). Spatial heterogeneity of soil algal communities within one plot is a well-known small and large-scale aspect connected to patchiness of vascular plant cover and also to disturbance caused by e. g. grazing livestock (Grondin and Johansen, 1993; Lukešová, 1993; Lukešová and Hoffmann, 1996; Adler et al., 2001). Whereas these reports were based on morphological investigations, in the here represented study also a PCR or cloning bias has to be taken in account. The sampling in September 2010 resulted, additionally to the samples from 2008, in clone libraries for HEW4S and HEW10S. For these samples nine and eleven sequences were retrieved, whereas only one OTU or no algal sequence was recovered in the samples of the joint effort in 2008.

The sampling site HEG7 was intensively investigated to obtain preferably the best coverage of green algal diversity. Altogether about 304 sequences of this sampling site were analyzed. Additionally to the samples of different seasons and different sampling points, described above, a sample of the B-Horizon obtained from the sampling in 2008 and an enrichment culture established from the sampling in March 2011 were analyzed (Table 6). A total of 60 OTUs were recovered (51 OTUs without the raw cultures). The number of OTUs obtained from the single clone libraries varied from five to 24 OTUs (Table 7), thus the clone library from 2008 exhibited with 21 OTUs a representative sample for this plot. Genomic DNA and green algal PCR-products could also be obtained from soil of the B-Horizon. Five OTUs were recovered, whereas Chlamydomonas OTU 73, Lobosphaera/Myrmecia OTU 20, Muriella OTU 42 and OTU 151 were also retrieved in the other clone libraries of HEG7, the Chlorellales relative OTU 46 was exclusively found here (Table 7). 


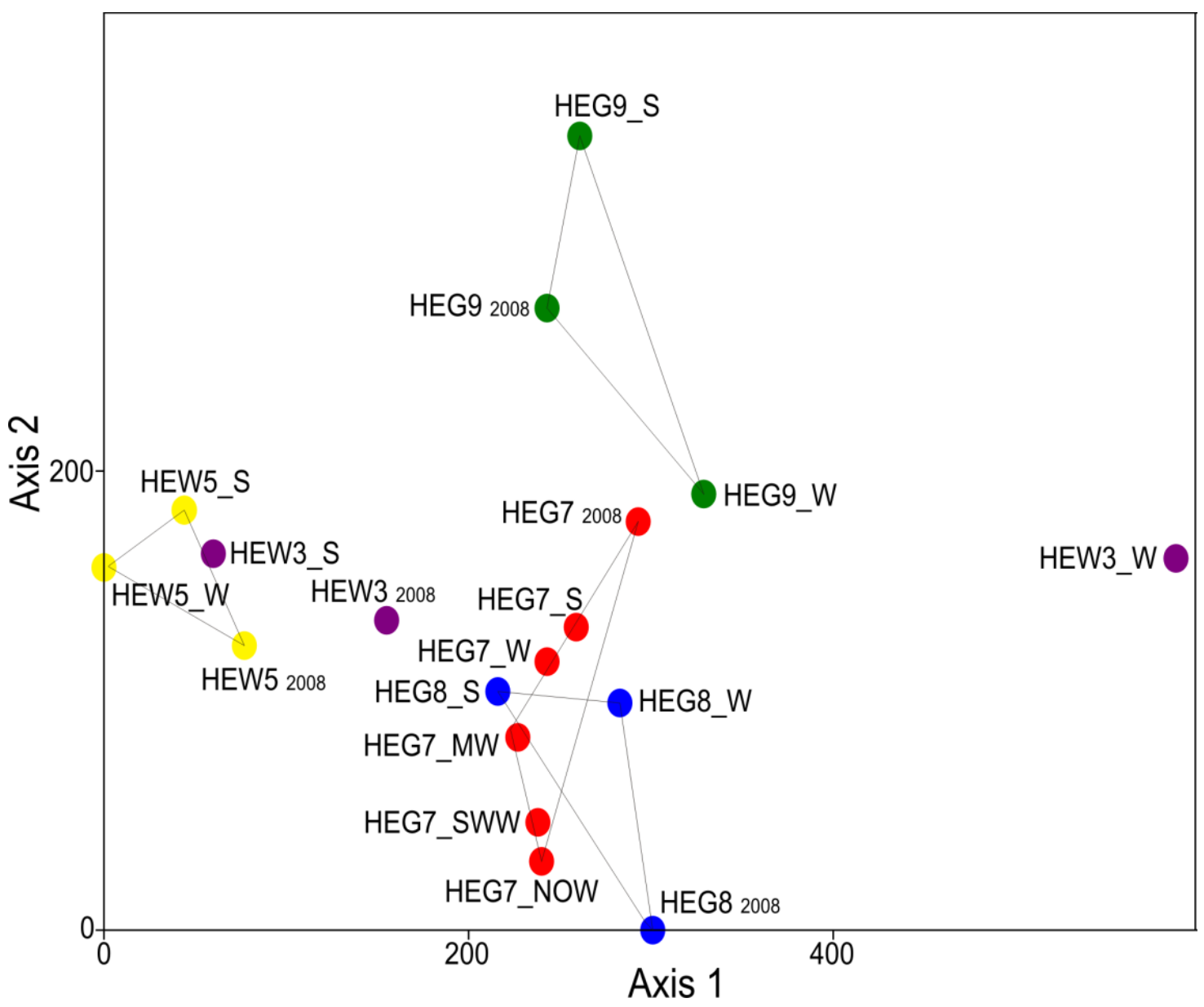

Fig. 8. Detrended Correspondence Analysis (DCA). Comparison of the seasonal green algal OTUcomposition in three selected grassland (HEG) and two forest (HEW) sampling sites of the Hainich-Dün Exploratory. The samples were taken in spring 2008 ('2008'), in September 2010 ('S') and March 2011 ('W'). Same colour of dots indicates same sampling site.

Light is a limiting factor for phototrophic soil algae, significant light penetration into soil were reported about 4-5 mm thus the highest soil algae density were in the upper $\mathrm{cm}$ and decreases rapidly with depth (Shields and Durrell, 1964; Tester and Morris, 1987; Hoffmann, 1989; Myers and Davis, 2003). Previous studies revealed by culturing also green algal genera like Chlamydomonas, Chlorella and Myrmecia from soil depth up to $18 \mathrm{~cm}$ (Willson and Forest, 1957; Fujita and Nakahara, 2006). The presence of algal cells may be feasible up to two meters soil depth caused by water seepage or burrowing activities of animals but same algae were found at surface and in deeper soils (Shields and Durrell, 1964; Hoffmann, 1989). Both approaches, culturing and cloning, may not clarify whether the algal cells were vegetative or resting stages, other adaption strategies were heterotrophy and reducing of catabolic reactions (Metting, 1981; Fujita and Nakahara, 2006). This may also partially explain why the clone libraries obtained from the 
enrichment cultures (performed with green algal preferring and eukaryotic PCR primer combinations) differed to those obtained directly from soil samples of plot HEG7 (Table 7). Remarkably the most abundant OTUs recovered from the direct soil samples like Chloroidium OTU 15 and Muriella OTU 42 were not found in the enrichment cultures. Whereas in the direct soil samples Trebouxiophyceae dominated, the enrichment cultures were more favorable for Chlorophyceae. Generally, the usage of liquid enrichment cultures preferred omnipresent algae ('weeds') and restrains the specialist (Hoffmann, 1989; Hoffmann et al., 2007). Furthermore these conditions are beneficial for aquatic species, algae which occur only in low numbers and resting stages, also the presence of Chlorophyceae seems to enhanced (Lukešová and Hoffmann, 1996; Hallmann et al., 2013a, 2015). 
Table 7. Distribution of the green algal OTUs in the $18 \mathrm{~S}$ rRNA gene clone libraries from selected grassland (three) and forest (four) soils of the Hainich-Dün Exploratory. The OTUs belong to the green algal classes of Trebouxiophyceae, Chlorophyceae and Ulvophyceae. Detailed description of clone libraries listed in Table 6.

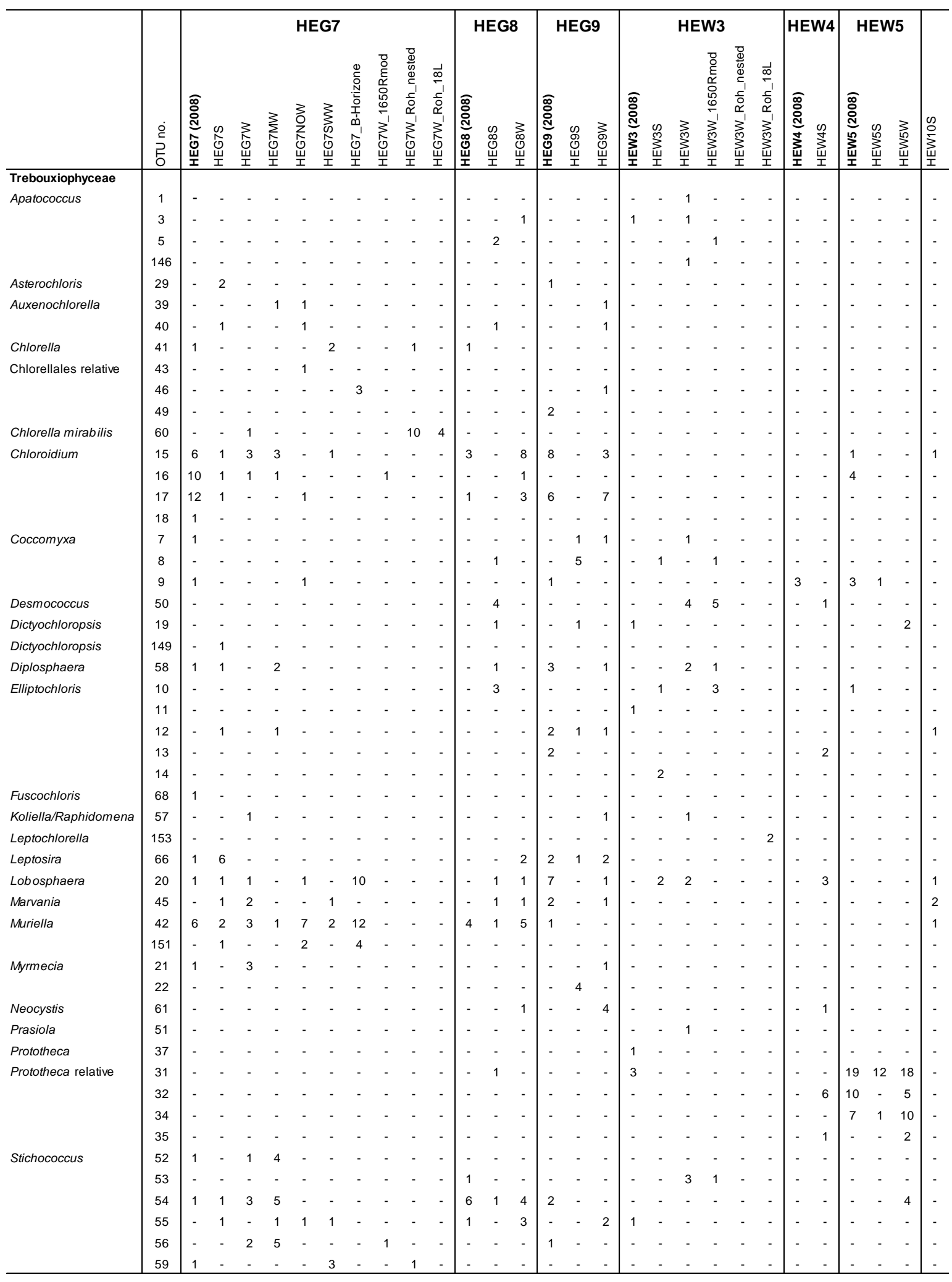


Table 7. Continued.

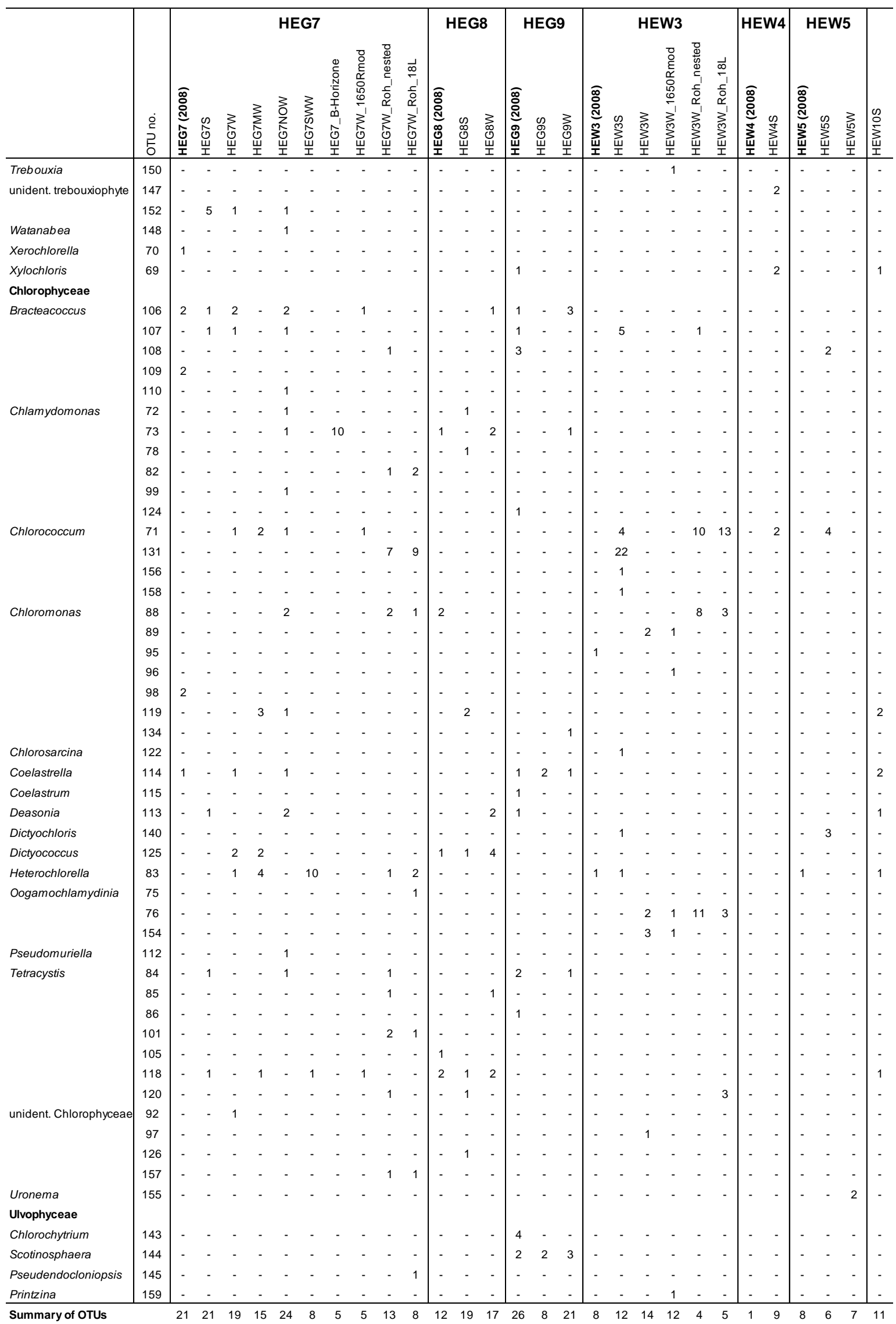




\section{Acknowledgements}

We thank Christiane Fischer, Heiko Nacke and Rolf Daniel for providing DNA-extracts obtained from the joint effort in 2008 and Nadine Herold and Fabian Alt for the kind supply for data of soil properties. We thank the managers of the three Exploratories, Swen Renner, Sonja Gockel, Kerstin Wiesner, and Martin Gorke for their work in maintaining the plot and project infrastructure; Simone Pfeiffer and Christiane Fischer giving support through the central office, Michael Owonibi for managing the central data base, and Markus Fischer, Eduard Linsenmair, Dominik Hessenmöller, Jens Nieschulze, Daniel Prati, Ingo Schöning, François Buscot, Ernst-Detlef Schulze, Wolfgang W. Weisser and the late Elisabeth Kalko for their role in setting up the Biodiversity Exploratories project. The work has been (partly) funded by the DFG Priority Program 1374 "InfrastructureBiodiversity-Exploratories" (DFG FR 905/16-1). Field work permits were issued by the responsible state environmental offices of Baden-Württemberg, Thüringen, and Brandenburg (according to $\S 72 \mathrm{BbgNatSchG).}$

\section{References}

Adler, P., Raff, D. and Lauenroth, W. (2001) The effect of grazing on the spatial heterogeneity of vegetation. Oecologia 128: 465-479.

Allan, E., Bossdorf, O., Dormann, C.F., Prati, D., Gossner, M.M., et al. (2014) Interannual variation in land-use intensity enhances grassland multidiversity. Proc Natl Acad Sci USA 111: 308-313.

Alt, F., Oelmann, Y., Herold, N., Schrumpf, M. and Wilcke, W. (2011) Phosphorus partitioning in grassland and forest soils of Germany as related to land-use type, management intensity, and land use-related pH. J Plant Nutr Soil Sci 174: 195-209.

Altschul, S.F., Gish, W., Meyers, E.W. and Lipman, D.J. (1990) Basic local alignment search tool. J Mol Biol 215: 403-410.

Bakieva, G.R., Khaibullina, L.S., Gaisina, L.A. and Kabirov, R.R. (2012) Ecological-floristic analysis of soil algae and cyanobacteria on the Tra-Tau and Yurak-Tau Mounts, Bashkiria. Eur Soil Sci 45: 873-881.

Bérard, A., Rimet, F., Capowiez, Y. and Leboulanger, C. (2004) Procedures for determining the pesticide sensitivity of indigenous soil algae - a possible bioindicator of soil contamination? Arch Environ Con Tox 46: 24-31.

Bérard, A., Dorigo, U., Humbert, J.F. and Martin-Laurent, F. (2005) Microalgae community structure analysis based on $18 \mathrm{~S}$ rDNA amplification from DNA extracted directly from soil as a potential soil bioindicator. Agron Sustain Dev 25: 285-291.

Blüthgen, N., Dormann, C.F., Prati, D., Klaus, V.H., Kleinebecker, T., et al. (2012) A quantitative index of land-use intensity in grasslands: Integrating mowing, grazing and fertilization. Basic Appl Ecol 13: 207-220. 
Brown, R.M., Larson, D.A. and Bold, H.C. (1964) Airborne algae: their abundance and heterogeneity. Science 143: 583-585.

Büdel, B., Colesie, C., Green, T.A., Grube, M., Suau, R.L., et al. (2014) Improved appreciation of the functioning and importance of biological soil crusts in Europe: the Soil Crust International Project (SCIN). Biodivers Conserv 23: 1639-1658.

Darienko, T., Gustavs, L., Mudimu, O., Rad Menendez, C., Schumann, R., Karsten, U., Friedl, T. and Pröschold, T. (2010) Chloroidium, a common terrestrial coccoid green alga previously assigned to Chlorella (Trebouxiophyceae, Chlorophyta). Eur J Phycol 45: 1469-4433.

Ettl, H. and Gärtner, G. (1995) Syllabus der Boden-, Luft- und Flechtenalgen. Gustav Fischer, Stuttgart.

Figueroa-Martinez, F., Nedelcu, A.M., Smith, D.R. and Reyes-Prieto, A. (2015) When the lights go out: the evolutionary fate of free-living colorless green algae. New Phytol DOI: 10.1111/nph.13279.

Fischer, M., Bossdorf, O., Gockel, S., Hänsel, F., Hemp, A., et al. (2010) Implementing large-scale and long-term functional biodiversity research: The Biodiversity Exploratories. Basic Appl Ecol 11: 473-485.

Freystein, K., Salisch, M. and Reißer, W. (2008) Algal biofilms on tree bark to monitor airborne pollutants. Biologia 63: 866-872.

Friedl, T. and O'Kelly, C.J. (2002) Phylogenetic relationships of green algae assigned to the genus Planophila (Chlorophyta): evidence from 18S rDNA sequence data and ultrastructure. Eur $J$ Phycol 37: 373-384.

Friedl, T. and Büdel, B. (2008) Photobionts. In: Nash, T.I. (ed) Lichen biology, 2nd edn. Cambridge University Press, Cambridge, pp. 9-26.

Friedl, T. and Rybalka, N. (2012) Systematics of the green algae: A brief introduction to the current status. In: Lüttge, U., Beyschlag, W., Francis, D. and Cushman, J. (eds) Progress in Botany No. 73. Springer, Heidelberg, pp. 259-280.

Fučíková, K., Lewis, P.O. and Lewis, L.A. (2014) Widespread desert affiliation of trebouxiophycean algae (Trebouxiophyceae, Chlorophyta) including discovery of three new desert genera. Phycological Res 62: 294-305.

Fujita, Y. and Nakahara, H. (2006) Variations in the microalgal structure in paddy soil in Osaka, Japan: comparison between surface and subsurface soils. Limnology 7: 83-91.

Gärtner, G. (1994) Zur Taxonomie aerophiler grüner Algenanflüge an Baumrinden. Ber nat-med Verein Innsbruck 81: 51-59.

Dal Grande, F., Beck, A., Cornejo, C., Singh, G., Cheenacharoen, S., Nelsen, M.P. and Scheidegger, C. (2014) Molecular phylogeny and symbiotic selectivity of the green algal genus Dictyochloropsis s.l. (Trebouxiophyceae): a polyphyletic and widespread group forming photobiont-mediated guilds in the lichen family Lobariaceae. New Phytol 202: 455-470.

Grondin, A.E. and Johansen, J.R. (1993) Microbial spatial heterogeneity in microbiotic crusts in Colorado National Monument. I. Algae. West N Am Nat 53: 24-30.

Hallmann, C., Stannek, L., Fritzlar, D., Hause-Reitner, D., Friedl, T. and Hoppert, M. (2013a) Molecular diversity of phototrophic biofilms on building stone. FEMS Microbiol Ecol 84: 355-372.

Hallmann, C., Wedekind, W., Hause-Reitner, D. and Hoppert, M. (2013b) Cryptogam covers on sepulchral monuments and re-colonization of a marble surface after cleaning. Environ Earth Sci 69: 1149-1160.

Hallmann, C., Friedenberger, H., Hause-Reitner, D. and Hoppert, M. (2015) Depth profiles of microbial colonization in sandstones. Geomicrobiol J 32: 365-379. 
Hallmann, C., Hodač, L., Faßhauer, F., Hoppert, M. and Friedl, T. (in prep.) Green algal communities from soil and tree bark in middle European forests: a molecular comparison. Chapter 5 of this thesis.

Hamby, R.K., Sim, L.E., Issel, L.E. and Zimmer, E.A. (1988) Direct RNA sequencing optimization of extraction and sequencing techniques for work with higher plants. Pl Mol Biol Rep 6: 179-197.

Hammer, Ø., Harper, D.A.T. and Ryan, P.D. (2001) PAST: Paleontological Statistics Software Package for education and data analysis. Palaeontol Electronica 4.

Hepperle, D. (2004) SeqAssem $\odot$. A sequence analysis tool, counting assembler and trace data visualization tool for molecular sequences. Win32-Version. Distributed by the author via: http://www.seqeuntix.de.

Herold, N., Schöning, I., Gutknecht, J., Alt, F., Boch, S., et al. (2014) Soil property and management effects on grassland microbial communities across a latitudinal gradient in Germany. Appl Soil Ecol 73: 41-50.

Hodač, L., Hallmann, C., Rosenkranz, H., Faßhauer, F. and Friedl, T. (2012) Molecular evidence for the wide distribution of two lineages of terrestrial green algae (Chlorophyta) over tropics to temperate zone. ISRN Ecol 2012: 795924.

Hodač, L., Hallmann, C., Spitzer, K. and Friedl, T. (in prep.) Molecular diversity of green and yellow-green algae isolated from German forests and grasslands.

Hoffmann, L. (1989) Algae of terrestrial habitats. Bot Rev 55: 77-105.

Hoffmann, L., Ector, L. and Kostikov, I. (2007) Algae flora from limed and unlimed forest soils in the Adrenne (Belgium). Syst Geogr Pl 77: 15-90.

Huber, T., Faulkner, G. and Hugenholtz, P. (2004) Bellerophon; a program to detect chimeric sequences in multiple sequence alignments. Bioinformatics 20: 2317-2319.

Huelsenbeck, J.P. and Ronquist, F. (2001) MrBayes: Bayesian inference of phylogenetic trees. Bioinformatics 17: 754-755.

Hunt, M.E., Floyd, G.L. and Stout, B.B. (1979) Soil algae in field and forest environments. Ecology 60: 362-375.

Johansen, J.R. (1993) Cryptogamic crusts of semiarid and arid lands of North America. J Phycol 29: $140-147$.

Johansen, J.R., Ashley, J. and Rayburn, W.R. (1993) Effects of rangefire on soil algal crusts in semiarid shrub-steppe of the lower Columbia Basin and their subsequent recovery. West $N \mathrm{Am}$ Nat 53: 73-88.

Kabirov, R.R. and Gaisina, L.A. (2009) Parameters of the productivity of soil algae in terrestrial ecosystems. Eur Soil Sci 42: 1374-1379.

Katoh, T. and Toh, H. (2008) Recent developments in the MAFFT multiple sequence alignment program. Brief Bioinform 9: 286-298.

Karsten, U., Schumann, T. and Mostaert, A.S. (2007a) Aeroterrestrial algae growing on man-made surfaces: What are their secrets of ecological success? In: Seckbach, J. (ed) Algae and Cyanobacteria in Extreme Environments. Springer Verlag, Dordrecht, the Netherlands, pp. 583-597.

Khaybullina, L.S., Gaysina, L.A., Johansen, J.R. and Krautová, M. (2010) Examination of terrestrial algae of the great smoky mountains national park, USA. Fottea 10: 201-215.

Kulichová, J., Škaloud, P. and Neustupa, J. (2014) Molecular diversity of green corticolous microalgae from two sub-Mediterranean European localities. Eur J Phycol 49: 345-355.

Lentendu, G., Wubet, T., Chatzinotas, A., Wilhelm, C., Buscot, F. and Schlegel, M. (2014) Effects of long term differential fertilization on eukaryotic microbial communities in an arable soil: a multiple barcoding approach. Mol Ecol 23: 3341-3355. 
Leliaert, F., Smith, D.R., Moreau, H., Herron, M.D., Verbruggen, H., Delwiche, C.F. and De Clerck, O. (2012) Phylogeny and molecular evolution of the green algae. CRC Crit Rev Plant Sci 31: 1-46.

Lewis, L.A. and McCourt, R.M. (2004) Green algae and the origin of land plants. Am J Bot 91: 1535-1556.

Ludwig, W., Strunk, O., Westram, R., Richter, L., Meier, H., et al. (2004) ARB: a software environment for sequence data. Nucl Acids Res 32: 1363-1371.

Lukešová, A. (1993) Soil algae in four secondary successional stages on abandoned fields. Arch Hydrobiol Suppl Algol Stud 71: 81-102.

Lukešová, A. and Hoffmann, L. (1996) Soil algae from acid rain impacted forest areas of Krusne hory Mts. 1. Algal communities. Vegetatio 125: 123-136.

Lukešová, A. (2001) Soil algae in brown coal and lignite post-mining areas in central Europe (Czech Republic and Germany). Restor Ecol 9: 341-350.

Lüttge, U. and Büdel, B. (2010) Resurrection kinetics of photosynthesis in desiccation-tolerant terrestrial green algae (Chlorophyta) on tree bark. Plant biol 12: 437-444.

Matsunaga, K., Kubota, K. and Harada, H. (2014) Molecular diversity of eukaryotes in municipal wastewater treatment processes as revealed by $18 \mathrm{~S}$ rRNA gene analysis. Microbes Environ 29: 401.

Metting, B. (1981) The systematics and ecology of soil algae. Bot Rev 47: 195-312.

Müller, J., Klaus, V.H., Kleinebecker, T., Prati, D., Hölzel, N. and Fischer, M. (2012) Impact of land-use intensity and productivity on bryophyte diversity in agricultural grasslands. PloS ONE 7: e51520.

Myers, P.E. and Davis, J.S. (2003) Recolonization of soils by algae in a northcentral Florida pine forest after controlled fire and soil sterilization. Nova Hedwigia 76: 207-219.

Nacke, H., Thürmer, A., Wollherr, A., Will, C., Hodač, L., Herold, N., Schöning, I., Schrumpf, M. and Daniel, R. (2011) Pyrosequencing-based assessment of bacterial community structure along different management types in German forest and grassland soils. PLoS ONE 6: e17000.

Němcová, Y., Eliáš, M., Škaloud, P., Hodač, L. and Neustupa, J. (2011) Jenufa gen. nov.: A new genus of coccoid green algae (Chlorophyceae, incertae sedis) previously recorded by environmental sequencing. J Phycol 47: 928-938.

Neustupa, J. (2001) Soil algae from marlstone-substratum based biotopes in the Nature park Džbán (Central Bohemia, Czech Republic) with special attention to the natural treeless localities. Algol Stud 101: 109-120.

Neustupa, J. and Škaloud, P. (2004) Contribution to the knowledge of soil algae of two abandoned industrial sedimentation basins in Eastern Bohemia. Natural recovery of man-made deposits in landscape (Biotic interactions and ore/ash-slag artificial ecosystems), 194-199.

Neustupa, J., Nemcová, Y., Veselá, J., Steinová, J. and Škaloud, P. (2013) Leptochlorella corticola gen. et sp. nov. and Kalinella apyrenoidosa sp. nov.: two new Chlorella-like green microalgae (Trebouxiophyceae, Chlorophyta) from subaerial habitats. Int J Syst Evol Microbiol 63: 377-387.

Novakovskaya, I.V. and Patova, E.N. (2007) Changes in soil algal communities in spruce phytocenoses under the influence of aerotechnogenic pollution. Eur Soil Sci 40: 576-582.

Novakovskaya, I.V. and Patova, E.N. (2008) Green algae in spruce forests in the north-east of European Russia. Biologia 63: 836-842.

Patova, E.N. and Dorokhova, M.F. (2008) Green algae in tundra soils affected by coal mine pollutions. Biologia 63: 831-835.

Reisigl, H. (1964) Zur Systematik und Ökologie alpiner Bodenalgen. Österr Bot Z 111: 402-499. 
Ruble, R.W. and Davis, J.S. (1988) Soil algae from fallow potato fields in south Florida (USA) marl. Nova Hedwegia 47: 403-414.

Schloss, P.D., Westcott, S.L., Ryabin, T., Hall, J.R., Hartmann, M., et al. (2009) Introducing mothur: open-source, platform-independent, community-supported software for describing and comparing microbial communities. Appl Environ Microbiol 75: 7537-7541.

Shields, L.M. and Durrell, L.W. (1964) Algae in relation to soil fertility. Bot Rev 30: 92-128.

Shimmel, S.M. and Darley, W.M. (1985) Productivity and density of soil algae in an agricultural system. Ecology 1439-1447.

Škaloud, P., Kalina, T., Nemjová, K., De Clerck, O. and Leliaert, F. (2013) Morphology and phylogenetic position of the freshwater green microalgae Chlorochytrium (Chlorophyceae) and Scotinosphaera (Scotinosphaerales, ord. nov., Ulvophyceae). J Phycol 49: 115-129.

Smith, V.H., Tilman, G.D. and Nekola, J.C. (1999) Eutrophication: impacts of excess nutrient inputs on freshwater, marine, and terrestrial ecosystems. Environ Pollut 100: 179-196.

Stamatakis, A., Hoover, P. and Rougement, J. (2008) A rapid bootstrap algorithm for the RAxML web-servers. Syst Biol 75: 758-771.

Starks, T.L., Shubert, L.E. and Trainor, F.R. (1981) Ecology of soil algae: a review. Phycologia 20: 65-80.

Tester, M. and Morris, C. (1987) The penetration of light through soil. Plant Cell Environ 10: 281-286.

Temraleeva, A.D., Pinskii, D.L., Patova, E.N. and Spirina, E.V. (2011) The use of algaecyanobacterial communities for the assessment of lead pollution of gray forest soils. Eur Soil Sci 44: 326-331.

Vd’ačný, P. and Foissner, W. (2008) Description of four new soil dileptids (Ciliophora, Haptoria), with notes on adaptations to the soil environment. Acta Protozool 47: 211.

Will, C., Thürmer, A., Wollherr, A., Nacke, H., Herold, N., Schrumpf, M., Gutknecht, J., Wubet, T., Buscot, F. and Daniel, R. (2010) Horizon-specific bacterial community composition of German grassland soils as revealed by pyrosequencing-based analysis of 16S rRNA genes. Appl Environ Microb 76: 6751-6759.

Willson, D. and Forest, H.S. (1957) An exploratory study on soil algae. Ecology 309-313.

Wöhler, I., Klass, S., Derakshani, M., Stellmacher, G., Winter, J.U. and Reisser, W. (1988) The occurence of terrestrial algae on two beech sites on a cambisol. Z Pflanzenernähr Bodenk 161: 31-34.

Zancan, S., Trevisan, R. and Paoletti, M.G. (2006) Soil algae composition under different agroecosystems in North-Eastern Italy. Agric Ecosyst Environ 112: 1-12.

Zenova, G.M., Shtina, E.A., Dedysh, S.N., Glagoleva, O.B., Likhacheva, A.A. and Gracheva, T.A. (1995) Ecological relations of algae in biocenoses. Mikrobiologiya 64: 121-133. 


\section{Summary}

Terrestrial green microalgae are important primary producers in various habitats like soils, stone (epilithic and endolithic), tree bark and artificial hard substrates. In this thesis, the molecular diversity of green algae (Chlorophyta) in terrestrial habitats was analyzed and assessed by mainly a culture-independent approach using molecular phylogenetics. This allowed the unambiguous re-identification of the same species or molecular operational taxonomic units (OTUs) and, therefore, changes in the taxonomic composition of the algal communities could be reliably assessed. The algal communities in soil and aerophytic algae in phototrophic biofilms on building stone, monuments, on tree bark and on manmade substrate from various sampling sites in Germany were investigated and compared. On building stones and stone monument surfaces also cyanobacteria and fungi were abundant and were analyzed as well. The soil and tree bark samples were obtained from defined research plots of the three German Biodiversity Exploratories, i.e. Hainich-Dün, Schorfheide-Chorin and Schwäbische Alb, which comprised different land use types (forest versus grassland) of different management intensities each.

From all sampling sites environmental DNA was isolated and 18S rRNA genes were amplified by PCR with a newly developed green algae preferring primer. Followed by cloning and sequencing the analyses resulted in a dataset of more than 3000 green algal partial sequences. Operational taxonomic units (OTUs) were calculated on the basis of partial sequences (including the hypervariable V4 region) followed by phylogenetic identification of representative full length sequences. For some subsets of samples also enrichment cultures were established and analyzed. In one example, the green algae dominated cover of a man-made hard substrate in an urban environment the different diversities obtained by the culture-independent approach and a culture-based method were compared.

All air exposed surfaces, like stone and tree bark, investigated in this study were clearly dominated by members of the green algal class Trebouxiophyceae. Regarding the studied building stones, the composition of microalgal communities including cyanobacteria differed markedly between apparently similar substrata of two wall areas. This is mainly due to differences in the exposure to sunlight (and hence water availability) and the occurrence of gypsum crusts. Thus, the green algae composition on the daylightexposed walls was dominated by Trebouxiophyceae, whereas OTUs in samples taken from a sampling site under low irradiance comprised also members of the Chlorophyceae. 
Interestingly, members of Chlorophyceae were preferably detected after enrichment in liquid crude cultures. The most abundant algae discovered in phototrophic biofilms on air exposed substrata were various OTUs representing the trebouxiophycean genera Apatococcus, Stichococcus, Trebouxia, and Coccomyxa.

The green algal diversity in soils was extensively higher than in aerophytic green biofilms. Significant differences between green algal communities in 27 grassland and 30 forest soils were detected. Besides other factors soil $\mathrm{pH}$ explains this observation at best. In relation to management intensities the effects on algal communities were indirect, i.e. soils in unmanaged forests had a markedly lower OTU richness than that of managed forest sites. At the latter, presumably a low light intensity caused by high cover of litter and understory was available to the algal communities which may explain the differences. However, this was not evident for the grassland plots. The soil algal communities comprised a high diversity of members from both classes, the Trebouxiophyceae and Chlorophyceae. The most common OTUs in soil with particular dominance in grassland were species/OTUs of Chloroidium, Stichococcus, Muriella, Tetracystis and Bracteacoccus. The most abundant OTU in the studied forest soils was a so far unidentified Prototheca-related trebouxiophycean alga. This presumably heterotrophic alga was exclusively retrieved from forest soils. 


\section{Danksagung}

An dieser Stelle möchte ich mich bei allen bedanken, die mich während meiner Dissertation begleitet und unterstützt haben.

Ich danke Prof. Dr. Thomas Friedl für die Bereitstellung und Ermöglichung meiner Doktorarbeit an einem sehr spannenden und vielseitigen Thema. Außerdem bedanke ich mich für die Unterstützung, wertvolle Anregungen und die Möglichkeit an Tagungen teilzunehmen zu dürfen.

PD Dr. Michael Hoppert danke ich für die Übernahme des Korreferats und die angenehme Zusammenarbeit an interessanten Projekten, deren Ergebnisse ich auf Tagungen präsentieren durfte. Zudem möchte ich mich für die Unterstützung und immer sehr hilfreiche und kompetente Beratung bedanken.

Ein großes Dankeschön geht an meinen Mitstreiter bei den Biodiversitäts-Exploratorien Ladislav Hodač, zudem an Fabian Faßhauer und Dr. Nicole Brinkmann, die für mich alle nicht nur sehr gute Kollegen waren, sondern auch zu guten Freunden geworden sind.

Ein liebes Danke an das SAG-Team für das angenehme und freundliche Arbeitsklima verbunden mit Rat und Tat, ich habe mich immer herzlich willkommen gefühlt: Dr. Maike Lorenz, Ilse Kunkel, Marlies Heinemann, Gabriele Curdt-Hollmann, Hella Timmermann, Rainer Freter und Henrike Schatt.

Dr. Bastian Steudel, Dr. Anastasiia Kryvenda, Nataliya Rybalka und Dr. Maria Siegesmund danke ich für die gute Zusammenarbeit und für das sehr angenehme Arbeitsklima im Labor und im Büro. Ich möchte mich auch bei den Diplomanden und Bachelorstudenten Kristin Pahlmann, Diana Fritzlar, Lorena Stannek, Karolin Spitzer, Juliane Kleinfeld und Henrike Friedenberger für die gute Zusammenarbeit bedanken.

Danke für die guten Kooperationsarbeiten an Dorothea Hause-Reitner, Wanja Wedekind, Dr. Heidrun Stück und Prof. Dr. Siegfried Siegesmund.

Ein ganz besonderer Dank geht an meine Familie für ihre liebevolle Unterstützung und das sie mir diese Ausbildung ermöglicht hat. 


\section{Publications}

Hallmann, C., Friedenberger, H., Hause-Reitner, D. and Hoppert, M. (2015) Depth profiles of microbial colonization in sandstones. Geomicrobiology Journal 32: 365-379.

Brinkmann, N., Hodač, L., Mohr, K.I., Hodačová, A., Jahn, R., Ramm, J., Hallmann, C., Arp, G. and Friedl, T. (2015) Cyanobacteria and diatoms in biofilms of two karstic streams in Germany and changes of their communities along calcite saturation gradients. Geomicrobiology Journal 32: 255-274.

Hodač, L., Brinkmann, N., Mohr, K.I., Arp, G., Hallmann, C., Ramm, J., Spitzer, K. and Friedl, T. (2015) Diversity of microscopic green algae (Chlorophyta) in calcifying biofilms of two karstic streams in Germany. Geomicrobiology Journal 32: 275-290.

Hallmann, C., Kirchhoff, N., Friedenberger, H. and Hoppert, M. (2014) Lebensgemeinschaften im Gestein. In: Siegesmund, S., Hoppert, M. and Epperlein, K. (eds). Natur, Stein, Kultur, Wein zwischen Saale und Unstrut. Mitteldeutscher Verlag, Halle (Saale), pp. 181-194.

Allan, E., Bossdorf, O., Dormann, C.F., Prati, D., Gossner, M., Tscharntke, T., Blüthgen, N., Bellach, M., Birkhofer, K., Boch, S., Böhm, S., Börschig, C., Chatzinotas, A., Christ, S., Daniel, R., Diekötter, T., Fischer, C., Friedl, T., Glaser, K., Hallmann, C., Hodač, L., et al. (2014) Inter-annual variation in land-use intensity enhances grassland multidiversity. Proceedings of the National Academy of Sciences 111: 308-313.

Hallmann, C., Stannek, L., Fritzlar, D., Hause-Reitner, D., Friedl, T. and Hoppert, M. (2013) Molecular diversity of phototrophic biofilms on building stone. FEMS Microbiology Ecology 84: 355-372. (corresponding author)

Hallmann, C., Wedekind, W., Hause-Reitner, D. and Hoppert, M. (2013) Cryptogam covers on sepulchral monuments and re-colonization of a marble surface after cleaning. Environmental Earth Sciences 69: 1149-1160. (corresponding author) 
Hodač, L., Hallmann, C., Rosenkranz, H., Faßhauer, F. and Friedl, T. (2012) Molecular Evidence for the Wide Distribution of Two Lineages of Terrestrial Green Algae (Chlorophyta) over Tropics to Temperate Zone. ISRN Ecology Vol. 2012, Article ID 795924. doi:10.5402/2012/795924.

Hallmann, C., Rüdrich, J., Enseleit, M., Friedl, T. and Hoppert, M. (2011) Microbial diversity on a marble monument - a case study. Environmental Earth Sciences 63: 1701-1711.

Hallmann, C., Fritzlar, D., Stannek, L. and Hoppert, M. (2011) Ascomycete fungi on dimension stone of the "Burg Gleichen", Thuringia. Environmental Earth Sciences 63: 1713-1722.

Hoppert, M., Hallmann, C., Stannek, L., Fritzlar, D. and Enseleit, M. (2010) MakroMikroflora in Fuge und Gestein. In: Siegesmund, S. and Hoppert, M. (eds). Die Drei Gleichen-Baudenkmäler und Naturraum. Edition Leipzig, Leipzig, pp. 254-263.

\section{Submitted publications:}

Hallmann, C., Hoppert, M., Mudimu, O. and Friedl, T. (2015) Microalgal biodiversity just outside the house door: a case study of an aerophytic green biofilm on an artificial hard substrate. [to be resubmitted to Journal of Phycology] (corresponding author)

Steudel, B., Hallmann, C., Lorenz, M., Abrahamczyk, S., Prinz, K., Herrfurth, C., Feussner, I., Martini, J.W.R. and Kessler, M. (2015) Allelopathic growth inhibition can lead to negative biodiversity-functioning relationships. [to be resubmitted to New Phytologist] 